\title{
Experimental and Modeling Studies of Creep \\ Performance of Modified 9Cr-1Mo Steels with or without Oxidation-Resistant Coating
}

\author{
by \\ Xiaozhou Zhang \\ A dissertation submitted to the \\ Faculty of Graduate and Postdoctoral Affairs \\ in partial fulfillment of the requirements for the degree of
}

Doctor of Philosophy in Mechanical Engineering

Ottawa-Carleton Institute for Mechanical and Aerospace Engineering

Department of Mechanical and Aerospace Engineering

Carleton University

Ottawa, Ontario

December, 2017 
The undersigned hereby recommends to the

Faculty of Graduate and Postdoctoral Affairs acceptance of the dissertation

\title{
Experimental and Modeling Studies of Creep Performance of Modified 9Cr-1Mo Steels with or without Oxidation-Resistant Coating
}

\author{
Submitted by Xiaozhou Zhang, B.Eng., M. A. Sc. \\ in partial fulfillment of the requirements for the degree of \\ Doctor of Philosophy in Mechanical Engineering
}

Doctor Ashok K. Koul, External Examiner

Professor Rong Liu, Thesis Supervisor

Senior Research Officer, Adjunct Professor Xijia Wu, Thesis Co-Supervisor

Associate Professor Jie Liu, Thesis Co-Supervisor

Professor Ronald E. Miller, Chair, Department of Mechanical and Aerospace Engineering

Ottawa-Carleton Institute for Mechanical and Aerospace Engineering

Department of Mechanical and Aerospace Engineering

Carleton University

Ottawa, Ontario

December, 2017 


\section{Abstract}

This thesis presents experimental and modeling studies of creep performance of modified $9 \mathrm{Cr}$ 1Mo steel with and without an oxidation-resistant coating. A deformation-mechanism-based truestress (DMTS) creep model is proposed for predicting creep rate and creep life of modified 9Cr1Mo steels. The DMTS model considers three well-recognized deformation mechanisms: dislocation glide, dislocation climb, and grain boundary sliding. Constant-load creep testing is conducted on modified 9Cr-1Mo steel in forged form, F91 (9Cr-1Mo-V-Nb). The creep performance of three types of F91 coupons, pristine, coated, and aged coupons is studied. The creep data obtained in the present study and those reported from the literature are used to validate the DMTS model. Four major achievements are obtained from this study. (i) The creep rate behavior of nine modified $9 \mathrm{Cr}$-1Mo steels in various product forms including tubes, pipes, plates, and forging is systematically characterized in terms of power-laws representing the aboveidentified deformation mechanisms; (ii) The creep strain-time behavior of the pristine and coated F91 steel is analyzed to verify the basic DMTS model and the modified DMTS model with consideration of oxidation, showing excellent agreement with the experimental observations; (iii) The effect of microstructural evolution is studied using aged F91 coupons, showing that Lave phase formation associated with grain boundary sliding is mostly responsible for the increased creep rate and shortening of creep life as compared to the pristine material; (iv) Last but not the least, long-term creep lives $\left(>10^{4}\right.$ hours) of modified Grade 91steels are predicted using the modified DMTS model, showing pronounced improvement over the basic model, indicating that oxidation effect is significant in long-time creep, whereas direct extrapolation from short-term 
creep test data is not correct for modified 9Cr-1Mo steels, because short-term creep life does not include enough oxidation effect. 


\section{Acknowledgments}

I would like to express my sincere gratitude to my thesis supervisors, Dr. Rong Liu, Dr. Xijia Wu and Dr. Jie Liu for providing me the opportunity to study on such interesting research topic. I sincerely appreciate the guidance, support, and patience they gave me over the course of my graduate studies.

Also, I am grateful for the NSERC-CRD funding from Natural Science \& Engineering Research Council of Canada (NSERC), the collaborative support from National Research Council Canada (NRC) and both financial and in-kind support from Kennametal Stellite Inc.

I would also like to thank my parents and parents-in-law for their unwavering support and encouragement which helped me persevere through trying times.

Finally, I would like to thank my wife Minyi for her immeasurable and continuing support and patience. I sincerely appreciate the support and sacrifice she has made to allow me for pursuing the work. I cannot imagine how I could go through this journey without her. 


\section{Table of Contents}

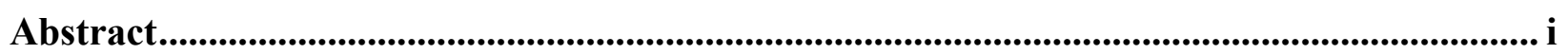

Table of Contents ..................................................................................................................... iv

List of Tables ............................................................................................................................ viii

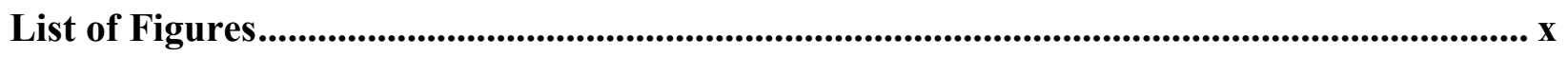

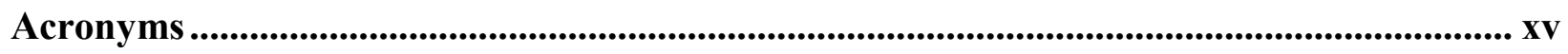

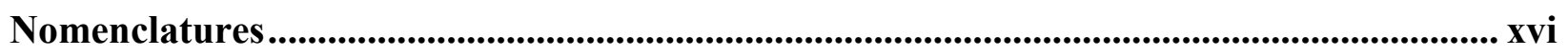

Chapter 1 Introduction.......................................................................................................... 1

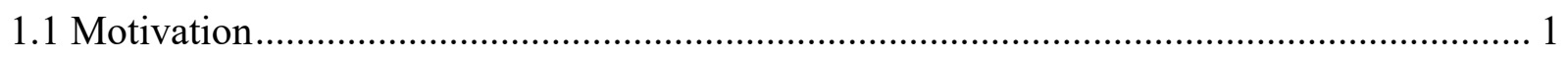

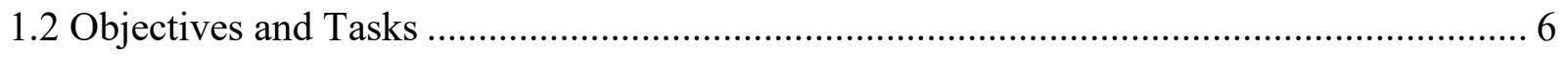

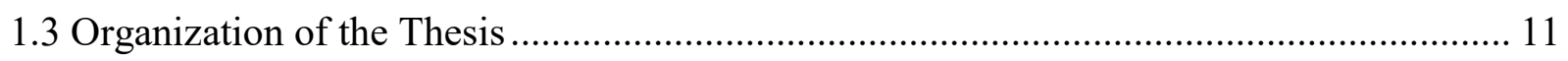

Chapter 2 Literature Review ............................................................................................................... 13

2.1 Modified 9Cr-1Mo Steels ................................................................................... 13

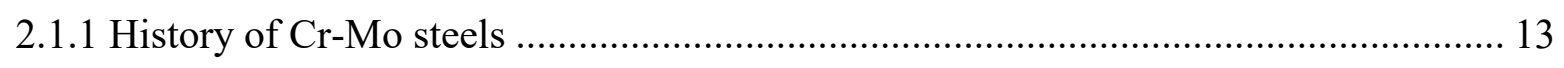

2.1.2 Microstructure of Cr-Mo steels.................................................................... 17

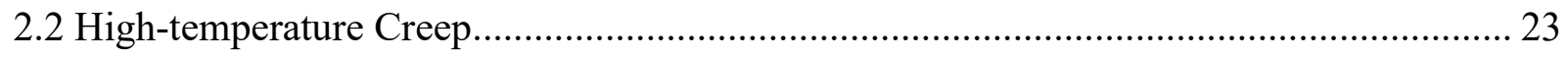

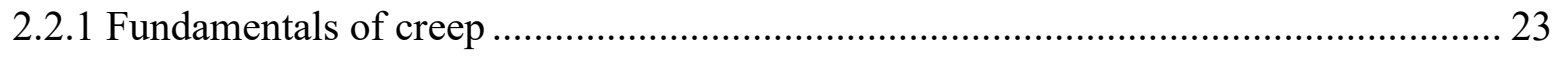

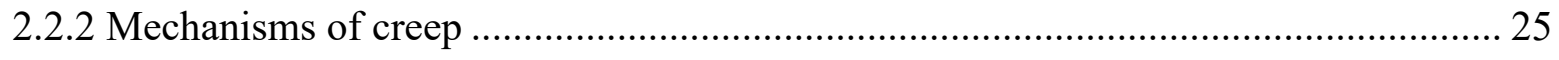

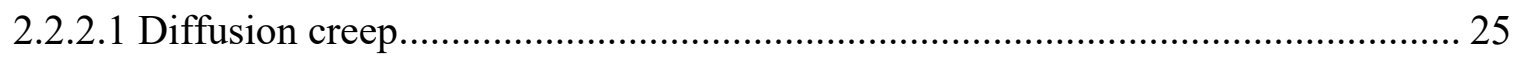

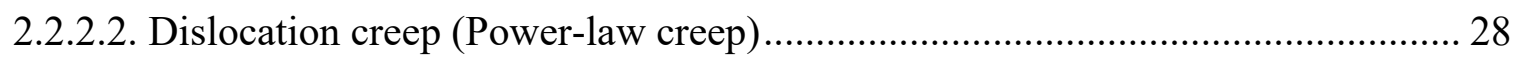

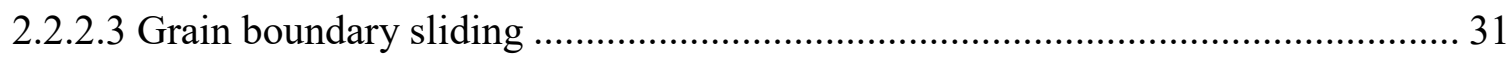

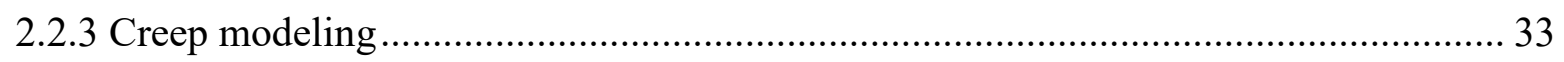

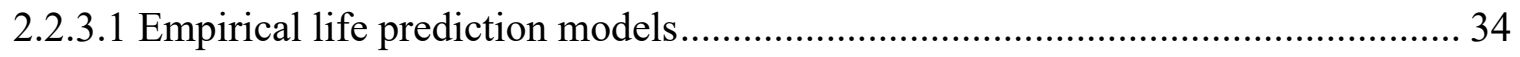


2.2.3.2 Physics-based models ................................................................................... 39

2.2.3.3 Deformation-mechanism maps ........................................................................... 41

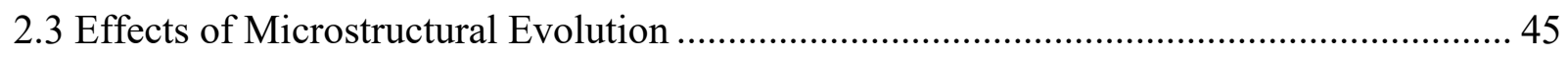

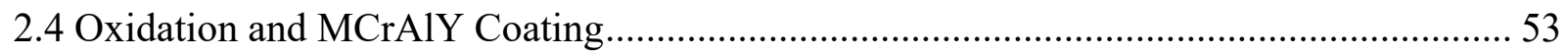

Chapter 3 Experimental Details .............................................................................................................. 57

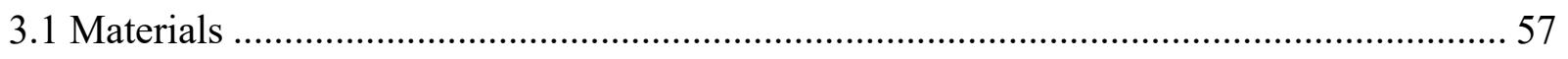

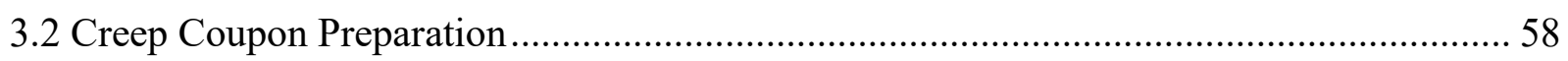

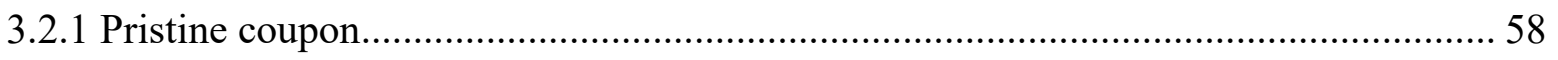

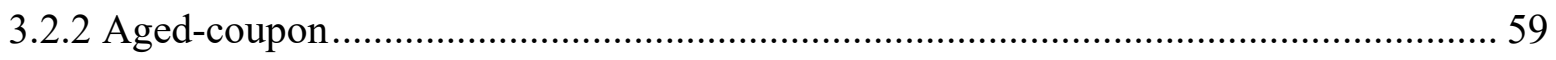

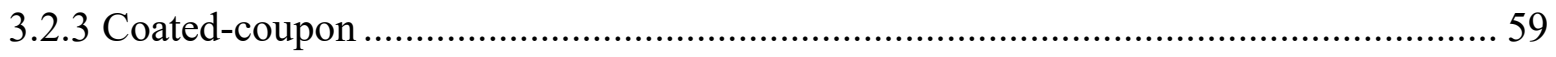

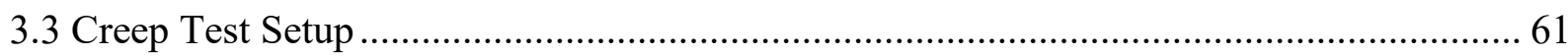

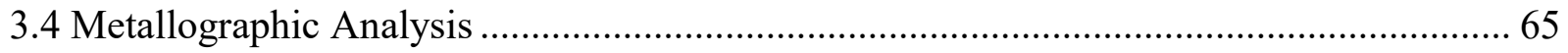

Chapter 4 Deformation Mechanism-based True-stress (DMTS) Creep Model...................... 68

4.1 Derivation of the Creep-constitutive Law from Deformation Mechanisms ........................ 69

4.2 Model Modification with Oxidation Effect ....................................................................... 76

Chapter 5 Modeling of Creep Behavior of Modified 9Cr-1Mo Steels ...................................... 79

5.1 Application of the DMTS Creep Model ………………................................................... 79

5.2 Model Validation for NIMS Grade 91 Steels ………………………………….............. 87

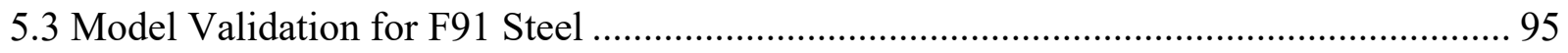

5.4 Strain-time Creep Curves of F91 Steel ……………............................................................ 97

5.5 Long-term Creep Life Prediction of Grade 91 Steels ...................................................... 104

5.5.1 Long-term creep lifetime prediction of NIMS Plate MgB ......................................... 109

5.5.2 Long-term creep lifetime prediction of various NIMS products ............................... 113

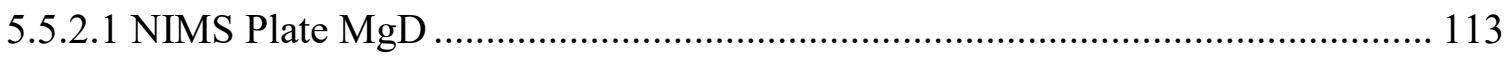

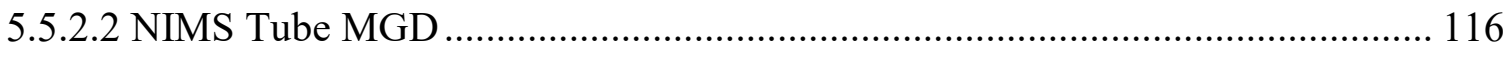


5.6 Summary of Model Validation ................................................................................... 122

Chapter 6 Model Modification with Oxidation Effect................................................................... 124

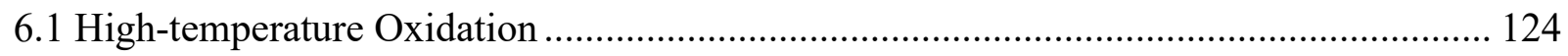

6.2 Oxide Scale Measurement and Modeling ……………….............................................. 125

6.3 Creep Strain-time Behavior of Coated F91 ………................................................... 130

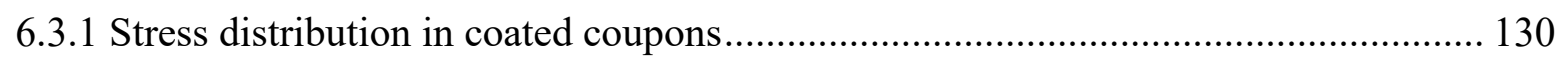

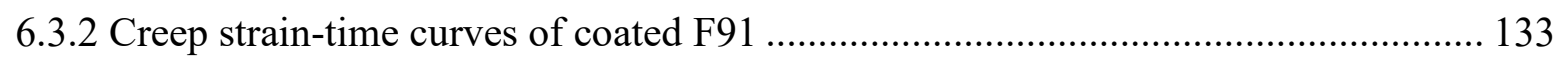

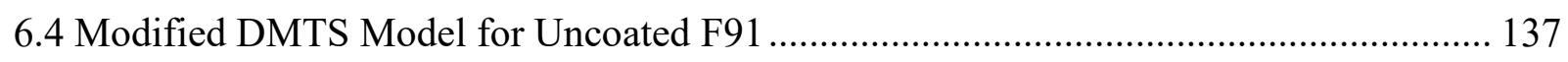

6.5 Modified DMTS Model for Creep Life Prediction........................................................... 140

6.6 Comparison between Larson-Miller Parameter Method and the Modified DMTS Model

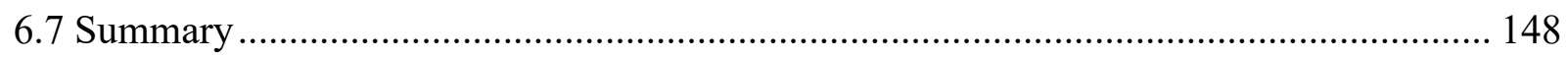

Chapter 7 Creep Performance of Heat-treated F91 Steel ............................................................. 149

7.1 Heat-treated High-chromium Steels ............................................................................ 149

7.2 Laves Phase Nucleation and Growth during Aging....................................................... 153

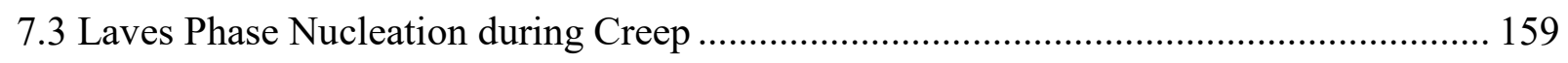

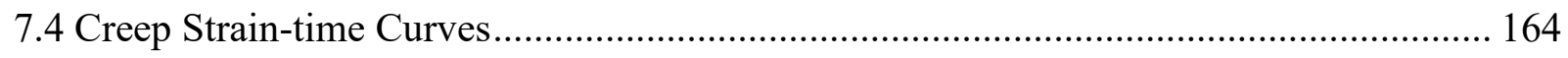

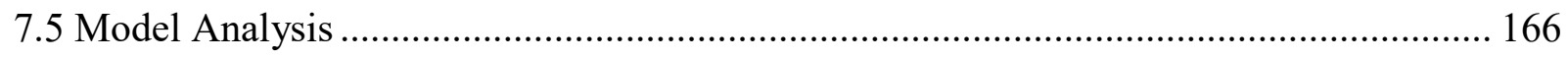

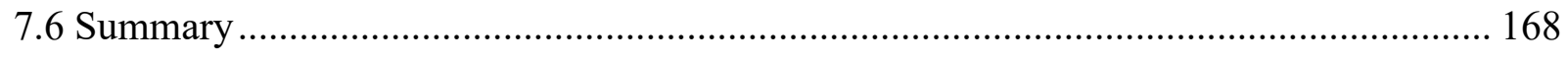

Chapter 8 Conclusions and Future Work ........................................................................................... 170

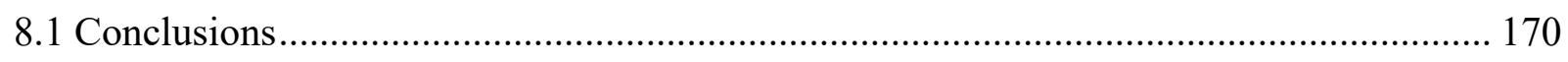

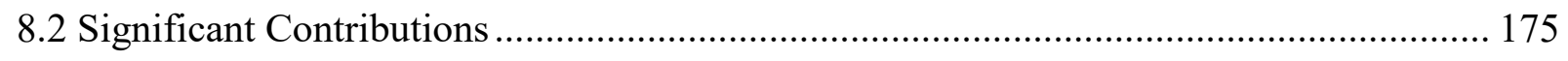

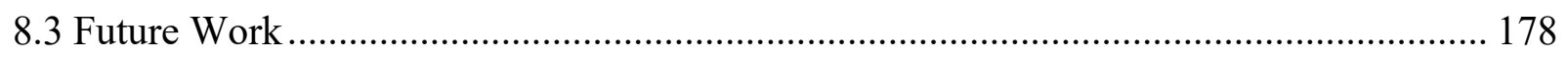

References.................................................................................................................................................. 180 
Appendix A: Nomenclature of creep strain-time curve .............................................. 189

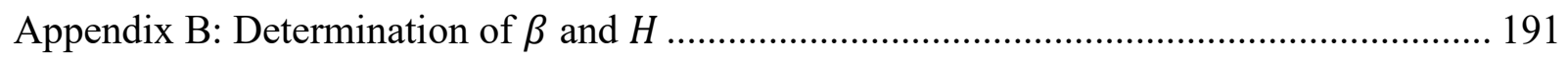

Appendix C: Raw data of creep tests and EDX analyses ............................................ 192

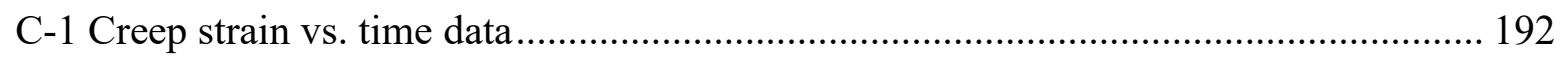

C-2 Elemental concentrations from EDX analyses ............................................... 193

C-2-1 EDX results of un-aged and aged coupons.................................................. 194

C-2-2 EDX results of fractured pristine coupons ................................................. 200

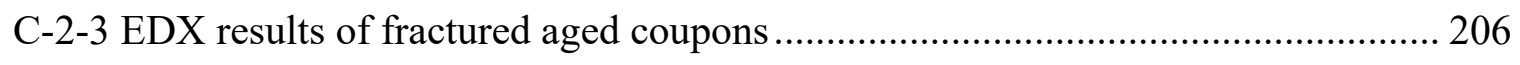

C-3 Area reduction measurements of creep-tested coupons ......................................... 212

C-4 Hardness test results................................................................................... 217 


\section{List of Tables}

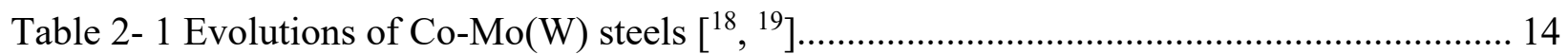

Table 2- 2 Chemical compositions of commercial and experimental CrMoW steels (wt.\%) [ $\left.{ }^{18},{ }^{19}\right]$

Table 2- 3 Ferrite stabilizers and austenite stabilizers .......................................................... 20

Table 2- $410^{5}$-hr creep-strength predictions of Grade 91 steel based on LMP $\left[{ }^{34}\right]$.................. 37

Table 2- 5 Common precipitation characteristics in $9-12 \%$ CrMoW martensitic steels $\left[{ }^{101}\right]$..... 51

Table 5- 1 Chemical compositions of modified 9Cr-1Mo steels $\left[{ }^{127}\right]$........................................ 82

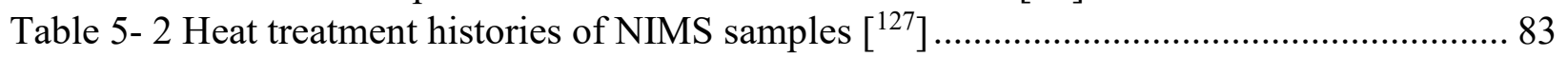

Table 5- 3 Ultimate tensile strength $(\sigma T)$ data of NIMS samples at elevated temperatures $\left[{ }^{127}\right] .84$

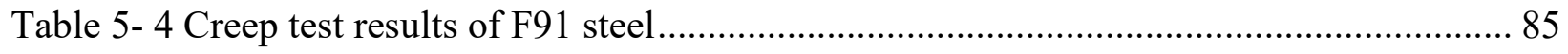

Table 5- 5 Mechanism parameters for 9Cr-1Mo-V-Nb steels .................................................. 89

Table 5- 6 Material property related model parameters for F91 steel ...................................... 98

Table 5- 7 Normalized dislocation multiplication factors $(M)$ by temperature ......................... 98

Table 5- 8 Critical strains at 90\%-TTR for F91 steel ......................................................... 107

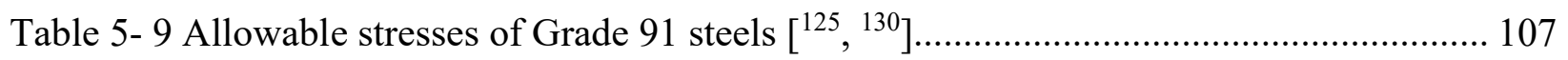

Table 5- 10 Summary of creep Life prediction of NIMS Plate MgB ..................................... 111

Table 5- 11 Summary of creep life prediction of NIMS Plate MgD ..................................... 114

Table 5- 12 Summary of creep life prediction results of NIMS Tube MGD ........................... 117

Table 5- 13 Summary of creep life prediction results of NIMS Pipe MGQ ........................... 120

Table 6- 1 Summary of oxidation loss and oxide rate coefficient Kox ................................. 128

Table 6- 2 Summary of stress distribution and coated-coupon creep test results .................... 133

Table 6- 3 Modified dislocation multiplication factor $M$................................................. 134

Table 6- 4 Comparison between LMP method and the modified DMTS model..................... 144

Table 7- 1 Hardness of the F91 coupon after aging heat treatment for different time durations 158

Table 7- 2 Comparison of aged-coupon and un-aged coupon creep test results ..................... 164

Table AP- 1 Creep test: minimum creep rate and time-to-rupture ....................................... 192

Table AP- 2 Creep test: summary of creep strain vs. time data........................................... 192

Table AP- 3 Elemental concentrations (wt.\%) of selected spots in un-aged coupon ................ 194

Table AP- 4 Elemental concentrations (wt.\%) of selected spots in $1000 \mathrm{hr}$ aged coupon ......... 195

Table AP- 5 Elemental concentrations (wt.\%) of selected spots in $2000 \mathrm{hr}$ aged coupon ......... 196

Table AP- 6 Elemental concentrations (wt.\%) of selected spots in $3000 \mathrm{hr}$ aged coupon ......... 197

Table AP- 7 Elemental concentrations (wt.\%) of selected spots in $4000 \mathrm{hr}$ aged coupon ......... 198

Table AP- 8 Elemental concentrations (wt.\%) of selected spots in $5000 \mathrm{hr}$ aged coupon ......... 199 
Table AP- 9 Elemental concentrations (wt.\%) of selected spots in fractured pristine coupon at $550^{\circ} \mathrm{C} / 220 \mathrm{MPa}$.

Table AP- 10 Elemental concentrations (wt.\%) of selected spots in fractured pristine coupon at $550^{\circ} \mathrm{C} / 240 \mathrm{MPa}$ 201

Table AP- 11 Elemental concentrations (wt.\%) of selected spots in fractured pristine coupon at $550^{\circ} \mathrm{C} / 260 \mathrm{MPa}$ 202

Table AP- 12 Elemental concentrations (wt.\%) of selected spots in fractured pristine coupon at $600^{\circ} \mathrm{C} / 130 \mathrm{MPa}$ 203

Table AP- 13 Elemental concentrations (wt.\%) of selected spots in fractured pristine coupon at $600^{\circ} \mathrm{C} / 140 \mathrm{MPa}$ 204

Table AP- 14 Elemental concentrations (wt.\%) of selected spots in fractured pristine coupon at $600^{\circ} \mathrm{C} / 160 \mathrm{MPa}$ 205

Table AP- 15 Elemental concentrations (wt.\%) of selected spots in fractured aged coupon at $550^{\circ} \mathrm{C} / 220 \mathrm{MPa}$. 206

Table AP- 16 Elemental concentrations (wt.\%) of selected spots in fractured aged coupon at $550^{\circ} \mathrm{C} / 240 \mathrm{MPa}$

Table AP- 17 Elemental concentrations (wt.\%) of selected spots in fractured aged coupon at $550^{\circ} \mathrm{C} / 260 \mathrm{MPa}$

Table AP- 18 Elemental concentrations (wt.\%) of selected spots in fractured aged coupon at $600^{\circ} \mathrm{C} / 130 \mathrm{MPa}$

Table AP- 19 Elemental concentrations (wt.\%) of selected spots in fractured aged coupon at $600^{\circ} \mathrm{C} / 140 \mathrm{MPa}$.

Table AP- 20 Elemental concentrations (wt.\%) of selected spots in fractured aged coupon at $600^{\circ} \mathrm{C} / 160 \mathrm{MPa}$. 


\section{List of Figures}

Fig. 1 - 1. Georgia power's plant: a coal-fired thermoelectric power generation scheme $\left[{ }^{4}\right] \ldots \ldots . . . .3$

Fig. 1 - 2. Korean Generation IV sodium-cooled fast reactor (SFR) material selection $\left[{ }^{5}\right]$........... 4

Fig. 1 - 3. General principle of material design. ................................................................... 4

Fig. 1 - 4. Task integration of experimental and modeling studies........................................ 11

Fig. 2- 1. Microstructure of as-received F91 at $1000 \mathrm{x}$ magnification. ..................................... 18

Fig. 2- 2. Microstructure of as-received F91 at $8000 \mathrm{x}$ magnification. ................................... 18

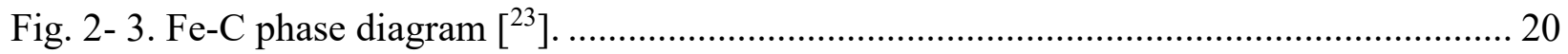

Fig. 2- 4. Microstructure of HT9 in (a) normalized (b) normalized and tempered conditions $\left[{ }^{18}\right]$.

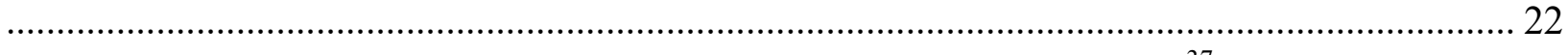

Fig. 2- 5. Schematic creep curves of a material at a constant temperature $\left[{ }^{37}\right]$...................... 24

Fig. 2- 6. Schematic creep curves of a material under constant stress $\left[{ }^{37}\right]$............................. 25

Fig. 2- 7. Vacancy flow mechanisms according to (a) Nabarro-Herring (b) Coble $\left[{ }^{46}\right]$.............. 26

Fig. 2- 8. Dislocation climb: (a) upward, under compression; (b) downward, under tension $\left[{ }^{43}\right] .27$

Fig. 2- 9. Dislocation glide limited by (a) discrete obstacles; (b) lattice resistance $\left[{ }^{38}\right]$............. 28

Fig. 2- 10. Climb of an edge dislocation, permitting continued glide over an obstacle $\left[{ }^{49}\right]$........ 29

Fig. 2- 11. Dislocation movement: (a) climb; (b)climb plus glide $\left[{ }^{38}\right]$. .................................... 30

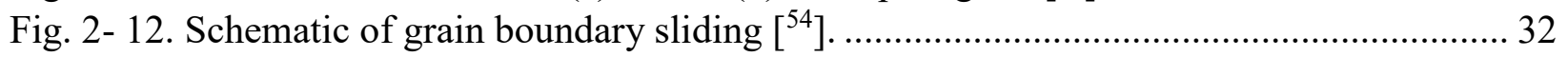

Fig. 2- 13. Larson-Miller parameters for various materials $\left[{ }^{69}\right]$............................................ 35

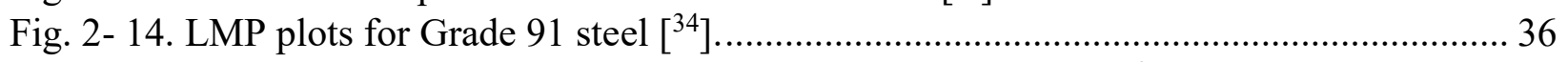

Fig. 2- 15. Stress dependence of steady-state creep rates for P91steel $\left[{ }^{73}\right]$............................. 38

Fig. 2- 16. Deformation-mechanism map of pure nickel with a grain size of $1 \mu \mathrm{m}\left[{ }^{85}\right]$............ 42

Fig. 2- 17. Schematic deformation-mechanisms map with response functions $\left[{ }^{87}\right]$.................. 43

Fig. 2- 18. Deformation mechanism maps for pure aluminum at homologous temperatures of .. 43

Fig. 2- 19. Deformation mechanism maps for pure aluminum at $\sigma G=10-6\left[{ }^{90}\right] \ldots \ldots \ldots \ldots \ldots . . . .44$

Fig. 2- 20. Deformation-mechanism maps with consideration of GBS mechanism: (a) revision of

pure nickel map by Ashby; (b) revision of aluminum map by Langdon and Mohamed $\left[{ }^{91}\right]$........ 44

Fig. 2- 21. Micrographs of $\mathrm{M}_{23} \mathrm{C}_{6}$ and $\mathrm{MX}$ re-crystallization near prior austenite grain boundary

$\left[{ }^{94}\right]$.

Fig. 2- 22. Illustration of martensitic 9Cr steel after tempering: (a) subgrain structure; (b)

distribution of M23C6 and MX in conventional $\left[{ }^{94}\right]$.

Fig. 2- 23. Comparison between $\mathrm{A}$ and $\mathrm{B}$ states of $\mathrm{P} 91$ creep curves at $600^{\circ} \mathrm{C}$ under two stresses:

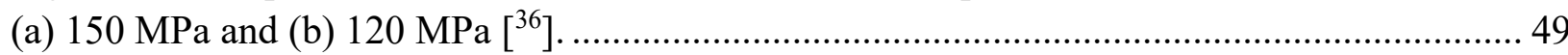

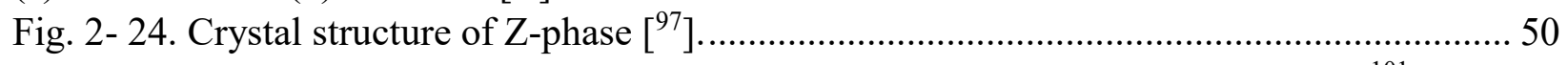

Fig. 2- 25. An illustration of the most common precipitates in $9-12 \%$ CrMoW steels $\left[{ }^{101}\right]$........ 51

Fig. 2- 26. Effects of microstructural changes on the creep strength of $9-12 \%$ Cr steels $\left[{ }^{36}\right]$... 52

Fig. 2- 27. The longitudinal cross-section of the oxide scale on T91 after creep-to-rupture for 31

hrs in the stagnant air at $650^{\circ} \mathrm{C}$ under a stress of $155 \mathrm{MPa}$ : (a) near the necking region and (b) in

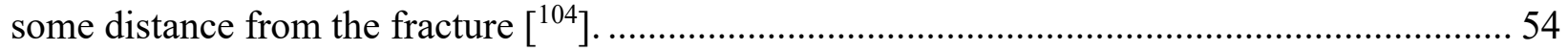


Fig. 2- 28. The hardness of VPS and HVOF coatings as a function of annealing temperature $\left[{ }^{109}\right]$. 55

Fig. 2- 29. $\beta$ precipitates volume fraction as a function of annealing temperature for VPS and

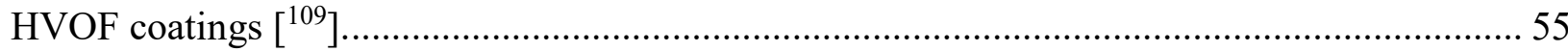

Fig. 3 - 1. Creep test coupon: (a) design drawing; (b) photo................................................. 59

Fig. 3-2. Coated coupon: (a) comparison with pristine coupon; (b) showing coating thickness. 60

Fig. 3- 3. Schematic drawing of main components of creep testing machine $\left[{ }^{111}\right] \ldots \ldots \ldots \ldots \ldots \ldots . . . . . . .62$

Fig. 3 - 4. Coupon assembly in extensometer with both connecting rods attached.................... 63

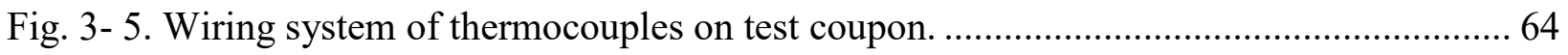

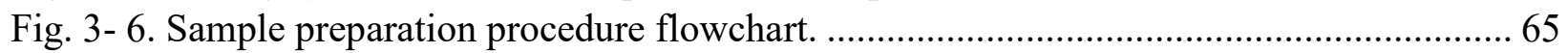

Fig. 3 - 7. Optical microscopes: (a) Olympus GX71; (b) Nikon SMZ1000............................. 66

Fig. 3 - 8. SEM/EDX facilities: (a) PHILIPS XL3053; (b) Tescan Vega- II XMU.................... 67

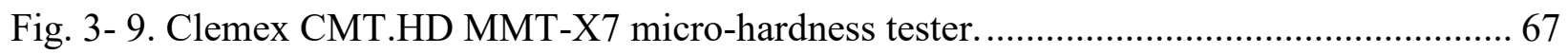

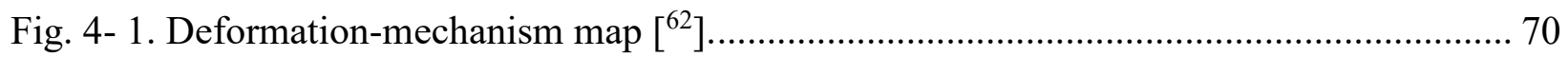

Fig. 4- 2. Time-dependent deformation hierarchical chart. ................................................ 70

Fig. 4- 3. Demonstration of the Arrhenius plot....................................................................... 73

Fig. 5- 1. Model parameter validation and life prediction flowchart......................................... 81

Fig. 5-2. Bilinear trends of ultimate tensile strengths of Grade 91 steels $\left[{ }^{127}\right]$......................... 84

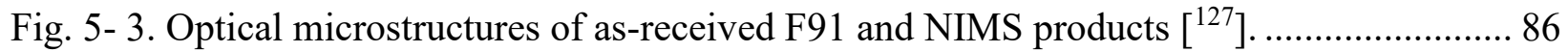

Fig. 5- 4. Power-law exponents according to the rate-stress map of NIMS plate MgB $\left[{ }^{127}\right]$....... 88

Fig. 5- 5. Minimum creep rates of NIMS Tube MGD (symbols: experimental data; lines: model).

Fig. 5- 6. Minimum creep rates of NIMS Tube MGF (symbols: experimental data; lines: model).

Fig. 5- 7. Minimum creep rates of NIMS Tube MGG (symbols: experimental data; lines: model).

Fig. 5- 8. Minimum creep rates of NIMS Plate MgA (symbols: experimental data; lines: model).

Fig. 5- 9. Minimum creep rates of NIMS Plate MgB (symbols: experimental data; lines: model).

Fig. 5- 10. Minimum creep rates of NIMS Plate MgC

(symbols: experimental data; lines: model).

Fig. 5- 11. Minimum creep rates of NIMS Plate MgD

(symbols: experimental data; lines: model).

Fig. 5- 12. Minimum creep rates of NIMS Pipe MGQ

(symbols: experimental data; lines: model).

Fig. 5- 13. Minimum creep rates of F91 collated with NIMS Plate MgB

(symbols: experimental data; lines: model). 
Fig. 5- 14. Experimental and model F91 creep curves at $500^{\circ} \mathrm{C}$. 99

Fig. 5- 15. Experimental and model F91 creep curves at $550^{\circ} \mathrm{C}$. 99

Fig. 5- 16. Experimental and model F91 creep curves at $600^{\circ} \mathrm{C}$. 100

Fig. 5- 17. Experimental and model F91 creep curves at $650^{\circ} \mathrm{C}$. 100

Fig. 5- 18. SEM images of longitudinal cross-section microstructure near the fracture region of the specimen tested at $550^{\circ} \mathrm{C}$ under different stress levels. 102

Fig. 5- 19. SEM images of longitudinal cross-section microstructure near the fracture region of the specimen tested at $600^{\circ} \mathrm{C}$ under different stress levels. ................................................ 103

Fig. 5- 20. Ruptured F91 coupons show pronounced necking behavior. ................................. 106

Fig. 5- 21. 90\%-TTR associated with strain. ................................................................. 106

Fig. 5- 22. Creep life prediction of NIMS Plate MgB. ...................................................... 112

Fig. 5- 23. Creep life prediction of NIMS Plate MgD............................................................. 115

Fig. 5- 24. Creep life prediction of NIMS Tube MGD.......................................................... 118

Fig. 5- 25. Creep life prediction of NIMS Pipe MGQ....................................................... 121

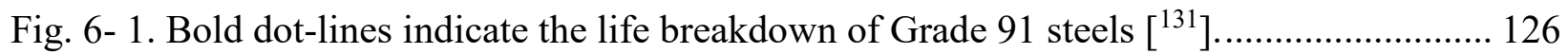
Fig. 6- 2. Optical microscope observations of cross-sections of ruptured uncoated F91 coupons showing oxide scale formation on the coupon surfaces.................................................. 126

Fig. 6- 3. Schematic drawing of creep-ruptured coupon cross section................................... 127

Fig. 6- 4. Kox Arrhenius-plot for activation energy and proportinal constant determination.... 129 Fig. 6- 5. Coating adhesiveness analysis of a ruptured coated-coupon: (a) as-ruptured state; (b) longitudinal cut............................................................................................... 132 Fig. 6- 6. The Young's modulus at elevated temperatures of HVOF coated F91 with MCrAlY (close symbol: experimental data; open symbol: extrapolated value) [ $\left.{ }^{109}\right]$..... 132 Fig. 6- 7. Creep strain-time curves of coated-coupons at $550^{\circ} \mathrm{C}$ and the DTMS model description.

Fig. 6- 8. Creep strain-time curves of coated-coupons at $600^{\circ} \mathrm{C}$ and the DTMS model description.

Fig. 6- 9. SEM microstructures of the longitudinal cross section near the fracture region of the coated-coupons at $550^{\circ} \mathrm{C}$ and $600^{\circ} \mathrm{C}$. 136 Fig. 6- 10. Comparison between basic and modified DMTS models for creep strain-time curves of uncoated F91coupons at $500^{\circ} \mathrm{C}$. 138 Fig. 6- 11. Comparison between basic and modified DMTS models for creep strain-time curves of uncoated $\mathrm{F} 91$ coupons at $550^{\circ} \mathrm{C}$. 138 Fig. 6- 12. Comparison between basic and modified DMTS models for creep strain-time curves of uncoated F91 coupons at $600^{\circ} \mathrm{C}$. 139

Fig. 6- 13. Comparison between basic and modified DMTS models for creep strain-time curves of uncoated F91 coupons at $650^{\circ} \mathrm{C}$. 
Fig. 6- 14. Comparison between basic and modified DMTS models for life prediction of $\mathrm{MgB}$ (symbols: experimental; solid lines: DMTS model; dash lines: modified DMTS model)........ 141 Fig. 6- 15. Comparison between basic and modified DMTS models for life prediction of MgD (symbols: experimental; solid lines: DMTS model; dash lines: modified DMTS model)........ 141 Fig. 6- 16. Comparison between basic and modified DMTS models for life prediction of MGD (symbols: experimental; solid lines: DMTS model; dash lines: modified DMTS model)......... 142 Fig. 6- 17. Comparison between basic and modified DMTS models for life prediction of MGQ (symbols: experimental; solid lines: DMTS model; dash lines: modified DMTS model)......... 142 Fig. 6- 18. Data required for the modified DMTS model..................................................... 144 Fig. 6- 19. The modified DMTS model prediction of NIMS Plate MgB in LMP plot with

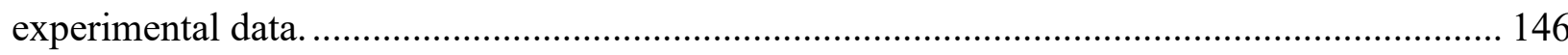

Fig. 6- 20. Microstructural analyses with mechanism indication pie-charts. 147

Fig. 7- 1. EDX spectra of the matrix, M23C6, Laves phase and Z-phase in un-aged F91......... 155

Fig. 7- 2. Laves phase nucleation during aging heat treatment. .............................................. 157

Fig. 7- 3. Variations of Mo concentration in Mo-rich clusters and particle size during aging... 158 Fig. 7- 4. Comparison in microstructure between un-aged and aged ruptured coupons tested at $550^{\circ} \mathrm{C}$ 160

Fig. 7- 5. Comparison in microstructure between un-aged and aged ruptured coupons tested at $600^{\circ} \mathrm{C}$ 161

Fig. 7- 6. Variations of Mo concentration with test duration in creep ruptured aged-coupons. . 163 Fig. 7- 7. Laves phase growth rates as a function of stress in aged-coupons during creep tests. 163 Fig. 7- 8. Creep strain-time curves of un-aged and aged coupons tested at $550^{\circ} \mathrm{C}$.................... 165

Fig. 7- 9. Creep strain-time curves of un-aged and aged coupons tested at $600^{\circ} \mathrm{C}$................... 165

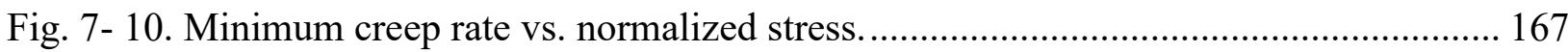

Fig. 7- 11. Comparison of minimum creep rate between two types of coupon without IDG..... 167

Fig. AP- 1. Typical creep strain-time curve and definition of transient strain $\left[{ }^{57}\right] \ldots \ldots \ldots \ldots \ldots \ldots \ldots . . .190$

Fig. AP- 2. Selected spots in un-aged coupon for EDX analysis. ............................................... 194

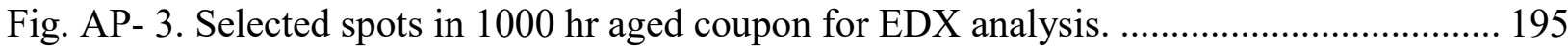

Fig. AP- 4. Selected spots in $2000 \mathrm{hr}$ aged coupon for EDX analysis. ...................................... 196

Fig. AP- 5. Selected spots in $3000 \mathrm{hr}$ aged coupon for EDX analysis. ...................................... 197

Fig. AP- 6. Selected spots in $4000 \mathrm{hr}$ aged coupon for EDX analysis. ..................................... 198

Fig. AP- 7. Selected spots in $5000 \mathrm{hr}$ aged coupon for EDX analysis. ...................................... 199

Fig. AP- 8. Selected spots in the fractured pristine coupon at $550^{\circ} \mathrm{C} / 220 \mathrm{MPa}$ for EDX analysis.

Fig. AP- 9. Selected spots in the fractured pristine coupon at $550^{\circ} \mathrm{C} / 240 \mathrm{MPa}$ for EDX analysis. 201

Fig. AP- 10. Selected spots in the fractured pristine coupon at $550^{\circ} \mathrm{C} / 260 \mathrm{MPa}$ for EDX analysis. 202 
Fig. AP- 11. Selected spots in the fractured pristine coupon at $600^{\circ} \mathrm{C} / 130 \mathrm{MPa}$ for EDX analysis.

Fig. AP- 12. Selected spots in the fractured pristine coupon at $600^{\circ} \mathrm{C} / 140 \mathrm{MPa}$ for EDX analysis. 204

Fig. AP- 13 Selected spots in the fractured pristine coupon at $600^{\circ} \mathrm{C} / 160 \mathrm{MPa}$ for EDX analysis.

Fig. AP- 14. Selected spots in the fractured aged coupon at $550^{\circ} \mathrm{C} / 220 \mathrm{MPa}$ for EDX analysis. 206

Fig. AP- 15 Selected spots in the fractured aged coupon at $550^{\circ} \mathrm{C} / 240 \mathrm{MPa}$ for EDX analysis. 207 Fig. AP- 16. Selected spots in the fractured aged coupon at $550^{\circ} \mathrm{C} / 260 \mathrm{MPa}$ for EDX analysis.

Fig. AP- 17. Selected spots in the fractured aged coupon at $600^{\circ} \mathrm{C} / 130 \mathrm{MPa}$ for EDX analysis.

Fig. AP- 18 . Selected spots in the fractured aged coupon at $600^{\circ} \mathrm{C} / 140 \mathrm{MPa}$ for EDX analysis.

Fig. AP- 19. Selected spots in the fractured aged coupon at $600^{\circ} \mathrm{C} / 160 \mathrm{MPa}$ for EDX analysis.

Fig. AP- 20. Cross section of original coupon.................................................................. 212

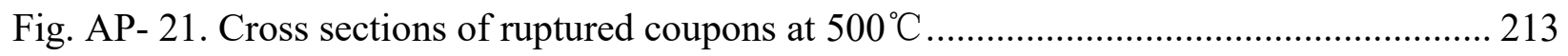

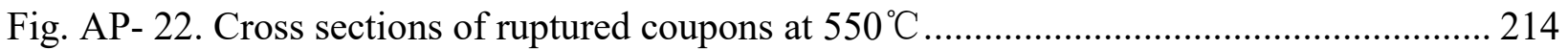

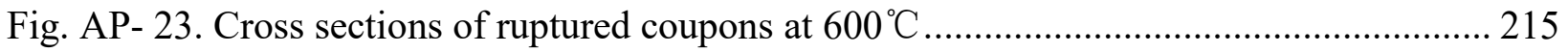

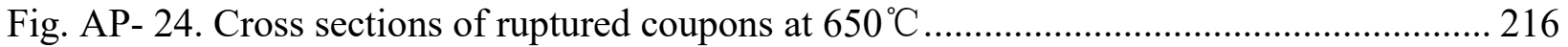

Fig. AP- 25. Indention surfaces of un-aged and aged coupons. ......................................... 217 


\section{Acronyms}

\begin{tabular}{|c|c|}
\hline ASME & American Society of Mechanical Engineers \\
\hline ASTM & American Society for Testing and Materials \\
\hline A-USC & Advanced Ultra-Supercritical \\
\hline BSE & Backscattered Electrons \\
\hline CSEF & Creep Strength-Enhanced Ferritic steel \\
\hline CT & Computed Tomography \\
\hline DMTS & Deformation-Mechanism-based True-Stress model \\
\hline EDX & Energy Dispersive X-ray \\
\hline FEM & Finite Element Method \\
\hline GBS & Grain Boundary Sliding \\
\hline HVOF & High-Velocity Oxy-Fuel \\
\hline ID & Intragranular Deformation \\
\hline IDC & Intragranular Dislocation Climb \\
\hline IDG & Intragranular Dislocation Glide \\
\hline LVDT & Linear Variable Displacement Transducer \\
\hline NIMS & National Institute for Materials Science (Japan) \\
\hline SEM & Scanning Electron Microscope \\
\hline TBC & Thermal Barrier Coating \\
\hline TEM & Transmission Electron Microscope \\
\hline TGO & Thermally Grown Oxide \\
\hline UTS & Ultimate Tensile Strength \\
\hline VPS & Vacuum Plasma Spraying \\
\hline
\end{tabular}




\section{Nomenclatures}

\begin{tabular}{|c|c|}
\hline$\varepsilon$ & strain \\
\hline$\dot{\varepsilon}$ & strain rate \\
\hline$\dot{\varepsilon}_{s s}$ & steady state strain rate \\
\hline$\dot{\varepsilon_{s}}, \dot{\varepsilon_{g}}, \dot{\varepsilon_{c}}$ & strain rate of GBS, IDG, IDC, respectively \\
\hline$\varepsilon_{0}$ & initial elastic-plastic strain \\
\hline$\varepsilon_{P}$ & engineering primary strain \\
\hline$\varepsilon_{S}$ & engineering secondary strain \\
\hline$\varepsilon_{t r}^{P}$ & primary creep coefficient \\
\hline$\varepsilon_{t r}^{S}$ & secondary creep strain \\
\hline$\varepsilon_{c r}$ & critical strain \\
\hline$D_{l}$ & lattice diffusion coefficient \\
\hline $\boldsymbol{b}$ & Burgers' vector \\
\hline $\boldsymbol{G}, \boldsymbol{\mu}$ & shear modulus \\
\hline $\boldsymbol{\sigma}$ & true stress \\
\hline$\sigma_{T}$ & ultimate tensile strength \\
\hline$\sigma_{0}$ & initial engineering stress \\
\hline$\rho_{m}$ & mobile dislocation density \\
\hline $\bar{v}$ & average dislocation velocity \\
\hline $\boldsymbol{m}, \boldsymbol{n}, \boldsymbol{p}$ & power exponents \\
\hline$A_{0}, B_{0}, C_{0}$ & proportional constants \\
\hline$Q, Q_{A}, Q_{B}, Q_{C}$ & activation energies for the respective mechanisms \\
\hline$M$ & dislocation multiplication factor \\
\hline $\boldsymbol{\beta}$ & material parameter \\
\hline $\boldsymbol{H}$ & work hardening coefficient of GBS \\
\hline$T$ & absolute temperature in $\mathrm{K}$ \\
\hline$t$ & exposure time \\
\hline TTR, $t_{r}$ & time to creep rupture \\
\hline $\boldsymbol{R}$ & gas constant \\
\hline $\boldsymbol{\delta}$ & oxide scale \\
\hline$K_{o x}$ & oxidation rate coefficient \\
\hline$\omega_{o x}$ & oxide scale coefficient \\
\hline
\end{tabular}




\section{Chapter 1 Introduction}

\subsection{Motivation}

With the growing needs of increasing energy efficiency and reducing $\mathrm{CO}_{2}$ greenhouse emission, steam turbines are required to operate at increasingly high temperatures. Since the 1940 s, $9 \mathrm{Cr}-1 \mathrm{Mo}$ steels have been widely used in boiler/pressure vessel and piping systems of various powergenerators from conventional coal-fired power plants to the advanced ultra-supercritical (A-USC) steam turbines, until the latest generation IV nuclear fast reactor $\left[{ }^{1},{ }^{2},{ }^{3}\right]$. Fig. 1 - 1 shows a picture of the Robert W Scherer Power Plant (Georgia, USA), a coal-fired thermoelectric powergeneration scheme $\left[{ }^{4}\right]$. Fig. 1- 2 shows the main components of Korean sodium-cooled fast reactor, where modified 9Cr-1Mo steel is used as the material for heat exchanger, pipe and steam generator, etc. $\left.{ }^{5}\right]$. For applications in such complicated engineering systems, there are many considerations to be taken in selecting the candidate materials. Apart from economic and logistic considerations, material properties such as hardness, tensile strength, creep strength, ductility, corrosion resistance, etc., are the major concerns as to whether the material can sustain the design load for the expected service period.

In material design/selection, the relationships between material's structure, properties and performance need to be considered, as shown in Fig. 1- 3. The composition and manufacturing process determine the microstructure of the material made, which control the properties of the material. The engineers have to decide which properties are suitable for the intended application. From a pure material development point of view, material engineers (suppliers) always strive to develop advanced materials with better properties. On the other hand, the mechanical design 
engineers (users) only want the material to have the desired properties at the lowest cost. Therefore, both sides have come to an understanding on which factors matter among the above relationships (Fig. 1- 3). The 9Cr-1Mo steels were developed as a group of creep strength-enhanced ferritic (CSEF) steels. As far as creep resistance is concerned, steam turbines are required to operate over $10^{5}$ hours, there are several factors that must be completely understood for the design of their components.

1. What are the effects of chemical composition and/or the manufacturing process (fabrication and heat treatment, etc.) on the material's creep performance?

2. Would the material microstructure change during long-time service, and if changed, would it affect the material's performance?

3. Does the operating environment have an effect on the material's performance?

These questions have not been fully answered by the studies reported in the literature. For example, prediction of long-term creep properties using short-term experiments is still rated as one of the most important challenges in assessing structural durability, as regarded by the UK energy sector $\left[{ }^{6},{ }^{7}\right]$. 


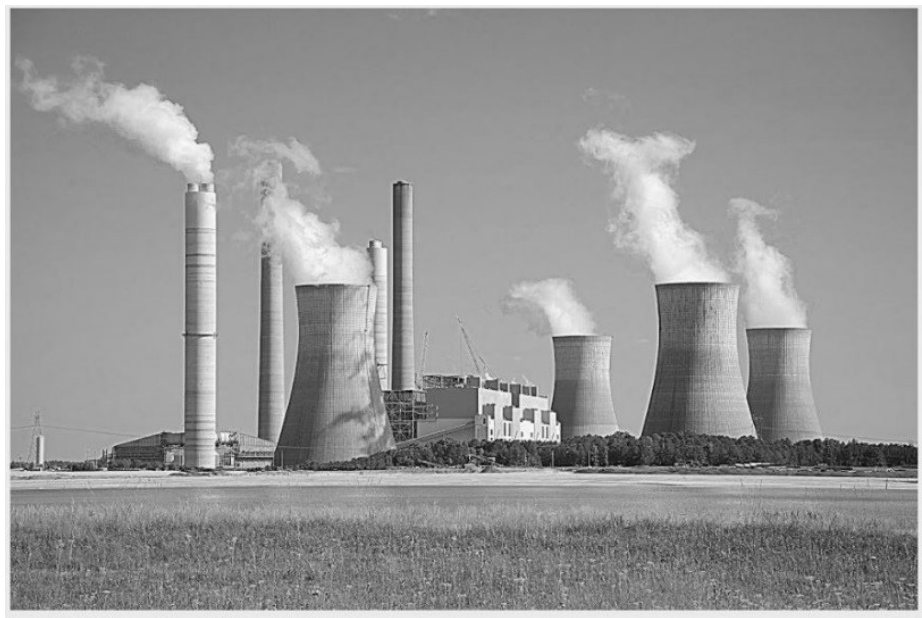

Robert W. Scherer Power Plant

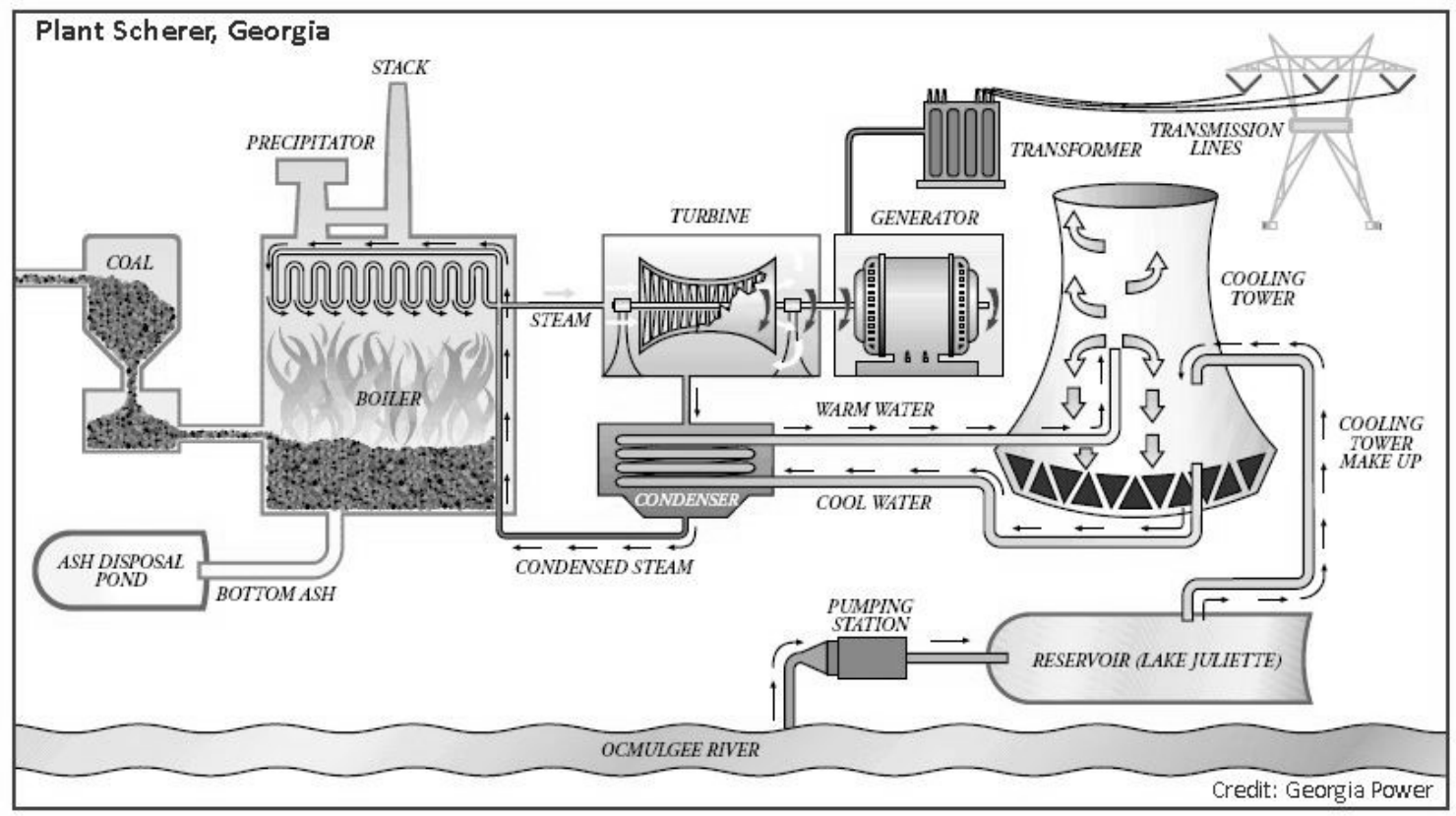

Fig. 1- 1. Georgia power's plant: a coal-fired thermoelectric power generation scheme $\left[{ }^{4}\right]$. 


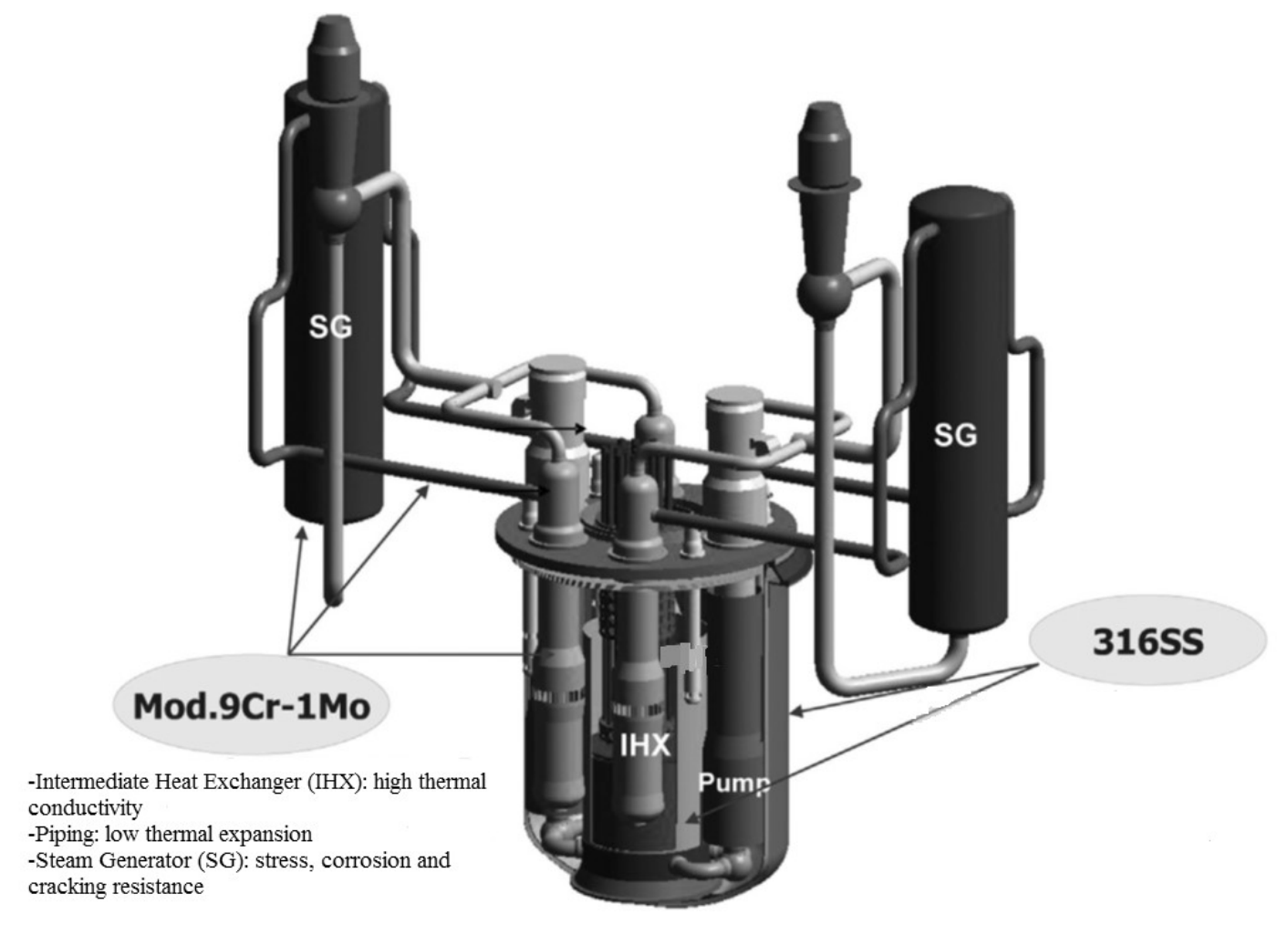

Fig. 1- 2. Korean Generation IV sodium-cooled fast reactor (SFR) material selection $\left.{ }^{5}\right]$.

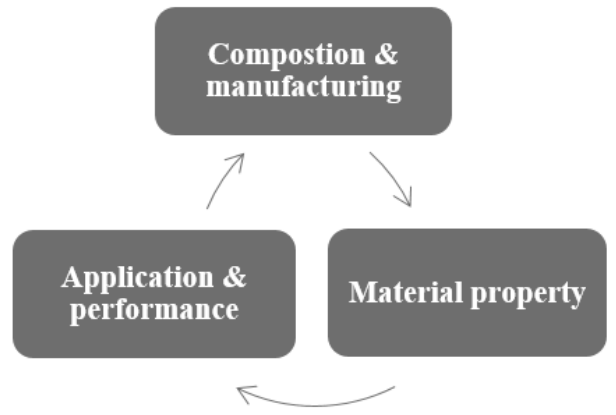

Fig. 1- 3. General principle of material design.

In this study, modified $9 \mathrm{Cr}-1 \mathrm{Mo}$ steel $-\mathrm{F} 91$ steel $(9 \mathrm{Cr}-1 \mathrm{Mo}-\mathrm{V}-\mathrm{Nb})$ is selected as the material of study to establish physics-based relationships between material's structure, properties, and performance. F91 steel belongs to the family of high $\mathrm{Cr}$ steels that were originally designed in the 1920s for conventional power-generation plants. More recently, it was modified and heat treated as $9 \mathrm{Cr}-1 \mathrm{Mo}-\mathrm{V}-\mathrm{Nb}$ steel with high hardness, good creep rupture properties, and excellent toughness 
at elevated temperatures, usually above $540^{\circ} \mathrm{C}\left[{ }^{8},,^{9},{ }^{10}\right]$. It has become a favorable material used widely throughout the piping and boiler industry nowadays. In fact, modified 9Cr-1Mo steels have been studied for decades. There exists abundant information on different types of modified $9 \mathrm{Cr}-$ 1Mo steels, which certainly benefits this study for validation and calibration of the proposed DMTS and modified models.

In service, in addition to material internal damage by creep mechanisms, surface damage oxidation is another life-limiting factor for materials in the A-USC steam environment or gas turbine environment, where the interaction between oxidation and creep is of concern. To prevent oxide penetration, oxidation-resistant coatings are usually applied to protect the components from environmental attack. Among such coatings, MCrAlY coating, where M represents Co or Ni or $\mathrm{Co} / \mathrm{Ni}$ combination, has been widely applied to gas turbine components, especially on the first and second stage turbine blades and nozzle guide vanes, where it may prevent high-temperature oxidation and hot corrosion $\left[{ }^{11},{ }^{12}\right]$. Also, it has often been applied as a bond coat between thermal barrel coating (TBC) and the metal substrate. Many studies on MCrAlY type coatings have been reported, including experimental investigation and analytical modeling. Thompson et al. investigated the creep behavior of vacuum plasma spray (VPS) NiCrAlY and CoNicrAlY coatings up to $850^{\circ} \mathrm{C}$, both coatings behaved in a manner obeying the power-law creep theory $\left[{ }^{13},{ }^{14}\right]$. The effect of plasma sprayed NiCrAlY coatings on the creep resistance of Ni-based alloy Inconel 690 at $760^{\circ} \mathrm{C}$ has been investigated. The experimental results demonstrated that the coating had a beneficial effect on the creep resistance of the substrate. For the coated alloy, the relationship between the applied stress and time-to-rupture was established using the Larson-Miller parameter method $\left[{ }^{15}\right]$. Although a few researchers have applied different coatings on $9 \mathrm{Cr}-1 \mathrm{Mo}$ steel to study oxidation at the microstructural level, their emphases were not on the relationship between 
oxidation and creep behavior of the material. Chang et al. applied an Al-Si coating on 9Cr-1Mo steel by hot dipping and then investigated the coating properties after exposure at $750^{\circ} \mathrm{C}, 850^{\circ} \mathrm{C}$ and $950^{\circ} \mathrm{C}$ in the stagnant air for up to 56 hours $\left[{ }^{16}\right]$. Emami et al. used laser surface alloying to coat $\mathrm{FeAl}$ on $9 \mathrm{Cr}-1 \mathrm{Mo}$ steel and studied the coating performance $\left[{ }^{17}\right]$. Creep behavior of F91 with MCrAlY coating is certainly of interest as an option to enhance the long-term creep performance of the material. However, the coating effect as oxidation protection on F91 has never been studied in the literature.

The motivation of this thesis research is to provide the steam turbine industry with long-term creep properties of F91 steel by establishing a physics-based approach to systematically characterize the creep performance of modified $9 \mathrm{Cr}-1 \mathrm{Mo}$ steels, and thereby to understand their properties that are controled by different deformation mechanisms, microstructural evolution and environmental effects, and furthermore to provide information to alloy designers to help them tailor the microstructure or apply environmental protection coatings for enhancing their long-term creep resistance for the above designated and other suited applications.

\subsection{Objectives and Tasks}

The three questions raised in the above section regarding the effects of processing, microstructure, and environment, are common to all material designs for high temperature applications. To systematically and completely understand these issues, a physics-based approach must be employed to analyze every variable including the various aspects of the physical factors involved. This approach involves a vast amount of experimental and analytical work. In the past, empirical approaches typically addressed one variable at a time but not relating the other variables, thus not 
providing a complete understanding of their interaction. Towards this goal, with regards to modified 9Cr-1Mo steels, the objectives of this thesis research are:

1. To develop a mechanism-based creep model based on material-intrinsic deformation-mechanisms and a modified creep model with oxidation influence included for characterizing creep performance of modified 9Cr-1Mo steels.

2. To provide a mechanism-delineated characterization of the creep rate behavior for modified 9Cr-1Mo steels in various product forms including tubes, pipes, plates and forged products with different heat treatment history.

3. To study the effect of oxidation on creep behavior of the pristine (uncoated and unaged) and coated F91 steel to validate the modified deformation-mechanism-based creep model with consideration of oxidation, and explore MCrAlY coating as a means for oxidation protection to enhance the long-term creep performance of modified 9Cr-1Mo steels.

4. To study the effect of microstructural evolution on creep behavior through metallurgical analyses and creep tests of aged F91 coupons, and quantitatively characterize the influence of microstructural changes on the creep performance of F91 in relation to the rate controlling deformation mechanism(s).

5. To establish a physics-based approach for long-term creep life prediction ( $>10^{4}$ hours) for modified 9Cr-1Mo steels under various stress and temperature conditions, considering all the involved deformation mechanisms and oxidation. 
To achieve these objectives, an experimental/metallurgical/mechanism-based analytical approach is implemented for doing the following tasks.

Task 1 -Literature Review. An extensive literature review is carried out to understand the current scope and state-of-the-art of research on modified $9 \mathrm{Cr}-1 \mathrm{Mo}$ steels. It also includes a review of creep phenomena; fundamental deformation mechanisms including diffusion, intragranular dislocation glide (IDG), intragranular dislocation climb (IDC), and grain boundary sliding (GBS); as well as existing creep models and life prediction methods.

Task 2 - Creep Testing. A series of creep tests are conducted for the following purposes:

1. First, pristine coupons are machined from as-received F91 bars to be creep-tested at temperatures varying from 500 to $650^{\circ} \mathrm{C}$, and under stresses varying between 80 $320 \mathrm{MPa}$. Such temperature and stress ranges are commonly reported in the literature. Thus, the test data were compared and combined with the available NIMS creep data for validation of the proposed model.

2. Second, six as-machined F91 coupons were subjected to additional aging heat treatment at $600^{\circ} \mathrm{C}$ for up to 5,000 hours and then tested under various stresses at $550^{\circ} \mathrm{C}$ and $600^{\circ} \mathrm{C}$. The aging process produced changes in the microstructures with the time of exposure. The subsequent creep tests on aged coupons were then carried out to investigate the effect of microstructural degradation on the creep behavior of the material.

3. To separate the effect of oxidation from the material-intrinsic creep behavior and to explore coating as a means to enhance the long-term creep performance of the 
modified 9Cr-1Mo steels, MCrAlY coated F91 coupons were creep-tested under the same stresses at $550^{\circ} \mathrm{C}$ and $600^{\circ} \mathrm{C}$ for comparison.

Task 3 - Metallurgical Examination. Metallurgical examination is always an important part of materials study. This thesis research, in particular, it is intended to find evidence of microstructural evolution, deformation and damage mechanisms in the aforementioned three types of coupons (pristine, aged, and coated), and degrees of environmental (oxidation) impact on the creep behavior of the coupons. Depending on the purpose, the following metallographic techniques were utilized in this study.

1. Optical microscopy techniques were used to pre-examine polished and etched surfaces of samples, and to measure the cross-section surface areas in pristine and oxidized conditions.

2. Scanning electron microscopy (SEM) techniques were mostly used to examine the microstructures in pristine and crept conditions.

3. Two SEM facilities with energy dispersive X-ray (EDX) were used to identify precipitates, e.g., the Laves phase, formed during microstructural evolution in the aged and crept coupons. Particularly, its effects on the operation of deformation mechanisms were analyzed, which provided a link between microstructural evolution and creep performance through deformation mechanism changing.

Task 4 - Model Development. First of all, a deformation-mechanism-based true-stress (DMTS) creep model was developed for modified 9Cr-1Mo steels, considering IDG, IDC, and GBS, based on the framework first proposed for a Ni-base superalloy-Waspaloy. In the present study, the applied stresses were normalized with the temperature-dependent 
ultimate tensile strength of F91 to facilitate mechanism delineation. Then, the effect of oxide scale formation during creep process was considered in the modification of the DMTS model.

Task 5 - Model Validation and Creep Analysis. The DMTS model and the modified DMTS model with oxidation consideration was validated using the creep data generated in this study as well as the NIMS creep data. In particular, the following creep analyses were performed.

1. The basic DMTS creep model was used to analyze the stress-temperature dependence of the minimum creep rates of various product forms of modified 9Cr-1Mo steels, including F91, to delineate the IDG, IDC and GBS mechanism contributions.

2. The basic DMTS creep model was used to analyze the creep strain-time behavior of coated F91 coupons.

3. The modified DMTS creep model was used to analyze the creep strain-time behavior of uncoated F91 coupons.

4. Last but not the least, long-term creep lives of modified 9Cr-1Mo steels was predicted using both the basic DMTS and the modified DMTS creep model with the mechanism parameters determined from short-term creep tests. 
As shown in Fig. 1- 4, the experimental and modeling studies of modified 9Cr-1Mo steels are integrated into this thesis, to achieve the goal of predicting long-term creep lives.

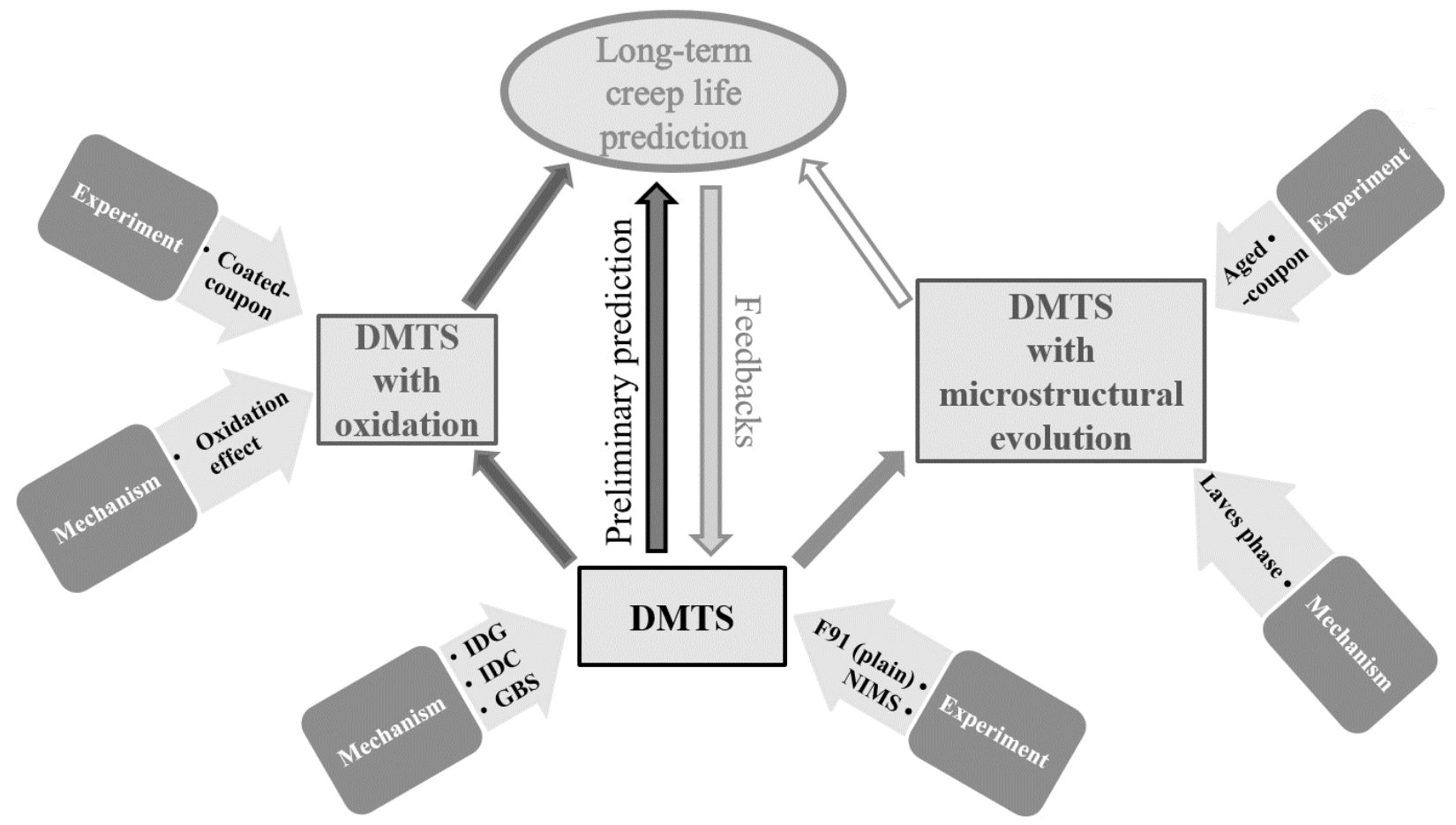

Fig. 1- 4. Task integration of experimental and modeling studies.

\subsection{Organization of the Thesis}

Chapter 1 is an introduction to this research, indicating the motivation, objectives and tasks to be performed. A comprehensive literature review is summarized in Chapter 2, where a fundamental understanding of the $9 \mathrm{Cr}-1 \mathrm{Mo}$ steel family with their manufacturing processes, basic microstructures and properties, concepts of creep and various aspects of the creep phenomena including empirical and analytical relationships as reported in the literature are reviewed. The experimental approach of this thesis study is outlined in Chapter 3, where the experimental methods including the material - F91 in the pristine, aged, and MCrAlY-coated conditions are 
detailed. A test plan is given as to generate creep data for comparison with the creep data reported in the literature and new data on uncoated and MCrAlY-coated F91. These creep test data are also used for validation of the proposed model. The detailed model development is described in Chapter 4. A deformation-mechanism-based modeling approach is taken to derive a true-stress creep model, first considering intragranular dislocation glide, climb, and grain boundary sliding mechanisms, and later modified to include the oxidation effect. Chapter 5 presents the model validation using the pristine coupon tests and microstructural evidence from this study as well as the evaluation of the model performance by analyzing and comparing the creep test results with the literature data. Chapter 6 analyzes the coated-coupon creep test results that are utilized to further validate the basic deformation-mechanism-based true-stress creep model and modify the model to include the oxidation effect and compare the results with the creep behavior of the pristine coupons. Chapter 7 elucidates the aged-coupon creep test results and a complete investigation of microstructural evolution regarding Laves phase formation and its effects on the creep performance of F91 steel. In the last chapter, Chapter 8, significant contributions and conclusions of this thesis research are summarized, and finally, suggestions for future research are made to further complete the understanding of creep behavior of modified 9Cr-1Mo steels. 


\section{Chapter 2 Literature Review}

\subsection{Modified 9Cr-1Mo Steels}

\subsubsection{History of $\mathrm{Cr}$-Mo steels}

Modified 9Cr-1Mo steels belong to the high-chromium steel family, which usually contain 9 - 12\% chromium (Cr). Grade 9 designates 9Cr steels, Grade 91 designates 9Cr-1Mo steels. Modified 9Cr-1Mo steels particularly contain additional alloying elements such as $\mathrm{V}$ and $\mathrm{Nb}$, which are further classified into different groups, such as T91 for tubing, P91 for piping, and F91 for forgings.

The Cr-Mo steels were first developed in the 1920s for applications in conventional power generators, such as boilers and piping systems at elevated temperature. In the $1940 \mathrm{~s}, \mathrm{Fe}-2.25 \mathrm{Cr}-$ 1.0Mo-0.3Si-0.45Mn-0.12C (wt.\%) steel was named as ASTM Grade 22, or T22, which is still widely used today. To enhance the corrosion resistance, more Cr was added to upgrade the steel, leading to Fe-9.0Cr-1.0Mo-0.6Si-0.45Mn-0.12C, an early version of 9Cr-1Mo (T9) steel. Mo and W were added to this type of steels as solutes, in order to improve both uniform and localized corrosion resistance, especially in chloric and sulphuric environments. In martensitic steels, they increase the hardness at higher tempering temperatures due to their effect on carbide precipitation. Ever since this material innovation, there has been a continuous demand to increase the operating temperatures of conventional fossil-fueled power generation systems. The demand has motivated the material engineers to develop several generations of Cr-Mo steels to improve their strengths at elevated temperatures. Table 2- 1 summarizes all generations of Grade 91 steels starting from the 1940s, typically T22 and T9, all the way to the fifth generation in development at present. Table 2- 2 lists the nominal compositions of commercial and experimental Cr-Mo (W) steels. Note that 
the additional names given in brackets are other names commonly adopted for a specific grade of Cr-Mo steels according to different standards or literature $\left[{ }^{18},{ }^{19}\right]$.

Table 2- 1 Evolutions of Co-Mo(W) steels [ $\left[{ }^{18},{ }^{19}\right]$

\begin{tabular}{|c|c|c|c|c|c|}
\hline Generation & Years & $\begin{array}{c}\text { Steel } \\
\text { modification }\end{array}$ & $\begin{array}{c}10^{5}-\mathrm{hr} \\
\text { rupture } \\
\text { strength, } \\
600^{\circ} \mathrm{C} \\
(\mathrm{MPa})\end{array}$ & Steels & $\begin{array}{c}\text { Max use } \\
\text { temperature } \\
\left({ }^{\circ} \mathrm{C}\right)\end{array}$ \\
\hline 1 & $1940-60$ & & 40 & T22, T9 & $520-538$ \\
\hline 2 & $1960-70$ & $\begin{array}{l}\text { Addition of } \\
\text { Mo,Nb, V }\end{array}$ & 60 & $\begin{array}{c}\text { EM12, } \\
\text { HCM9M, } \\
\text { HT9, НT91 }\end{array}$ & 565 \\
\hline 3 & $1970-85$ & $\begin{array}{c}\text { Optimization } \\
\text { of } \mathrm{C}, \mathrm{Nb}, \mathrm{V}, \\
\mathrm{N}\end{array}$ & 100 & $\begin{array}{l}\text { HCM12, } \\
\text { Mod. 91 } \\
\text { HCM2S }\end{array}$ & $593-620$ \\
\hline 4 & $1985-95$ & $\begin{array}{c}\text { Partial } \\
\text { substitution } \\
\text { of } \mathrm{W} \text { for Mo } \\
\text { and adding } \\
\mathrm{Cu}, \mathrm{B}\end{array}$ & 140 & $\begin{array}{c}\text { NF616, } \\
\text { E911, } \\
\text { HCM12A }\end{array}$ & 620 \\
\hline 5 & Developing & $\begin{array}{c}\text { Increase W } \\
\text { and adding } \\
\text { Co }\end{array}$ & 180 & $\begin{array}{c}\text { NF12, } \\
\text { SAVE12 }\end{array}$ & 650 \\
\hline
\end{tabular}


Table 2- 2 Chemical compositions of commercial and experimental CrMoW steels (wt.\%) $\left[{ }^{18},{ }^{19}\right]$

\begin{tabular}{|c|c|c|c|c|c|c|c|c|c|c|c|}
\hline Grade & $\mathrm{C}$ & Si & Mn & $\mathrm{Cr}$ & Mo & $\mathbf{W}$ & $\mathbf{V}$ & $\mathbf{N b}$ & B & $\mathbf{N}$ & Other \\
\hline $\begin{array}{c}\mathrm{T} 22 \\
(2.25 \mathrm{Cr} 1 \mathrm{Mo})\end{array}$ & $\begin{array}{l}0.15 \\
\max \end{array}$ & 0.3 & 0.45 & 2.25 & 1.0 & & & & & & \\
\hline $\begin{array}{c}\mathrm{T} 23 \\
(2.25 \mathrm{Cr} 1.6 \mathrm{WVNb})\end{array}$ & 0.06 & 0.2 & 0.45 & 2.25 & 0.1 & 1.6 & 0.25 & 0.05 & 0.003 & & \\
\hline $\begin{array}{c}\mathrm{T} 24 \\
(2.25 \mathrm{Cr} 1 \mathrm{MoVTi})\end{array}$ & 0.08 & 0.3 & 0.50 & 2.25 & 1.0 & & 0.25 & & 0.004 & $\begin{array}{l}0.03 \\
\max \end{array}$ & $0.07 \mathrm{Ti}$ \\
\hline $\begin{array}{c}\text { HT9 } \\
\text { (12Cr1MoWV) }\end{array}$ & 0.2 & 0.4 & 0.6 & 12.0 & 1.0 & 0.5 & 0.25 & & & & $0.5 \mathrm{Ni}$ \\
\hline $\begin{array}{c}\text { HT91 } \\
(12 \mathrm{Cr} 1 \mathrm{MoV})\end{array}$ & 0.2 & 0.4 & 0.6 & 12.0 & 1.0 & & 0.25 & & & & $0.5 \mathrm{Ni}$ \\
\hline $12 \mathrm{CrMoV}$ & 0.20 & 0.30 & .50 & 12.0 & 1.0 & & .25 & & & & $0.70 \mathrm{Ni}$ \\
\hline EM12 & 0.10 & 04 & 1 & 9.5 & 2.0 & & 30 & 0.40 & & & \\
\hline $\begin{array}{c}\text { ORNL } \\
\text { 3Cr3WV }\end{array}$ & 0.10 & 0.14 & 0.50 & 3.0 & & 3.0 & 0.25 & & & & \\
\hline $\begin{array}{c}\text { ORNL } \\
\text { 3Cr3WVTa }\end{array}$ & 0.10 & 0.14 & 0.50 & 3.0 & & 3.0 & 0.25 & & & & $0.10 \mathrm{Ta}$ \\
\hline T9 (9Cr1M & 2 & & & 9.0 & & & & & & & \\
\hline $\begin{array}{l}\text { T91, F91, P } \\
(\operatorname{Mod} 9 \text { Cr1N }\end{array}$ & 0.10 & 0.4 & 0.40 & 9.0 & 1.0 & & 0.2 & 0.08 & & 0.05 & \\
\hline HCM12 & 10 & 3 & 0.55 & 12.0 & 1.0 & 1.0 & 25 & 0.05 & & 0.1 & \\
\hline $\mathrm{pE9}$ & 11 & & & 9.0 & 1 & 1.0 & 0 & 0.1 & & 0. & \\
\hline T92 (NF61 & 07 & 0.06 & 0.45 & 9.0 & 0.50 & 1.8 & 0.20 & 0.05 & 0.004 & 0.06 & \\
\hline W.Nr.1. & 15 & 0.4 & 0 . & 11.0 & 0.5 & & 0.30 & 0.25 & 0.008 & 0.03 & $0.70 \mathrm{Ni}$ \\
\hline MAN & 14 & 0.4 & 0.75 & 10.8 & 0.75 & & 20 & 0.15 & 0.009 & 0.02 & $0.90 \mathrm{Ni}$ \\
\hline TB12 & 0.10 & 0.06 & 0.05 & 12.0 & 0.50 & 1.8 & 0.20 & 0.05 & 0.004 & 0.06 & $0.1 \mathrm{Ni}$ \\
\hline TB12M & 0.13 & 0.25 & 0.50 & 11.0 & 0.50 & 1.8 & 0.20 & 0.06 & & 0.06 & $1.0 \mathrm{Ni}$ \\
\hline T122 (HCM12A) & 0.11 & 0.1 & 0.60 & 12.0 & 0.40 & 2.0 & 0.25 & 0.05 & 0.003 & 0.06 & $\begin{array}{l}0.3 \mathrm{Ni} \\
1.0 \mathrm{Cu} \\
\end{array}$ \\
\hline NF12 & 0.08 & 0.2 & 0.50 & 11.0 & 0.20 & 2.6 & 0.20 & 0.07 & 0.004 & 0.05 & $\begin{array}{l}3.0 \mathrm{Co} \\
0.07 \mathrm{Ta}\end{array}$ \\
\hline SAVE12 & 0.10 & 0.3 & 0.20 & 11.0 & & 3.0 & 0.20 & 0.07 & & 0.04 & $0.04 \mathrm{Nd}$ \\
\hline
\end{tabular}


The second-generation of Cr-Mo steels started with 9-12\% Cr content, in which the high $\mathrm{Cr}$ content was added to improve oxidation/corrosion resistance under elevated-temperature operating conditions. In this generation, in addition to the higher $\mathrm{Cr}$ content, carbide-forming alloying elements such as niobium $(\mathrm{Nb})$ and vanadium $(\mathrm{V})$ were added to the original $\mathrm{T} 22$ and $\mathrm{T} 9$ compositions to introduce precipitate strengthening. Some grades contain a small amount of W, partially as an alternative of Mo, in addition to the solid solution strengthening by Mo $\left[{ }^{18}\right]$. The Mo and W have similar strengthening effects by enhancing hardness, hardenability, and toughness, as well as creep strength at elevated temperatures. Corrosion resistance and machinability are also improved by adding these elements. In the Cr-Mo (W) steels family, the Mo and W contents are often adjusted for particular applications.

For the third generation, in addition to an optimized combination of $\mathrm{C}, \mathrm{Nb}$, and $\mathrm{V}$, nitrogen (N) were added. The F91 belongs to this generation, and it has been extensively used by the power generation industry all over the world. The maximum operating temperature for this generation of Cr-Mo steels is $593-620^{\circ} \mathrm{C}\left[{ }^{20},{ }^{21},{ }^{22}\right]$. Due to the ferritic/martensitic microstructure of this generation steels, they were primarily considered in the 1970 s for elevated temperature in-core applications (cladding, wrappers, and ducts) for fast breeder reactors in the nuclear power industry. Since then, continuous demand to improve the properties of Cr-Mo or Cr-M-W family of steels for nuclear power generators has increased $\left[{ }^{18}\right]$.

The fourth generation primarily substituted $\mathrm{W}$ for some amount of Mo and utilized Ni and B (boron). They were designed for $620^{\circ} \mathrm{C}$ operating conditions with the $600^{\circ} \mathrm{C}-10^{5}$ hour creep-rupture strength of $140 \mathrm{MPa}$. The new generation in development, i.e., the fifth generation, is aimed at higher operating temperature $-650^{\circ} \mathrm{C}$. By adding $\mathrm{Co}$ (cobalt) up to $3.0 \mathrm{wt} . \%$ with the $600^{\circ} \mathrm{C}-10^{5}$ hour creep-rupture strength targeted at $180 \mathrm{MPa}\left[{ }^{18},{ }^{19}\right]$. 


\subsubsection{Microstructure of Cr-Mo steels}

To achieve the desired strength, solid-solution alloying is often not enough. Also, microstructure has to be tailored to maximize the strengthening effect. Some additives to the Cr-Mo steels are just to facilitate the introduction of additional strengthening mechanism via precipitation hardening. The desirable microstructure of $9-12 \% \mathrm{Cr}$ steels is $100 \%$ martensite after quenching. In general, the steels are first normalized (or austenitized) at $1080^{\circ} \mathrm{C}\left(1975^{\circ} \mathrm{F}\right)$ for 4 hours. During this austenitization (normalization) treatment, $100 \%$ austenite is formed by balancing the austenite and ferrite stabilizers. Then, the materials are quenched by either at-temperature-air cooling or liquidcoolant cooling for 1 - 2 hours, during which the $100 \%$ austenite transforms to $100 \%$ martensite. Subsequently, the materials are tempered at $800^{\circ} \mathrm{C}\left(1470^{\circ} \mathrm{F}\right)$ for 5 hours, followed by attemperature-air cooling, to allow precipitation within the materials. The as-received F91 bar products are normalized and air-cooled. The typical martensitic microstructure of this steel under scanning electron microscopy (SEM) is shown in Fig. 2- 1 and Fig. 2- 2, which is isotropic in both longitudinal and transverse cross-sections. Fig. 2- 1 clearly shows the prior austenite grain boundaries which are conferred from austenitization, while Fig. 2- 2 shows that precipitates are located on the boundaries. 


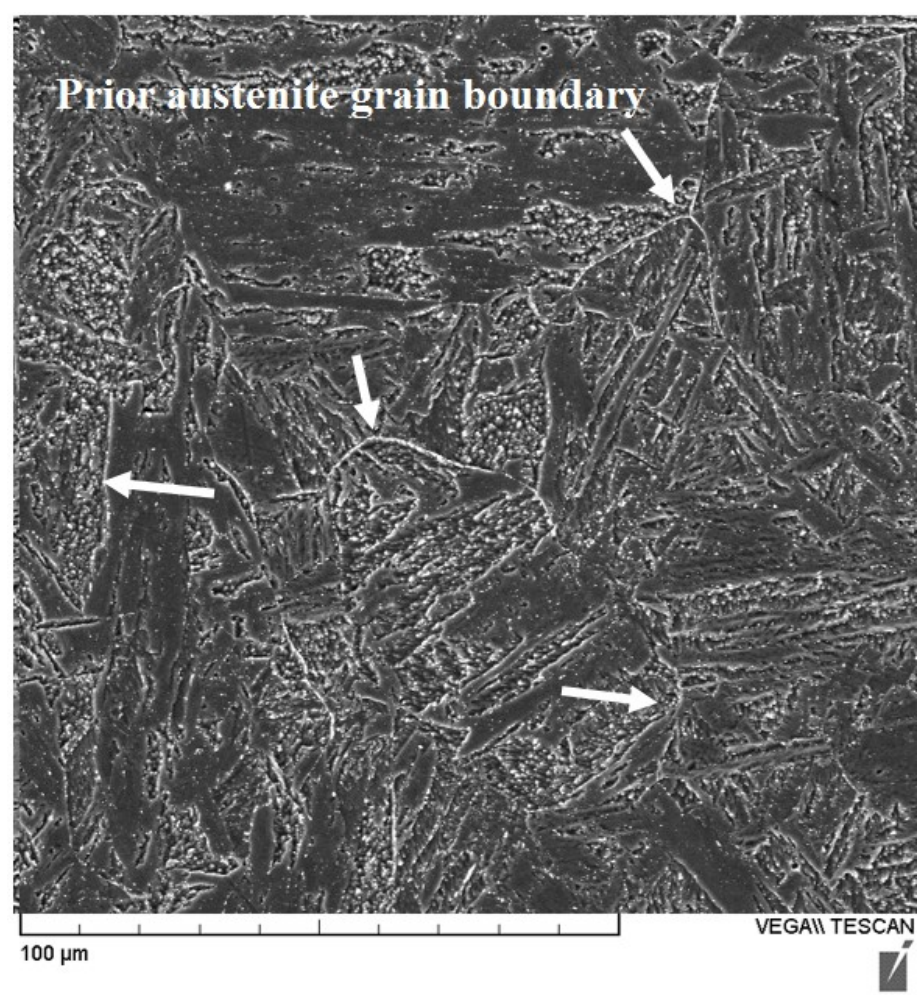

Fig. 2- 1. Microstructure of as-received F91 at 1000 x magnification.

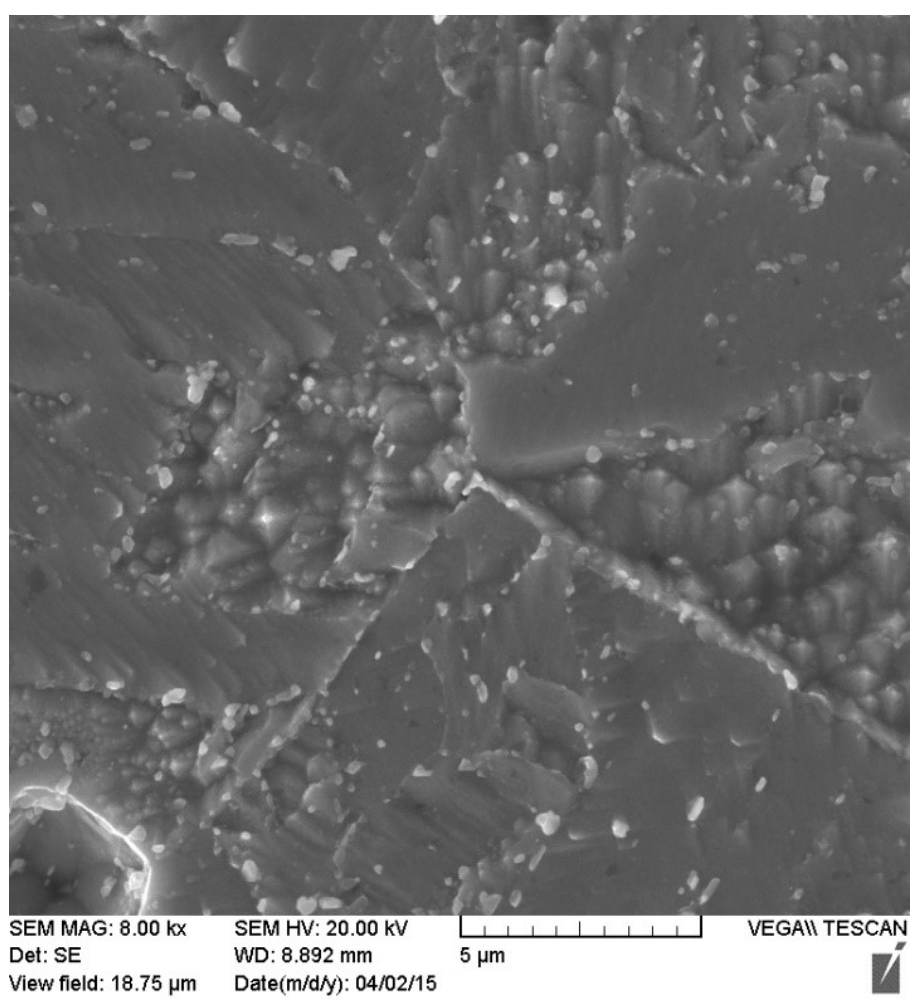

Fig. 2- 2. Microstructure of as-received F91 at 8000 x magnification. 
As the chemical compositions of this family of steels have changed for generations, metallurgists use F91 as the benchmark for comparison nowadays. In other words, F91 is a "base broth" with different "spices" (elements) added to improve its properties. Understanding the effect of chemical composition on the microstructure of F91 is crucial for understanding the material's structure-property relationships during creep, as it sets an example for the whole family of Cr-Mo steels.

First of all, it is essential to understand the effects of alloying with regards to austenite stabilizing and ferrite stabilizing in F91, since the 100\% martensitic structure is transformed from the $100 \%$ austenitic structure. Generally, alloying elements in steels, such as $\mathrm{Cr}, \mathrm{Mo}, \mathrm{W}, \mathrm{Al}, \mathrm{Ti}$, $\mathrm{Nb}, \mathrm{Si}$, etc., are ferrite stabilizers that stabilize the body-centered cubic (b.c.c.) ferrite phase. Whereas $\mathrm{C}, \mathrm{N}, \mathrm{Mn}, \mathrm{Ni}, \mathrm{Cu}$, etc., are austenite stabilizers that stabilize the face-centered cubic (f.c.c.) austenite phase. The Fe-C phase diagram is shown in Fig. 2- 3. These typical elements are categorized in Table 2-3. The ferrite stabilizers raise the eutectoid point, therefore shrinking the austenite ( $\gamma$-phase) region in the Fe-C phase diagram $\left[{ }^{23}\right]$. The austenite stabilizers, on the other hand, lower the eutectoid temperature, thereby enlarging the austenite region $\left[{ }^{24}\right]$. 


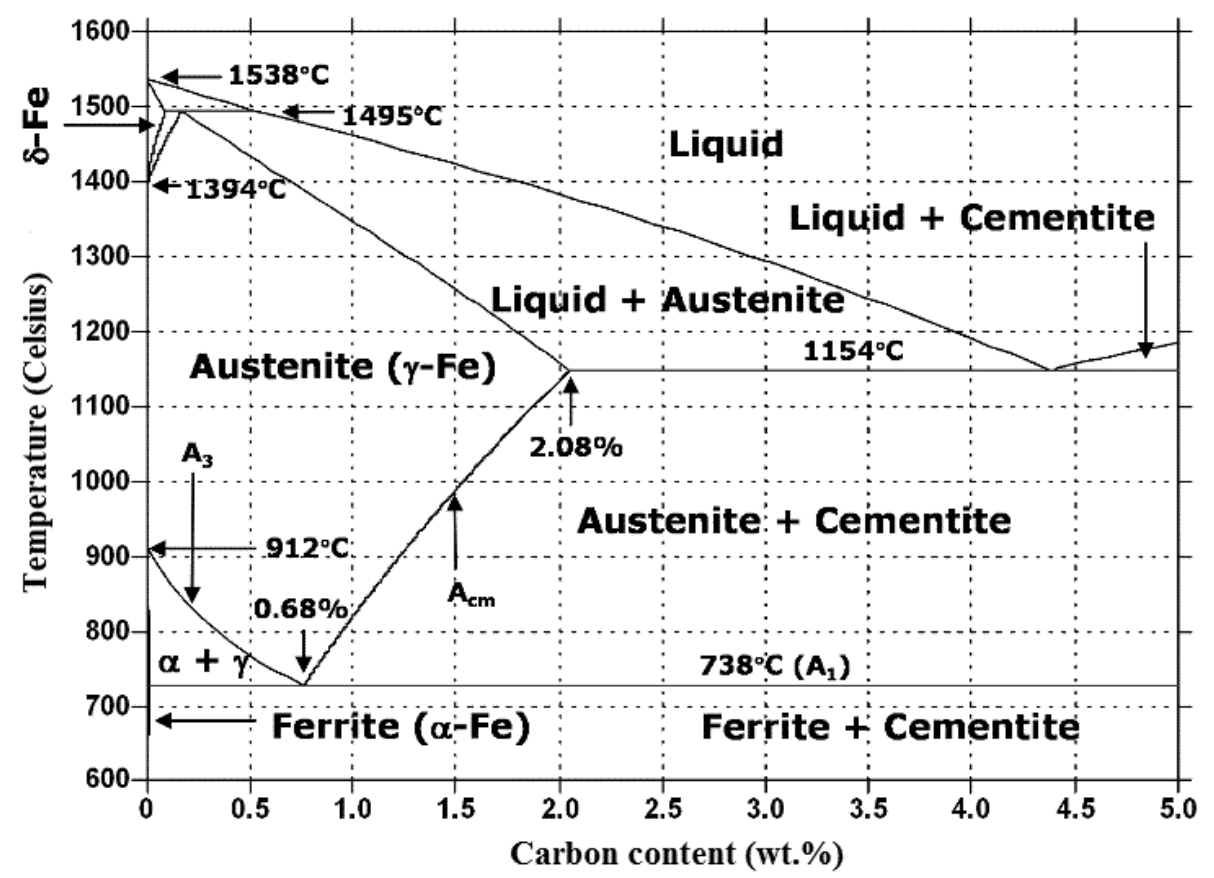

Fig. 2- 3. Fe-C phase diagram $\left[{ }^{23}\right]$.

Table 2- 3 Ferrite stabilizers and austenite stabilizers

\begin{tabular}{cc} 
Ferrite stabilizer & $\mathrm{Cr}, \mathrm{Mo}, \mathrm{W}, \mathrm{Al}, \mathrm{Ti}, \mathrm{Nb}, \mathrm{Si}$ \\
\hline Austenite stabilizer & $\mathrm{C}, \mathrm{N}, \mathrm{Mn}, \mathrm{Ni}, \mathrm{Cu}, \mathrm{Co}$
\end{tabular}

In particular, $\mathrm{C}$ and $\mathrm{N}$ are strong austenite stabilizers having a minimum solubility in ferrite, which induce the formation of carbides, nitrides, or carbonitrides. In addition to the role as a ferrite stabilizer, $\mathrm{Cr}$ provides corrosion and oxidation resistance. $\mathrm{C}$ and $\mathrm{Cr}$ may react to form carbides $\mathrm{M}_{7} \mathrm{C}_{3}$ and $\mathrm{M}_{23} \mathrm{C}_{6}$ in $2-12 \%$ Cr steels. The Cr-rich $\mathrm{M}_{23} \mathrm{C}_{6}$ is the major precipitate in such steels, which forms during tempering and remains present throughout the elevated-temperature exposure. Mo and W are ferrite stabilizers, whose amount must be limited in F91 in order to avoid ferrite formation during austenitization. They provide relatively high solid-solution strengthening of the steels $\left[{ }^{20}\right]$. Sometimes $\mathrm{W}$ is chosen to partially replace Mo for fusion reactor applications because of its low radioactivity. $\mathrm{W}$ is in the same column with Mo in the periodic table, and it behaves 
similarly to Mo in the steel. Normally, they do not form carbides or nitrides in $9-12 \%$ Cr steels $\left[{ }^{25}\right.$, ${ }^{26}$ ]. However, during tempering, Mo and $\mathrm{W}$ are distributed in the solid solution and get involved in precipitation of $\mathrm{M}_{23} \mathrm{C}_{6}$ and $\mathrm{MX}$, where $\mathrm{X}$ represents either $\mathrm{C}$ or $\mathrm{N}$ or a combination of the two. In particular, after a long-time exposure at elevated temperatures, a large portion of the Mo or $\mathrm{W}$ content in the steel could be found in the $\mathrm{M}_{23} \mathrm{C}_{6}$ and Laves phase. $\mathrm{V}$ and $\mathrm{Nb}$ in $9-12 \% \mathrm{Cr}$ steels are expected to form MX, resulting in the formation of carbides (MC), nitrides (MN), or carbonitrides $[\mathrm{M}(\mathrm{C}, \mathrm{N})]\left[{ }^{27},{ }^{28}\right]$. There is evidence to show that Laves-phase forms during the exposure of $9-12 \%$ steels at $600-650^{\circ} \mathrm{C}$. This reaction removes Mo and $\mathrm{W}$ from the solid solution, thus reducing the solid-solution strengthening effect $\left[{ }^{18},{ }^{29}\right]$.

In some cases, a small amount (about $1 \%$ ) of $\delta$-ferrite may be present in Cr-Mo steels, especially in the $12 \%$ Cr steels. For example, the duplex steel EM12 (Table 2- 2) contains about $50 \% \delta$-ferrite due to the presence of $2.0 \%$ Mo. The general microstructures of most $9-12 \% \mathrm{Cr}$ steels in the family are similar, even the latest grades have similar microstructure to the earlier generations. Fig. 2- 4 (a) and (b) show the transmission electron microscopy (TEM) microstructure of HT9 (Table 2-2) in the normalized condition and normalized-tempered conditions, respectively. It clearly shows that martensitic laths have a high dislocation density in the normalized condition (a); while the dislocation structure is recovered after tempering (b) and the laths becomes elongated to a typical width of $0.25-0.5 \mu \mathrm{m}\left[{ }^{18}\right]$. 

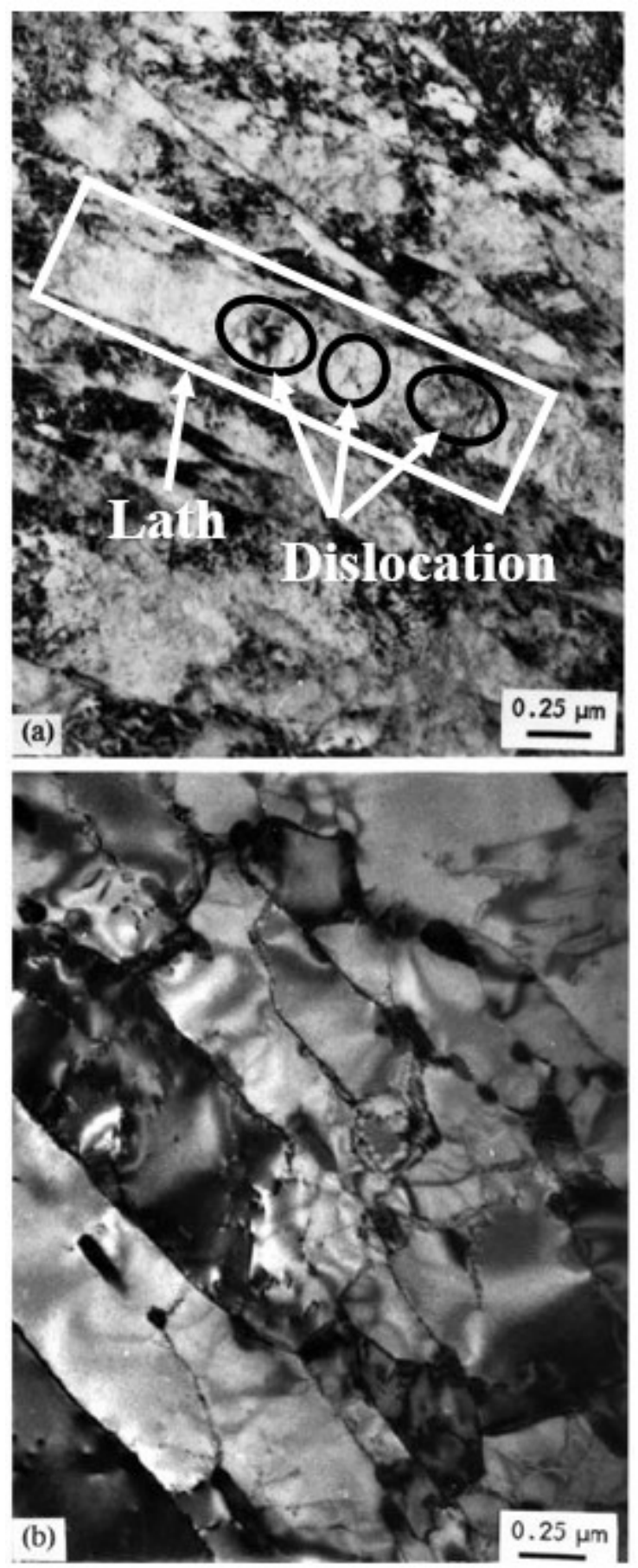

Fig. 2- 4. Microstructure of HT9 in (a) normalized (b) normalized and tempered conditions $\left[{ }^{18}\right]$. 


\subsection{High-temperature Creep}

\subsubsection{Fundamentals of creep}

Creep refers to the time-dependent deformation of material taking place at a stress level which is below the material yield strength at elevated-temperatures that above 0.3 homologous temperature (the ratio of current temperature to the material melting point, $T_{m}$, in Kelvin) $\left[{ }^{30},{ }^{31}\right]$. Creep phenomenon was first observed by Andrade in the early twentieth century, and the creep strain was first described as a power-law function of time with a power-index of $1 / 3\left[{ }^{32}\right]$. Since then, numerous creep studies have been conducted on various materials, mostly under constant-load creep conditions. Literature on this topic is too vast to be fully covered in the limited space of this thesis. Basically, the creep strain vs. time relationships can be schematically summarized as illustrated in Fig. 2- 5 at constant temperature, and Fig. 2- 6 at constant load or stress. The abscissa is time, where $t_{r}$ represents time-to-rupture; and the ordinate is strain as represented by $\varepsilon$. A typical creep curve can be divided into three stages as marked in these two figures. Stage I is the primary stage where creep rate decreases with time; Stage II is the secondary stage, also known as the steady-state stage, where creep rate remains constant and is the minimum during the entire creep process; Stage III is the tertiary stage, where creep rate accelerates until the specimen rupture at the end. Under high stress and high temperature conditions, stages I and II can be relatively short and the specimen only exhibits the stage III behavior. With regards to Grade 91 steels, creep tests are normally conducted in the temperature range $450-750^{\circ} \mathrm{C}\left[{ }^{33}\right]$.

Material creep strength has always been one of the critical design criteria for engineering components operating at elevated temperatures. For steam turbine components, it is usually required that the materials withstand the operating temperature for $10^{5}$ hours under a sustained 
load (stress) without failure. The higher the stress, the higher the creep strength of the material is. However, $10^{5}$ hours are a very long time unpractical to achieve through laboratory testing. Most creep tests are conducted in laboratories for short periods, usually $<5,000$ hours. Extensive experimental investigations on creep behavior of $9 \mathrm{Cr}-1 \mathrm{Mo}$ steels have been conducted $\left[{ }^{34},{ }^{35},{ }^{36}\right]$. Comprehensive creep data on 9Cr-1Mo steels are also available from some open source database, e.g., National Institute for Materials Science (NIMS), Japan.

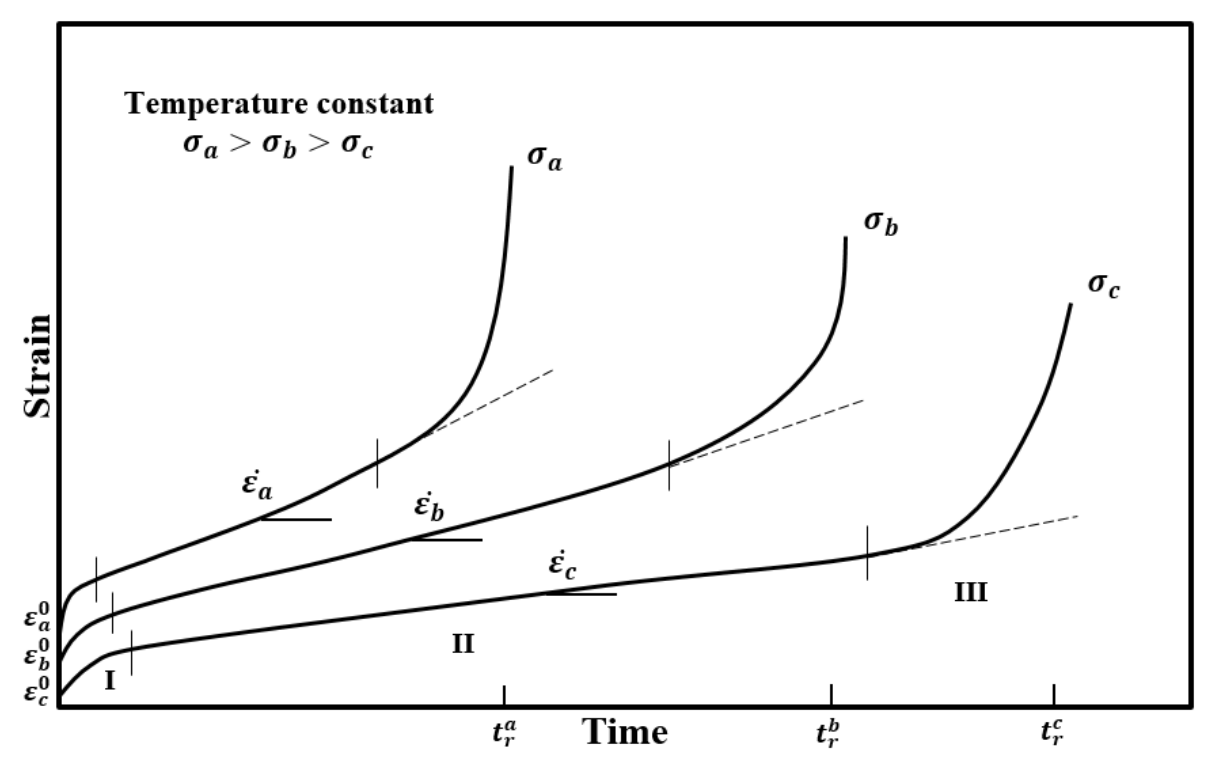

Fig. 2- 5. Schematic creep curves of a material at a constant temperature $\left[{ }^{37}\right]$. 


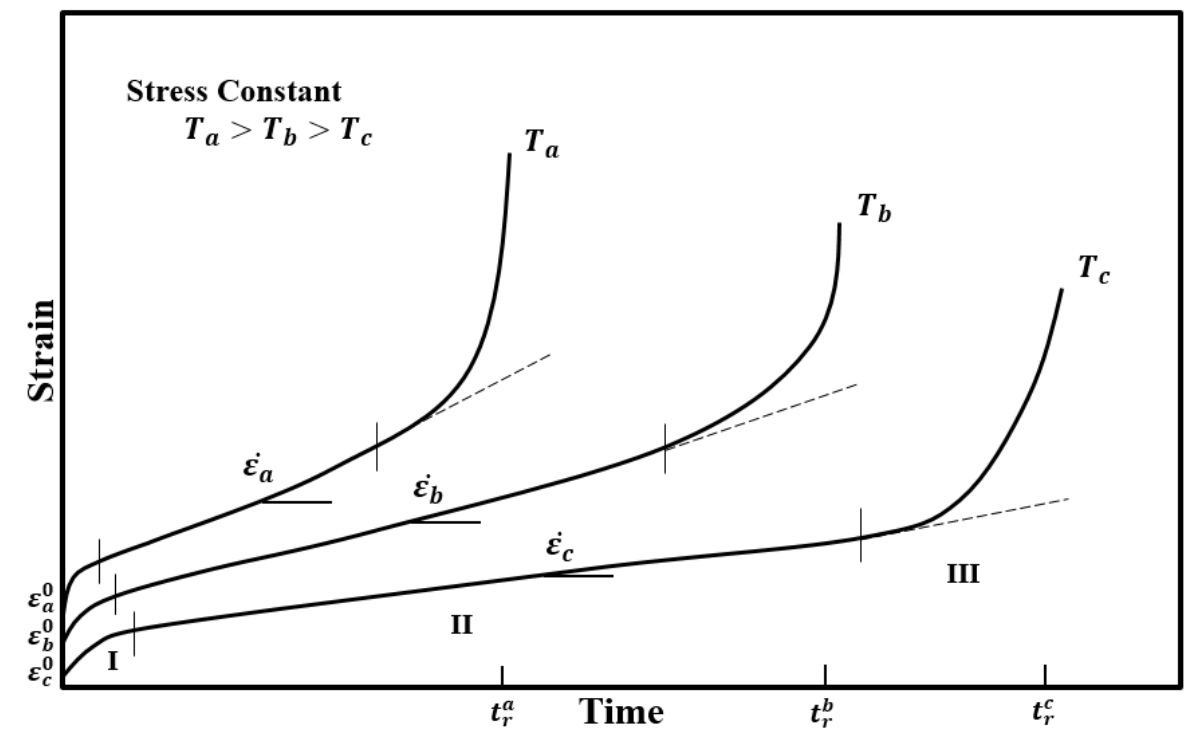

Fig. 2- 6. Schematic creep curves of a material under constant stress $\left[{ }^{37}\right]$.

\subsubsection{Mechanisms of creep}

Creep occurs by a plethora of mechanisms in a complex combination under stress at elevatedtemperature. As discussed previously, the temperature affects the microstructure, and hence the properties of the material will change with time during creep. Meanwhile, the applied stress will generally expedite the microstructural change, which complicates creep mechanisms even more in both macroscopic and microscopic scales. In general, considering creep behavior of materials, deformation mechanisms can be categorized into three domains: (1) diffusion creep; (2) dislocation creep by dislocation glide, or glide-plus-climb; (3) grain boundary sliding [ $\left.{ }^{38},{ }^{39},{ }^{40},{ }^{41}\right]$.

\subsubsection{Diffusion creep}

Diffusion creep tends to occur at very low-stress levels, i.e., the applied stress is at a ratio $<10^{-4}$ to the shear modulus, even though this value is subject to variation with metal types. There are 
essentially two mechanisms, Nabarro-Herring-Coble creep and Harper-Dorn creep, in the diffusion creep domain.

Fig. 2- 7 illustrates the mechanism of Nabarro-Herring-Coble creep. The flux of vacancies flows either inside the crystal lattice (Fig. 2- 7-a) or along the grain boundaries by matter diffusion, which results in an increase in the length of the specimen. By Nabarro-Herring creep, the strain rate is related to the vacancy flux as expressed by $\left[{ }^{42},{ }^{43}, 44,45\right]$

$$
\dot{\varepsilon}=A \frac{D_{l} G b}{k T}\left(\frac{b}{d}\right)^{2}\left(\frac{\sigma}{G}\right)
$$

where $A$ is Nabarro-Herring proportional constant, typically having a value in $10-15$ range; $D_{l}$ is the lattice diffusion coefficient; $b$ is Burgers' vector; $d$ is grain diameter; $G$ is shear modulus.
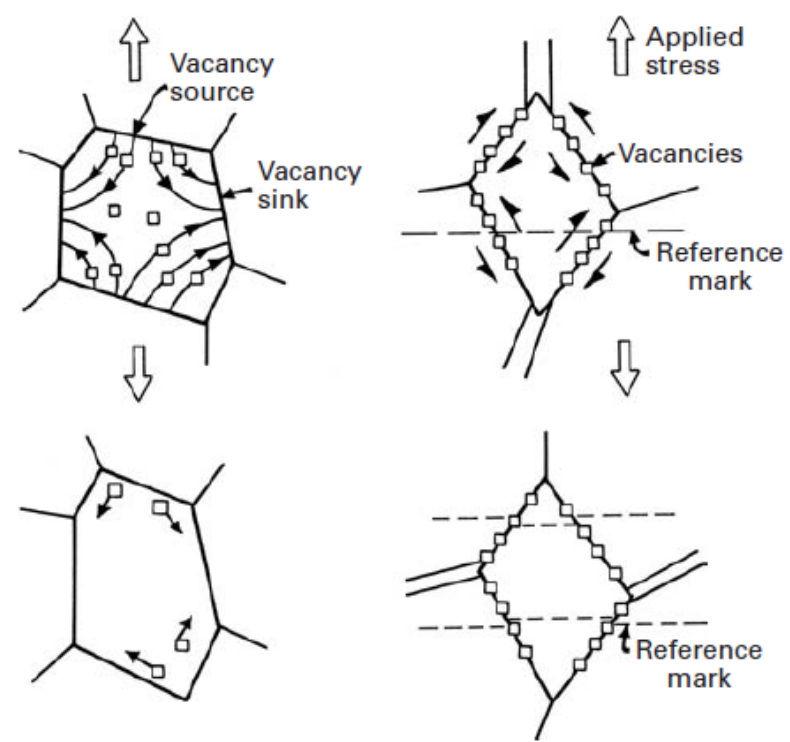

(a)

(b)

Fig. 2- 7. Vacancy flow mechanisms according to (a) Nabarro-Herring (b) Coble $\left[{ }^{46}\right]$. 
In aluminum, at a high temperature under low stress, Harper and Dorn observed another diffusional creep mechanism and proposed the Harper-Dorn creep that occurs exclusively by dislocation climb. Fig. 2- 8 schematically shows the dislocation climb behavior of creep. Under compression, the vacancies are attracted by dislocation lines, while the opposite occurred when tensile stress applied. The Harper-Dorn creep rate is governed by $\left[{ }^{47}\right]$

$$
\dot{\varepsilon}=A \frac{D_{l} G b}{k T}\left(\frac{\sigma}{G}\right)
$$

where $A$ in the Harper-Dorn equation is typically equal to $10^{-11}$. The other symbolic signs represent the same meaning as in the Nabarro-Herring equation. Since grain boundary movement is not involved, the creep rate is independent of the grain size parameter $d$.

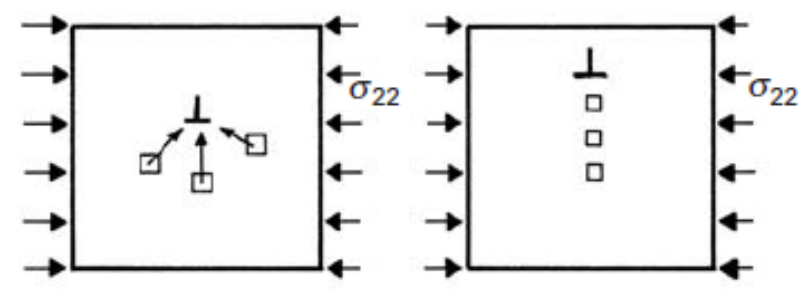

(a)

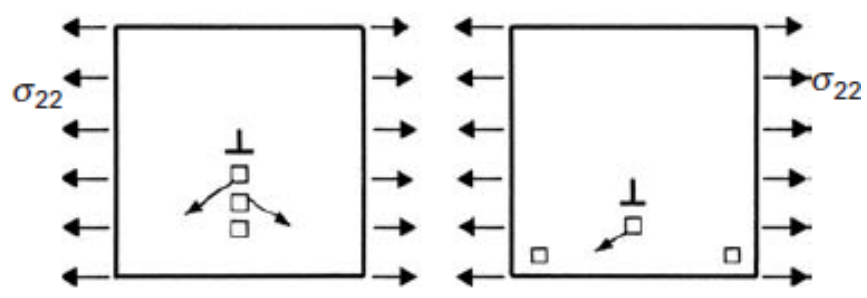

(b)

Fig. 2- 8. Dislocation climb: (a) upward, under compression; (b) downward, under tension $\left[{ }^{43}\right]$.

It is obvious to note that all types of diffusion creep have a power exponent of 1 . Since most complex engineering alloys contain elements to retard diffusion, and the alloys are most used under stresses higher than the diffusion-dominance stress (see deformation mechanism maps later), diffusion creep is not of concern in the present study. 


\subsubsection{Dislocation creep (Power-law creep)}

In a crystalline solid, below the ideal shear strength, the motion of dislocations is possible to take place via dislocation glide, which can produce irreversible (plastic) deformation along independent slip systems. Dislocation glide is a dynamic process where the strain-rate is expressed, firstly by Orowan in $1940\left[{ }^{48}\right]$, as:

$$
\dot{\varepsilon}=\rho_{m} b \bar{v}
$$

where $b$ is the Burgers' vector of the dislocation, $\rho_{m}$ is the mobile dislocation density, and $\bar{v}$ is the average dislocation velocity.
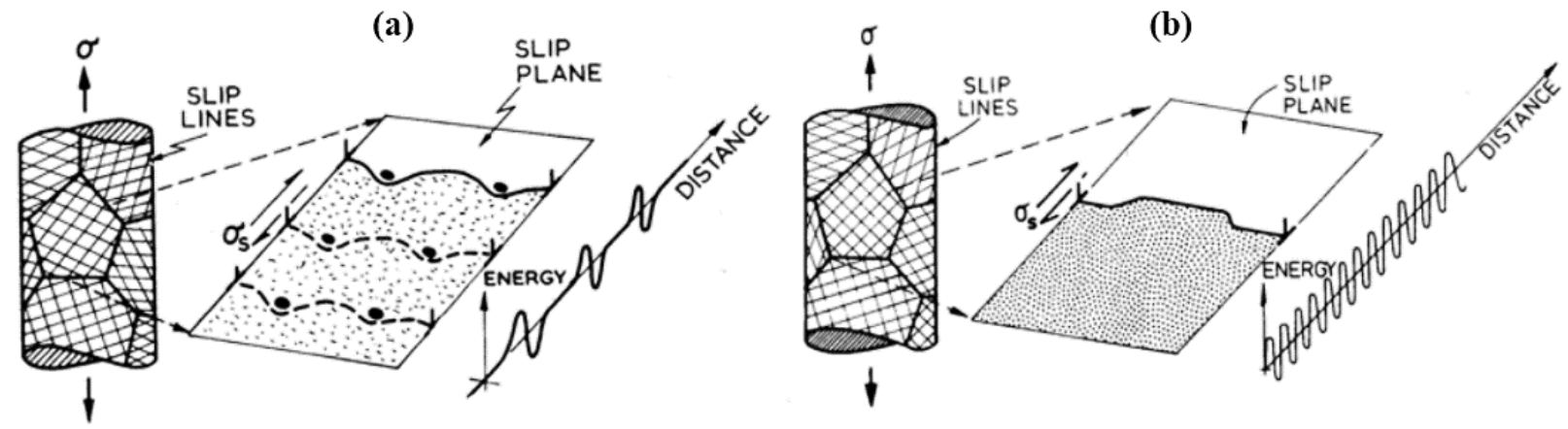

Fig. 2- 9. Dislocation glide limited by (a) discrete obstacles; (b) lattice resistance $\left[{ }^{38}\right]$.

In a complex engineering alloy, large solutes, second phase particles, and grain boundaries may be present as obstacles to dislocation glide along the active slip planes (Fig. 2- 9). At high temperatures, a gliding and dislocation will acquire a higher degree of freedom through climb when it absorbs vacancies, and piled-up dislocations at the obstacles can jump out of the obstructed slip plane and continue to glide on another slip plane. This climb plus glide motion enables the material to deform continuously in time, leading to a phenomenon known as creep. Fig. 2- 10 
illustrates the event when an edge dislocation moves along different crystal lattice planes in a stepwise slip process, i.e., climb plus glide $\left[{ }^{49}\right]$. The difference between climb-only and climb plus glide is illustrated in Fig. 2- $11\left[{ }^{38}\right]$. The rate equation of dislocation climb creep, first developed

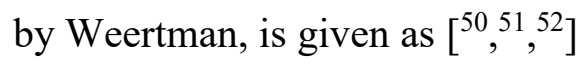

$$
\dot{\varepsilon}=A \frac{D_{l} G b}{k T}\left(\frac{\sigma}{G}\right)^{n}
$$

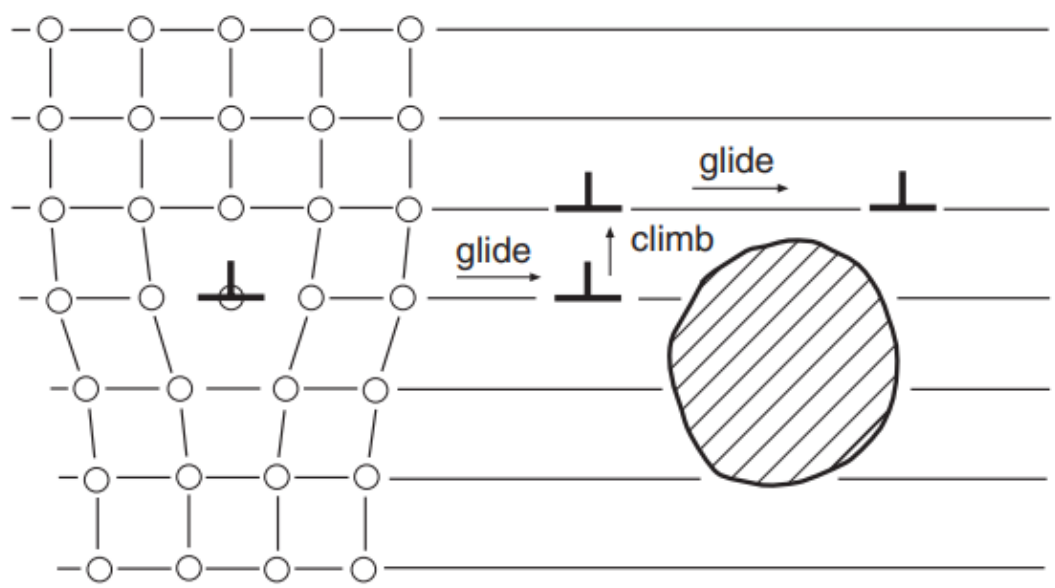

Fig. 2- 10. Climb of an edge dislocation, permitting continued glide over an obstacle $\left[{ }^{49}\right]$.

where the power exponent $n \sim 3-8$ indicates creep occurrence due to climb, which is also known as power-law creep; $n \geq 10$ indicates clime plus glide creep, which is also known as power-lawbreakdown creep, due to creep strain rate enhanced by glide; whereas $n=1$ indicates Harper-Dorn creep, which is a special case of climb-only creep. 


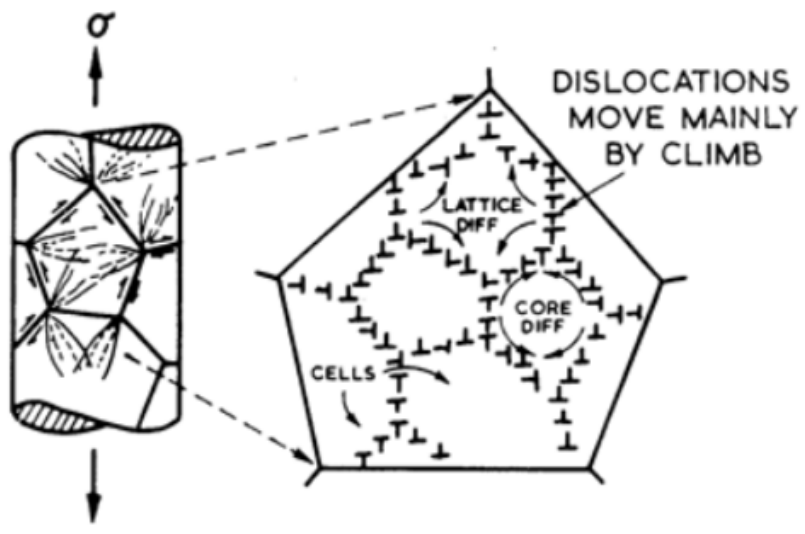

(a)

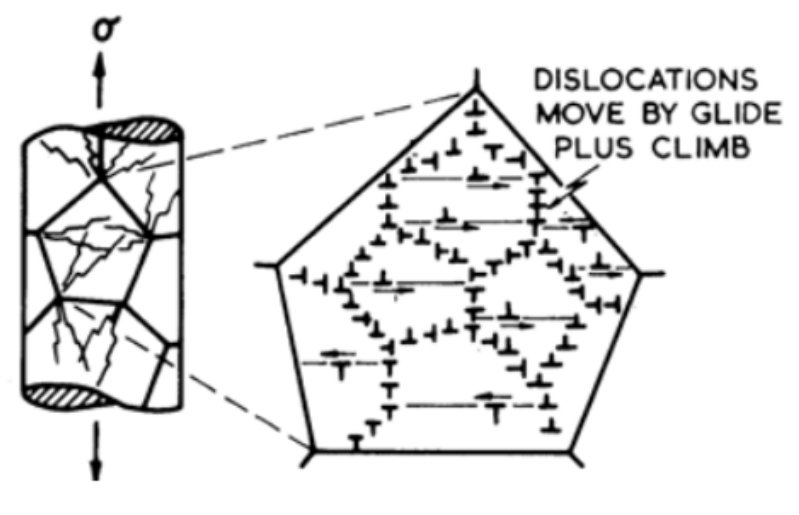

(b)

Fig. 2- 11. Dislocation movement: (a) climb; (b)climb plus glide $\left[{ }^{38}\right]$. 


\subsubsection{Grain boundary sliding}

Grain boundary sliding (GBS) is a deformation mechanism that mainly involves dislocation climb plus glide along grain boundaries at temperatures above $0.3 T_{m}$. In a polycrystalline material, grain boundary dislocation glide does not proceed along perfect crystallographic planes but on the grain boundaries, and it is also obstructed by grain boundary triple junctions or grain boundary precipitates (obstacles). Therefore, grain boundary dislocation climb assisted by diffusion flow is a necessary step to allow GBS to proceed. It plays an important role during primary and secondary creep, and through the process, it may also initiate intercrystalline cracks, which then can propagate $\left[{ }^{53},{ }^{54},{ }^{55},{ }^{56}\right]$. Fig. 2 - 12 shows the GBS movement schematically $\left[{ }^{54}\right]$. The dislocation pileups at the triple point lead to intragranular slip in the adjacent grain and may cause wedge crack. Wu and Koul have developed a constitutive equation for GBS-controlled creep in the presence of grain boundary precipitates, and the behavior is govern by $\left[{ }^{57},{ }^{58}\right]$

$$
\varepsilon=\frac{\sigma}{\beta^{2} H}\left[1-\exp \left(-\frac{\beta^{2} H \dot{\varepsilon}_{S} t}{\sigma(\beta-1)}\right)\right]+\dot{\varepsilon}_{S} t
$$

where $\dot{\varepsilon}_{S}=A \exp \left(-\frac{Q}{R T}\right)\left(\frac{\sigma}{\sigma_{T}}\right)^{p}$ is the steady-state GBS creep rate; $\beta$ is the material parameter; $H$ is the work hardening coefficient; $\sigma_{T}$ is the ultimate tensile strength; $Q$ is the activation energy of GBS; $R$ is the gas constant. 


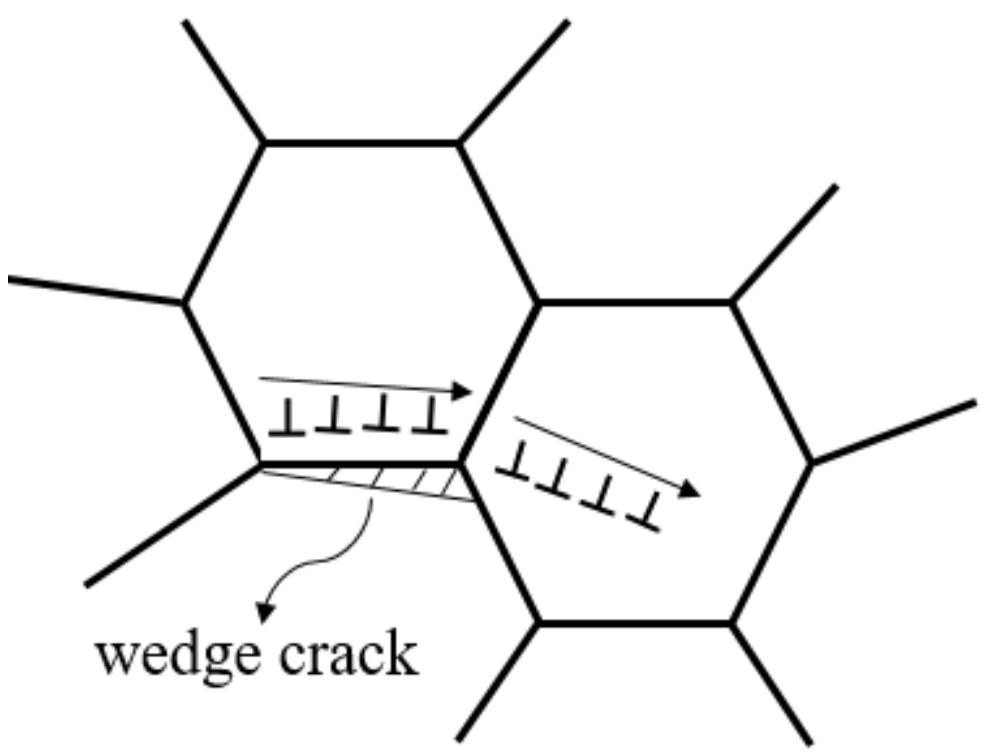

Fig. 2- 12. Schematic of grain boundary sliding $\left[{ }^{54}\right]$. 


\subsubsection{Creep modeling}

Long-term creep tests are time-consuming for targeted service periods of $10^{5}$ hours or more. Primarily, as the environmental regulations on $\mathrm{CO}_{2}$ greenhouse emission reduction become eminent (e.g., Canada's total greenhouse gas emission reduction sets to $17 \%$ by $2020\left[{ }^{59}\right]$ ), power generation equipment needs to operate more efficiently, i.e., at higher temperatures. This almost leaves no time for new equipment upgrade to wait for long-term creep tests of a new design. Therefore, developing creep models capable of predicting long-term performance of materials based on short-term test data is not only of academic interest but also urgent for new and updated engineering design.

In general, there are three test parameters involved in a creep test, i.e., stress, temperature and time, and one response variable — strain to be measured. The purpose of analytical modeling is to establish relationships between creep strain and its derivative, strain rate, with the test parameters (temperature, stress and time), and use the relationships for prediction or extrapolation of the material's long-term performance beyond the tested range. Therefore, creep modeling has been mainly focused on two aspects: the creep strain-time behavior, and creep rupture life.

A significant number of extrapolation formulas and models have been proposed by researchers, which can be divided into two categories: (i) empirical (over 30 types), and (ii) physics or mechanism-based models. Three most common models of the first group are Monkman-Grant relationship, Larson-Miller, Orr-Sherby-Dorn, $\left[{ }^{37},{ }^{60},{ }^{61}\right]$. These models have been widely used, and are often compared to each other. The effort in the second category is relatively new, for example, $\mathrm{Wu}$ et al. developed a true-stress model based on the aforementioned fundamental deformation 
mechanisms for a Ni-base superalloy, Waspaloy, for gas turbine disk applications $\left[{ }^{62}\right]$. It has also been applied to Cobalt-base alloy Mar-M-509 for gas turbine nozzle guide vane applications $\left[{ }^{63}\right.$,

$\left.{ }^{64}\right]$. More recently, It is used successfully by the author of this thesis to characterize the creep rate behavior for various products of modified $9 \mathrm{Cr}-1 \mathrm{Mo}$ steels, including tubes, pipes, plates and forging $\left[{ }^{65}\right]$. The approach is taken in this study to further investigate the effects of thermomechanical processing history, microstructural evolution, as well as an environmental impact - oxidation.

\subsubsection{Empirical life prediction models}

Regarding creep life, numerous empirical relationships have been proposed based on observations from short-term creep tests on various materials. A few popular ones are reviewed here as examples. The Monkman-Grant relationship, which relates creep rupture time to minimum creep rate, is given as $\left[{ }^{66}\right]$

$$
t_{f} \cdot \dot{\varepsilon}_{s}^{m}=C
$$

where $t_{f}$ is creep failure time; $\dot{\varepsilon}_{s}$ is steady-state creep rate; $m$ and $C$ are constants. Monkman and Grant reported that the values of exponent $m$ fell in the range of $0.8-0.95$, and $C$ in the range of $3-20$.

Another relationship was proposed by Larson and Miller (1952), between the applied stress $\sigma$ and a temperature-compensated creep rupture parameter called the Larson-Miller parameter $P_{L M}$, as $\left[{ }^{67}\right]$

$$
P_{L M}=T\left(\log t_{r}+C_{L M}\right)
$$


where $P_{L M}$ is the Larson-Miller Parameter (LMP); $T$ is absolute temperature; $t_{r}$ is time to creep rupture, and $C_{L M}$ is the $\mathrm{LM}$ constant. Note that $t_{r}$ could also be the time to attain a certain amount of creep strain, such as $0.5 \%\left[{ }^{68}\right]$.

Fig. 2- 13 shows the Larson-Miller plots for various materials $\left[{ }^{69}\right]$. One method to obtain the LM constant $C_{L M}$ is as follows: to fit a single regression equation to all creep data of one type of material, first, $P_{L M}$ is represented by a cubic equation of the logarithm of $\sigma$; then a regression analysis is performed on the variable $T \log t_{r}$, and accordingly, the LM constant $C_{L M}$ can be obtained as the regression coefficient $\left[{ }^{70},{ }^{71}\right]$.

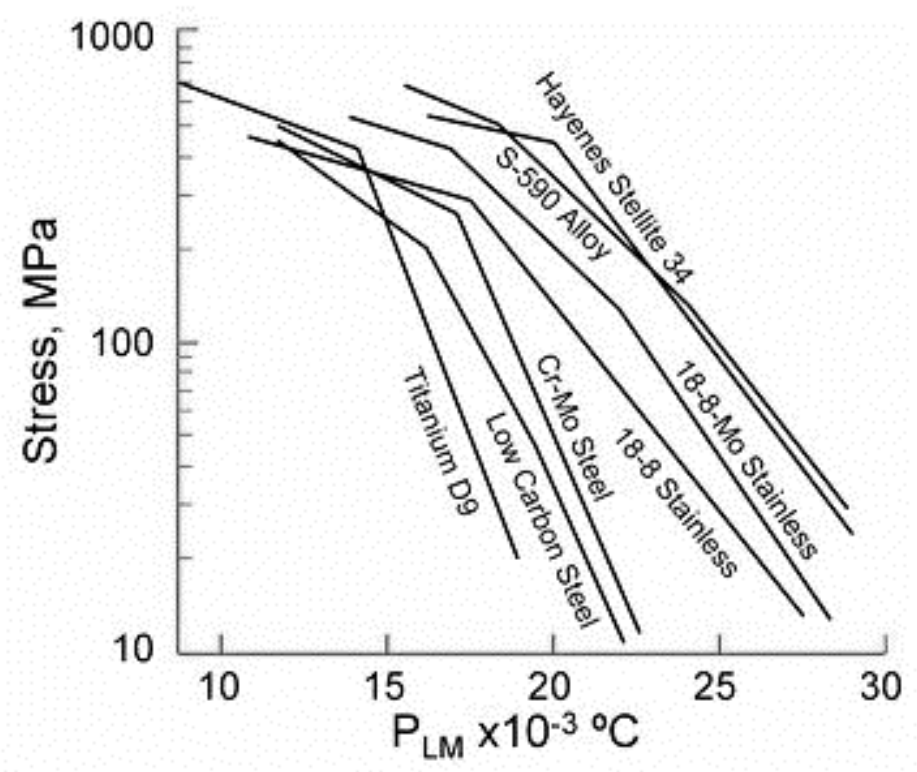

Fig. 2- 13. Larson-Miller parameters for various materials $\left[{ }^{69}\right]$.

In the early days of adopting LMP for creep rupture analysis, a universal value of 20 (when the time and temperature were measured in units of hour and Kelvin) was assigned to $C_{L M}$, and it worked quite well in many cases for graphical representation $\left[{ }^{67}\right]$. When this methodology was 
applied on more and more materials, it was addressed by many researchers that $C_{L M}=20$ was not suitable for all kinds of materials, and in fact it should vary from 8 to $57\left[{ }^{71},{ }^{72}\right]$. For high $\mathrm{Cr}$ martensitic steel in particular, Tamura et al. concluded that a larger value, $C_{L M} \sim 30$ was justified by fitting $\left[{ }^{70}\right]$; in another study, $C_{L M}=33$ was applied on Grade 91 steel $\left[{ }^{34}\right]$. Once the regression equation between $\log \sigma$ and LMP was obtained, the creep-strength could be predicted by extrapolation to the expected creep lifetime (e.g. $10^{5}$ hours) at a given temperature. Fig. 2- 14 shows the LMP of Grate 91 steels and Table 2- 4 lists the predicted creep-strength results based on the LMP values $\left.{ }^{34}\right]$.

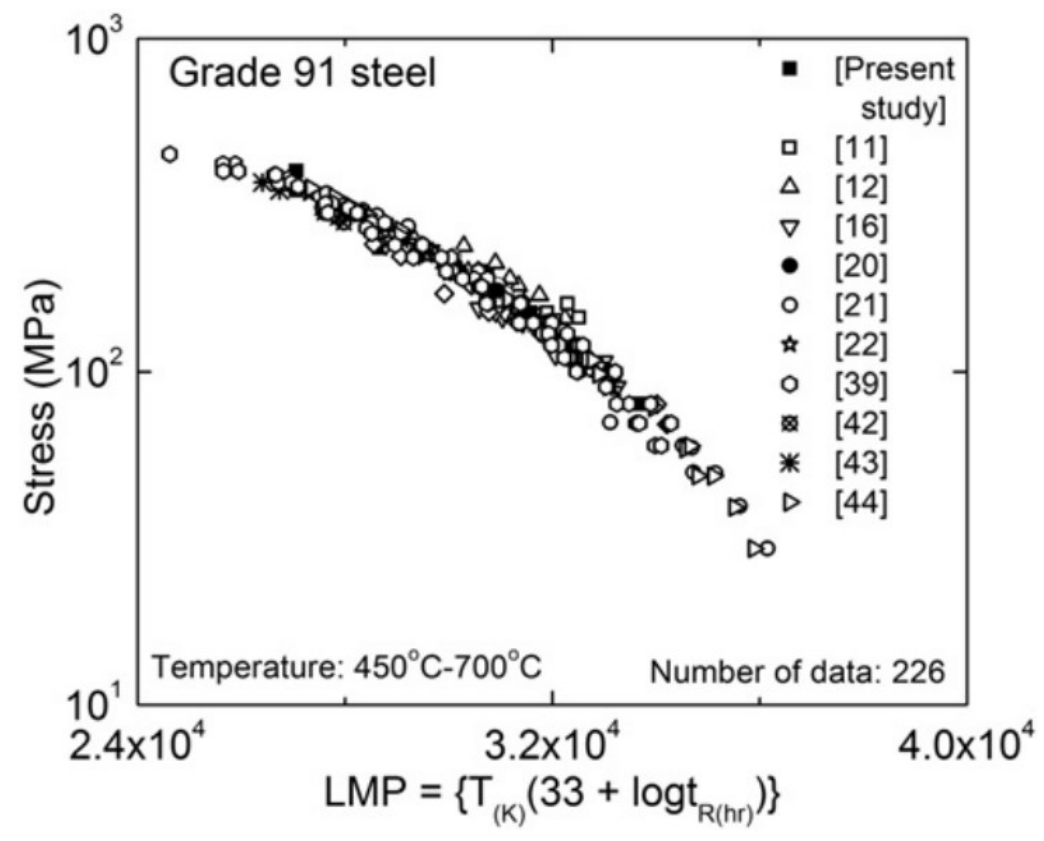

Fig. 2- 14. LMP plots for Grade 91 steel $\left[{ }^{34}\right]$. 
Table 2- $410^{5}$-hr creep-strength predictions of Grade 91 steel based on LMP $\left[{ }^{34}\right]$

\begin{tabular}{ccc}
\hline $\begin{array}{c}\text { Temperature } \\
\left({ }^{\circ} \mathrm{C}\right)\end{array}$ & $\begin{array}{c}\text { Rupture life } \\
(\mathrm{hr})\end{array}$ & $\begin{array}{c}\text { Predicted allowable stress } \\
(\mathrm{MPa})\end{array}$ \\
\hline 500 & $10^{5}$ & 241 \\
525 & $10^{5}$ & 199 \\
550 & $10^{5}$ & 161 \\
575 & $10^{5}$ & 123 \\
600 & $10^{5}$ & 91 \\
625 & $10^{5}$ & 68 \\
650 & $10^{5}$ & 47 \\
675 & $10^{5}$ & 33 \\
700 & $10^{5}$ & 21 \\
\hline
\end{tabular}

From the discussion above, it is clear that LMP is an empirical model without considering any physical deformation mechanisms. Although LMP is simple for interpolation and extrapolation when the data are complete to cover the application region, uncertainty still exists regarding the failure mechanism and failure mode. For example, as shown in Fig. 2- 15, there are apparently two creep mechanisms dominating separately: one in the low-stress regime $(<100 \mathrm{MPa})$ and one in the high-stress regime $\left.(\geq 100 \mathrm{MPa}){ }^{73}\right]$. Therefore, if all short-term creep data are obtained from high-temperature and low-stress test conditions, extrapolation from the low-stress LMP master curve to high stress is not warranted, and vice versa. Therefore, the LMP method has to rely on a large amount of test data, which is costly to collect, both in time and money. Furthermore, the LMP method does not provide answers to the specific questions concerned in the present research. 


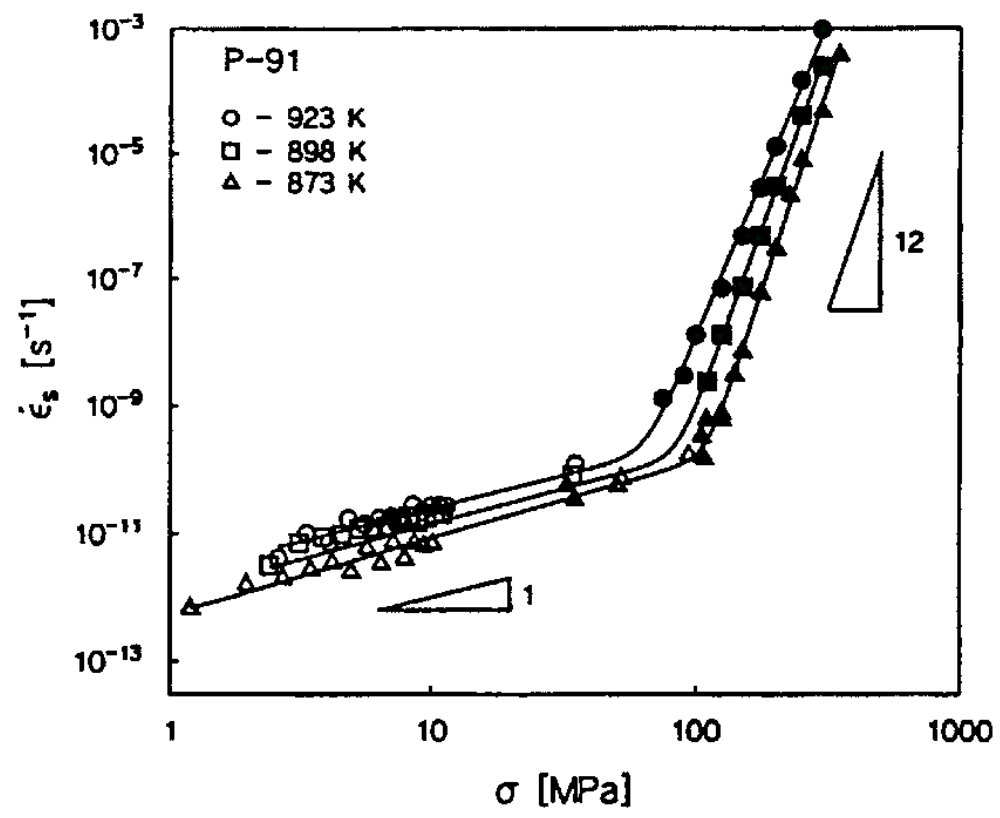

Fig. 2- 15. Stress dependence of steady-state creep rates for P91steel $\left[{ }^{73}\right]$.

Similarly, the applied stress can also be correlated with the Orr-Sherby-Dorn parameter $\theta$ :

$$
\theta=\frac{Q}{2.303 \cdot R \cdot T}-\log t_{f}
$$

where $R$ is gas constant; $Q$ is the activation energy.

Among these three equations, if one assumes $m=1$ in Eq. (2-6) and assuming that the steadystate creep rate is driven by stress in an exponential law, the Larson-Miller parameter can be derived from the Monkman-Grant relationship; if taking the steady-state creep rate as a power law of stress, the Orr-Sherby-Dorn parameter can be derived from Monkman-Grant relationship [ $\left.{ }^{66},{ }^{74}\right]$.

Other methods attend to predict creep life from creep curve analysis. Abe proposed the following relationship for Grade 91 steel $\left[{ }^{75},{ }^{76},{ }^{77}\right]$ :

$$
g=t_{r} / t_{m}
$$


where $t_{r}$ is creep rupture time, and $t_{m}$ is the time to reach the steady-state creep. The parameter $g$ is observed as:

$$
\begin{aligned}
& g=1 /\left(1.10 \times 10^{-1} \log \sigma+2.90 \times 10^{-3}\right) \text { at } 40 \text { to } 100 \mathrm{MPa} \\
& g=1 /\left(4.05 \times 10^{-1} \log \sigma-5.89 \times 10^{-1}\right) \text { at } 100 \text { to } 260 \mathrm{MPa}
\end{aligned}
$$

Here, the prediction factor $g$ is divided for two stress regions: one in the low-stress regime $(<100 \mathrm{MPa})$ and one in the high-stress regime $(\geq 100 \mathrm{MPa})$.

There are also other creep models that have been applied to other alloys. For example, recently, the Wilshire creep model has been combined with finite element method (FEM) model, emphasizing creep life prediction against specific creep strains for Ni-based alloys $\left[{ }^{78}\right]$. The Wilshire model, however, is still an empirical equation that does not link the material performance to controlling creep mechanisms. This type of empirical correlations will not digress further.

\subsubsection{Physics-based models}

Analytical or mechanism-based models have been developed based on various theories or hypothesis, such as damage mechanics, activation kinetics theory, and deformation mechanisms such as diffusion creep, power-law (dislocation) creep, dislocation glide, grain-boundary sliding, etc., as described above. In most cases, one or several mechanisms are operating in certain conditions, and others have negligible effects. In order to reduce variables, the controlling deformation mechanisms must be well understood. Regarding this, the deformation-mechanism maps, which will be introduced in next section, helps to identify the dominant deformation mechanism. 
A continuum damage mechanics based model has been applied on modified 9Cr-1Mo steels and validated through FEM simulation for the temperature range $450-650^{\circ} \mathrm{C}\left[{ }^{79}\right]$. The damage mechanics model treats the total deformation as the sum of elastic strain and viscoelastic strain, the latter described by a hyperbolic sine rate equation depending on the effective stress of $\sigma /(1-$ $D$ ), where $D$ is the damage parameter varying from 0 to 1 (failure), reflecting the effect of internal void growth $\left[{ }^{80},{ }^{81},{ }^{82}\right]$. The hyperbolic sine rate function attempts to consolidate the power-law and power-law breakdown phenomena, but it has missed the GBS contribution, where grain size and grain boundary precipitates play important roles, which is relevant to modified $9 \mathrm{Cr}$ - $1 \mathrm{Mo}$ steels.

A modified Bird-Mukherjee-Dorn (BMD) relation has also been used to describe the creep behavior of Grade 91 steels; such relationship is essentially an expanded form of the Norton equation $\left[{ }^{83}\right]$. Threshold stress, $\sigma_{t h}$, is introduced to Eq. (2-4), and the equation is then re-written as

$$
\dot{\varepsilon}=A \frac{D_{l} G b}{k T}\left(\frac{\sigma-\sigma_{t h}}{G}\right)^{n}
$$

where $\sigma_{t h}$ is defined as the threshold stress below which no creep deformation occurs. Hence, the effective stress of creep becomes the term $\left(\sigma-\sigma_{t h}\right)$.

In the above formulations, no particular deformation mechanisms are concerned. It is implied that the proposed rate equation covers all, but still lacks the clarity with regards to the underlying physics. To advance the understanding of creep phenomenon, a new approach to creep modeling has been proposed by Wu and Koul, which emphasizes the roles of deformation mechanisms such as intragranular dislocation glide, dislocation climb, grain boundary sliding, and derives the creep strain equation based on the above creep mechanisms $\left[{ }^{57},{ }^{58},{ }^{62},{ }^{84}\right]$. Using this approach, a truestress creep model has been developed recently, which provides a physics-based description of the 
entire creep deformation process with regard to the strain-time history (primary, secondary, and tertiary creep), rupture strain and lifetime by a transgranular/intergranular failure mode, and it has been shown to be in good agreement with experimental observations on Ni/Co-based superalloys $\left[{ }^{62},{ }^{63}\right]$.

\subsubsection{Deformation-mechanism maps}

Ashby first developed the deformation-mechanism maps in 1972, which have been well recognized in the creep studies ever since $\left[{ }^{85}\right]$. The deformation-mechanism maps aim to identify the dominant creep mechanism under different loading conditions, i.e., temperature and stress combinations, in a two-dimensional stress/temperature diagrams. The diagram is divided into various fields. Within a field, one mechanism is dominant, i.e., it provides a greater strain-rate than any other mechanisms. The stress coordinate is normalized to $\sigma / \mu$, where $\sigma$ is applied engineering stress, $\mu$ is the shear modulus; the temperature coordinate is homologues temperature, $T / T_{M}$. In his first report, six distinguishable and independent mechanisms - defect-less flow, glide motion of dislocations, dislocation creep, diffusional flow, Nabarro-Herring and Coble creep, and twinning, were proposed to assemble deformation-mechanism maps for pure metals such as silver, nickel, copper, etc. Fig. 2- 16 demonstrates the deformation-mechanism map for pure nickel as an example $\left[{ }^{85},{ }^{86}\right]$. Fig. 2- 17 categorizes the rate equations applicable to those identified mechanisms in the map $\left[{ }^{87},{ }^{88}\right]$. Other than Ashby's method, Langdon and Mohamed used different approaches to construct maps by considering the same deformation mechanisms. In one case, maps were constructed by plotting the normalized grain size $(d / b)$ versus normalized stress $(\sigma / G)$ at a constant temperature $\left[{ }^{89}\right]$; another case was to use normalized grain size $(d / b)$ versus normalized temperature $\left(T_{M} / T\right)$ at a constant normalized stress $\left[{ }^{90}\right]$. Fig. 2- 18 and Fig. 2- 19 show the two 
cases respectively. However, as one may notice, GBS is not included in those deformationmechanism maps. Lüthy et.al revised aforementioned maps by considering GBS mechanism, and the conclusion was that GBS regions were important at all temperatures and feasible for a wide range of normalized stress. Fig. 2- 20 demonstrates the revisions of the pure nickel map by Ashby and the aluminum map of Langdon and Mohamed, wherein GBS mechanism is taken into account $\left[{ }^{91}\right]$.

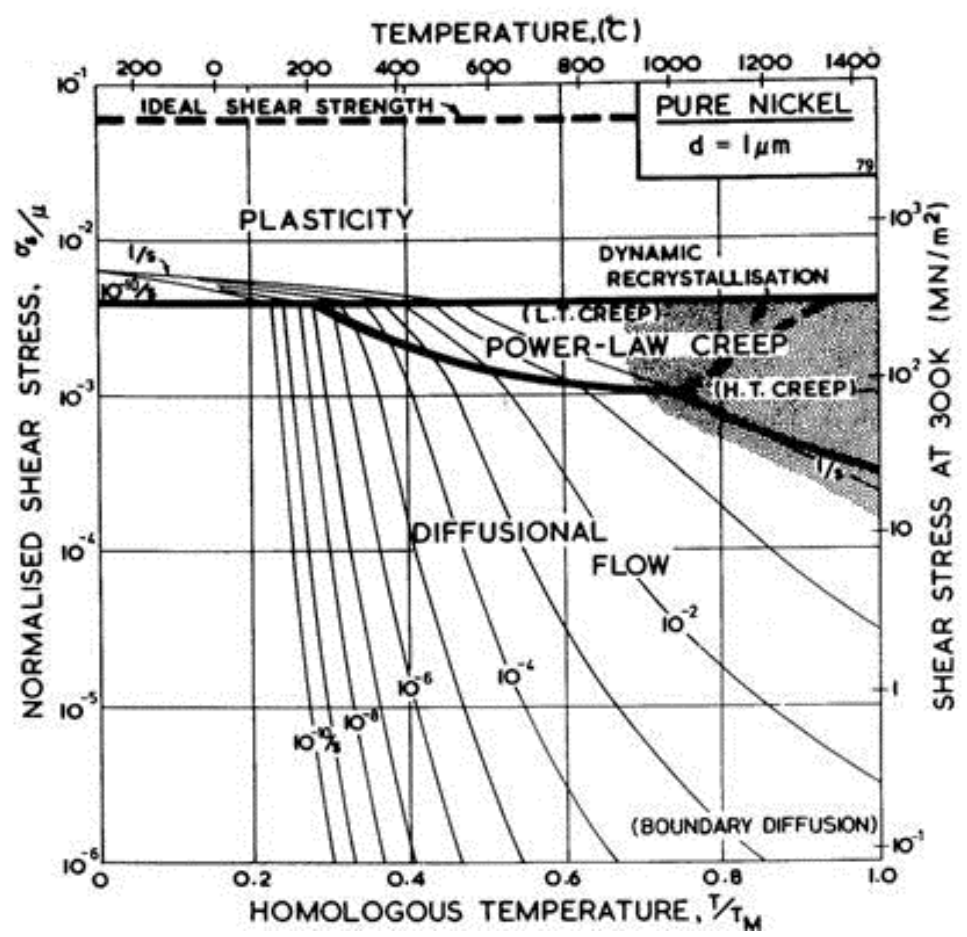

Fig. 2- 16. Deformation-mechanism map of pure nickel with a grain size of $1 \mu \mathrm{m}\left[{ }^{85}\right]$. 


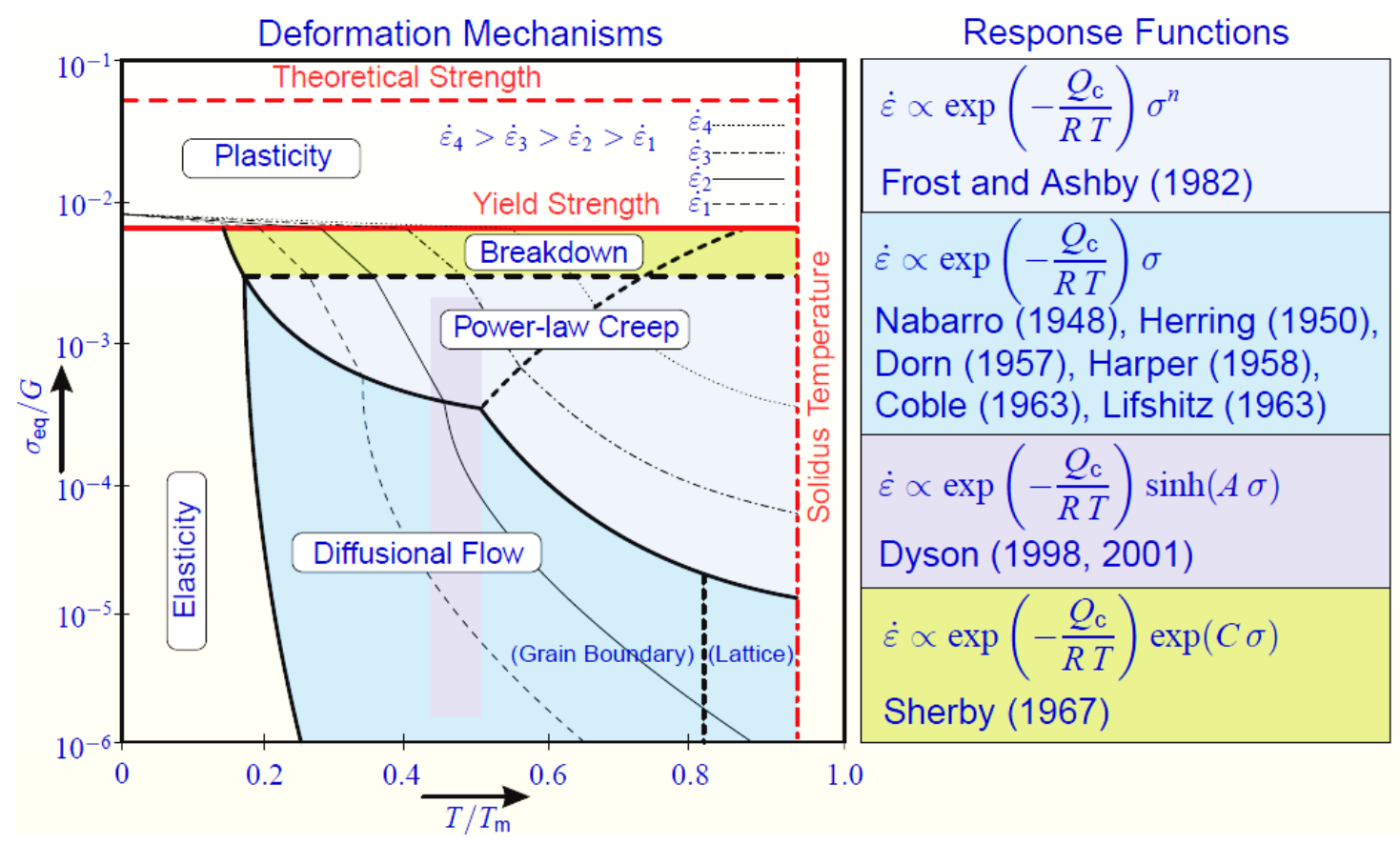

Fig. 2- 17. Schematic deformation-mechanisms map with response functions $\left[{ }^{87}\right]$.

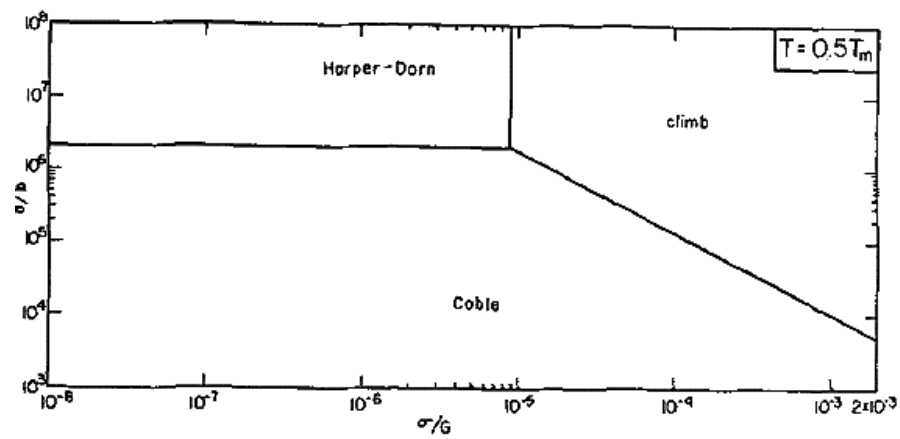

(a)

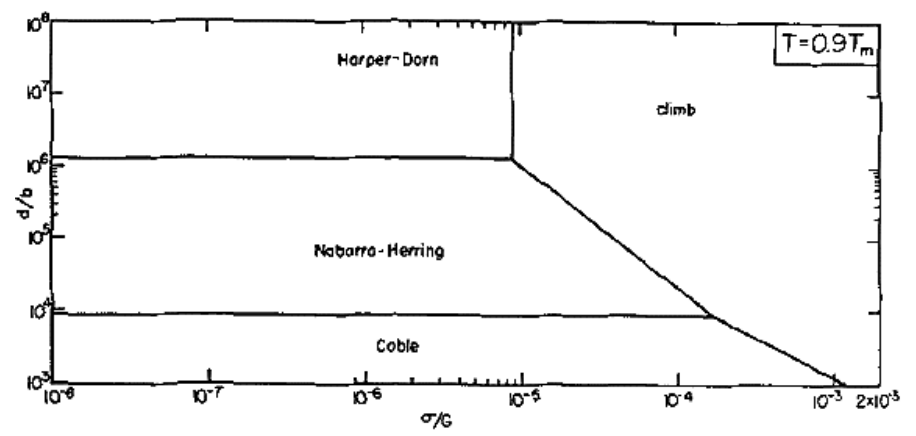

(b)

Fig. 2- 18. Deformation mechanism maps for pure aluminum at homologous temperatures of (a) $0.5 T_{M}$, (b) $0.9 T_{M}\left[{ }^{89}\right]$. 


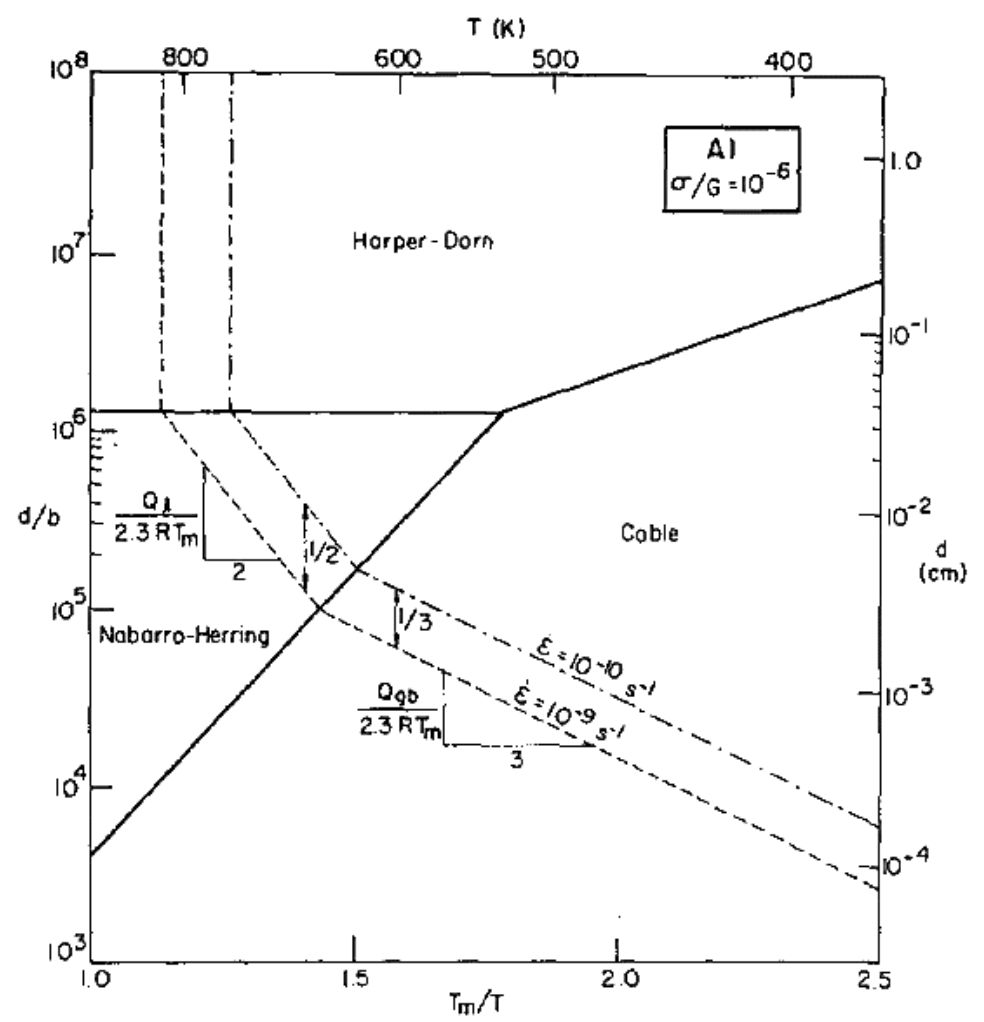

Fig. 2- 19. Deformation mechanism maps for pure aluminum at $\frac{\sigma}{G}=10^{-6}\left[{ }^{90}\right]$.

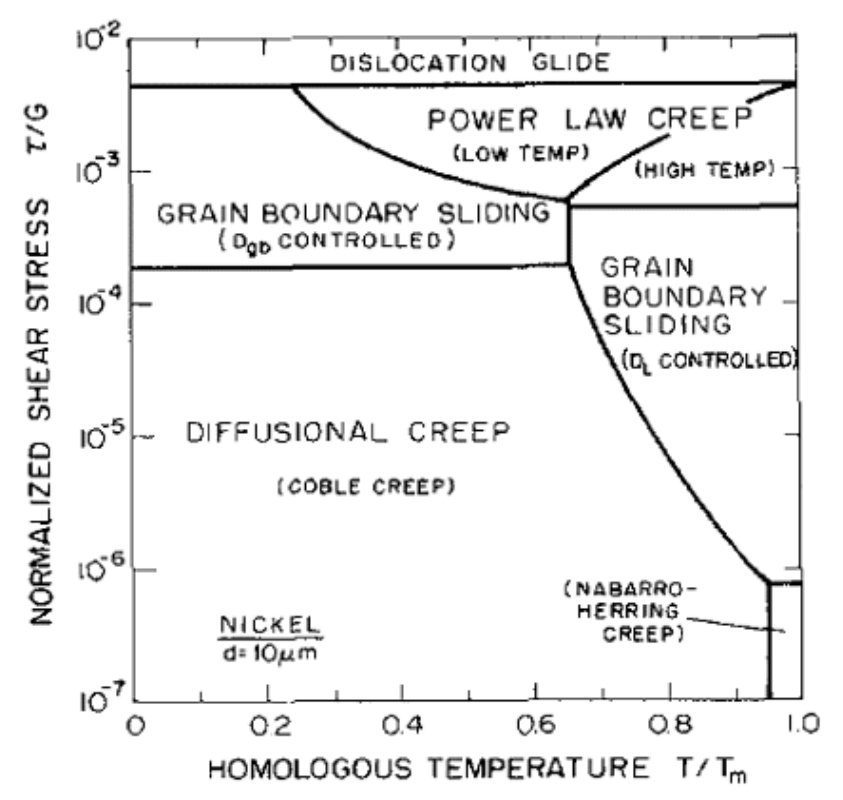

(a)

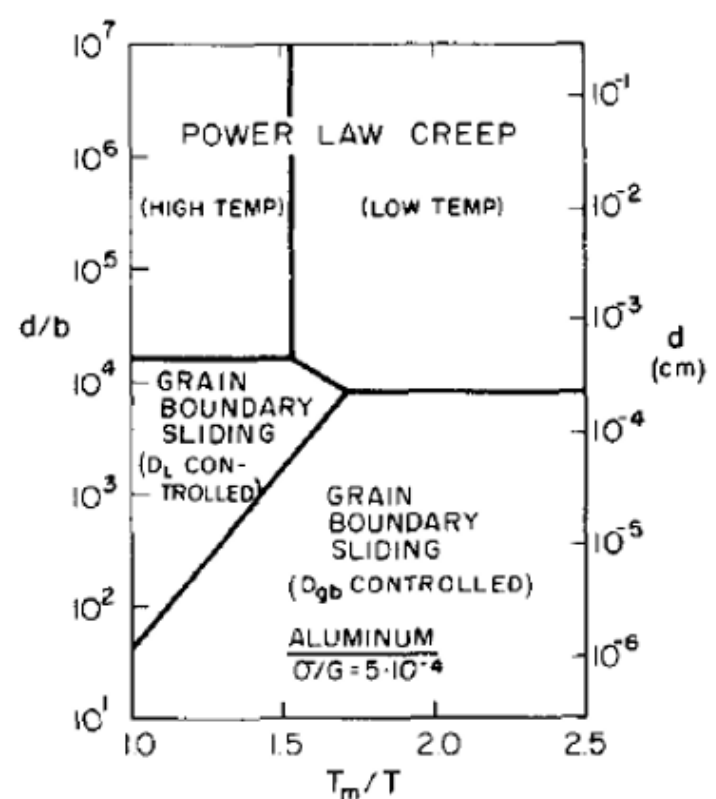

(b)

Fig. 2- 20. Deformation-mechanism maps with consideration of GBS mechanism: (a) revision of pure nickel map by Ashby; (b) revision of aluminum map by Langdon and Mohamed $\left[{ }^{91}\right]$. 


\subsection{Effects of Microstructural Evolution}

As described above, Grade 91 steels have a tempered-martensitic structure. After the tempering heat treatment, the strength of the steels depends on the tempered martensite microstructure and the precipitates formed. Hence, their creep strength is generally provided by three mechanisms: (1) solution hardening, (2) dislocation hardening and (3) precipitation hardening $\left[{ }^{29}\right]$. As a matter of fact, the microstructural evolution in such steels occurs continuously under creep conditions $\left[{ }^{92}\right]$.

When Cr-Mo steels are put into elevated-temperature service, the initial tempered martensitic microstructure will change. In addition, if loads are applied, which is mostly intended for service conditions, creep deformation can occur in the steels at stress levels that are well below the yield strength at elevated temperatures. Inherently, creep of 9Cr-1Mo steels occurs with an evolving microstructure. During the long-time exposure at elevated temperatures, the microstructure of 9$12 \% \mathrm{Cr}$ steels can change significantly $\left[{ }^{93}\right]$. The rate of microstructural changes increases as the temperature increases, but the dislocation density will decrease due to elevated-temperature recovery and annihilation (Fig. 2- 4). Particularly, $\mathrm{M}_{23} \mathrm{C}_{6}$ and $\mathrm{MX}$ precipitates become coarsened along with the reduction in dislocation density. For F91, evidence of $\mathrm{M}_{23} \mathrm{C}_{6}$ coarsening (60 - 300 $\mathrm{nm})$ can be commonly observed, as well as the MX $(5-80 \mathrm{~nm})$ particles, although the latter has a much slower coarsening rate than the former. As an effect of such particle coarsening, F91 was found to be fully recovered with equiaxed subgrains after 30,000 hours of creep at $600^{\circ} \mathrm{C}\left[{ }^{20}\right]$. Fig. 2- 21 shows the detailed morphologies of $\mathrm{M}_{23} \mathrm{C}_{6}$ and $\mathrm{MX}$ in TEM micrographs; Fig. 2- 22 illustrates the distributions of $\mathrm{M}_{23} \mathrm{C}_{6}$ and $\mathrm{MX}$ in lath martensite structures $\left[{ }^{94}\right] \cdot \mathrm{M}_{23} \mathrm{C}_{6}$ is a Cr-rich compound, and a large portion of Mo and $\mathrm{W}$ can be found in it, especially after long-time exposure at elevated-temperatures; $\mathrm{MX}$ is often detected to be V nitrides, and $\mathrm{Nb}$ carbonitrides $\left[{ }^{95}\right]$. Both particles play the role to maintain the martensitic lath structure; specifically, the $\mathrm{M}_{23} \mathrm{C}_{6}$ particles 
stabilize the lath boundaries, and the MX particles retain the dislocation density. Therefore, coarsening of $\mathrm{M}_{23} \mathrm{C}_{6}$ and MX particles during creep could have an adverse effect on the properties of the material $\left[{ }^{95}\right]$.

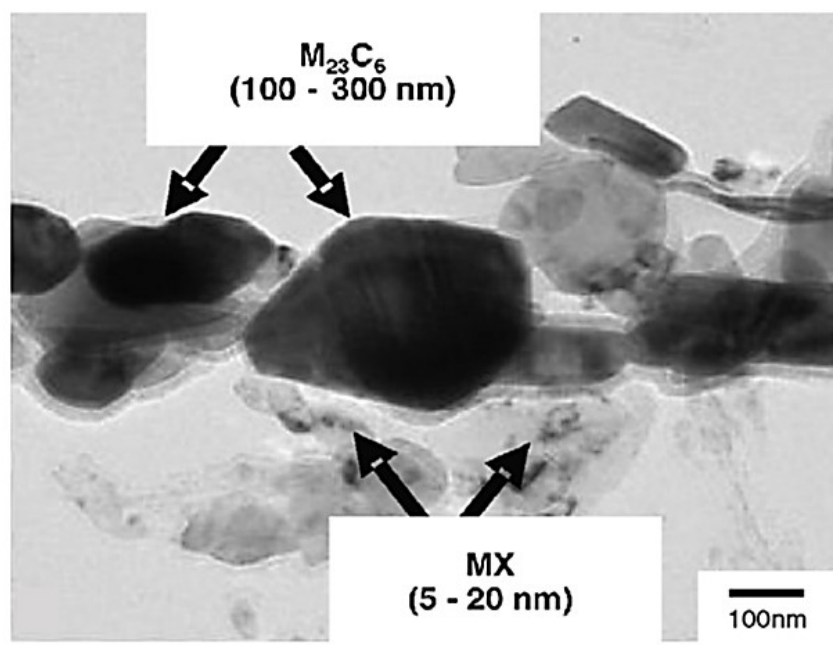

Fig. 2- 21. Micrographs of $\mathrm{M}_{23} \mathrm{C}_{6}$ and $\mathrm{MX}$ re-crystallization near prior austenite grain boundary $\left[{ }^{94}\right]$. 


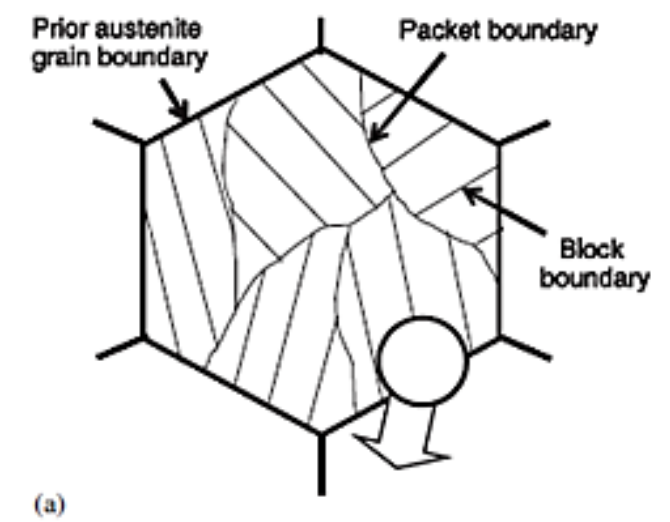

(a)

(b)

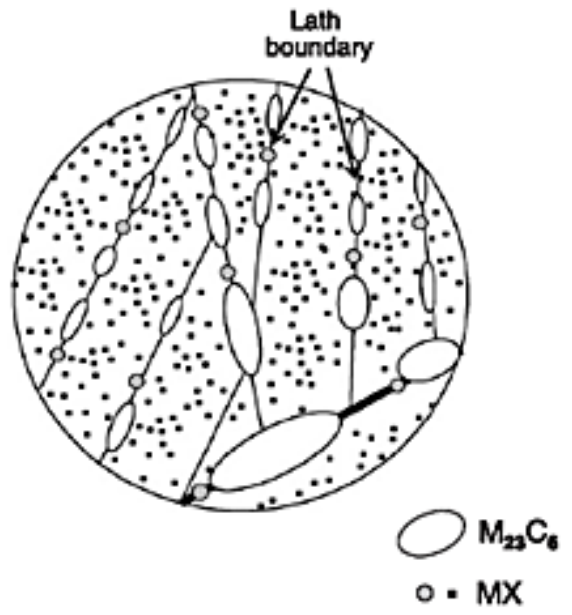

Fig. 2- 22. Illustration of martensitic $9 \mathrm{Cr}$ steel after tempering: (a) subgrain structure; (b) distribution of M23C6 and MX in conventional [ $\left.{ }^{94}\right]$.

Moreover, it has been found that $\mathrm{A}_{2} \mathrm{~B}$ intermetallic particles (also known as topologically closed packed phase), i.e., Laves phase, could form when the steels are exposed at an elevated temperature along with the $\mathrm{M}_{23} \mathrm{C}_{6}$ and $\mathrm{MX}$ coarsening. The Laves phase typically has a composition of $(\mathrm{FeCr})_{2}(\mathrm{Mo}, \mathrm{W})$ in $9-12 \% \mathrm{Cr}$ steels. For most of the $9-12 \% \mathrm{Cr}-\mathrm{Mo}$ steels investigated, Laves phase can form during tempering and creep at $400-600^{\circ} \mathrm{C}$, and it quickly coarsens, and the applied stress can accelerate the process $\left[{ }^{95},{ }^{96},{ }^{97}\right]$. For example, it has been shown by both empirical data and Johnson-Mehl-Avrami-Kolmogorov (JMAK) equation that Laves phase would form after prolonged aging at 600 to $650^{\circ} \mathrm{C}$ with tungsten (W) from the solid solution. The JMAK equation describes the phase transformation kinetics for the growth of the 
Laves phase volume fraction, usually as a sigmoidal curve of time $\left[{ }^{98}\right]$. Laves phase can cause embrittlement, and it absorbs the solid-solution strengthening elements, such as Mo and W in 9 $12 \% \mathrm{Cr}$ steels $\left[{ }^{18},{ }^{99}\right]$. However, in F91, the Laves phase was found at $600^{\circ} \mathrm{C}$ but almost none at $650^{\circ} \mathrm{C}$. In E911 (see Table 2- 2), with additional $1 \% \mathrm{~W}$, Laves phase was found at $650^{\circ} \mathrm{C}$ after $10^{5}$ hours exposure. Because of the higher concentrations of Mo and W, Laves phase was stabilized at the higher temperature $\left[{ }^{98}\right]$. A study showed by comparing the as-received P91 specimen with the $10^{4}$ hours aging heat treatment specimen at $600^{\circ} \mathrm{C}$ and $650^{\circ} \mathrm{C}$ that the creep behaviors of these two specimens were significantly different, as illustrated in Fig. $2-23\left[{ }^{36}\right]$. The suggestion is that longterm aging may induce microstructural changes via Laves phase formation, which could be the cause of the reduction of creep life. 

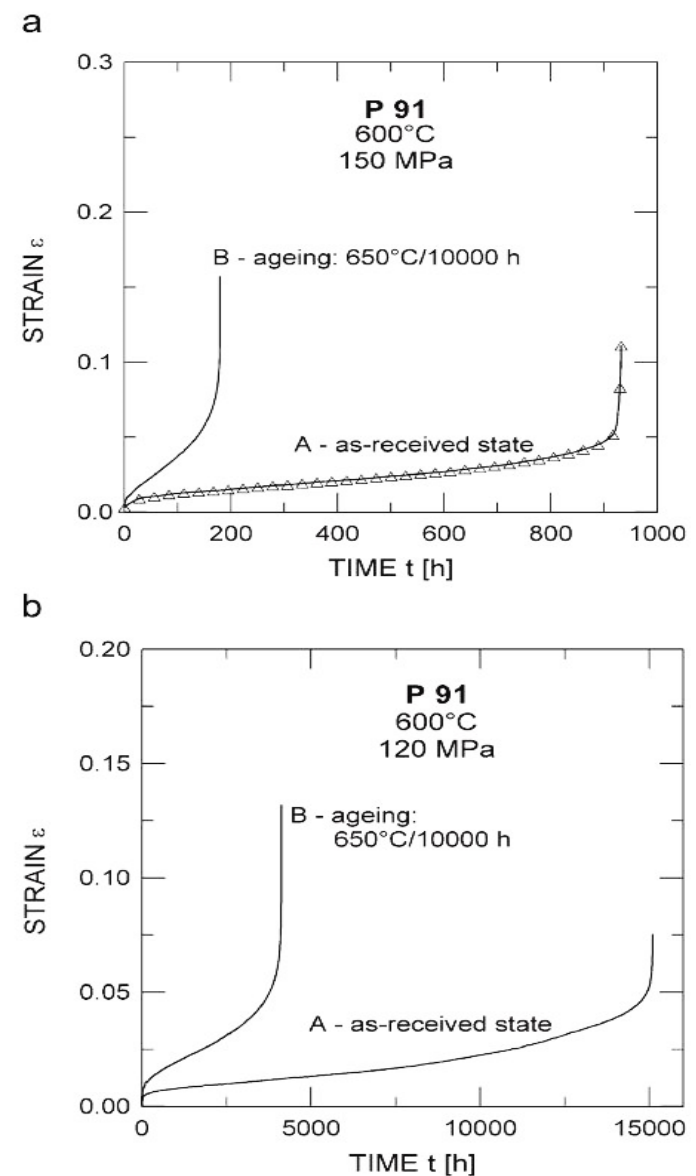

Fig. 2- 23. Comparison between $\mathrm{A}$ and $\mathrm{B}$ states of $\mathrm{P} 91$ creep curves at $600^{\circ} \mathrm{C}$ under two stresses: (a) $150 \mathrm{MPa}$ and (b) $120 \mathrm{MPa}\left[{ }^{36}\right]$.

Z-phase (size $\sim 50 \mathrm{~nm}$ ) is another type of Cr-rich nitride compound (sometimes, with $\mathrm{Nb}$ and/or $\mathrm{V}$ as partial substitutes of $\mathrm{Cr}$ ), which can also be found in 9-12\% Cr-Mo steels. Fig. $2-24$ illustrates the crystal structure of Z-phase: original Z-phase, $\mathrm{CrNbN}$, has lattice parameters $a=$ $0.304 \mathrm{~nm}$ and $c=0.739 \mathrm{~nm}$; modified Z-phase, $\mathrm{Cr}(\mathrm{V}, \mathrm{Nb}) \mathrm{N}$, has a smaller value for $a$, with $a=$ $0.286\left[{ }^{97}\right]$. It is still debatable whether the effect of Z-phase is beneficial or deleterious to creep strength, but there is little argument on the fact that it absorbs MX, or in other words, MX transforms into $\mathrm{Z}$ phase. High $\mathrm{Nb}$ concentration may accelerate the precipitation of $\mathrm{Z}$-phase, as found by Danielsen and Hald $\left[{ }^{97}\right]$. In their studies, few Z phase was found in the $12 \mathrm{Cr}-\mathrm{Mo}-\mathrm{V}$ steel $\mathrm{X} 20$ with high $\mathrm{Cr}$ but without $\mathrm{Nb}$ after exposure for an extended period $(150,000$ hours $)$ at $600^{\circ} \mathrm{C}$. 
However, $12 \% \mathrm{Cr}-\mathrm{V}-\mathrm{Nb}$ steels, such as $\mathrm{X} 19 \mathrm{CrMoVNbN} 11-1$, containing $\mathrm{Nb}$ content about 0.15 wt.\%, generally had Z-phase precipitated after a period of 10,000 30,000 hours. Strang and Vodared revealed the relationship between Z-phase and creep strength, and suggested that the creep lifetime of $11-12 \% \mathrm{Cr}-\mathrm{Mo}-\mathrm{V}-\mathrm{Nb}-\mathrm{N}$ steel was shortened by the Z-phase [ $\left.{ }^{100}\right]$.

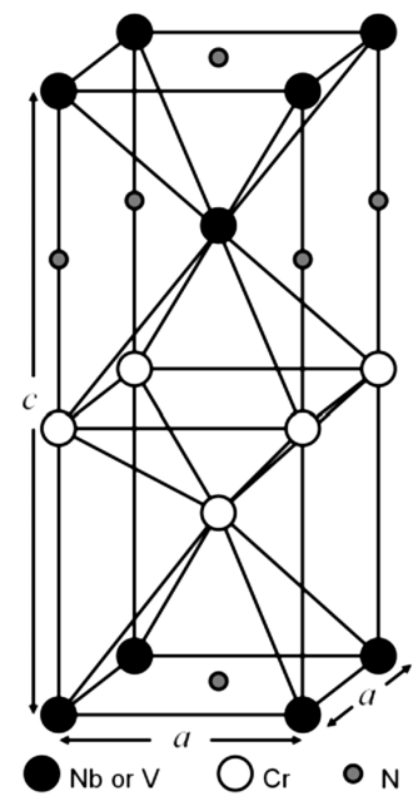

Fig. 2- 24. Crystal structure of Z-phase $\left[{ }^{97}\right]$.

Table 2- 5 categorizes these precipitates along with their composition, size, and shape; Fig. 2- 25 captures all the above precipitates in one micrograph $\left[{ }^{101}\right]$. A schematic sketch reflecting the creep strength in relation to the microstructural changes is shown in Fig. 2- $26\left[{ }^{36}\right]$. Take Laves phase, for example, the appearance of Laves phase may enhance the creep strength at the very early stage when the particle is small, but the benefit will soon be offset once it coarsens to a large particle during long time exposure [ $\left.{ }^{102}\right]$. As implied by the relationships shown in Fig. 2- 26, various effects of strengthening mechanisms and particles/elements in the microstructure on creepstrength should be carefully investigated and evaluated. Note that $\mathrm{M}_{6} \mathrm{C}$ particles usually form in $12 \% \mathrm{Cr}$ steels but not in $9 \mathrm{Cr}$ steels $\left[{ }^{18}\right]$. Therefore it will not be considered in this study. 
Table 2- 5 Common precipitation characteristics in 9 - 12\% CrMoW martensitic steels $\left[{ }^{101}\right]$

\begin{tabular}{|c|c|c|c|c|c|}
\hline Precipitation & Composition & $\begin{array}{l}\text { Minor } \\
\text { content }\end{array}$ & $\begin{array}{c}\text { Crystal } \\
\text { structure }\end{array}$ & Size and shape & $\begin{array}{c}\text { Nucleation } \\
\text { period }\end{array}$ \\
\hline $\mathrm{M}_{23} \mathrm{C}_{6}$ & $\mathrm{Cr}_{23} \mathrm{C}_{6}$ & $\begin{array}{l}\text { Fe, Mo, } \\
\text { W, B }\end{array}$ & cubic & $\begin{array}{l}\approx 100 \mathrm{~nm} \text {, coarsening } \\
\text { rate high }\end{array}$ & tempering \\
\hline MX & $\begin{array}{l}\mathrm{NbC}, \mathrm{VN}, \\
(\mathrm{Nb}, \mathrm{V})(\mathrm{C}, \mathrm{N})\end{array}$ & $\mathrm{Cr}, \mathrm{C}$ & cubic & $\begin{array}{l}\text { sphere of various sizes, } \\
\text { coarsen very slowly }\end{array}$ & tempering \\
\hline $\mathrm{M}_{2} \mathrm{X}$ & $\mathrm{Cr}_{2} \mathrm{~N}$ & V & hexagon & $\begin{array}{c}\text { stable in high N steels, } \\
\text { few in low N steels, } \\
\text { morphologically like Z- } \\
\text { phase }\end{array}$ & tempering \\
\hline Laves phase & $\mathrm{Fe}_{2}(\mathrm{Mo}, \mathrm{W})$ & $\mathrm{Cr}, \mathrm{Si}$ & hexagon & $\begin{array}{c}\text { various size and shape, } \\
\text { can be larger than most } \\
\text { other particles }(> \\
200 \mathrm{~nm})\end{array}$ & $\begin{array}{c}\text { long-term } \\
\text { thermal } \\
\text { exposure }\end{array}$ \\
\hline Z-phase & $\begin{array}{c}\mathrm{CrNbN}, \\
\mathrm{Cr}(\mathrm{Nb}, \mathrm{V}) \mathrm{N}\end{array}$ & $\begin{array}{c}\mathrm{Fe}, \mathrm{Mo}, \\
\mathrm{W}\end{array}$ & tetragon & $\begin{array}{c}\text { faceted particles, absorb } \\
\text { MX, may be larger than } \\
1 \text { micron }\end{array}$ & $\begin{array}{c}\text { long-term } \\
\text { thermal } \\
\text { exposure }\end{array}$ \\
\hline
\end{tabular}

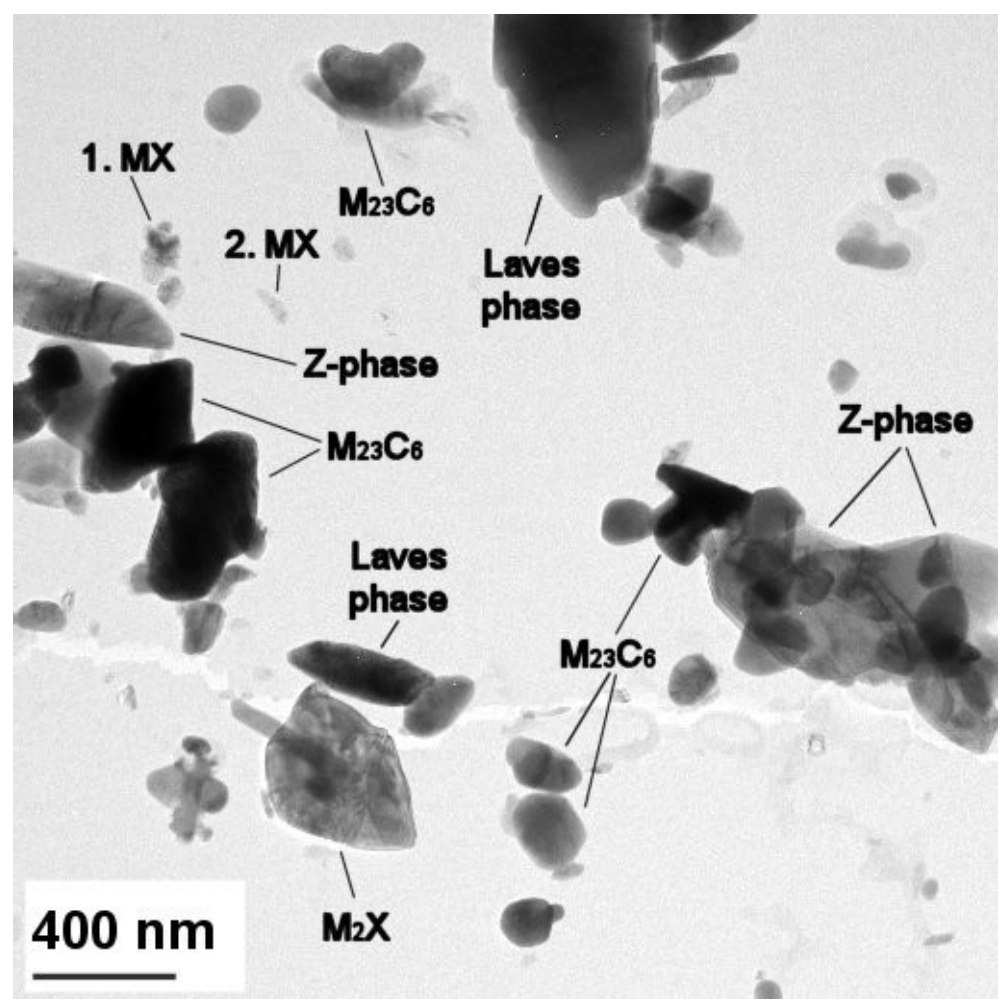

Fig. 2- 25. An illustration of the most common precipitates in $9-12 \%$ CrMoW steels $\left[{ }^{101}\right]$. 


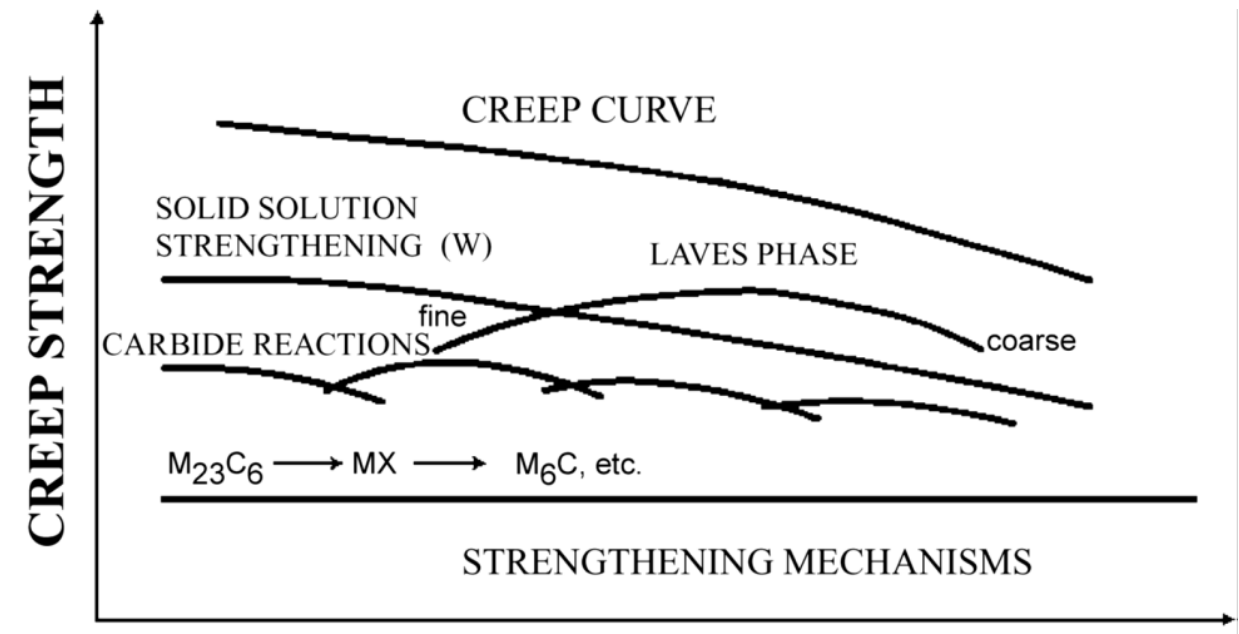

TIME

Fig. 2- 26. Effects of microstructural changes on the creep strength of $9-12 \% \mathrm{Cr}$ steels $\left[{ }^{36}\right]$. 


\subsection{Oxidation and MCrAIY Coating}

Other than creep itself, oxidation is another life-limiting factor for materials in the A-USC steam environment or gas turbine environment; particularly, when the interaction between oxidation and creep is paramount $\left[{ }^{103}\right]$. Severe oxidation has been observed on creep-rupture T91 steel, as shown in Fig. 2- 27, where the oxidation products were mostly Fe-oxides or Cr-rich oxides only after creep test at $650^{\circ} \mathrm{C}$ under $155 \mathrm{MPa}$ for 31 hours $\left[{ }^{104}\right]$. In another study, Tian et al. found that creep of T91 in the lead-bismuth eutectic (LBE) environment also suffered from oxidation. LBE is a eutectic alloy with lead (44.5\%) and bismuth (55.5\%) used as the coolant in nuclear reactors owing to its low melting temperature $\left(123.5^{\circ} \mathrm{C}\right)$ but a high boiling point $\left(1670^{\circ} \mathrm{C}\right)$. Their study showed that the oxide formation occurred at the interface of the LBE and T91, consisting of $\mathrm{Fe}_{3} \mathrm{O}_{4}, \mathrm{Fe}-\mathrm{Cr}$ and an internal oxidation zone (IOZ) $\left[{ }^{105}\right]$. The oxidation process was accelerated by elevatedtemperature although the high $\mathrm{Cr}$ content provided relatively high oxidation/corrosion resistance for such steels $\left[{ }^{18}\right]$. 


\section{(a)}

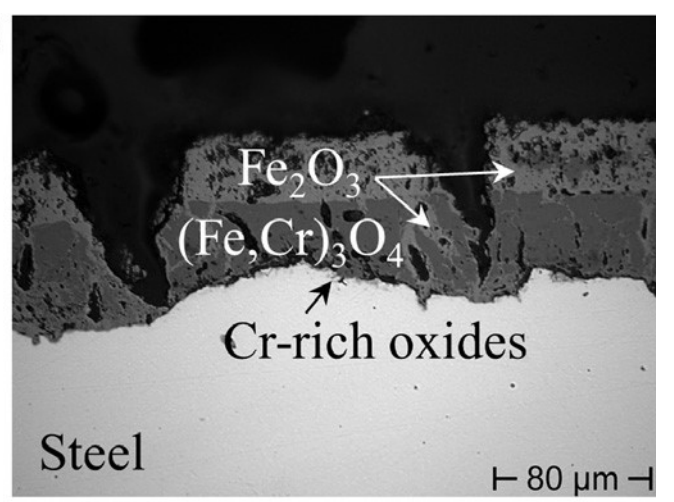

(b)

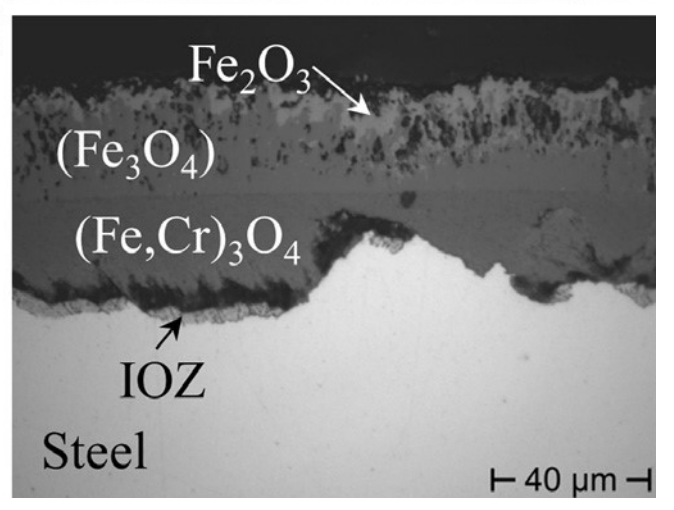

Fig. 2- 27. The longitudinal cross-section of the oxide scale on T91 after creep-to-rupture for 31 hrs in the stagnant air at $650^{\circ} \mathrm{C}$ under a stress of $155 \mathrm{MPa}$ : (a) near the necking region and (b) in some distance from the fracture $\left[{ }^{104}\right]$.

Coating technologies are well established as an important method to protect the substrate material for many purposes, especially under severe working conditions such as at elevated temperatures, or in oxidation/corrosion environments. Typically, MCrAlY is widely used as an environmental protection coating for industrial gas turbine engine components. The $\mathrm{Cr}$ and $\mathrm{Al}$ in the coating are sacrificial elements to form a continuous thermally grown oxide (TGO) layer on the coating surface, thus preventing the substrate from oxidation $\left[{ }^{106},{ }^{107},{ }^{108}\right]$.

Many deposition technologies may be used to apply the coating, which produce different microstructures that affect the mechanical properties of MCrAlY coating. For example, highvelocity oxy-fuel (HVOF) coating exhibits a higher hardness than vacuum plasma spraying (VPS) coating (Fig. 2- 28), while VPS deposition process results in large volume fraction of Al-rich $\beta$ 
phase than the HVOF (Fig. 2- 29) $\left.{ }^{109}\right]$. Both technologies have been evaluated to provide promising coating properties $\left[{ }^{14},{ }^{110}\right]$. In this study, the creep properties of MCrAlY-coated and uncoated F91 shall be compared.

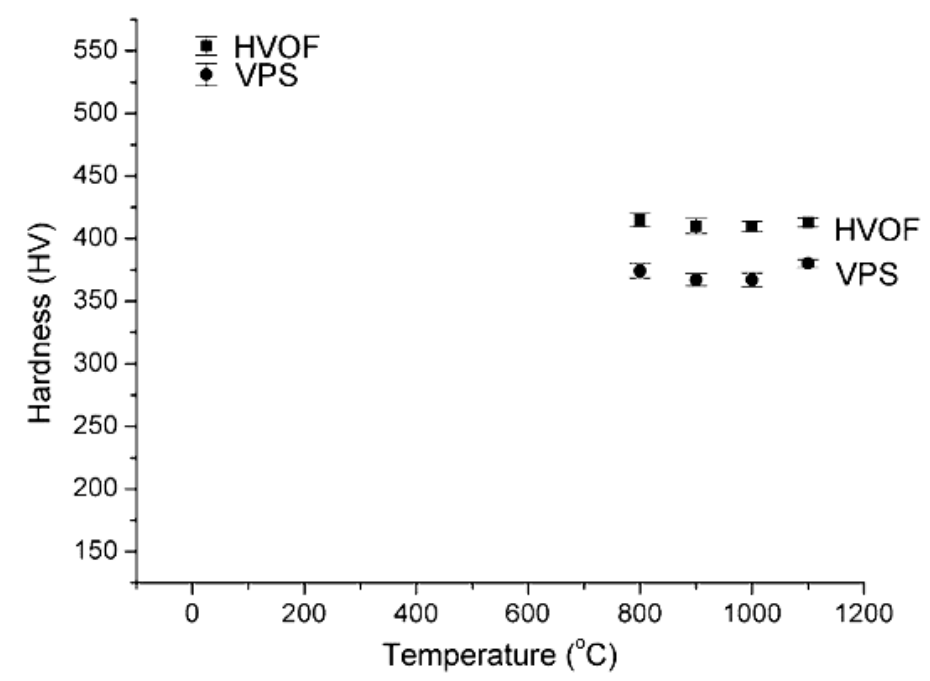

Fig. 2- 28. The hardness of VPS and HVOF coatings as a function of annealing temperature $\left[{ }^{109}\right]$.

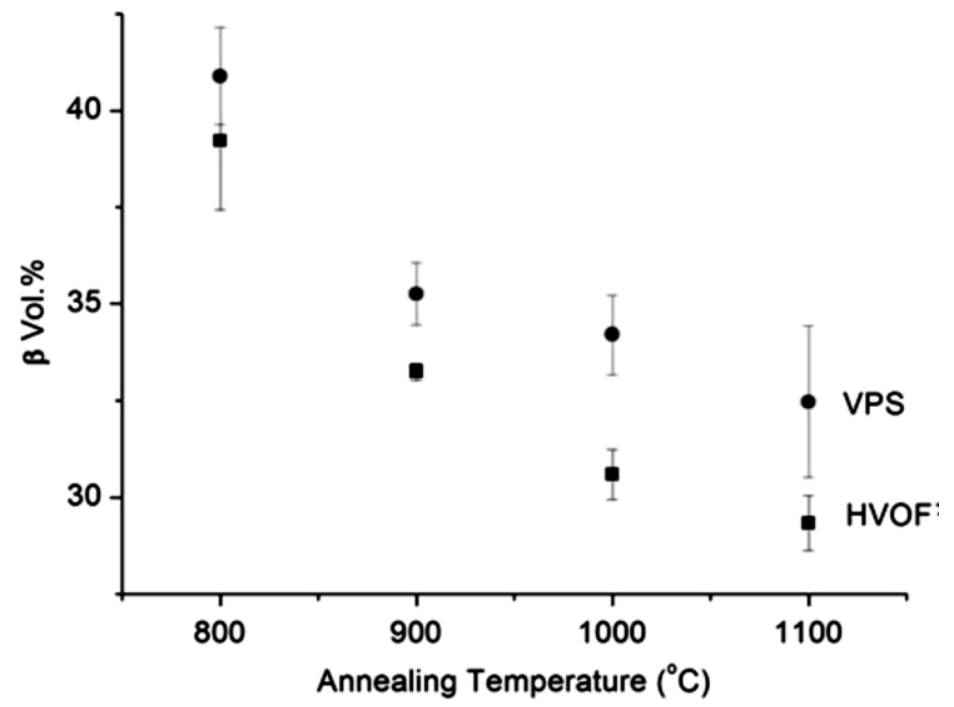

Fig. 2- 29. $\beta$ precipitates volume fraction as a function of annealing temperature for VPS and HVOF coatings $\left[{ }^{109}\right]$. 
In summary, the fundamentals of creep for modified Grade 91 have been studied extensively during the past three decades, and the established knowledge of creep mechanisms has been well recognized and acknowledged in the contemporary academia. However, there are still problems remaining unsolved when the long-term creep performance of materials becomes the most concerned issue in a recent decade. In this study, first, a model that can integrate different wellestablished deformation mechanisms into one constitutive equation is proposed. For a long time when the industry has been adopting empirical models, the proposed model first provides a new perspective of assessing long-term creep performance of materials with the ability to identify deformation mechanisms within one constitutive equation. Second, based on the review of microstructural evolution effects on long-term creep behavior, the Laves phase nucleation and growth that may affect the creep strength of materials are tackled in this thesis. Third, as one of the significant environmental impacts, oxidation, is also studied to cope with the rationality of long-term creep life prediction. 


\section{Chapter 3 Experimental Details}

\subsection{Materials}

In this study, F91 steel is selected as the baseline material for creep performance evaluation. The product standard follows ASME SA182-01 Grade F91. The chemical composition of the asreceived F91 raw bars is listed in Table 3- 1. Creep testing was first performed on this baseline material, then on heat-treated F91 and coated F91 under the same conditions for comparison. The heat treatment of the as-received F91 bar consisted of the following processes: (1) normalizing $1080^{\circ} \mathrm{C}\left(1975^{\circ} \mathrm{F}\right)$ for 4 hours; (2) temperature-air cooling for $1-2$ hours; (3) tempering at $800^{\circ} \mathrm{C}$ $\left(1470^{\circ} \mathrm{F}\right)$ for 5 hours; (4) air cooling to room-temperature. Table 3- 2 provides the roomtemperature mechanical properties of the as-received F91, which are obtained according to standard DIN 50125.

Table 3- 1 Chemical composition (wt.\%) of as-received F91 raw bar

\begin{tabular}{ccc}
\hline Element & Nominal & As-received \\
\hline $\mathrm{Cr}$ & $8.00-9.50$ & 8.38 \\
$\mathrm{Mo}$ & $0.85-1.05$ & 0.94 \\
$\mathrm{~V}$ & $0.18-0.25$ & 0.22 \\
$\mathrm{Nb}$ & $0.06-0.10$ & 0.067 \\
$\mathrm{C}$ & $0.08-0.12$ & 0.100 \\
$\mathrm{Mn}$ & $0.30-0.60$ & 0.43 \\
$\mathrm{Cu}$ & $0.4(\max )$ & $\mathrm{N} / \mathrm{A}$ \\
$\mathrm{Si}$ & $0.20-0.50$ & 0.32 \\
$\mathrm{~N}$ & $0.03-0.07$ & 0.053 \\
$\mathrm{Ni}$ & $0.40(\max )$ & 0.18 \\
$\mathrm{P}$ & $0.02(\max )$ & 0.020 \\
$\mathrm{~S}$ & $0.01(\max )$ & 0.010 \\
$\mathrm{Ti}$ & $0.01(\max )$ & 0.007 \\
$\mathrm{Al}$ & $0.02(\max )$ & 0.011 \\
$\mathrm{Zr}$ & $0.01(\max )$ & 0.001 \\
$\mathrm{Fe}$ & Balance & Balance \\
\hline
\end{tabular}


Table 3- 2 Room-temperature mechanical properties of as-received F91 bar

\begin{tabular}{cccccc}
\hline $\begin{array}{c}\text { Diameter } \\
(\mathrm{mm})\end{array}$ & $\begin{array}{c}\text { Yield Strength at } \\
0.2 \% \text { offset } \\
(\mathrm{MPa})\end{array}$ & $\begin{array}{c}\text { Tensile } \\
\text { Strength } \\
(\mathrm{MPa})\end{array}$ & $\begin{array}{c}\text { Elongation } \\
(\%)\end{array}$ & $\begin{array}{c}\text { Reduction of } \\
\text { Area } \\
(\%)\end{array}$ & $\begin{array}{c}\text { Hardness } \\
(\mathrm{BHN})\end{array}$ \\
\hline 10.0 & 484.0 & 659.0 & 27.5 & 72.0 & $204-213$ \\
\hline
\end{tabular}

\subsection{Creep Coupon Preparation}

\subsubsection{Pristine coupon}

F91 bars of 7/8 inches in diameter and 4 inches in length were purchased from Merchant US ALLOYS, but were manufactured by METAL RAVNE d.o.o, Slovenian Steel Group. The bars were machined into creep test coupon, as shown in Fig. 3- 1, by Kennametal Stellite Inc. The creep coupon has a straight gauge length of 0.791 inch and a gauge section diameter of 0.158 inch. A low stress grinding technique was employed to minimize residual stress in the final coupons. As the last step of specimen preparation, the gauge section was polished by hand using silicon carbide papers, from grade 180 to 1200 . The purpose of polishing was to minimize stress concentration on the coupon surface that might have an adverse effect on creep life. 


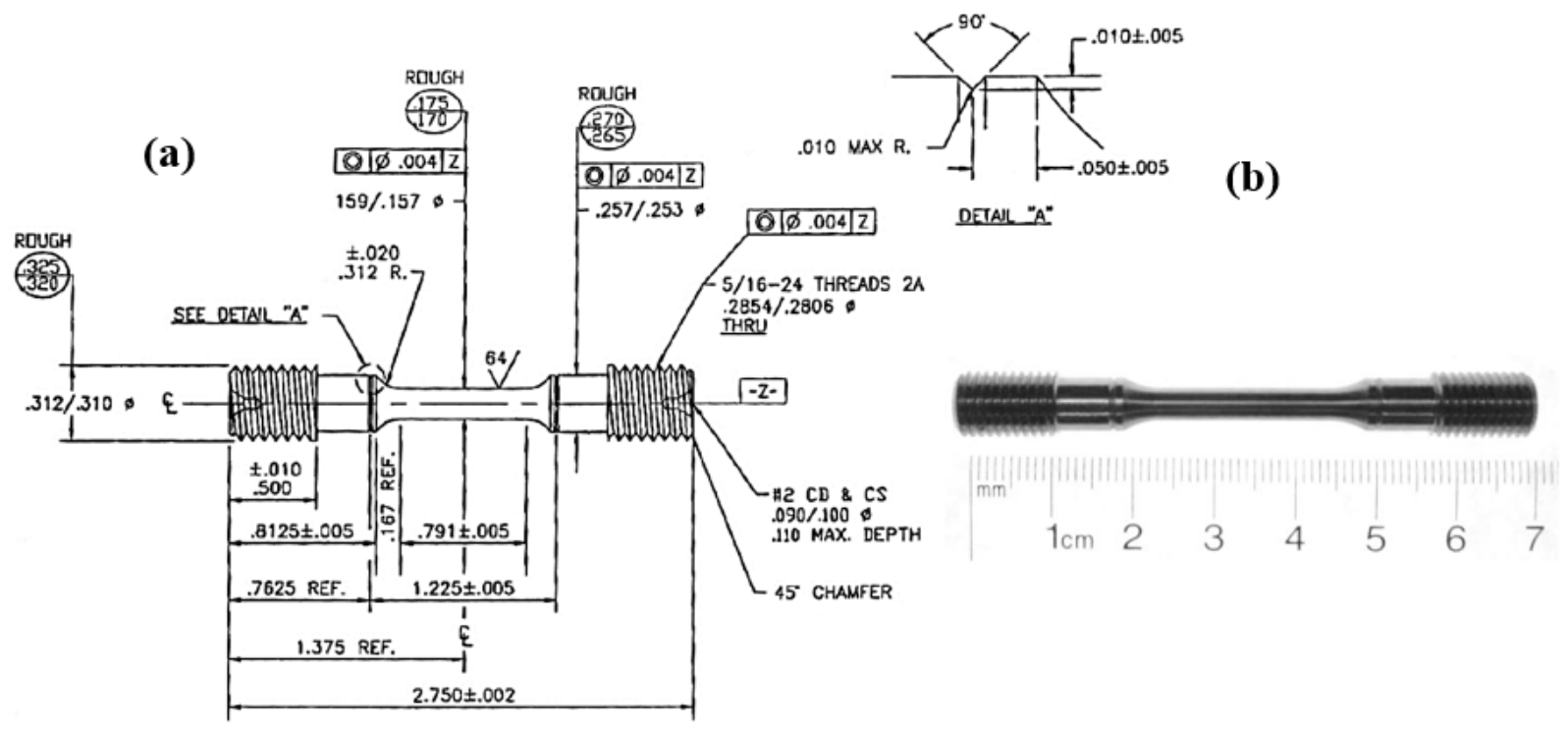

Fig. 3- 1. Creep test coupon: (a) design drawing; (b) photo.

\subsubsection{Aged-coupon}

A group of six coupons in the as-machined form was subjected to an aging heat treatment in a box furnace (Lindberg/Blue M, max temperature of $1500^{\circ} \mathrm{C}$ ) at $600^{\circ} \mathrm{C}$ for 5,000 hours prior to creep testing. A traveler coupon was also given the same aging heat treatment, but taken out and sectioned at pre-determined time intervals for metallurgical examination.

\subsubsection{Coated-coupon}

Another group of six coupons was coated with MCrAlY powder, using HVOF deposition technique. The MCrAlY powders were purchased from Praxair Canada Inc. with specification as given in Table 3- 3. Coating deposition was carried out by Kennametal Stellite Inc. The coating has a thickness about $280 \mu \mathrm{m}$, as shown in Fig. 3- 2. The coating was dense with minimal porosity that the process had allowed and it possessed good adhesion with the F91 substrate. 
Table 3- 3 Co-210-24/Co-241-3 CoNiCrAlY powder data sheet

\begin{tabular}{|c|c|c|c|c|c|}
\hline Element & Co & $\mathrm{Ni}$ & $\mathrm{Cr}$ & $\mathrm{Al}$ & $\mathrm{Y}$ \\
\hline $\begin{array}{c}\text { Composition } \\
\text { (wt.\%) }\end{array}$ & Balance & 32.0 & 21.0 & 8.0 & 0.5 \\
\hline Description & $\begin{array}{ll}\text { - } & \text { Atomiz } \\
\text { - } & \text { Size: }-4 \\
\text { - } & \text { Corrosi } \\
\text { - } & \text { Heating } \\
\text { - } & \text { Typical } \\
& \text { environ }\end{array}$ & $\begin{array}{l}+20 \mu \mathrm{r} \\
\text { d oxida } \\
\text { nent is } \\
\text { d for ei } \\
1 \text { prote }\end{array}$ & $\begin{array}{l}\text { stance } \\
\text { ating } \\
\text { for o } \\
\text { ating }\end{array}$ & $38^{\circ} \mathrm{C}$ & \\
\hline
\end{tabular}
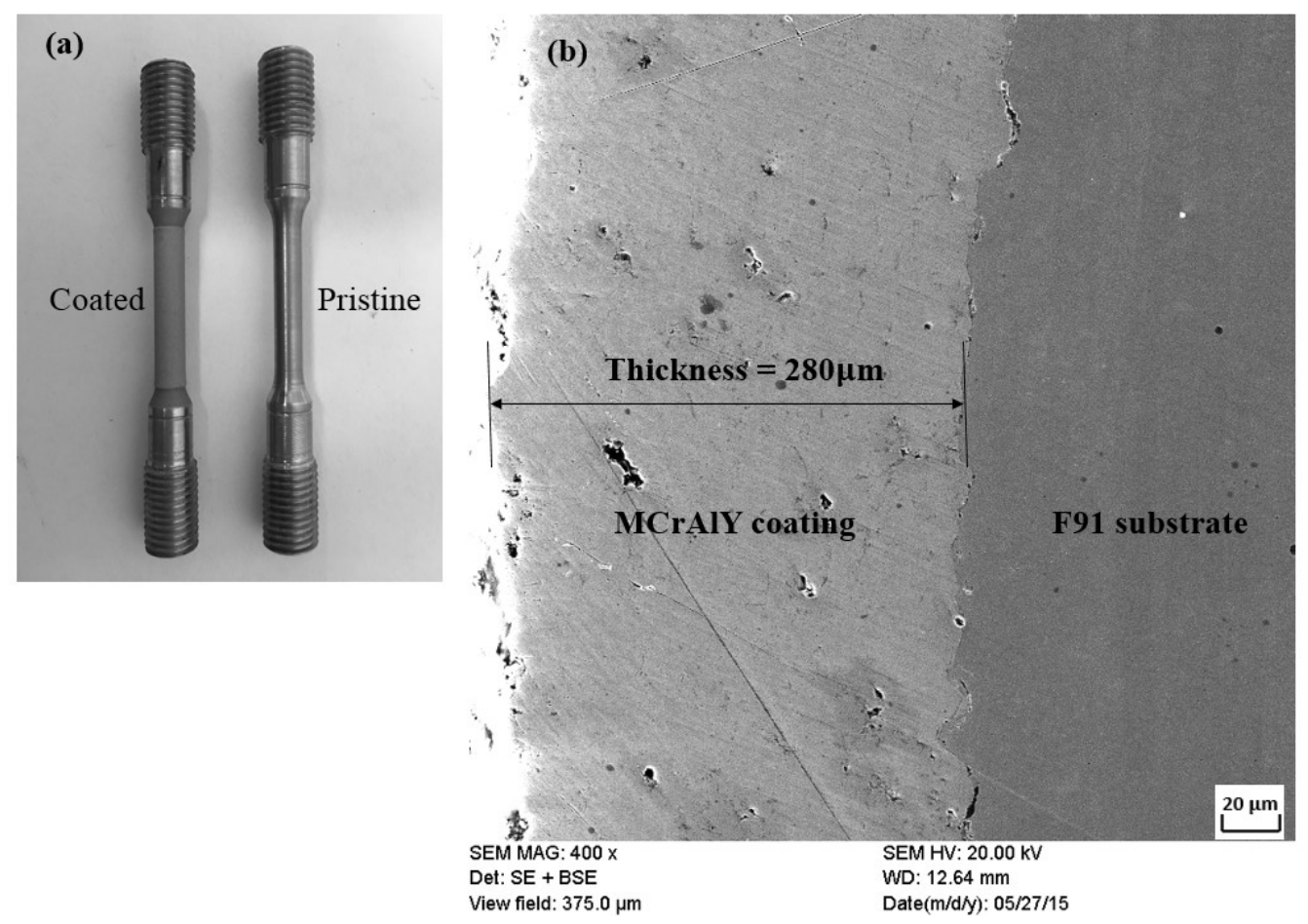

Fig. 3- 2. Coated coupon: (a) comparison with pristine coupon; (b) showing coating thickness.

Therefore, in total, three groups of creep test coupon were prepared and categorized as: (1) pristine, (2) aged, and (3) coated coupons. 


\subsection{Creep Test Setup}

Creep tests were performed in the Structures, Materials and Manufacturing Laboratory, National Research Council Canada (NRC-CNRC) Ottawa, on three SATEC constant-load creep frames. Each frame equips with an ATS three-zone furnace/temperature controller. Fig. 3- 3 schematically shows the test setup [ $\left.{ }^{111}\right]$. This constant-load frame has two lever ratios, 1:20 and 1:3. All creep tests in this study were conducted with the 1:3 ratio, because it was more convenient to set up the load with minimum accumulated errors. According to facility maintenance regulations, the creep frames were calibrated every three months or right after a long-term creep test. The ATS threezone furnace/temperature controller ensured that the test chamber heated evenly from bottom to top. In addition, three thermocouples were wired to the test coupon to monitor temperatures at two ends and the middle of the coupon. The coupon temperature in the test chamber was controlled within $\pm 3.0^{\circ} \mathrm{C}$. A data acquisition unit was connected to the thermocouples and a linear variable displacement transducer (LVDT) output, shown in Fig. 3- 3. During the creep tests, the LVDT converted coupon linear strain to a voltage signal. A computer with FileZilla $\left[{ }^{112}\right]$ file transfer client and YOKOGAWA MW100 data acquisition unit along with the MW100 View [ $\left.{ }^{113}\right]$ were used to process the strain-time data. 


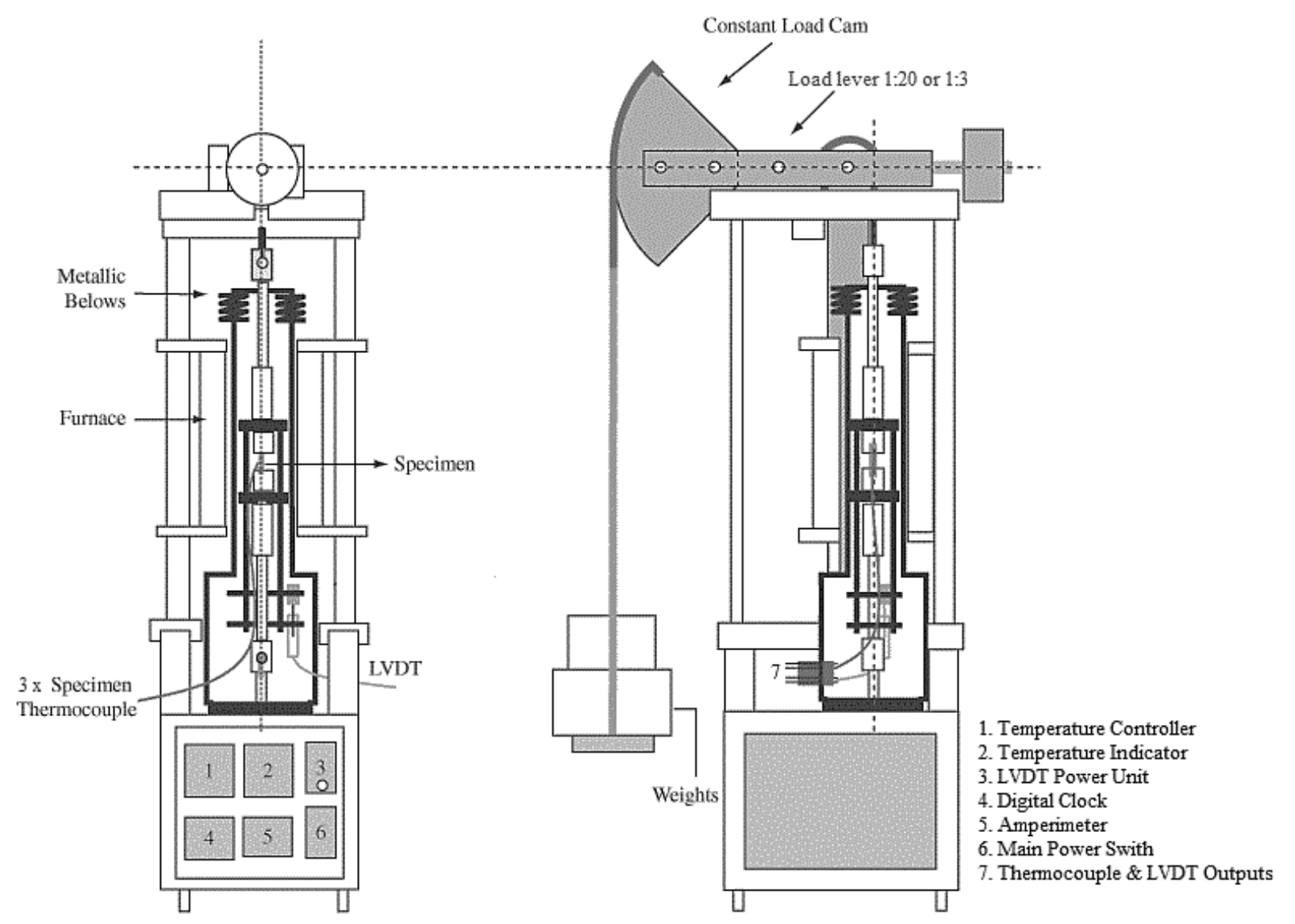

Fig. 3- 3. Schematic drawing of main components of creep testing machine $\left[{ }^{111}\right]$.

In the tests, the creep coupon was installed in an extensometer-holder, but the two ends were connected to the grips. Fig. 3- 4 shows the coupon assembly process in steps. COMBAT boron nitride coating, a liquid form anti-oxidation coating that can be used up to $1372^{\circ} \mathrm{C}$, was applied on the coupon threads and grip screw to prevent oxidation between the joints and threads $\left[{ }^{114}\right]$. Once the coupon holder assembly was installed in the furnace, the coupon was wired with three Omega DP462 thermocouples at two ends and middle. Fig. 3- 5 shows the wiring system of the thermocouples with Omega DP462 thermometers. The signals sent through the signal output panel and were transferred via FTP client FileZilla to lab computers for temperature profile monitoring. The test matrix is given in Table 3-4, showing the number of coupons for each test condition. The 
repeated tests showed good repeatability with respect to the time-to-rupture that were in the factor of two. $550^{\circ} \mathrm{C}$ and $600^{\circ} \mathrm{C}$ were selected to perform creep test on aged coupons because these two temperature levels were commonly reported in the literature for Laves phase nucleation and growth during long-term thermal exposure. Also, coated coupons were tested at these temperature levels, in order to provide comparison with pristine and aged-coupon test data.
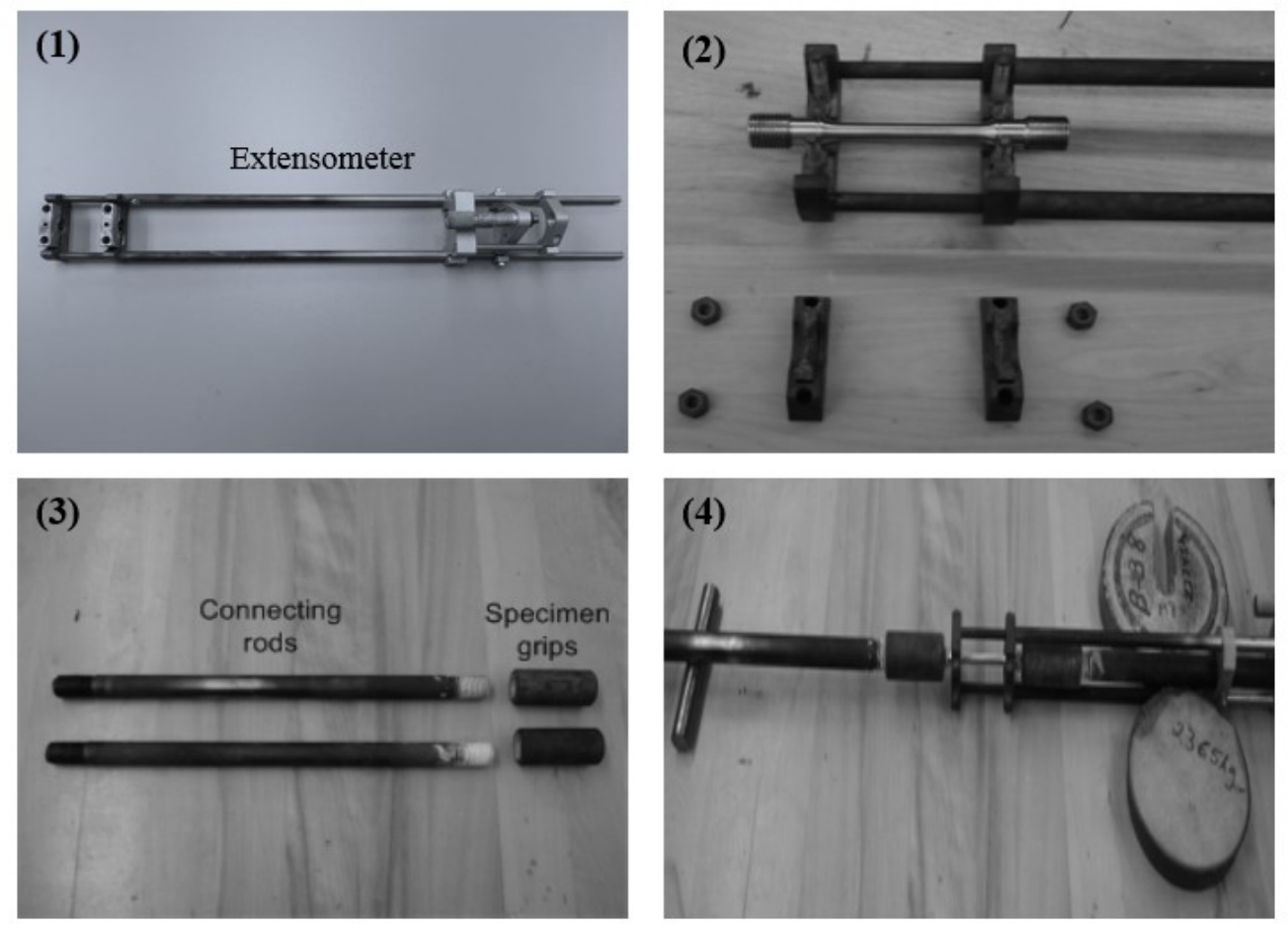

Fig. 3- 4. Coupon assembly in extensometer with both connecting rods attached. 


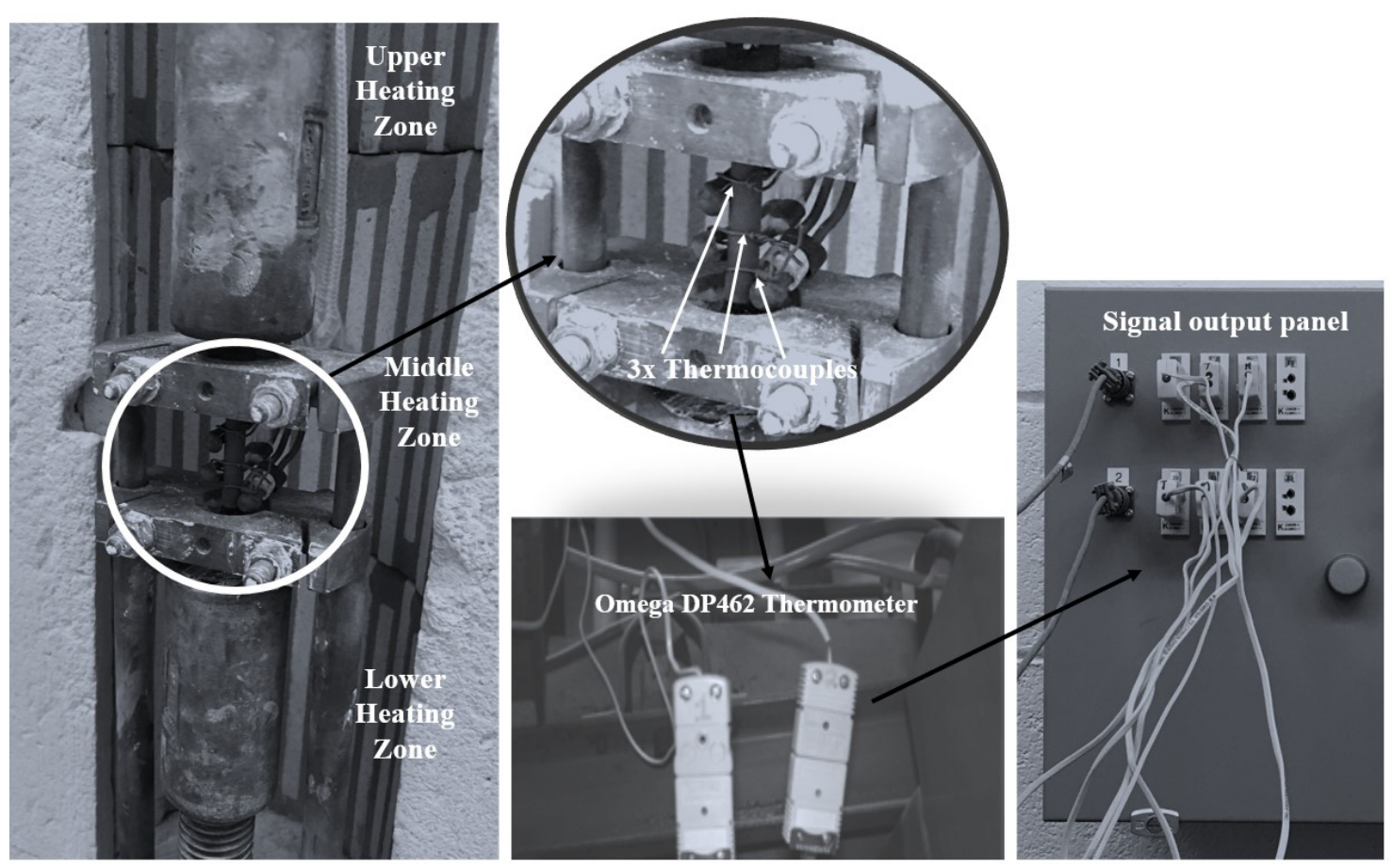

Fig. 3- 5. Wiring system of thermocouples on test coupon.

Table 3- 4 Creep test matrix for three types of sample preparation

\begin{tabular}{|c|c|c|c|c|}
\hline $\begin{array}{c}\text { Temperature } \\
\left({ }^{\circ} \mathrm{C}\right)\end{array}$ & $\begin{array}{l}\text { Stress } \\
(\mathrm{MPa})\end{array}$ & Pristine coupon & Aged coupon & Coated coupon \\
\hline \multirow{3}{*}{500} & 320 & 2 & \multirow{3}{*}{$\mathrm{N} / \mathrm{A}$} & \multirow{3}{*}{ N/A } \\
\hline & 300 & 1 & & \\
\hline & 280 & 1 & & \\
\hline \multirow{3}{*}{550} & 260 & 5 & 1 & 1 \\
\hline & 240 & 3 & 1 & $1 *$ \\
\hline & 220 & 2 & 1 & 1 \\
\hline \multirow{3}{*}{600} & 160 & 2 & 1 & $1 *$ \\
\hline & 140 & 1 & 1 & $1 *$ \\
\hline & 130 & 3 & 1 & 1 \\
\hline \multirow{3}{*}{650} & 110 & 2 & \multirow{3}{*}{$\mathrm{N} / \mathrm{A}$} & \multirow{3}{*}{ N/A } \\
\hline & 100 & 1 & & \\
\hline & 80 & 1 & & \\
\hline
\end{tabular}

Note: Numbers indicate repeats of creep test.

An asterisk* indicates the test still ongoing. 


\subsection{Metallographic Analysis}

Metallographic analyses were performed on creep coupons to examine composition and microstructures, and also to observe the failure mode. Both optical and scanning electron microscope (SEM) with energy dispersive X-ray spectroscopy (EDX) detector were employed in these studies. Sample preparation for metallographic analysis followed the procedure chart shown in Fig. 3- 6.

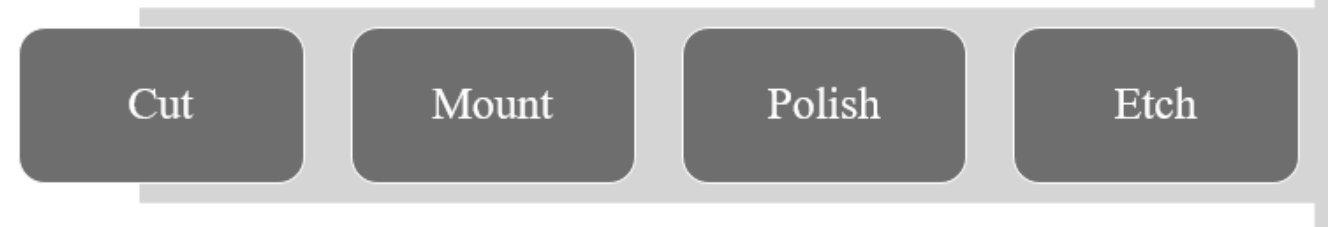

Optical/

SEM/EDX

Fig. 3- 6. Sample preparation procedure flowchart.

The precision cutting machine, Buehler ISOMET 2000 and Struers Secotom-10 were used to expose surface/section/areas of interest. Two methods of mounting were used: (1) metallographic compression mounting (hot mounting) which embedded samples into epoxy resins powders at $180^{\circ} \mathrm{C}$ under a pressure of $20 \mathrm{kN}$ for 10 minutes; (2) cold mounting, which embedded samples into epoxy resins without heat and pressure, but with mixing 100:45 (by weight) epoxy resin and hardener, and immersing the sample into the mixture for 9 hours at room temperature. Although cold mounting requires more time, the advantages are apparent: minimizing temperature and pressure influence during mounting and providing a clear view of samples. Both methods were used alternatively, depending on the sample condition. 
All metallographic analysis samples were ground following ASTM E3-11 standard guide for preparation of metallographic specimens $\left[{ }^{115}\right]$. Then, silicon carbide papers from grade 180, 240, $320,400,600,800$, to 1200 were used to polish the samples and then followed by $3 \mu \mathrm{m}$ diamond suspension polishing and $0.1 \mu \mathrm{m}$ colloidal silica suspension polishing as the final step.

The polished samples were etched with $3 \mathrm{ml} \mathrm{HNO}_{3}+100 \mathrm{ml}$ ethanol (95\%) solution for about $60 \sim 90$ seconds, which was suggested in ASTM E407-07 standard practice for microetching metals and alloys $\left[{ }^{116}\right]$. Etching was essential to expose and emphasize the grain boundaries, metallic phases, and precipitates in F91.

Two optical microspores: Olympus GX71 with magnification from 50 to 1000 and Nikon SMZ1000 with magnifications from 8 to 80 , as shown in Fig. 3- 7, were used in this study. The Olympus was mainly used to pre-examine polished and etched surfaces of samples. The lower magnification Nikon was used for area measurement of sample surfaces.

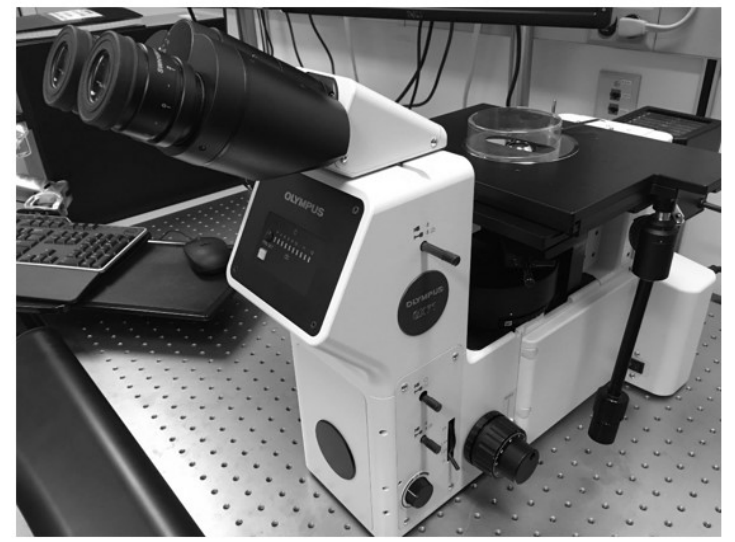

(a)

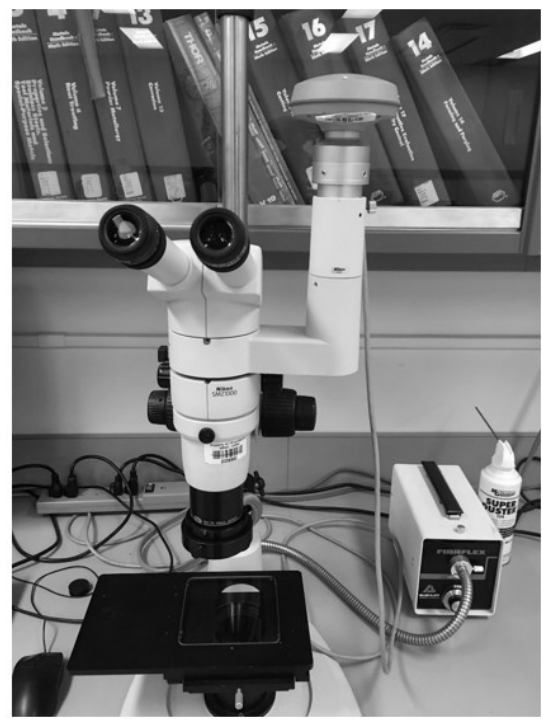

(b)

Fig. 3- 7. Optical microscopes: (a) Olympus GX71; (b) Nikon SMZ1000. 
Two SEM/EDX instruments were employed for microstructural analyses in the present study: one is PHILIPS XL3053 with energy dispersive X-ray (EDX), Bruker AXS D8 with $20 \mathrm{KeV}$ beam, the other is Tescan Vega-II XMU VPSEM (Fig. 3- 8). A Clemex microhardness tester (Fig. 3- 9) was used to measure the hardness of the specimens on Vickers scale with the setting of 200 gram force (gf) and 10 seconds dwell time $\left[{ }^{117}\right]$.

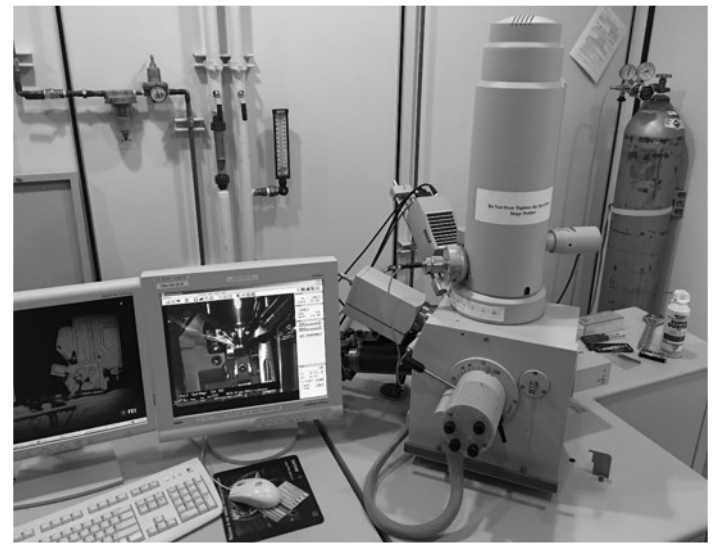

(a)

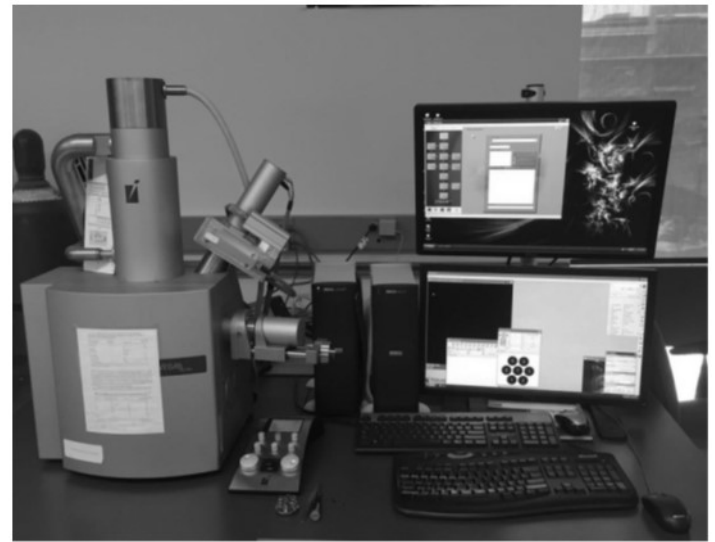

(b)

Fig. 3- 8. SEM/EDX facilities: (a) PHILIPS XL3053; (b) Tescan Vega-II XMU.

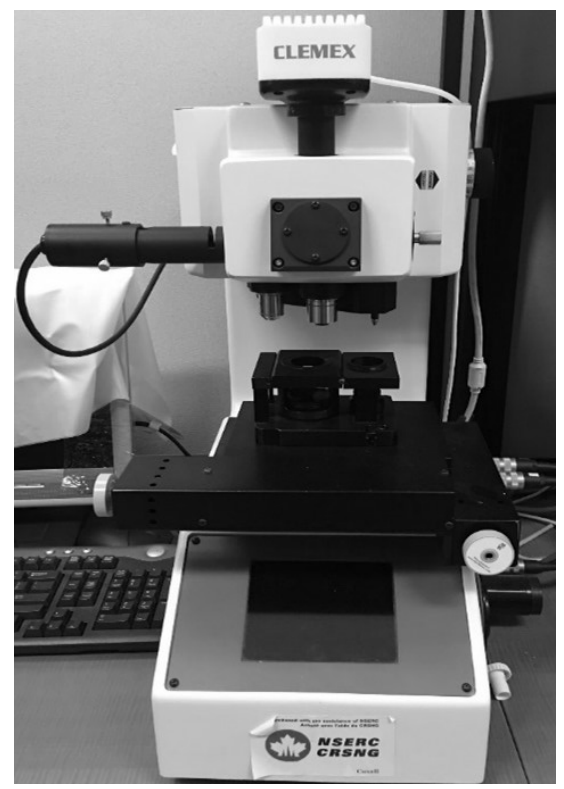

Fig. 3- 9. Clemex CMT.HD MMT-X7 micro-hardness tester. 


\section{Chapter 4 Deformation Mechanism-based True-stress (DMTS) Creep Model}

In Chapter 2 literature review, it has been discussed that creep rate and creep life are the functions of stress and temperature, which can also be significantly influenced by microstructural evolution and test environment. Although numerous empirical equations have been proposed over the past one hundred years, there is no single model that can describe all the phenomena in creep. The most profound reason for the lack of the consistency in modeling is that those empirical equations do not have the physical "genome" relating deformation/damage mechanisms with microstructure. It is noteworthy that by combining the kinetics of deformation and damage mechanisms and superimposing microstructural evolution in this methodology is the only vehicle to translate shortterm test observations with the long-term creep performance prediction.

The present research utilizes a deformation mechanism-based true-stress (DMTS) creep model as the starting framework $\left[{ }^{62},{ }^{63}\right]$. This model is formulated based on the well-recognized deformation mechanisms including intragranular dislocation glide (IDG), intragranular dislocation climb (IDC) and grain boundary sliding (GBS) for polycrystalline materials. In this chapter, the work made by previous research for the model is delicately summarized and demonstrated. The acronym DMTS shall be used throughout the later chapters for brevity.

In addition, the DMTS model has built-in mechanism-based failure criteria for creep lifetime prediction, indicating transgranular/intergranular fracture mode; whereas empirical creep curve equations such as the $\theta$-projection method does not include deformation/fracture mechanism, and empirical life prediction equations such as the Larson-Miller parameter method are not explicitly related to creep deformation. The DMTS model has been applied to a Ni/Co-based superalloyWaspaloy/Mar-M-509, showing good agreement with experimental observations $\left[{ }^{62},{ }^{63}\right]$. In the 
present study, this model shall be extended for creep analyses of F91 in the pristine, aged and coated conditions. Note that the modeling work on NIMS-modified Grade 91 steels and F91 pristine material, as part of the present thesis study, has already been published $\left[{ }^{65}\right]$.

\subsection{Derivation of the Creep-constitutive Law from Deformation Mechanisms}

It is well understood that the rate-independent elastic-plastic deformation occurs at low temperatures, i.e., $T<0.3 T_{m}$. As temperature increases, dislocation mobility increases due to thermal activation and vacancy diffusion, which accelerates dislocations to overcome obstacles. Therefore, time-dependent deformation well below the yield strength of the material, i.e., creep, is manifested. Creep at elevated temperatures is basically assisted by two major diffusion processes: grain boundary diffusion and lattice diffusion. The former assists dislocation climb and glide along grain boundaries, causing grain boundary sliding (GBS); the latter assists dislocation climb and glide within the grain interior, resulting in power-law and power-law breakdown phenomena, the total of which is referred as intragranular deformation (ID). Particularly at high stresses, dislocation glide dominates, which is often associated with strain-hardening as dislocations pile up at obstacles along the path $\left[{ }^{62},{ }^{18},{ }^{73}\right]$. Fig. $4-1$ shows a sketch of deformation-mechanism map $\left.{ }^{62}\right]$. Fig. 4- 2 shows the hierarchical chart of time-dependent deformation mechanisms. 


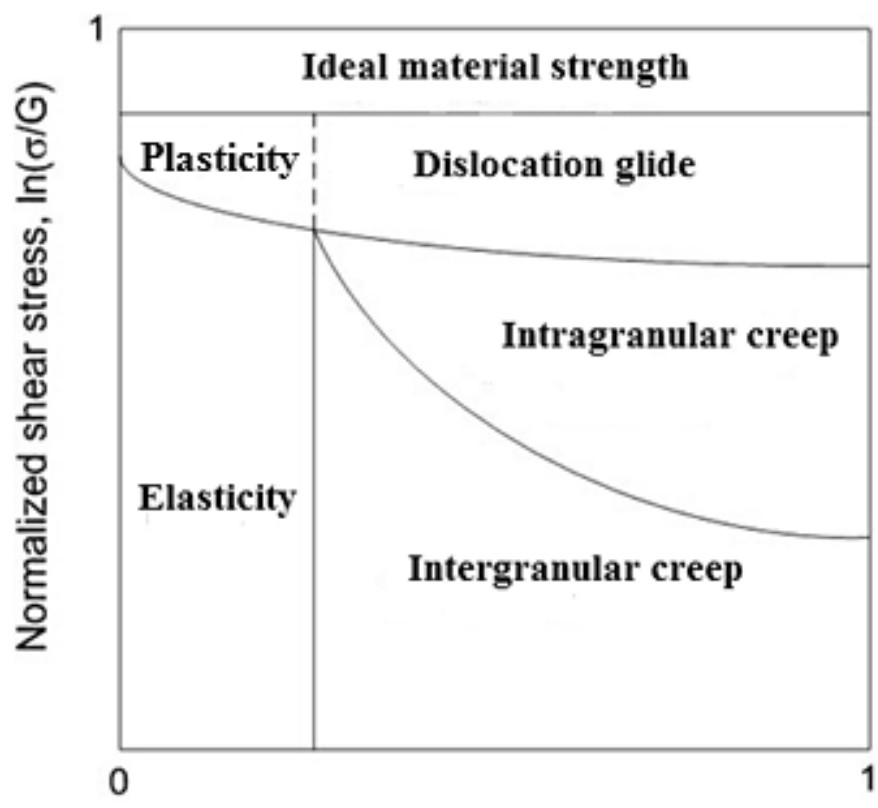

Homologous temperature, $T / T_{m}$

Fig. 4- 1. Deformation-mechanism map $\left[{ }^{62}\right]$.

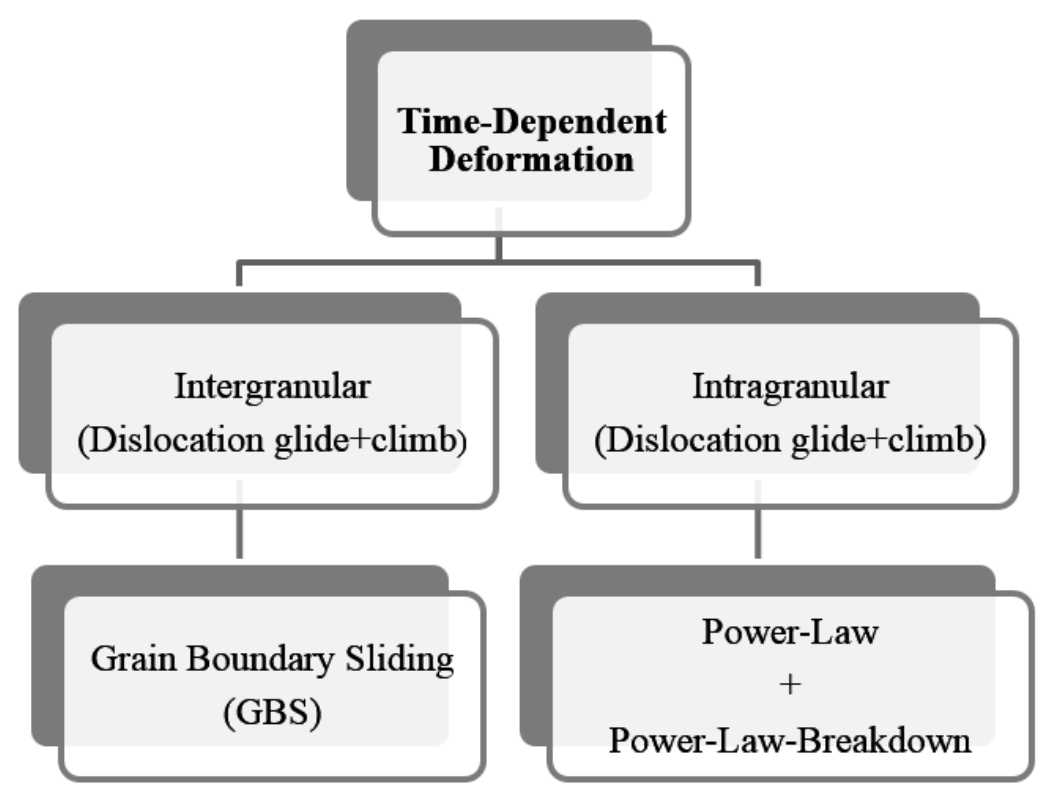

Fig. 4- 2. Time-dependent deformation hierarchical chart. 
Ever since 1929 after Norton $\left[{ }^{118}\right]$, creep rate $\dot{\varepsilon}_{s}$ is often described by a power-law in the form of

$$
\dot{\varepsilon}_{S}=A_{0} \exp \left(-\frac{Q_{C}}{R T}\right)\left(\frac{\sigma_{S}}{E}\right)^{n}
$$

where $A_{0}$ is a constant, $R$ is the universial gas constant, and $E$ is the Young's modulus of the material (shear modulus, $G$, may be used instead).

Subsequently, the Norton equation is used to express the rate of an underlying deformation mechanism, but it is noteworthy that the stress exponent $n$ possesses distinct values for different mechanisms. For example, in pure metals over a wide range of temperature and strain rate, power-law creep proceeds with an exponent $\sim 5$ until the temperature decreases below $0.5 \sim 0.6$ homologous temperature for the material, where power-law-breakdown occurs, and $n$ increases and $Q_{C}$ generally decreases. In solid solution alloys, power-law creep has an index $\sim 3$ at intermediate stresses $\left[{ }^{119},{ }^{120}\right]$. Diffusion creep generally has a low power-law exponent of 1 . The power-law creep exponent $n$ has been reported to be 10 or higher for modified 9Cr-1Mo steel (P91 where $\mathrm{P}$ signifies pipe material) at the temperature range from $600-650^{\circ} \mathrm{C}$ with the applied stress higher than $100 \mathrm{MPa}$, and the value remains close to 1 at very low stresses $\left[{ }^{73}\right]$. NF616 (P92) has a power-law creep exponent $n$ ranging from 6 to 16 at approximatly 120 and $160 \mathrm{MPa}$, at 600 and $650^{\circ} \mathrm{C}$, respectively $\left[{ }^{121}\right]$. Another study on modified $9 \mathrm{Cr}-1$ Mo steel showed an $n$-value changing from 3 to 10 as stress increased from 80 to $200 \mathrm{MPa}$ : the exponent $n$ was found to be about 5 to 6 at high temperatures and low stresses, but it turned into much higher values in the intermediate and higher stress regions $\left[{ }^{18}\right]$. Using the DMTS model, it is shown that the change in power-law exponent in modified Grade 91 is merely a reflection of the dominance of certain deformation mechanisms in different stress-temperature regions. 
First, for mathematical generality and simplicity, the creep rates of GBS, intragranular dislocation glide (IDG) and intragranular dislocation climb (IDC) are all expressed as power-law equations

$$
\begin{aligned}
& \dot{\varepsilon_{S}}=A_{0} \exp \left(-\frac{Q_{A}}{R T}\right)\left(\frac{\sigma}{\sigma_{T}}\right)^{p} \\
& \dot{\varepsilon_{g}}=B_{0} \exp \left(-\frac{Q_{B}}{R T}\right)\left(\frac{\sigma}{\sigma_{T}}\right)^{n} \\
& \dot{\varepsilon_{C}}=C_{0} \exp \left(-\frac{Q_{C}}{R T}\right)\left(\frac{\sigma}{\sigma_{T}}\right)^{m}
\end{aligned}
$$

where $\dot{\varepsilon}_{S}, \dot{\varepsilon}_{g}, \dot{\varepsilon}_{c}$ are creep rates of GBS, IDG, IDC, respectively; $A_{0}, B_{0}, C_{0}$ are the proportional constants; $Q_{A}, Q_{B}, Q_{C}$ are activation energies for the respective mechanisms; $R$ is the universal gas constant, $8.32 \mathrm{~J} / \mathrm{K} \cdot \mathrm{mol}$, and $T$ is absolute temperature in $\mathrm{K} ; \sigma$ is the true stress, and $\sigma_{T}$ is the ultimate tensile strength of the tested material at an elevated-temperature.

In the above relations, the activation energy $\left(Q_{A}, Q_{B}, Q_{C}\right)$ can be obtained from the Arrhenius plot, as shown schematically in Fig. 4- 3. For demonstration purpose, Eq. (4-1) is used to derive Eq. (4-1a) in the logarithm form:

$$
\dot{\varepsilon}_{S}=A_{0} \exp \left(-\frac{Q_{A}}{R T}\right)\left(\frac{\sigma}{\sigma_{T}}\right)^{p} \frac{\text { Arrhenius equation }}{\rightarrow} \ln \dot{\varepsilon}_{S}=-\frac{Q_{A}}{R}\left(\frac{1}{T}\right)+\ln A_{0}^{\prime}
$$

where $A_{0}^{\prime}=A_{0} \cdot\left(\frac{\sigma}{\sigma_{T}}\right)^{p}$. 


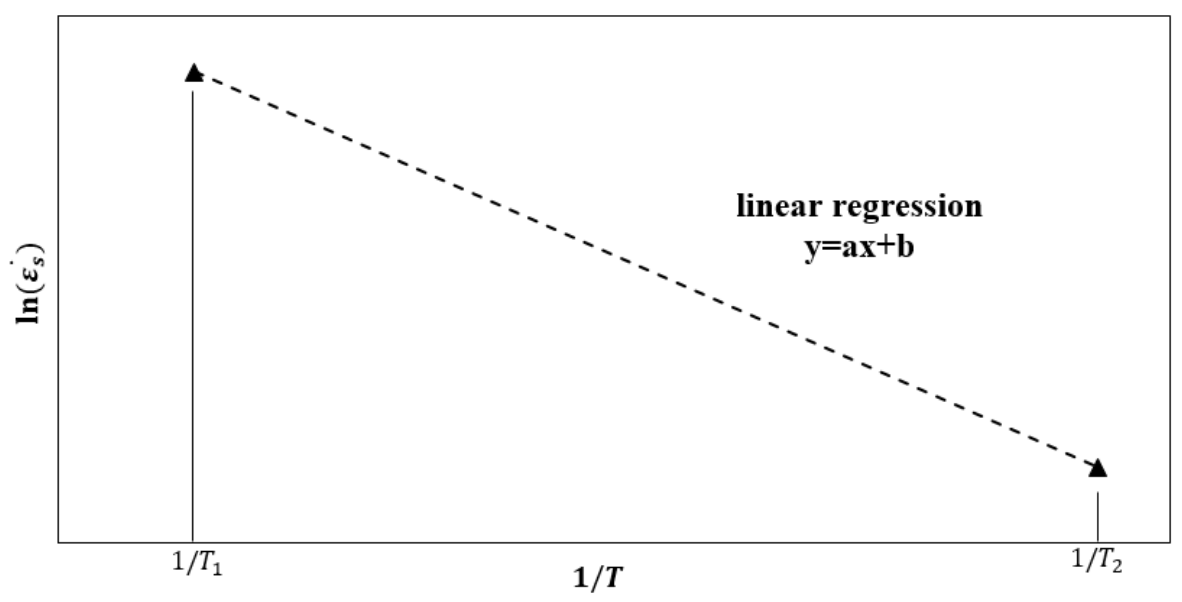

Fig. 4- 3. Demonstration of the Arrhenius plot.

From the linear regression of the data, $a=-\frac{Q_{A}}{R}$ and $b=\ln A_{0}^{\prime}$. Then, the activation energy $Q_{A}$ and the proportional constant $A_{0}$ for the particular mechanism can be evaluated.

By physical deformation decomposition, the total creep rate is given as

$$
\dot{\varepsilon_{S S}}=\dot{\varepsilon_{S}}+\dot{\varepsilon_{g}}+\dot{\varepsilon_{c}}
$$

Also, by the rule of incompressible flow, the true stress increases with elongation of the specimen, following the relationship:

$$
\begin{aligned}
& \sigma=\sigma_{0} \exp (\varepsilon) \\
& \varepsilon=\ln (1+e)
\end{aligned}
$$

where $\sigma_{0}$ is initial stress (engineering stress), $\varepsilon$ is true-strain, $e$ is engineering strain. Substituting Eq. (4-5) into Eqs. (4-1) to (4-3), by the first approximation of the Taylor series, the following equations can be obtained:

$$
\dot{\varepsilon}_{s}=A \sigma^{p}=A \sigma_{0}^{p} \exp (p \varepsilon) \approx(1+p \varepsilon) A \sigma_{0}^{p}=(1+p \varepsilon) \dot{\varepsilon}_{s 0}
$$




$$
\begin{gathered}
\dot{\varepsilon}_{g}=B \sigma^{n}=B \sigma_{0}^{n} \exp (n \varepsilon) \approx(1+n \varepsilon) B \sigma_{0}^{n}=(1+n \varepsilon) \dot{\varepsilon}_{g 0} \\
\dot{\varepsilon_{c}}=(1+M \varepsilon) C \sigma^{m}=(1+M \varepsilon) C \sigma_{0}^{m} \exp (m \varepsilon) \approx(1+M \varepsilon+m \varepsilon) C \sigma_{0}^{m} \\
=(1+M \varepsilon+m \varepsilon) \dot{\varepsilon}_{c 0}
\end{gathered}
$$

where $\dot{\varepsilon}_{s 0}, \dot{\varepsilon}_{g 0}, \dot{\varepsilon}_{c 0}$ are the initial strain rates at $\sigma_{0}$, and $M$ is the dislocation multiplication factor.

From Eq. (4-4), the total strain rate $\dot{\varepsilon}_{s s}$ is the summation of the rates of GBS, IDG, and IDC, which can be re-written into

$$
\dot{\varepsilon}_{s s}=\dot{\varepsilon}_{s}+\dot{\varepsilon}_{g}+\dot{\varepsilon}_{c}=(1+p \varepsilon) \dot{\varepsilon}_{s 0}+(1+n \varepsilon) \dot{\varepsilon}_{g 0}+(1+M \varepsilon+m \varepsilon) \dot{\varepsilon}_{c 0}
$$

Then Eq. (4-10) can be integrated into

$$
\varepsilon=\frac{1}{M^{\prime}}\left[\exp \left(M^{\prime} k t\right)-1\right]
$$

where

$$
\begin{aligned}
M^{\prime} & =\left[p \dot{\varepsilon}_{s 0}+n \dot{\varepsilon}_{g 0}+(m+M) \dot{\varepsilon}_{c 0}\right] / k \\
k & =\dot{\varepsilon}_{s 0}+\dot{\varepsilon}_{g 0}+\dot{\varepsilon}_{c 0}
\end{aligned}
$$

Eq. (4-11) basically describes the secondary stage of creep when $M^{\prime} k$ is small or time is relatively short, and the tertiary stage when $M^{\prime} k$ is large or time is relatively long.

For transient creep by GBS, the creep strain function has been derived to be [7]

$$
\varepsilon_{G B S}=\frac{\sigma}{\beta^{2} H}\left[1-\exp \left(-\frac{\beta^{2} H \dot{\varepsilon}_{S} t}{\sigma(\beta-1)}\right)\right]+\dot{\varepsilon}_{S} t
$$

where $\beta$ is the material parameter, $H$ is the work hardening coefficient of GBS. Appendix B gives details about how to derive $\beta$ and $H\left[{ }^{57}\right]$. Combining Eqs. (4-11) and (4-14), only the transient part 
of Eq. (4-14) should be taken, since the steady-state part is already included in Eq. (4-11), then the total creep strain equation is given as follows:

$$
\begin{gathered}
\varepsilon=\varepsilon_{0}+\varepsilon_{t r}^{P}\left[1-\exp \left(-\frac{t}{t_{T}}\right)\right]+\frac{1}{M^{\prime}}\left[\exp \left(M^{\prime} k t\right)-1\right] \\
\varepsilon_{t r}^{P}=\frac{\sigma}{\beta^{2} H} \\
t_{T}=\frac{\sigma(\beta-1)}{\beta^{2} H \dot{\varepsilon}_{s}} \\
t_{P}=4.6 t_{T}
\end{gathered}
$$

where $\varepsilon_{0}$ is initial elastic-plastic strain, which is assigned to offset the experimental compliance; $\varepsilon_{t r}^{P}$ is primary creep coefficient; $t_{P}=4.6 t_{T}$ is the primary creep time. By differentiating Eq. (415) with respect to time, $t$, the total creep rate is obtained as

$$
\dot{\varepsilon}=\frac{\varepsilon_{t r}^{P}}{t_{T}} \exp \left(-\frac{t}{t_{T}}\right)+k \exp \left(M^{\prime} k t\right)
$$

With Eq. (4-15), the entire creep deformation process, i.e., primary, secondary and tertiary creep, can be described, based on the participating deformation mechanisms. Steady-state creep is often emphasized over primary or tertiary creep because it takes a relatively large fraction of creep life under real application conditions.

Regarding creep rupture, the material may fail either transgranularly or intergranularly, depending on whether ID or GBS is dominating. Based on this rationale, the creep rupture criterion can be proposed as $\left[{ }^{65}\right]$

$$
T T R=\min \left[t\left(\varepsilon_{s, \text { critical }}\right), t\left(\varepsilon_{g} / \varepsilon_{c, \text { critical }}\right)\right]
$$


Eq. (4-17) implies that the time-to-rupture, TTR is defined either by GBS or intragranular ductility reaching a critical level, whichever comes first in time. Therefore, creep lifetime can be predicted as associated with the respective mechanism strain level $\left[{ }^{65}\right]$.

The proposed creep model has combined the physics of deformation and failure, which allows the description and prediction of creep deformation behavior, failure modes and rupture lifetime, using the same set of equations. According to this model, the creep rates given by Eqs. (4-3) to (4-6) are functions of true stress, which can serve as constitutive laws in the finite element method (FEM) for component analysis. For constant-load creep test analysis, however, the creep rate equations can be reduced to engineering formula with respect to the engineering stress for each test condition.

\subsection{Model Modification with Oxidation Effect}

Since most of the creep tests are conducted in air, oxidation will have an influence on the creep behavior of materials, especially during long-term creep. Conventional creep analysis do not take oxidation effect explicitly into consideration, assuming that it is naturally borne with the material coupon behavior. However, when dealing with materials with environmental protection via coating, this assumption would not be correct, and using the air-creep data to predict the behavior of coated components would lead to erroneous results. Therefore, for complete mechanism-delineation, it is necessary to separate oxidation effect from intrinsic creep behavior and properties of materials.

To take oxidation effect into consideration in creep modeling, the parabolic oxidation law can be used to describe the growth of oxide scale, $\delta$, as $\left[{ }^{122},{ }^{123},{ }^{124}\right]$ 


$$
\delta=\sqrt{2 K_{o x} t}
$$

where $K_{o x}$ is the oxidation rate coefficient, which is an Arrhenius-type constant; $t$ is exposure time.

Because the Fe-oxides or Fe-Cr-oxides, (a mixture of $\mathrm{Fe}_{3} \mathrm{O}_{4}, \mathrm{FeO}, \mathrm{Fe}_{2} \mathrm{O}_{3}$, and $(\mathrm{Fe}, \mathrm{Cr})_{3} \mathrm{O}_{4}$ are loose and often fall off the specimen surface during creep testing, oxide scale formation actually reduces the specimen load-bearing area, as given by

$$
A_{x}=A_{0}-2 \pi r \delta
$$

Then Eq. (4-5) can be re-written as

$$
\sigma=\frac{P}{A_{x}} \exp (\varepsilon)
$$

where, $P$ is the applied load; $A_{x}$ is the radial cross-section area of specimen; $A_{0}$ is the original radial cross-section area; and $r$ is the original radius of specimen. Subsititute Eq. (4-19) into Eq. (4-20):

$$
\sigma=\frac{P}{A-2 \pi r \delta} \exp (\varepsilon)=\frac{P}{A\left(1-\omega_{o x}\right)} \exp (\varepsilon)=\frac{\sigma_{0}}{1-\omega_{o x}} \exp (\varepsilon)
$$

where

$$
\omega_{o x}=\frac{2 \pi r \delta}{\pi r^{2}}=\frac{2 \delta}{r}
$$

Subtitue Eq. (4-21) into Eqs. (4-1) - (4-3), Eq. (4-7) - (4-9) become Eq. (4-22) - (4-24):

$$
\begin{gathered}
\dot{\varepsilon}_{S}=A \sigma^{p}=A\left(\frac{\sigma_{0}}{1-\omega_{o x}}\right)^{p} \exp (p \varepsilon) \approx \frac{1+p \varepsilon}{\left(1-\omega_{o x}\right)^{p}} A \sigma_{0}^{p}=\frac{1+p \varepsilon}{\left(1-\omega_{o x}\right)^{p}} \dot{\varepsilon}_{s 0}^{\cdot} \\
\dot{\varepsilon_{S}}=B \sigma^{n}=B\left(\frac{\sigma_{0}}{1-\omega_{o x}}\right)^{n} \exp (n \varepsilon) \approx \frac{1+n \varepsilon}{\left(1-\omega_{o x}\right)^{n}} B \sigma_{0}^{n}=\frac{1+n \varepsilon}{\left(1-\omega_{o x}\right)^{n}} \dot{\varepsilon}_{g 0} \\
\dot{\varepsilon}_{c}=(1+M \varepsilon) C \sigma^{m}=(1+M \varepsilon) C\left(\frac{\sigma_{0}}{1-\omega_{o x}}\right)^{m} \exp (m \varepsilon) \approx \frac{1+M \varepsilon+m \varepsilon}{\left(1-\omega_{o x}\right)^{m}} C \sigma_{0}^{m}
\end{gathered}
$$




$$
=\frac{1+M \varepsilon+m \varepsilon}{\left(1-\omega_{o x}\right)^{m}} \varepsilon_{c 0}^{\cdot}
$$

Then Eq. (4-10) is converted to Eq. (4-25):

$$
\dot{\varepsilon}_{S S}=\dot{\varepsilon}_{S}+\dot{\varepsilon}_{g}+\dot{\varepsilon}_{c}=\frac{1+p \varepsilon}{\left(1-\omega_{o x}\right)^{p}} \dot{\varepsilon}_{s 0}+\frac{1+n \varepsilon}{\left(1-\omega_{o x}\right)^{n}} \dot{\varepsilon}_{g 0}+\frac{1+M \varepsilon+m \varepsilon}{\left(1-\omega_{o x}\right)^{m}} \dot{\varepsilon}_{c 0}
$$

Finally, by the same integration process, Eq. (4-15) should remain the same, but Eq. (4-12) and (4-13) should be replaced by Eq. (4-26) and (4-27):

$$
\begin{aligned}
& M^{\prime}=\left[\frac{p}{\left(1-\omega_{o x}\right)^{p}} \dot{\varepsilon}_{s 0}+\frac{n}{\left(1-\omega_{o x}\right)^{n}} \dot{\varepsilon}_{g 0}+\frac{m+M}{\left(1-\omega_{o x}\right)^{m}} \dot{\varepsilon}_{c 0}\right] / k \\
& k=\frac{1}{\left(1-\omega_{o x}\right)^{p}} \dot{\varepsilon}_{s 0}+\frac{1}{\left(1-\omega_{o x}\right)^{n}} \dot{\varepsilon}_{g 0}+\frac{1}{\left(1-\omega_{o x}\right)^{m}} \dot{\varepsilon}_{c 0}
\end{aligned}
$$

Since now $M^{\prime}$ and $k$ include the oxidation-modified term for each mechanism, Eqs. (4-15) natually describes the creep strain-time response with the involved mechanism contributions as well as the oxidation effect, and it natually reduces to material-intrinsic behavior when oxidation effect is absent.

In summary, the strain rate equations, Eqs. (4-22) - (4-27) should override Eqs. (4-7) - (4-12), when oxidation effect is taken into account explicitly in creep testing. 


\section{Chapter 5 Modeling of Creep Behavior of Modified 9Cr-1Mo Steels}

\subsection{Application of the DMTS Creep Model}

As discussed in Chapter 4, understanding creep deformation mechanisms of materials is crucial for accurate creep life prediction, which can also benefit material design and selection. In this chapter, the proposed DMTS creep model is validated with experimental creep data from both literature and present research. Steels of the same grade are supposed to have similar mechanical properties due to similar compositions, manufacturing processes, and heat treatments, etc. Chapter 2 summarizes the similarities of tempered martensitic Grade 91 steels with typical tempered martensitic microstructure and precipitates. However, slight variations may still have a strong influence on the creep performance of these materials. For instance, Ni is a minor alloying element in Grade 91 steels, usually with less than 0.2 wt.\% concentration. With a slightly higher $\mathrm{Ni}$ concentration of $0.28 \mathrm{wt} . \%$, the creep strength of the same grade steel can be reduced by $\sim 3 \mathrm{MPa}$ at elevated temperatures, which could shorten the material life over thousands of hours $\left[{ }^{125}\right]$. Another example, comparing creep rupture times of $9 \mathrm{Cr}-1 \mathrm{~W}$ steels with two different heat treatments: standard heat treatment $\left(1\right.$ hour tempering at $\left.950^{\circ} \mathrm{C}\right)$ and long-term tempering $(20$ hours at $750^{\circ} \mathrm{C}$ ), coupons from two different heat treatments exhibited identical primary and secondary creep behaviour, but the long-term tempered coupons had earlier tertiary creep over thousands of hours to cause premature rupture due to larger laths/subgrains coarsening rates [ $\left.{ }^{126}\right]$. Therefore, to learn the complex variations in creep behavior of Grade 91 steels, it is necessary to understand the effects of composition, processing, and microstructure on the creep performance of these materials. As a first step, the contributions of fundamental deformation mechanisms via intragranular deformation (ID) as well as grain boundary sliding (GBS) to the creep resistance of 
materials with particular microstructures need to be quantified, using the DMTS model developed in Chapter 4. The mechanism quantification analysis also serves as model validation for different product forms such as plates, pipes, and tubes of Grade 91 steels, which can then be used to predict the long-term creep strength along with the microstructural evolution of these products.

In this chapter, the creep data obtained from the experiments described in Chapter 3 and the creep data from NIMS-Creep Data Sheet No.43 for various forms of 9Cr-1Mo-V-Nb steel are used to validate the DMTS model $\left[{ }^{127}\right]$. Since the creep tests conducted in this study are all short-term creep tests with rupture times $<10^{4}$ hours, at first, analysis of the creep test data is performed using the basic DMTS creep model, in the context of Eqs. (11) - (13), as conventionally done without considering oxidation contribution. Analysis with the consideration of oxidation for comparison will be detailed in the next chapter.

The creep behavior of a metallic material is generally classified into three distinctive stages (Fig. 2- 5 and Fig. 2- 6): primary, secondary, and tertiary creep. The proceeding of this chapter starts with model validation for the basic deformation mechanisms involved, followed by a description of the creep curve consisting of the three stages aforementioned, and finally performs long-term creep life prediction, as shown in the flowchart of Fig. 5- 1. In the following sections of this chapter, first, the stress-rate map from Eq. (4-10) is used to categorize mechanism parameters for eight types of NIMS Grade 91 steels. Corresponding to various manufactural processes and heat treatment histories, the values of mechanism parameters for Grade 91 steels are determined. Second, F91 creep rate data are collated for one type NIMS steel, MgB, to determine the mechanism parameters of F91 creep rate equation. Third, the F91 creep rate model is extended to fit F91 experimental strain-time curves. Finally, long-term creep life prediction is performed for several selected NIMS Grade 91 steels based on the short-term creep data of these materials. 


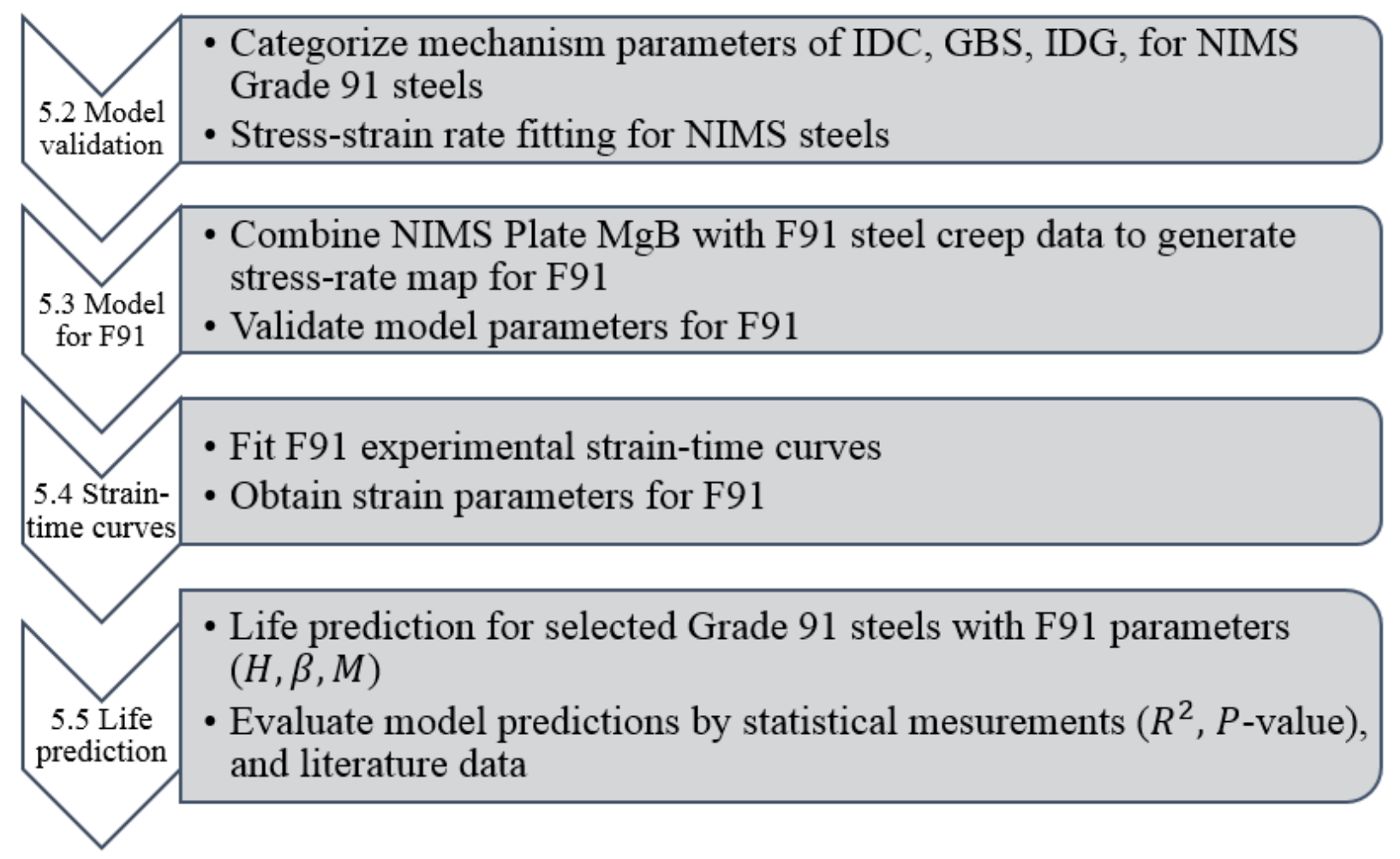

Fig. 5- 1. Model parameter validation and life prediction flowchart.

For comparison with F91 steel being studied, the chemical compositions of the NIMS modified 9Cr-1Mo steels are given in Table 5- 1 along with that of F91 steel. The heat treatment histories of all the materials concerned in this research are reported in Table 5- 2. The roomtemperature tensile properties of F91 are given in Table 3- 2.

Ultimate tensile strengths $\left(\sigma_{T}\right)$ at elevated temperatures from $100^{\circ} \mathrm{C}$ to $750^{\circ} \mathrm{C}$ are reported on the NIMS creep data sheet, which are used as the stress normalization factors in the present study. Because of the small deviation among various Grade 91 steels, the mean value is taken as the normalization strength at a specific temperature for F91 (Note: mean values are only for F91, all other Grade 91 products shall use their actual values). As shown in Fig. 5- 2, variation of $\sigma_{T}$ with 
temperature exhibits two linear regions, $100-400^{\circ} \mathrm{C}$ region and, $450-750^{\circ} \mathrm{C}$ region, the tensile strength of Grade 91 steels degrades faster in the high-temperature region. Tensile strengths at $575^{\circ} \mathrm{C}$ and $625^{\circ} \mathrm{C}$ are interpolated values from the bi-linear curve shown in Fig. 5- 2. Table 5- 3 lists $\sigma_{T}$ data for various Grade 91 steels at elevated temperatures.

Table 5- 1 Chemical compositions of modified 9Cr-1Mo steels [ $\left.{ }^{127}\right]$

\begin{tabular}{|c|c|c|c|c|c|c|c|c|c|c|c|c|c|c|c|}
\hline \multirow{2}{*}{ Type } & \multirow{2}{*}{$\begin{array}{l}\text { NIMS } \\
\text { Code }\end{array}$} & \multicolumn{14}{|c|}{ Chemical composition (wt.\%) } \\
\hline & & $\mathrm{C}$ & $\mathrm{Si}$ & $\mathrm{Mn}$ & $\mathrm{P}$ & $\mathrm{S}$ & $\mathrm{Ni}$ & $\mathrm{Cr}$ & Mo & V & $\mathrm{Nb}$ & $\mathrm{N}$ & $\mathrm{Al}$ & $\mathrm{Ti}$ & $\mathrm{Zr}$ \\
\hline \multirow{3}{*}{ Tube } & MGD & 0.10 & 0.29 & 0.41 & 0.010 & 0.001 & 0.10 & 8.41 & 0.90 & 0.185 & 0.07 & 0.0480 & 0.016 & 0.001 & $<0.001$ \\
\hline & MGF & 0.11 & 0.25 & 0.42 & 0.013 & 0.001 & 0.06 & 8.41 & 0.91 & 0.200 & 0.08 & 0.0530 & 0.001 & 0.006 & $<0.001$ \\
\hline & MGG & 0.10 & 0.38 & 0.37 & 0.018 & 0.002 & 0.12 & 8.60 & 0.85 & 0.190 & 0.08 & 0.0458 & 0.002 & $<0.001$ & $<0.001$ \\
\hline \multirow{3}{*}{ Plate } & $\begin{array}{l}\mathrm{MgA} \\
\mathrm{MgB}\end{array}$ & 0.08 & 0.34 & 0.49 & 0.005 & 0.004 & 0.09 & 8.34 & 0.89 & 0.23 & 0.07 & 0.0590 & 0.012 & $<0.001$ & $<0.001$ \\
\hline & $\mathrm{MgC}$ & 0.10 & 0.24 & 0.44 & 0.005 & 0.001 & 0.04 & 8.74 & 0.84 & 0.21 & 0.076 & 0.0582 & 0.014 & $<0.001$ & $<0.001$ \\
\hline & $\mathrm{MgD}$ & 0.11 & 0.29 & 0.45 & 0.008 & 0.001 & 0.08 & 8.44 & 0.99 & 0.21 & 0.090 & 0.0500 & 0.023 & 0.001 & $<0.001$ \\
\hline Pipe & MGQ & 0.11 & 0.24 & 0.43 & 0.014 & 0.002 & 0.08 & 8.31 & 0.92 & 0.19 & 0.07 & 0.0460 & 0.001 & 0.005 & $<0.001$ \\
\hline F91 & & 0.10 & 0.32 & 0.43 & 0.020 & 0.010 & 0.18 & 8.38 & 0.94 & 0.22 & 0.067 & 0.0530 & 0.011 & 0.007 & $<0.001$ \\
\hline
\end{tabular}


Table 5- 2 Heat treatment histories of NIMS samples $\left[{ }^{127}\right]$

\begin{tabular}{|c|c|c|c|}
\hline Type & NIMS Code & Processing and thermal history & Standard \\
\hline \multirow{9}{*}{ Tube } & & Hot extruded and cold drawn & \multirow{9}{*}{ ASME SA-213/SA-213M Grade T91 } \\
\hline & MGD & $1050^{\circ} \mathrm{C} / 10 \mathrm{~min} \mathrm{AC}$ & \\
\hline & & $780^{\circ} \mathrm{C} / 40 \mathrm{~min} \mathrm{AC}$ & \\
\hline & & Hot extruded & \\
\hline & MGF & $1045^{\circ} \mathrm{C} / 60 \mathrm{~min} \mathrm{AC}$ & \\
\hline & & $780^{\circ} \mathrm{C} / 60 \mathrm{~min} \mathrm{AC}$ & \\
\hline & \multirow{3}{*}{ MGG } & Hot rolled & \\
\hline & & $1050^{\circ} \mathrm{C} / 15 \mathrm{~min} \mathrm{AC}$ & \\
\hline & & $790^{\circ} \mathrm{C} / 60 \mathrm{~min} \mathrm{AC}$ & \\
\hline \multirow{15}{*}{ Plate } & \multirow{4}{*}{$\mathrm{MgA}$} & Hot rolled & \multirow{15}{*}{ ASME SA-387/SA-387M Grade 91} \\
\hline & & $1050^{\circ} \mathrm{C} / 10 \mathrm{~min} \mathrm{AC}$ & \\
\hline & & $770^{\circ} \mathrm{C} / 60 \mathrm{~min} \mathrm{AC}$ & \\
\hline & & $740^{\circ} \mathrm{C} / 8.4 \mathrm{hr} \mathrm{FC}$ & \\
\hline & \multirow{4}{*}{$\mathrm{MgB}$} & Hot rolled & \\
\hline & & $1050^{\circ} \mathrm{C} / 10 \mathrm{~min} \mathrm{AC}$ & \\
\hline & & $770^{\circ} \mathrm{C} / 60 \mathrm{~min} \mathrm{AC}$ & \\
\hline & & $740^{\circ} \mathrm{C} / 60 \mathrm{~min} \mathrm{FC}$ & \\
\hline & \multirow{4}{*}{$\mathrm{MgC}$} & Hot rolled & \\
\hline & & $1060^{\circ} \mathrm{C} / 90 \mathrm{~min} \mathrm{AC}$ & \\
\hline & & $760^{\circ} \mathrm{C} / 60 \mathrm{~min} \mathrm{AC}$ & \\
\hline & & $730^{\circ} \mathrm{C} / 8.4 \mathrm{hr} \mathrm{FC}$ & \\
\hline & \multirow{3}{*}{$\mathrm{MgD}$} & Hot rolled & \\
\hline & & $1050^{\circ} \mathrm{C} / 30 \mathrm{~min} \mathrm{AC}$ & \\
\hline & & $780^{\circ} \mathrm{C} / 30 \mathrm{~min} \mathrm{AC}$ & \\
\hline \multirow{3}{*}{ Pipe } & \multirow{3}{*}{ MGQ } & Hot rolled & \multirow{3}{*}{ ASME SA-335/SA-335M Grade P91 } \\
\hline & & $1060^{\circ} \mathrm{C} / 60 \mathrm{~min} \mathrm{AC}$ & \\
\hline & & $780^{\circ} \mathrm{C} / 60 \mathrm{~min} \mathrm{AC}$ & \\
\hline \multirow{3}{*}{ F91 } & & Forged & \multirow{3}{*}{ ASME SA182-01Grade F91 } \\
\hline & & $1080^{\circ} \mathrm{C} / 4 \mathrm{hr} \mathrm{AC}$ & \\
\hline & & $800^{\circ} \mathrm{C} / 5 \mathrm{hr} \mathrm{AC}$ & \\
\hline
\end{tabular}

Note: $\mathrm{AC}=$ air cooling

$\mathrm{FC}=$ furnace cooling 


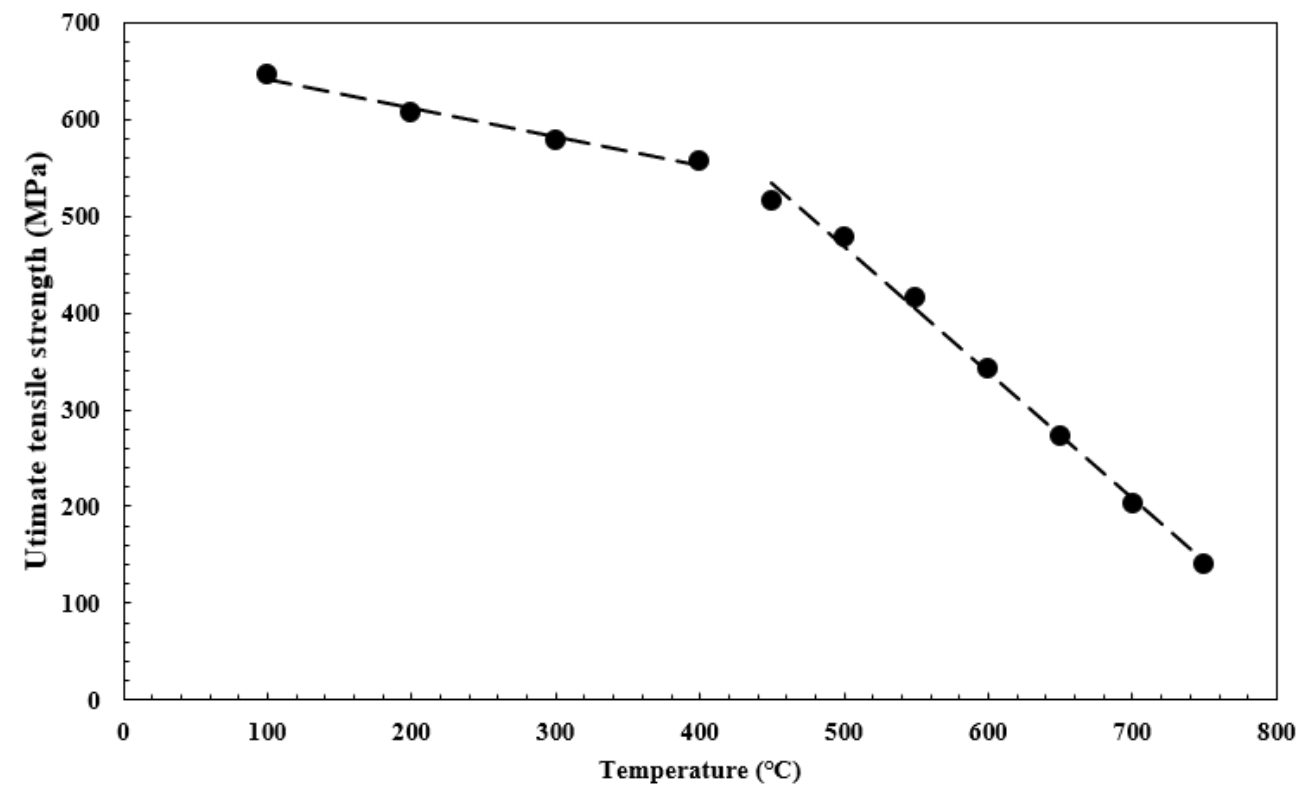

Fig. 5- 2. Bilinear trends of ultimate tensile strengths of Grade 91 steels $\left[{ }^{127}\right]$.

Table 5- 3 Ultimate tensile strength $\left(\sigma_{T}\right)$ data of NIMS samples at elevated temperatures $\left[{ }^{127}\right]$

\begin{tabular}{cccccccccc}
\hline \multirow{2}{*}{ NIMS reference code } & \multicolumn{7}{c}{ Ultimate tensile strength (MPa) } \\
\cline { 3 - 10 } & & $450^{\circ} \mathrm{C}$ & $500^{\circ} \mathrm{C}$ & $550^{\circ} \mathrm{C}$ & $575^{\circ} \mathrm{C}$ & $600^{\circ} \mathrm{C}$ & $625^{\circ} \mathrm{C}$ & $650^{\circ} \mathrm{C}$ & $700^{\circ} \mathrm{C}$ \\
\hline \multirow{2}{*}{ Tube } & MGD & N/A & 478 & 412 & $375^{\mathrm{a}}$ & 344 & $305^{\mathrm{a}}$ & 267 & 199 \\
& $\mathrm{MGF}$ & N/A & 487 & 418 & $381^{\mathrm{a}}$ & 347 & $309^{\mathrm{a}}$ & 270 & 201 \\
& $\mathrm{MGG}$ & N/A & 489 & 419 & $379^{\mathrm{a}}$ & 340 & $306^{\mathrm{a}}$ & 266 & 200 \\
\multirow{4}{*}{ Plate } & $\mathrm{MgA}$ & 508 & 444 & 399 & N/A & 320 & N/A & 266 & N/A \\
& $\mathrm{MgB}$ & 506 & 477 & 417 & N/A & 330 & N/A & 277 & N/A \\
& $\mathrm{MgC}$ & 523 & 480 & 427 & $385^{\mathrm{a}}$ & 355 & $326^{\mathrm{a}}$ & 290 & N/A \\
& $\mathrm{MgD}$ & N/A & 478 & 413 & $373^{\mathrm{a}}$ & 343 & $308^{\mathrm{a}}$ & 268 & N/A \\
F91 & $\mathrm{MGQ}$ & N/A & 464 & 402 & $366^{\mathrm{a}}$ & 333 & $300^{\mathrm{a}}$ & 266 & N/A \\
\hline
\end{tabular}

Note: ${ }^{a}$ values are interpolated

${ }^{\mathrm{b}}$ mean values of the columns. 
The creep test results of minimum creep rate $\left(\dot{\varepsilon}_{s S}\right)$ and time-to-rupture (TTR) hours from the present research are reported in Table 5- 4.

Table 5- 4 Creep test results of F91 steel

\begin{tabular}{cccc}
\hline $\begin{array}{c}\text { Temperature } \\
{ }^{\circ} \mathrm{C}\end{array}$ & $\begin{array}{c}\text { Stress } \\
\text { MPa }\end{array}$ & $\begin{array}{c}\dot{\varepsilon}_{s s} \\
\text { strain } \% / \mathrm{hr}\end{array}$ & $\begin{array}{c}\text { TTR } \\
\text { hr }\end{array}$ \\
\hline \multirow{2}{*}{500} & 320 & $4.99 \mathrm{E}-4$ & 2142.5 \\
& 300 & $2.38 \mathrm{E}-4$ & 3503.7 \\
& 280 & $2.31 \mathrm{E}-4$ & 4223.8 \\
\hline \multirow{2}{*}{550} & 260 & $4.99 \mathrm{E}-2$ & 81.3 \\
& 240 & $1.09 \mathrm{E}-2$ & 306.0 \\
& 220 & $4.61 \mathrm{E}-3$ & 891.4 \\
\hline \multirow{2}{*}{600} & 160 & $3.42 \mathrm{E}-2$ & 180.6 \\
& 140 & $6.24 \mathrm{E}-3$ & 833.6 \\
& 130 & $3.00 \mathrm{E}-3$ & 1602.0 \\
\hline \multirow{2}{*}{650} & 110 & $7.98 \mathrm{E}-2$ & 78.8 \\
& 100 & $1.82 \mathrm{E}-2$ & 244.8 \\
& 80 & $4.45 \mathrm{E}-3$ & 873.4 \\
\hline
\end{tabular}

Microstructural analysis of F91 specimens was performed using an optical microscope. The as-received F91 coupon has a conventional martensitic lath structure with prior-austenite boundaries and precipitations. Comparison of F91 microstructure with NIMS tube, plate, and pipe materials is shown in Fig. 5- 3. It is seen that these Grade 91 steels have the similar microstructure with precipitates mainly located on grain/lath boundaries. 

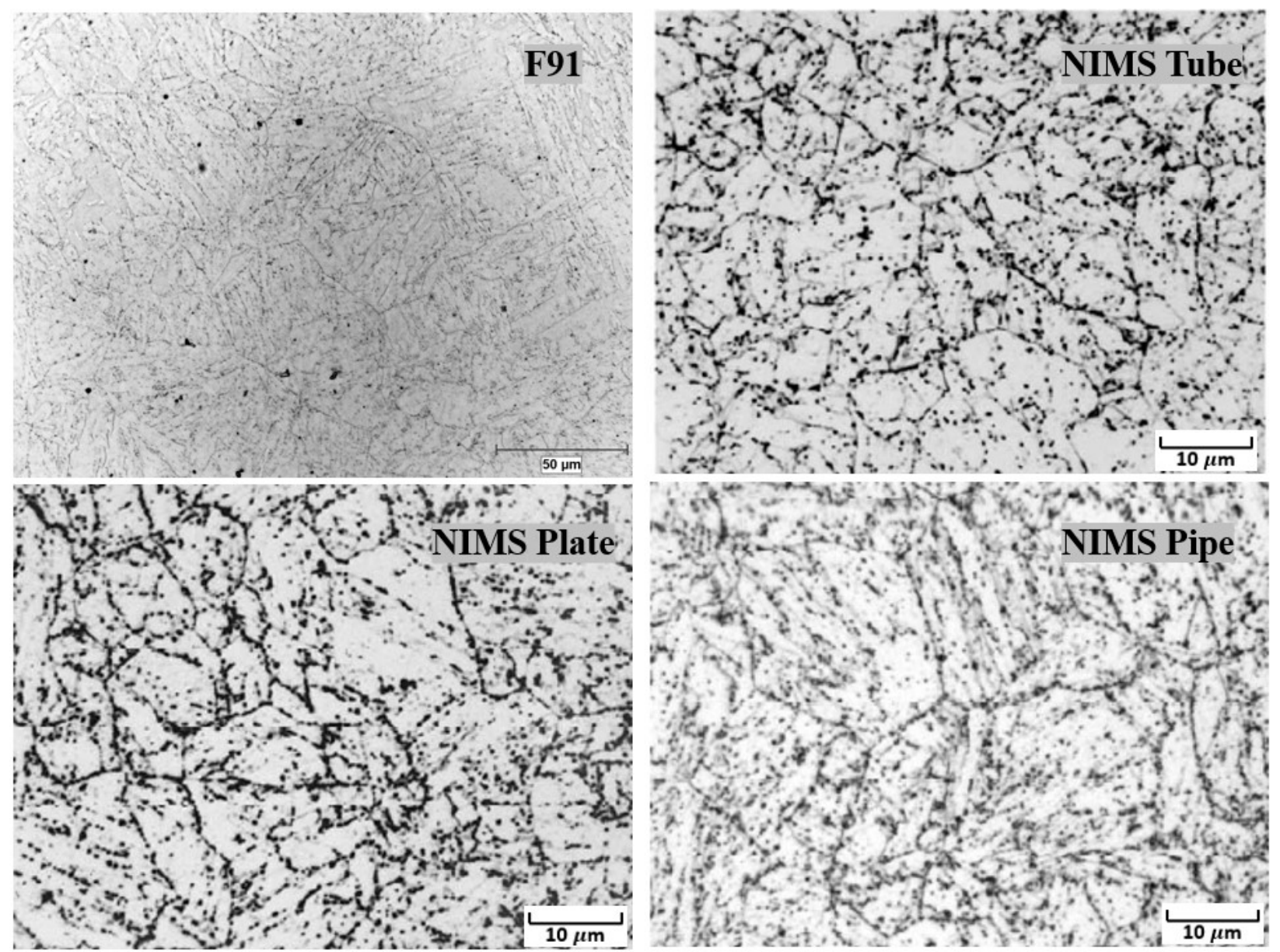

Fig. 5- 3. Optical microstructures of as-received F91 and NIMS products $\left[{ }^{127}\right]$. 


\subsection{Model Validation for NIMS Grade 91 Steels}

NIMS published Creep Data Sheet No. 43A in 2014 for $9 \mathrm{Cr}-1 \mathrm{Mo}-\mathrm{V}-\mathrm{Nb}$ steels (modified 9Cr-1Mo), which were manufactured via different processes into three shapes: tube, plate, and seamless pipe. All the NIMS samples were tempered martensitic steels, but plate $\mathrm{MgA}, \mathrm{MgB}$, and $\mathrm{MgC}$ experienced a stress relieving heat treatment up to 8.4 hours. Plates $\mathrm{MgA}$ and $\mathrm{MgB}$ had the same chemical composition and manufacturing process, except different stress relieving heat treatments. $\mathrm{MgA}$ was aged at $730^{\circ} \mathrm{C}$ for 8.4 hours, while $\mathrm{MgB}$ at $740^{\circ} \mathrm{C}$ for 60 minutes. Tubes MGD and MGF were extruded steels. All other samples were hot rolled. In this study, F91 was forged and machined into steel bars. Thermal histories and manufacturing processes endowed different mechanical properties, including creep performance which will be discussed later.

According to Eq. (4-10), minimum creep rate $\left(\dot{\varepsilon}_{s S}\right)$ can be expressed as a combination of power-laws representing the different participation mechanisms. Normalization of the applied engineering stress $(\sigma)$ by UTS at a specific test temperature $\left(\sigma_{T}\right)$ is used to categorize the stress regions from low to high. The value $\leq 0.35$ is designated as low stress region; $0.35-0.5$ as intermediate stress region; $\geq 0.6$ as high stress region. Modified Grade 91 steels are designed to serve at temperatures below $750^{\circ} \mathrm{C}$, therefore, $600-750^{\circ} \mathrm{C}$ is considered as high temperature range, $500-600^{\circ} \mathrm{C}$ is considered as intermediate temperature range, and $450-500^{\circ} \mathrm{C}$ is considered as low temperature range.

The first step in model calibration is to categorize the creep data into a stress-rate map. Taking NIMS plate MgB as an example, as shown in Fig. 5- 4, the low-stress region exhibits a power exponent of around 6, the intermediate-stress region has a power exponent of about 16 , and the high-stress region appears to have a much higher exponent value of about 29. Not all steels exhibit three distinctive stress exponents. For example, tube MGG, plate MgD, and pipe MGQ do not 
exhibit the high-exponent region. In the creep rate versus stress map (Fig. 5- 4) the apparent stress dependence may be the result of competition between different creep mechanisms, each dominates in a stress region at different temperatures. Generally, IDG mechanism dominates in the highstress region at low temperatures; IDC mechanism dominates in the low-stress region at high temperatures; whereas GBS mechanism usually takes place in between $\left[{ }^{62}\right]$. Within their dominant regions, IDC, IDG, and GBS assume a constant power exponent, $m, n, p$, respectively.

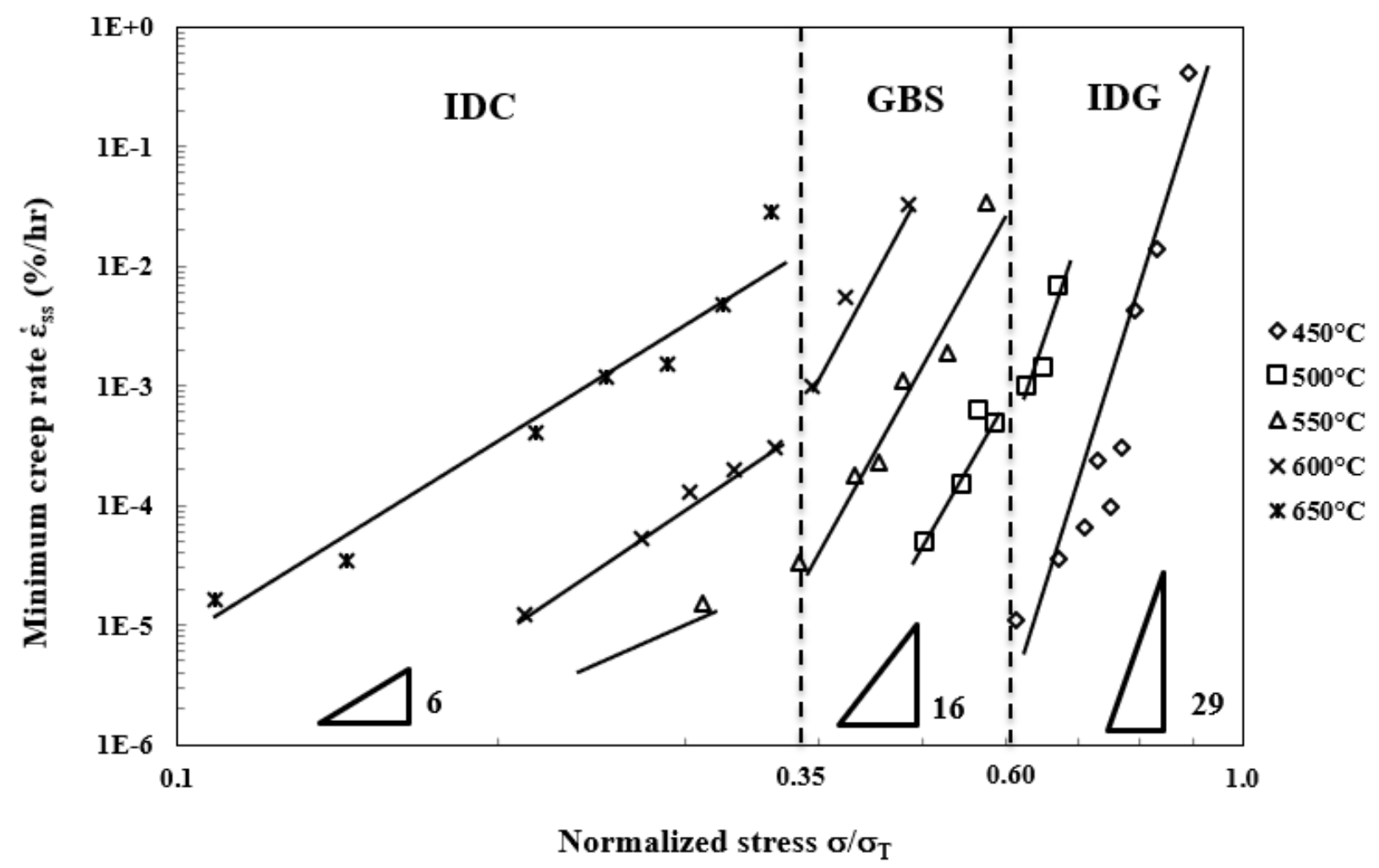

Fig. 5- 4. Power-law exponents according to the rate-stress map of NIMS plate $\operatorname{MgB}\left[{ }^{127}\right]$.

The second step is to obtain the mechanism parameters, $A_{0}, B_{0}, C_{0}$ and $Q_{A}, Q_{B}, Q_{C}$ of Eqs. (41) to (4-3), using the Arrhenius plots, for GBS, IDG and IDC, separately. Through the above stress-dependence (power-law fitting) and temperature-dependence (Arrhenius plot fitting) 
analyses, the mechanisms parameter values are determined, as reported in Table 5- 5. Then, the total steady-state creep rates are calculated, according to Eq. (4-10). The predicted steady-state creep rate versus stress curves are compared with the experimental data, as shown in Fig. 5- 5 to Fig. 5- 12, for various modified 9Cr-1Mo steel products. Note that all symbols representing NIMS data are taken from the reference $\left[{ }^{127}\right]$.

Table 5- 5 Mechanism parameters for $9 \mathrm{Cr}-1 \mathrm{Mo}-\mathrm{V}-\mathrm{Nb}$ steels

\begin{tabular}{|c|c|c|c|c|c|c|c|c|c|c|}
\hline \multirow{2}{*}{ Type } & \multirow{2}{*}{$\begin{array}{l}\text { NIMS } \\
\text { Code }\end{array}$} & \multicolumn{3}{|c|}{ IDC } & \multicolumn{3}{|c|}{ GBS } & \multicolumn{3}{|c|}{ IDG } \\
\hline & & $C_{0}$ & $Q_{c}$ & $m$ & $A_{0}$ & $Q_{A}$ & $p$ & $B_{0}$ & $Q_{B}$ & $n$ \\
\hline \multirow{3}{*}{ Tube } & MGD & $6.48 \mathrm{E}+19$ & 378360 & 6.6 & $6.65 \mathrm{E}+20$ & 384916 & 10.1 & $5.02 \mathrm{E}+26$ & 416042 & 18.8 \\
\hline & MGF & $1.18 \mathrm{E}+20$ & 413953 & 4 & $1.42 \mathrm{E}+23$ & 392762 & 11.9 & $3.32 \mathrm{E}+27$ & 430377 & 18.3 \\
\hline & MGG & $2.65 \mathrm{E}+17$ & 346811 & 5.5 & $2.88 \mathrm{E}+23$ & 384808 & 14.5 & N/A & N/A & $\mathrm{N} / \mathrm{A}$ \\
\hline \multirow{4}{*}{ Plate } & $\mathrm{MgA}$ & $3.00 \mathrm{E}+23$ & 439995 & 6.4 & $2.64 \mathrm{E}+27$ & 428738 & 17.3 & $9.48 \mathrm{E}+32$ & 487460 & 25.7 \\
\hline & $\mathrm{MgB}$ & $3.55 \mathrm{E}+25$ & 475105 & 6 & $9.65 \mathrm{E}+26$ & 423139 & 16.3 & $1.20 \mathrm{E}+34$ & 493867 & 28.8 \\
\hline & $\mathrm{MgC}$ & $1.02 \mathrm{E}+17$ & 337118 & 6.2 & $3.53 \mathrm{E}+25$ & 413529 & 14.7 & $2.14 \mathrm{E}+29$ & 439903 & 24 \\
\hline & $\mathrm{MgD}$ & $6.36 \mathrm{E}+17$ & 348076 & 6 & $1.33 \mathrm{E}+22$ & 350738 & 16.5 & N/A & N/A & N/A \\
\hline Pipe & MGQ & $3.09 \mathrm{E}+19$ & 380931 & 6 & $1.34 \mathrm{E}+26$ & 413596 & 16.5 & $\mathrm{~N} / \mathrm{A}$ & $\mathrm{N} / \mathrm{A}$ & N/A \\
\hline F91 & & $1.48 \mathrm{E}+23$ & 455345 & 4.5 & $1.97 \mathrm{E}+29$ & 465346 & 15.6 & $7.79 E+33$ & 488184 & 28.8 \\
\hline
\end{tabular}




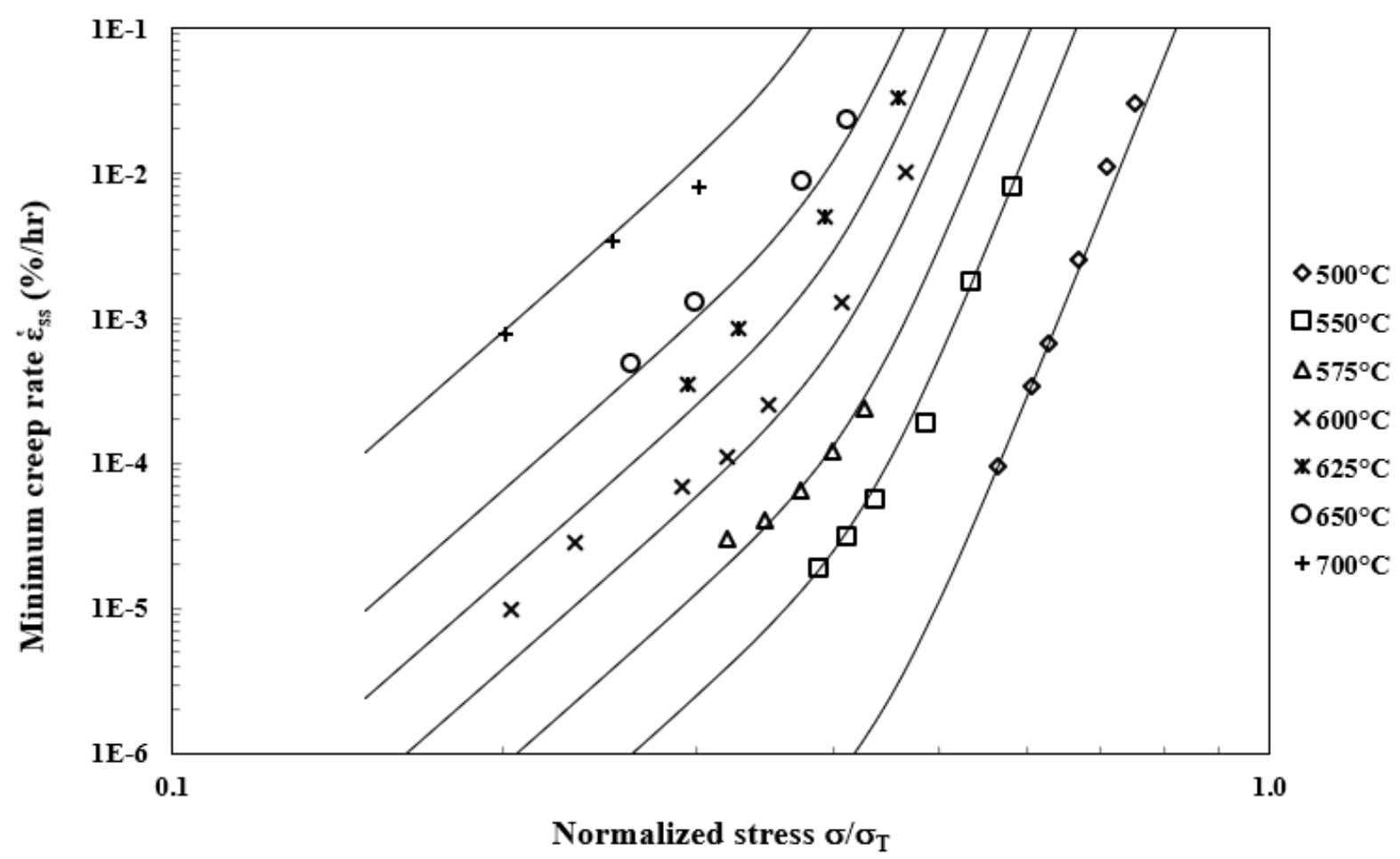

Fig. 5- 5. Minimum creep rates of NIMS Tube MGD (symbols: experimental data; lines: model).

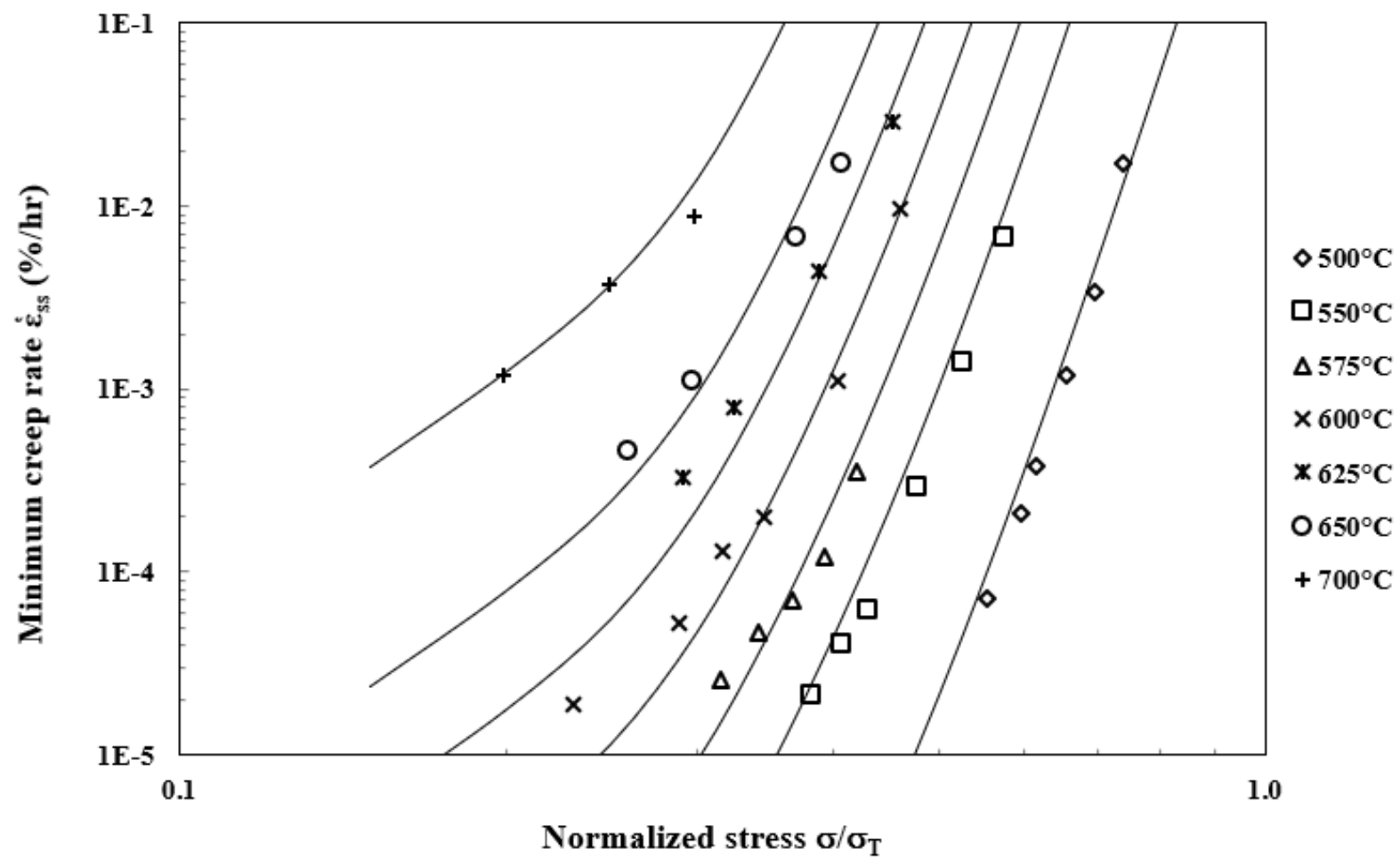

Fig. 5- 6. Minimum creep rates of NIMS Tube MGF (symbols: experimental data; lines: model). 


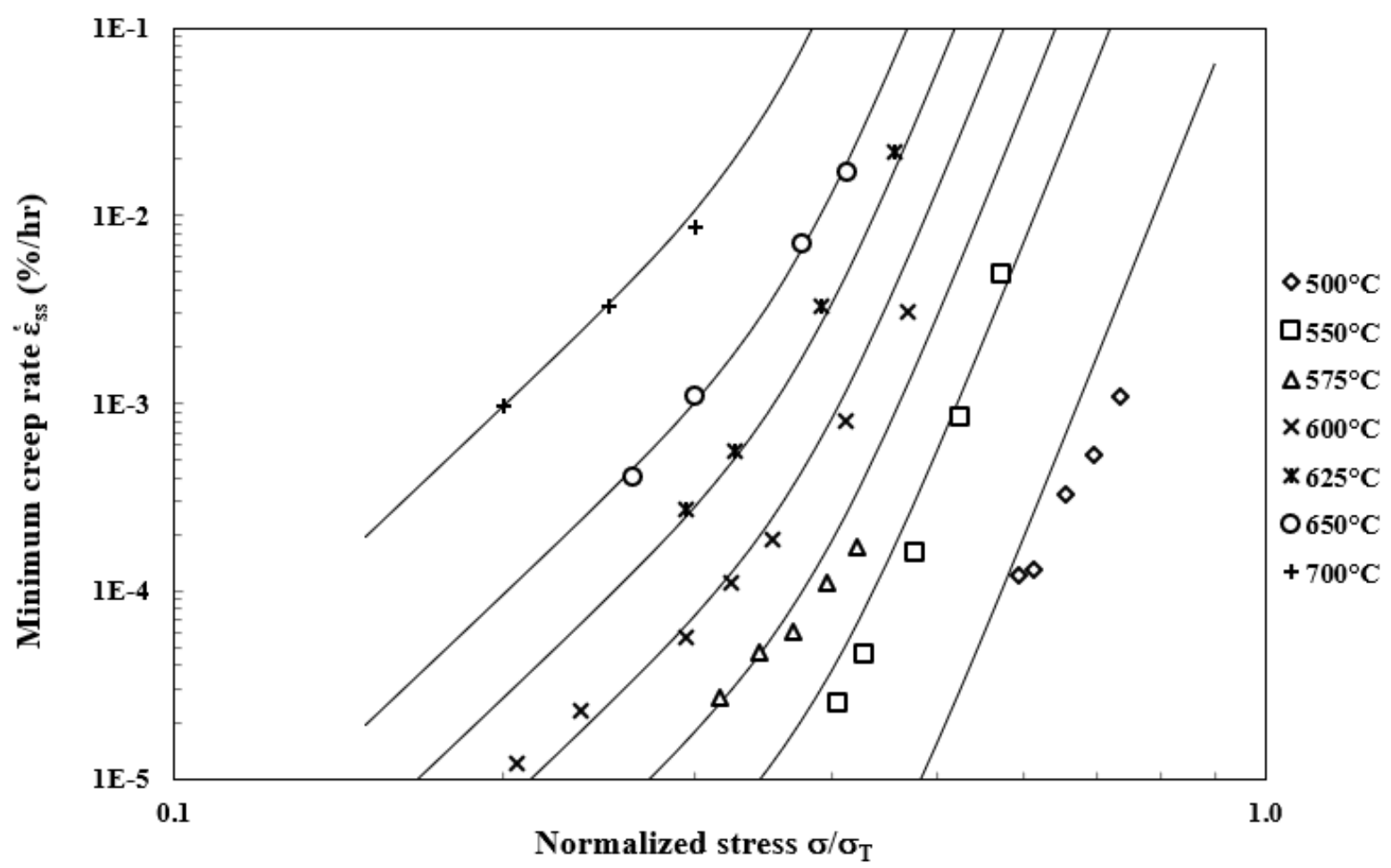

Fig. 5- 7. Minimum creep rates of NIMS Tube MGG (symbols: experimental data; lines: model).

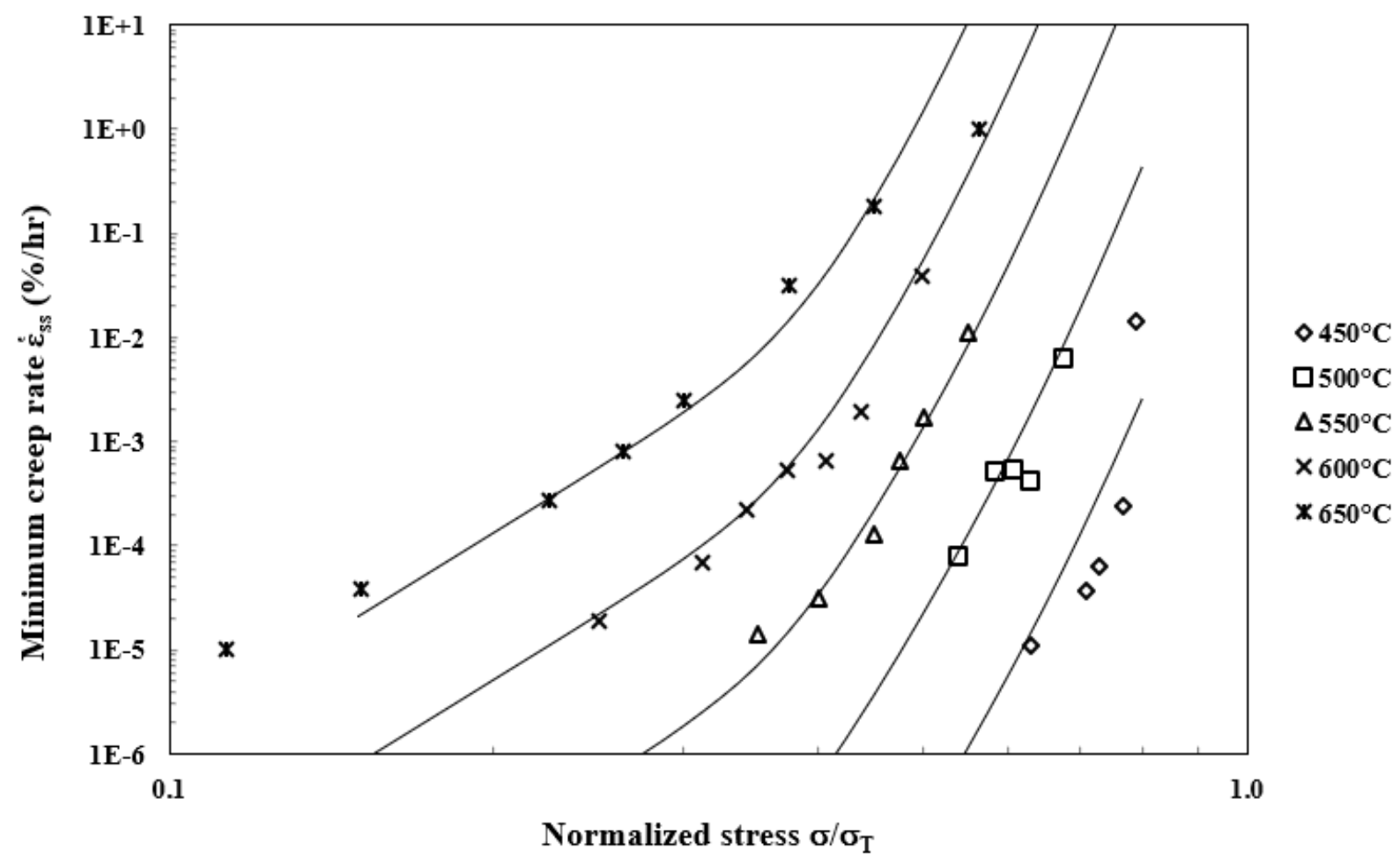

Fig. 5- 8. Minimum creep rates of NIMS Plate MgA (symbols: experimental data; lines: model). 


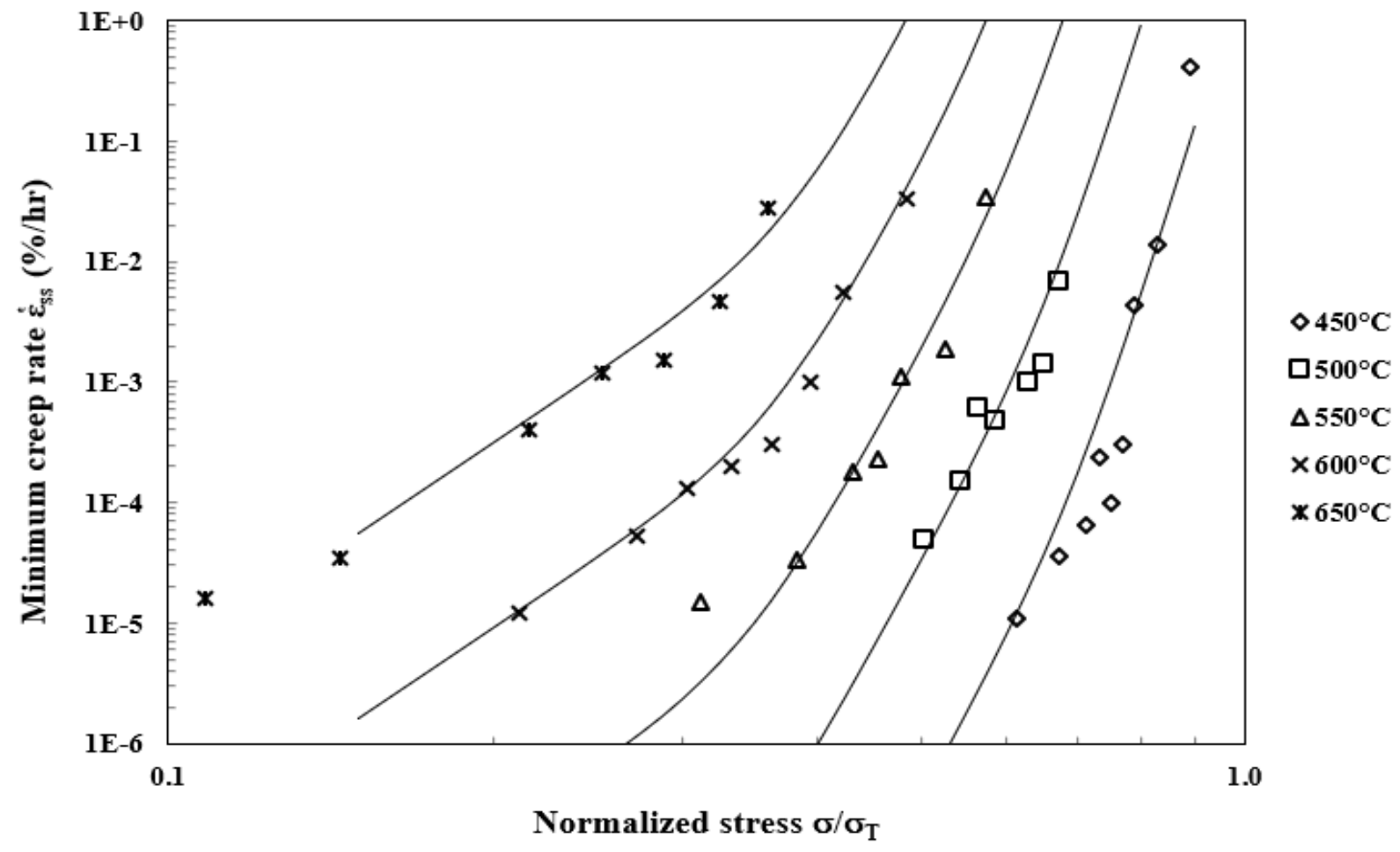

Fig. 5- 9. Minimum creep rates of NIMS Plate MgB (symbols: experimental data; lines: model).

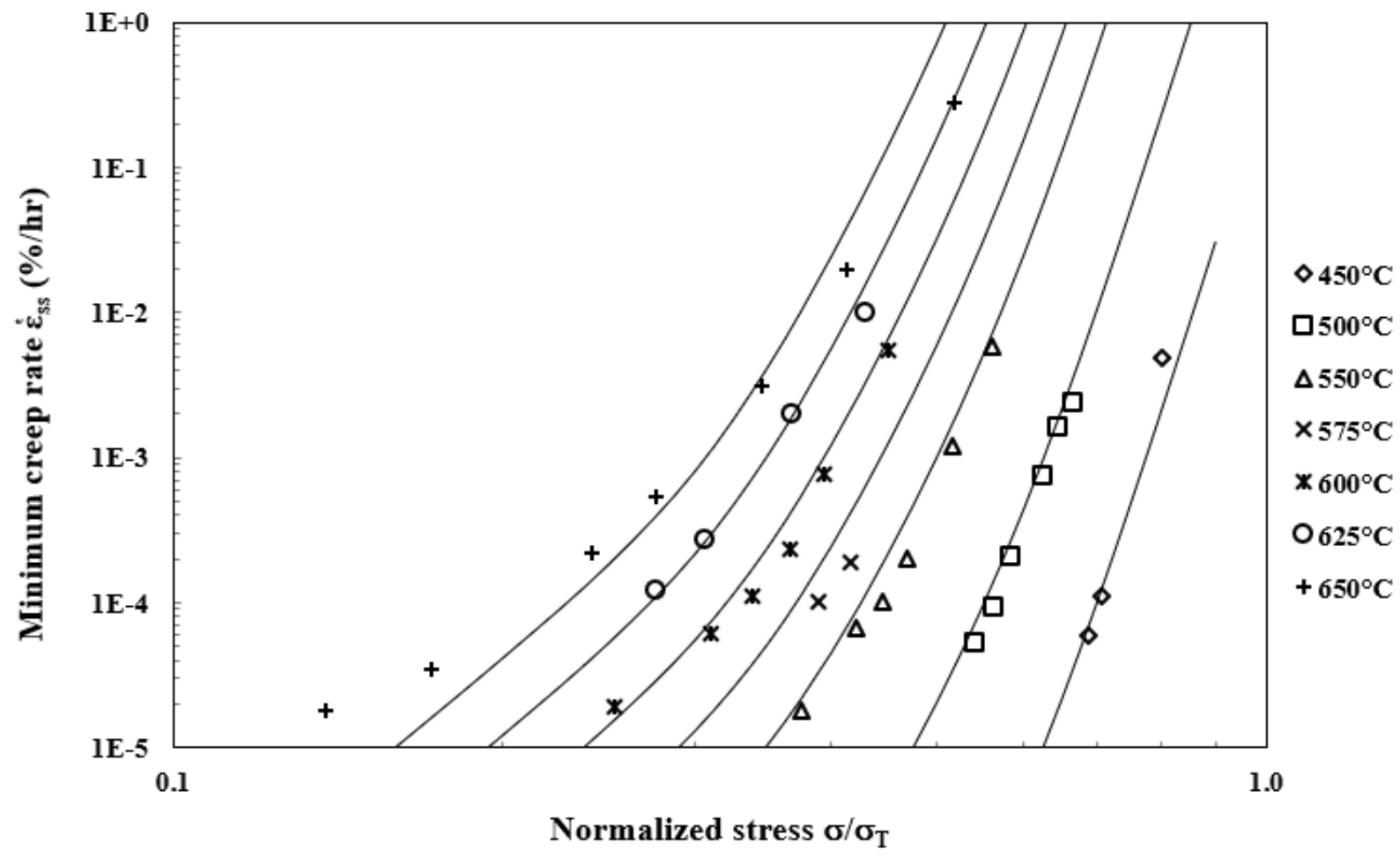

Fig. 5- 10. Minimum creep rates of NIMS Plate $\mathrm{MgC}$ (symbols: experimental data; lines: model). 


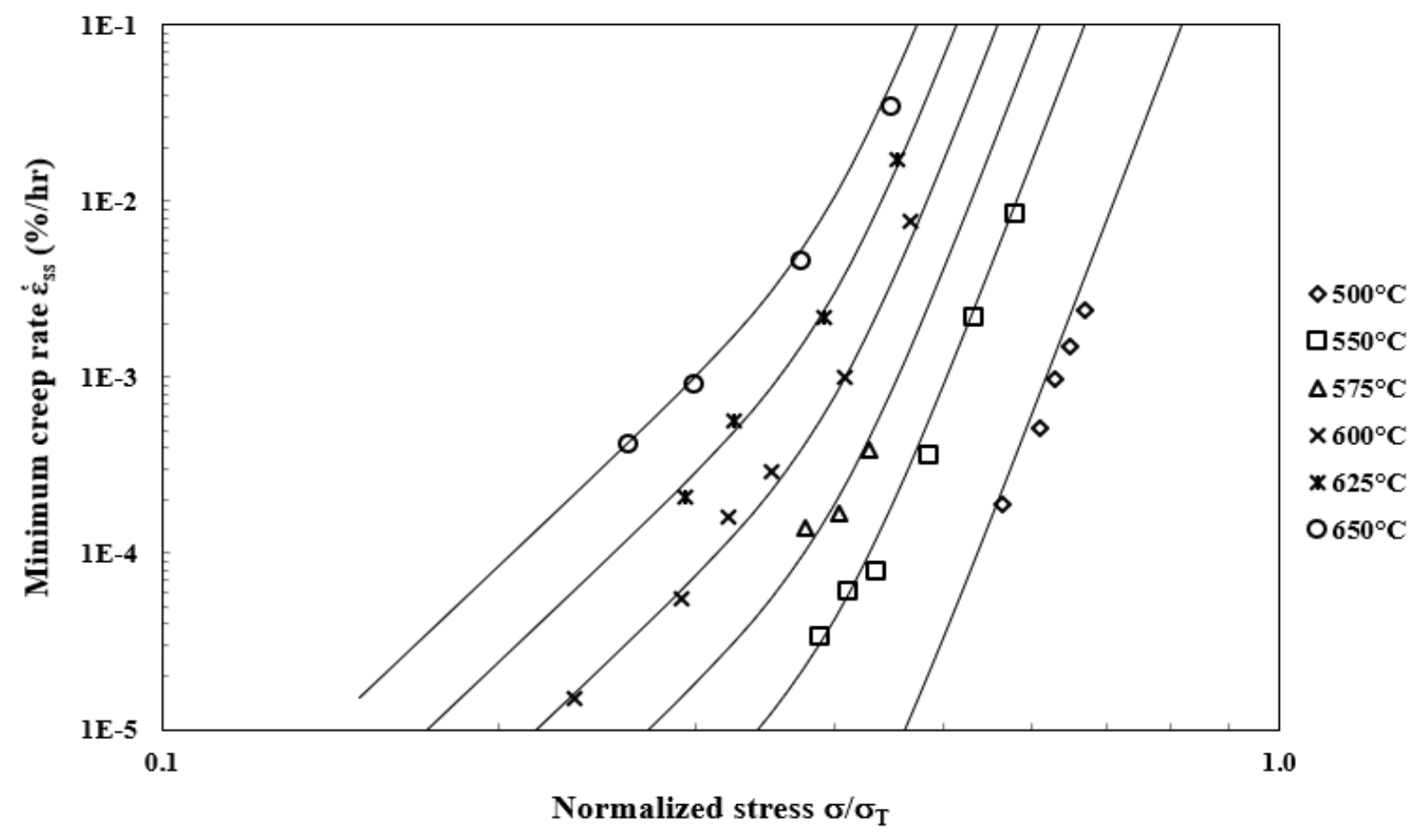

Fig. 5- 11. Minimum creep rates of NIMS Plate MgD (symbols: experimental data; lines: model).

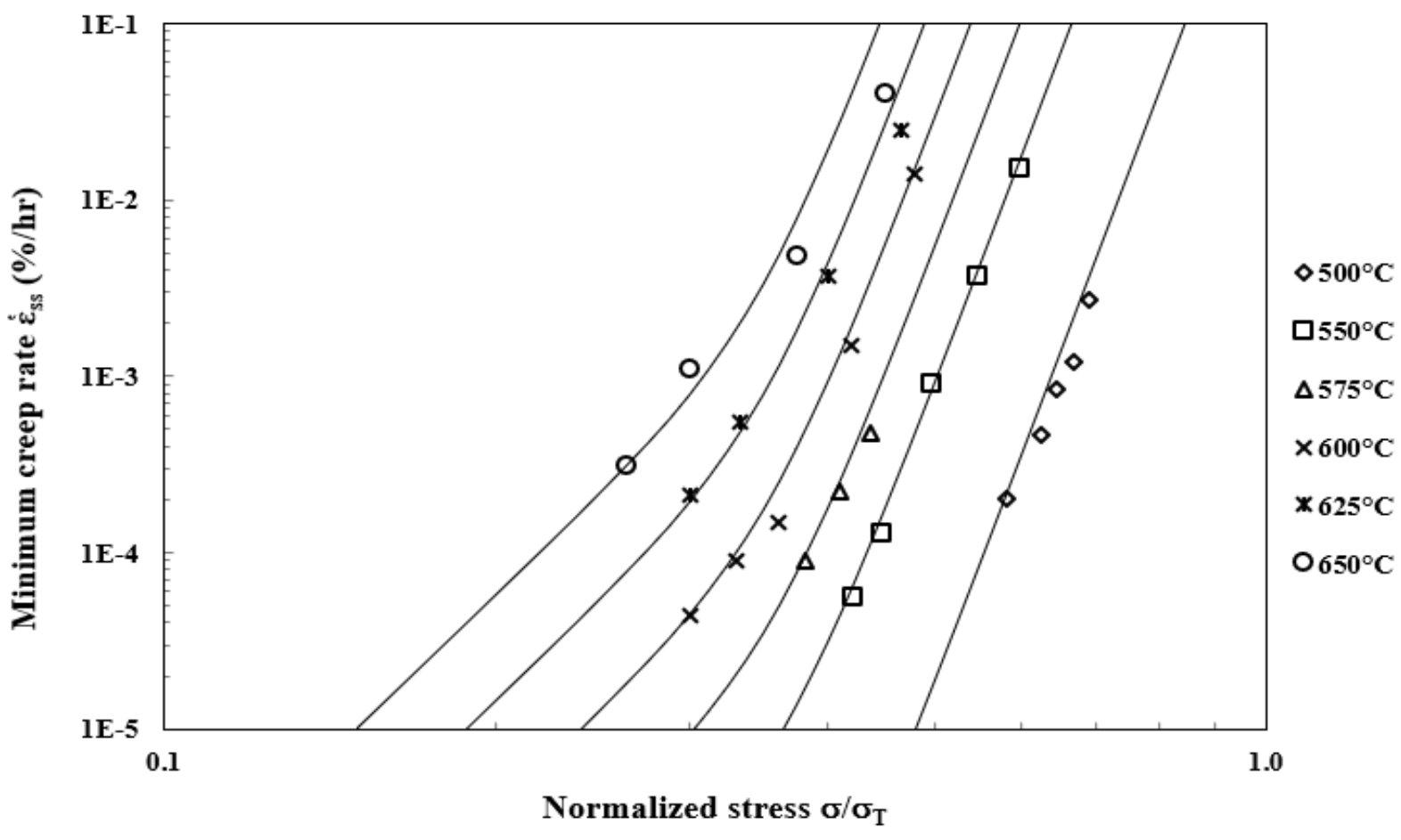

Fig. 5- 12. Minimum creep rates of NIMS Pipe MGQ (symbols: experimental data; lines: model). 
The creep stress-rate curves are in good agreement with the experimental data - the average coefficient of determination $\left(R^{2}\right)$ of all fitting lines is 0.99 . This demonstrates that the model is suitable for the NIMS steels. Among the NIMS steels, three product forms are available according to different standard codes. Tubes are manufactured for boiler and heat exchangers according to ASME SA-213/SA-213M Grade T91, plates for boilers and pressure vessels according to ASME SA-387/SA-387M Grade 91, and the seamless pipes for high-temperature service according to ASME SA-335/SA-335M Grade P91. The steels produced following the same standard show the similar creep behavior. By comparison, the power exponent $p$ of GBS is about 12 for tubes, 16 for plates and the pipe; while the power exponent $n$ of IDG is about 18 for tubes and 26 for plates. However, the power exponent $m$ of IDC is approximately 6 for all types of NIMS products. The activation energies of GBS and IDG follow the same trend, i.e., those for plates are higher than those for tubes. The pronounced differences in the power exponent and activation energy indicate that manufacturing process affects the creep behavior of the modified Grade 91 steels. Hot-rolled and forged microstructures, in general, are heavier "worked" with higher dislocation density, creating larger barriers for dislocation glide either within the grain interior (affecting IDG) or along grain or lath boundaries (affecting GBS). On the other hand, IDC is a diffusion-controlled mechanism and its stress dependence is less affected by thermomechanical processing, which is the reason why all Grade 91 steels have the similar IDC exponent about 6. Furthermore, discrepancies in the parameter values are shown for the same type products with different forming processes. For instance, Tube MGG is hot rolled while MGD and MGF are hot extruded, MGG does not show the high-power exponent in IDG and Pipe MGQ shows the same phenomena with only IDC and GBS to control the minimum creep rates. 
All the NIMS steels are tempered martensitic steels. The normalizing temperature range was from $1045^{\circ} \mathrm{C}$ to $1060^{\circ} \mathrm{C}$, and the tempering temperature varied between $760^{\circ} \mathrm{C}$ and $780^{\circ} \mathrm{C}$. Also, plates $\mathrm{MgA}, \mathrm{MgB}$, and $\mathrm{MgC}$ experienced a stress relieving heat treatment at $730^{\circ} \mathrm{C}$ or $740^{\circ} \mathrm{C}$, from 1 hour to 8.4 hours, with furnace cooling. It appears that hot rolled products tempered at $780^{\circ} \mathrm{C}$ and $790^{\circ} \mathrm{C}$ do not have an IDG region. This is perhaps due to the reason that tempering at higher temperatures relieved the martensitic laths to allow more inter-lath or grain boundary sliding. According to the NIMS record, plates $\mathrm{MgA}$ and $\mathrm{MgB}$ are identical, except that $\mathrm{MgA}$ experienced a much longer stress relieving heat treatment than $\mathrm{MgB}$ at the same temperature. The creep behavior of both is very similar, which means that the duration of the stress relief did not have a significant impact on creep.

\subsection{Model Validation for F91 Steel}

This section is focused on determination of the model mechanism parameters for F91 steel. Since the experimental data on F91 are limited, mostly fall into $0.35-0.60$ stress range, they are collated with the data on $\operatorname{MgB}$ (Fig. 5- 9). The two reasons for selecting this product are as follow: (1) These two materials have similar heat treatment history; (2) The creep behavior and rupture lives of these two materials under the same test condition are the closest among various forms of the steels. The data for both materials are combined to validate the model parameters for F91. The calibrated model for F91 is illustrated in Fig. 5- 13. The fitted lines are in good agreement with the experimental data. The average correlate coefficient of determination $\left(R^{2}\right)$ for $500^{\circ} \mathrm{C} 550^{\circ} \mathrm{C}, 600^{\circ} \mathrm{C}$ and $650^{\circ} \mathrm{C}$ fitting lines is 0.88 . With such close correlation of minimum creep rate, the strain-time curves will be further analyzed using the mechanism parameters in Fig. 5- 13 and Table 5- 5, thus 
to evaluate the creep resistance of F91. Note that all closed symbols in Fig. 5- 13 are from reference $\left[{ }^{127}\right]$; open symbols are F91 creep test data obtained from the present study.

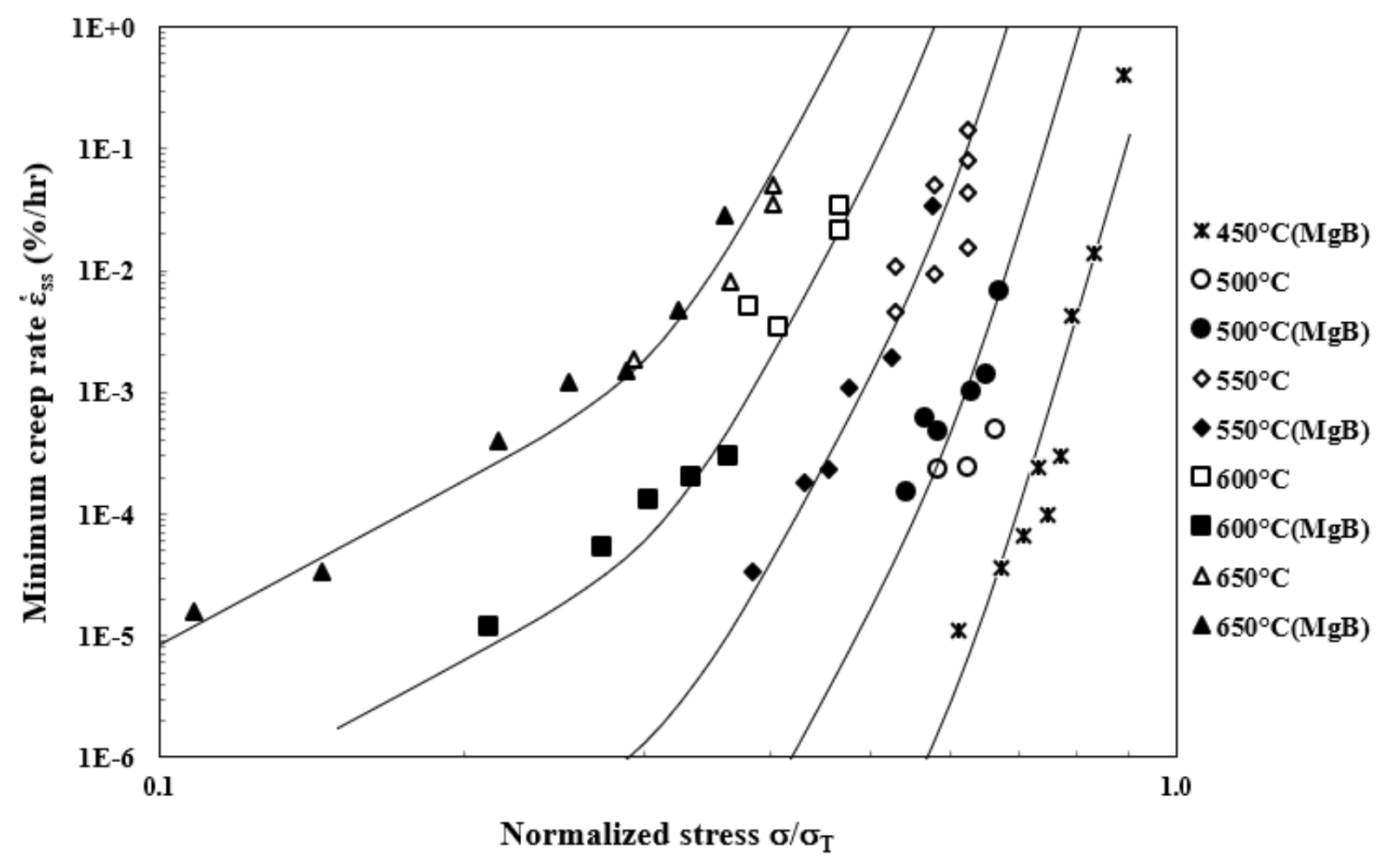

Fig. 5- 13. Minimum creep rates of F91 collated with NIMS Plate MgB (symbols: experimental data; lines: model). 


\subsection{Strain-time Creep Curves of F91 Steel}

In the previous section, the minimum creep rates favorably fit with the deformation mechanismbased rate equations for F91 steel. To fully characterize the creep behavior of F91 steel, its creep strain-time curve must also be analyzed, using Eq. (4-15a) with the determination of the work hardening coefficient $(H), \beta$-parameter, and the dislocation multiplication factor $M$, of the material.

From an experimental creep time-strain curve, the primary strain $\dot{\varepsilon}_{t r}^{P}$, primary time $t_{t r}^{P}$, and minimum creep rate $\dot{\varepsilon}_{s S}$ can be easily determined, as shown in Fig. AP- 1 (Appendix A). From these observations, the work hardening coefficient $(H)$ and $\beta$-parameter of the material can be calculated using Eq. (4-15a). Apparently, $\beta$ is a material constant for a given microstructure, while $H$ is changing with temperature, because of its dependence on the elastic modulus $\left[{ }^{57}\right]$. Dislocation multiplication factor $(M)$ can be obtained from curve fitting for the tertiary stage behavior, which is also a temperature-dependent parameter. $M$ and $H$ values are given in Table 5- 7 which are obtained from F91 strain-time curves at temperatures $500^{\circ} \mathrm{C}, 550^{\circ} \mathrm{C}, 600^{\circ} \mathrm{C}, 650^{\circ} \mathrm{C}$, together with the interpolated or extrapolated values for other temperatures. Model parameters for F91 are listed in Table 5- 5 and Table 5- 6. The model fitted time-strain creep curves of F91 are obtained from the DMTS model with these parameters for the temperatures of $500^{\circ} \mathrm{C}, 550^{\circ} \mathrm{C}, 600^{\circ} \mathrm{C}$ and $650^{\circ} \mathrm{C}$ at different stress levels, as shown in Fig. 5- 14 to Fig. 5- 17, respectively, together with the experimental data for comparison. Solid lines represent the experimental observations, and the dash lines represent Eq. (4-15) predictions. 
Table 5- 6 Material property related model parameters for F91 steel

\begin{tabular}{|c|c|c|c|c|c|c|c|}
\hline Temp & Stress & $\varepsilon_{t r}^{P}$ & $t_{t r}^{P}$ & strain/s & $\begin{array}{c}\text { Work } \\
\text { hardening } \\
\text { coefficient } \\
H \\
\mathrm{GPa}\end{array}$ & $\begin{array}{l}\text { Dislocation } \\
\text { multiplication } \\
\text { factor } \\
M\end{array}$ & $\begin{array}{c}\text { Material } \\
\text { parameter } \\
\beta\end{array}$ \\
\hline \multirow{3}{*}{500} & 320 & $6.53 \mathrm{E}-03$ & $1.80 \mathrm{E}+05$ & $1.38 \mathrm{E}-09$ & \multirow{3}{*}{47.16} & \multirow{3}{*}{1000} & 1.008 \\
\hline & 300 & $6.29 \mathrm{E}-03$ & $3.60 \mathrm{E}+05$ & $6.61 \mathrm{E}-10$ & & & \\
\hline & 280 & $5.94 \mathrm{E}-03$ & $3.31 \mathrm{E}+05$ & $6.81 \mathrm{E}-10$ & & & \\
\hline \multirow{3}{*}{550} & 260 & $6.14 \mathrm{E}-03$ & $1.69 \mathrm{E}+03$ & $1.39 \mathrm{E}-07$ & \multirow{3}{*}{41.15} & \multirow{3}{*}{300} & \\
\hline & 240 & $5.94 \mathrm{E}-03$ & $7.45 \mathrm{E}+03$ & 3.03E-08 & & & \\
\hline & 220 & $5.15 \mathrm{E}-03$ & $1.51 \mathrm{E}+04$ & $1.28 \mathrm{E}-08$ & & & \\
\hline \multirow{3}{*}{600} & 160 & $6.34 \mathrm{E}-03$ & $2.52 \mathrm{E}+03$ & $9.51 \mathrm{E}-08$ & \multirow{3}{*}{25.41} & \multirow{3}{*}{200} & \\
\hline & 140 & $5.45 \mathrm{E}-03$ & $1.19 \mathrm{E}+04$ & $1.73 \mathrm{E}-08$ & & & \\
\hline & 130 & 4.90E-03 & $2.16 \mathrm{E}+04$ & $8.60 \mathrm{E}-09$ & & & \\
\hline \multirow{3}{*}{650} & 110 & $1.16 \mathrm{E}-02$ & $1.98 \mathrm{E}+03$ & 2.22E-07 & \multirow{3}{*}{8.58} & \multirow{3}{*}{30} & \\
\hline & 100 & $1.04 \mathrm{E}-02$ & $7.92 \mathrm{E}+03$ & $5.00 \mathrm{E}-08$ & & & \\
\hline & 80 & $1.14 \mathrm{E}-02$ & $3.49 \mathrm{E}+04$ & $1.24 \mathrm{E}-08$ & & & \\
\hline
\end{tabular}

Table 5- 7 Normalized dislocation multiplication factors $(M)$ by temperature

\begin{tabular}{ccc}
\hline Temp & $\begin{array}{c}\text { Dislocation } \\
\text { multiplication } \\
\text { factor } M\end{array}$ & $\begin{array}{c}\text { Work } \\
\text { hardening } \\
\text { coefficient } H\end{array}$ \\
\hline${ }^{\circ} \mathrm{C}$ & & $\mathrm{GPa}$ \\
\hline 450 & 1135 & 63.43 \\
500 & 1000 & 47.16 \\
550 & 300 & 41.15 \\
575 & 383 & 30.56 \\
600 & 200 & 25.41 \\
625 & 82 & 17.41 \\
650 & 30 & 8.58 \\
700 & 20 & 3.00 \\
\hline
\end{tabular}




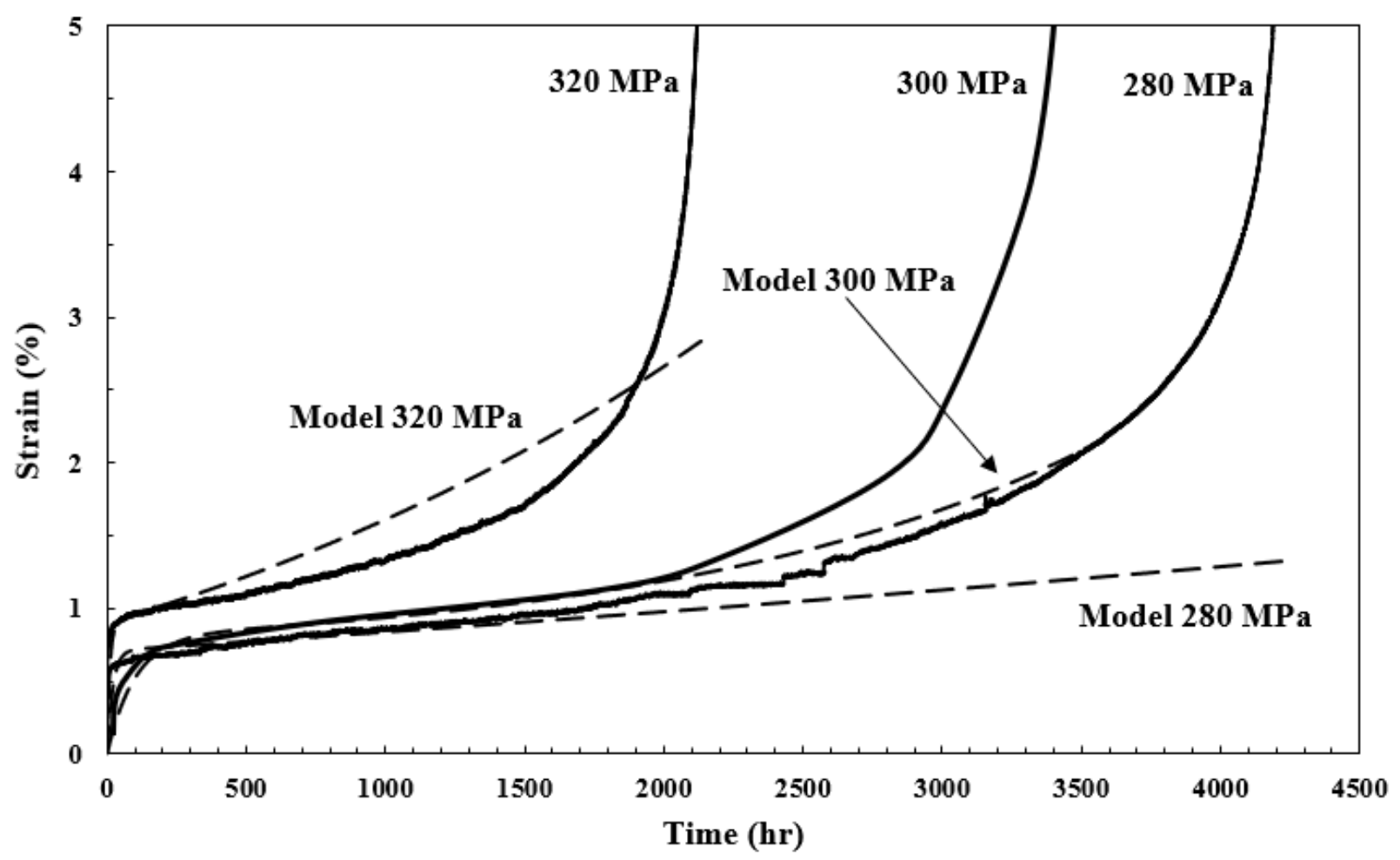

Fig. 5- 14. Experimental and model F91 creep curves at $500^{\circ} \mathrm{C}$.

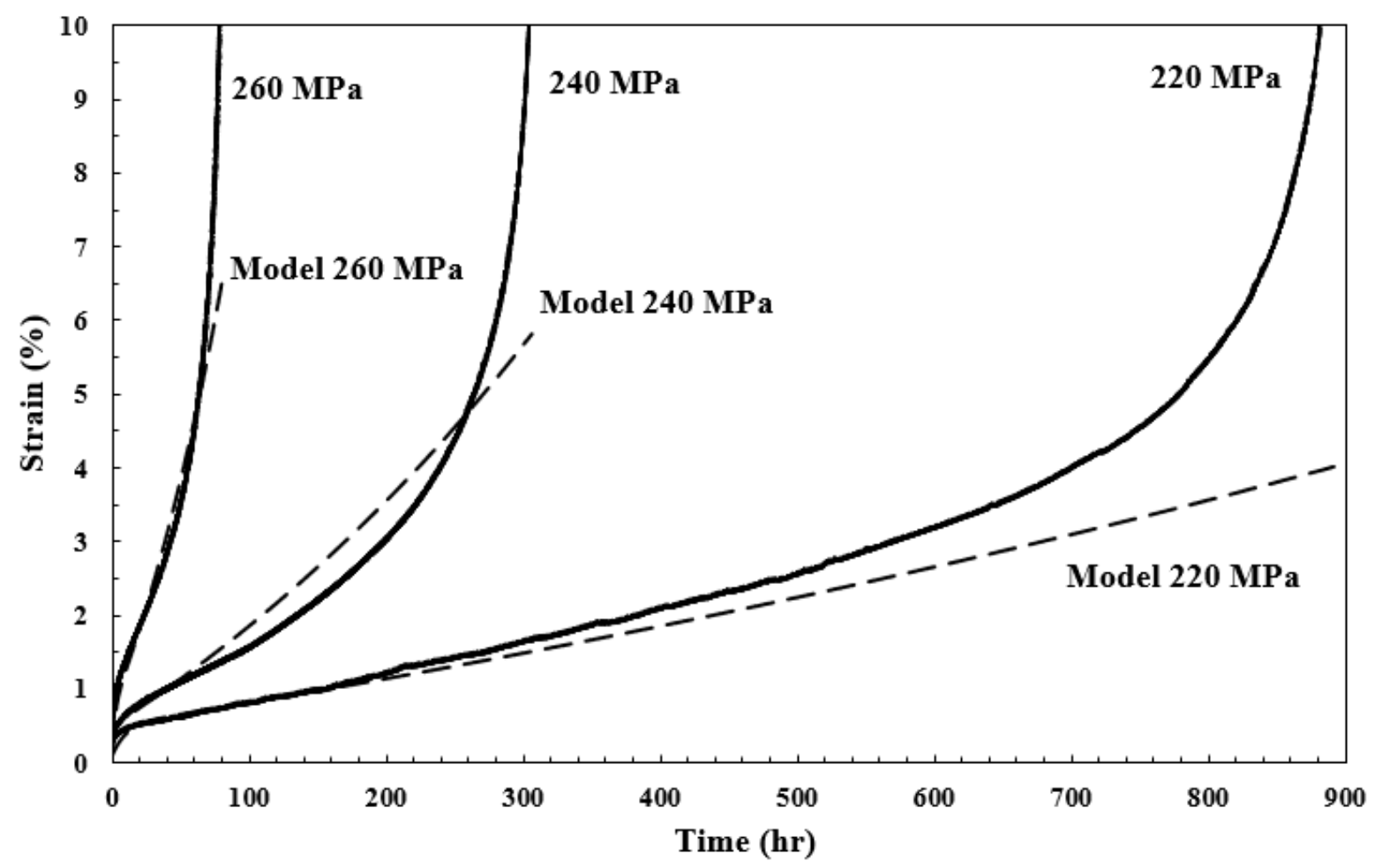

Fig. 5- 15. Experimental and model F91 creep curves at $550^{\circ} \mathrm{C}$. 


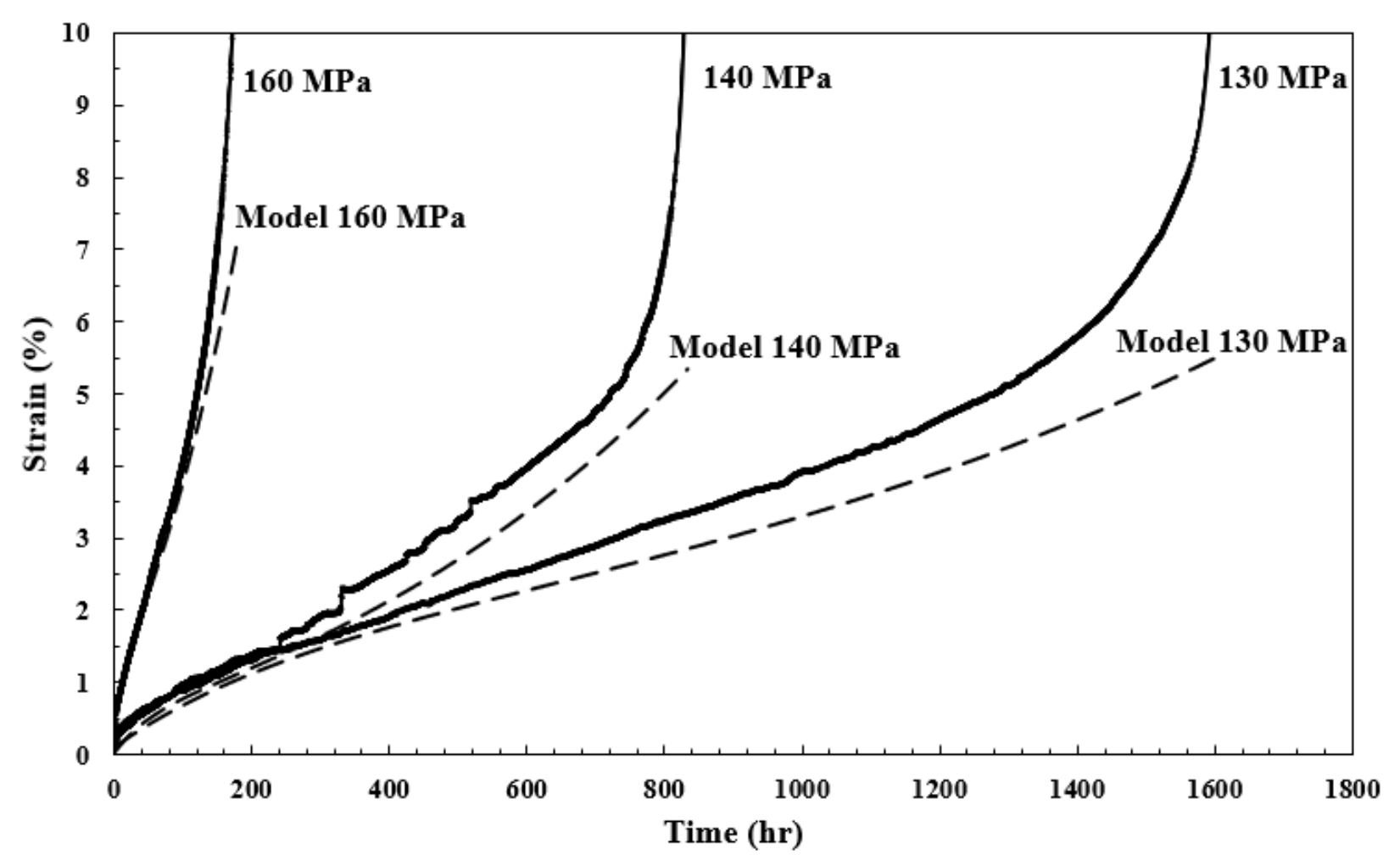

Fig. 5- 16. Experimental and model F91 creep curves at $600^{\circ} \mathrm{C}$.

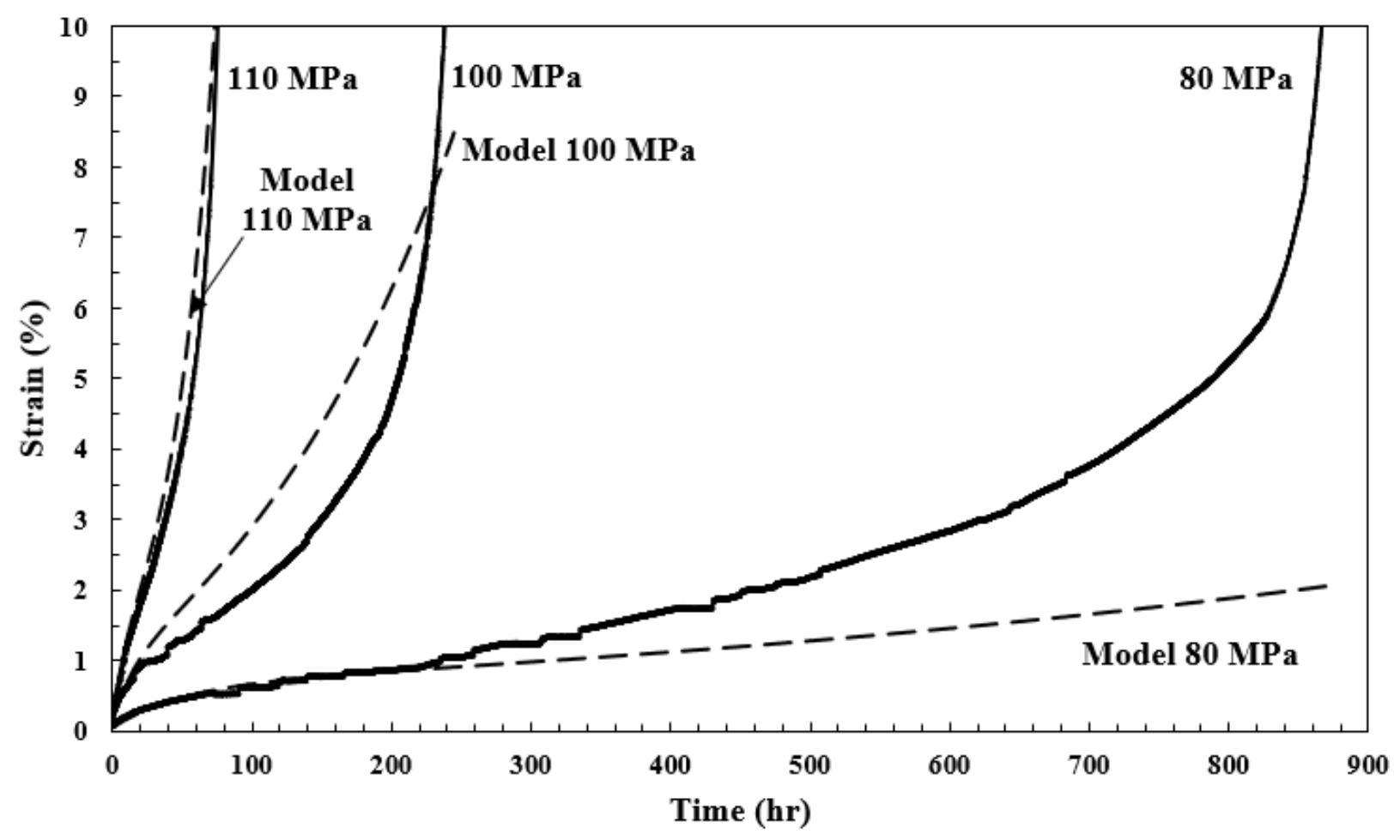

Fig. 5- 17. Experimental and model F91 creep curves at $650^{\circ} \mathrm{C}$. 
It can be seen that the creep life predictions for most of the test conditions are in very good agreement with the experimental observations, except the scenario towards long-term creep when oxidation effect cannot be negligible (description of these creep curves using the modified DMTS model will be discussed in next chapter). All the creep curves have a remarkable transient period, indicating the operation of GBS. Fig. 5- 18 and Fig. 5- 19 show the longitudinal cross-section microstructures near the fracture region of the specimens, tested at $550^{\circ} \mathrm{C}$ and $600^{\circ} \mathrm{C}$. According to the rate-stress map in Fig. 5- 4, the normalized stress $\geq 0.60$ indicates that the dominant deformation mechanism is IDG, while $0.35-0.60$ values indicate GBS prevailing. At $550^{\circ} \mathrm{C}$ under stress 260 and $240 \mathrm{MPa}$, the stress/UTS ratio is over or close to 0.60 , the microstructure at rupture contains elongated martensitic laths with a few large voids (Fig. 5- 18), which is apparently caused by extensive intragranular deformation. For $550^{\circ} \mathrm{C}$ under $220 \mathrm{MPa}$, and $600^{\circ} \mathrm{C}$ under 160,140 , and $130 \mathrm{MPa}$ (Fig. $5-18$ and Fig. 5- 19), the stress/UTS ratios fall in $0.35-0.60$, martensitic laths tend to maintain the original shape with intergranular defects, which suggests that GBS is the dominant deformation mechanism. The microstructural evidence shows that the coupon failure modes agree with the model prediction.

The creep behavior analysis of this section assumes a "constant structure" of the material, i.e., no microstructural evolution and environment condition affect creep rate. However, as learned from Chapter 2 discussion, this is a very gross assumption. As a matter of fact, predictions based on such an assumption for long-term creep over 300 hours fall below the experimental strain level, in particular, the model prediction does not show the tertiary creep stage, which indicates that the model underestimates the IDC in F91 under the specified conditions. Microstructural evolution occurring during "long-term" creep test would certainly affect the material's creep behavior. It was observed in the creep test that the F91 material suffered severe oxidation at the high 
temperatures. In addition, the formation of Laves phase was found after aging heat treatment or in long-term creep. These two factors can significantly affect the material's long-term creep behavior, which will be addressed with the modified DMTS model in Chapter 6 and Chapter 7, considering the effects of oxidation and microstructural degradation.
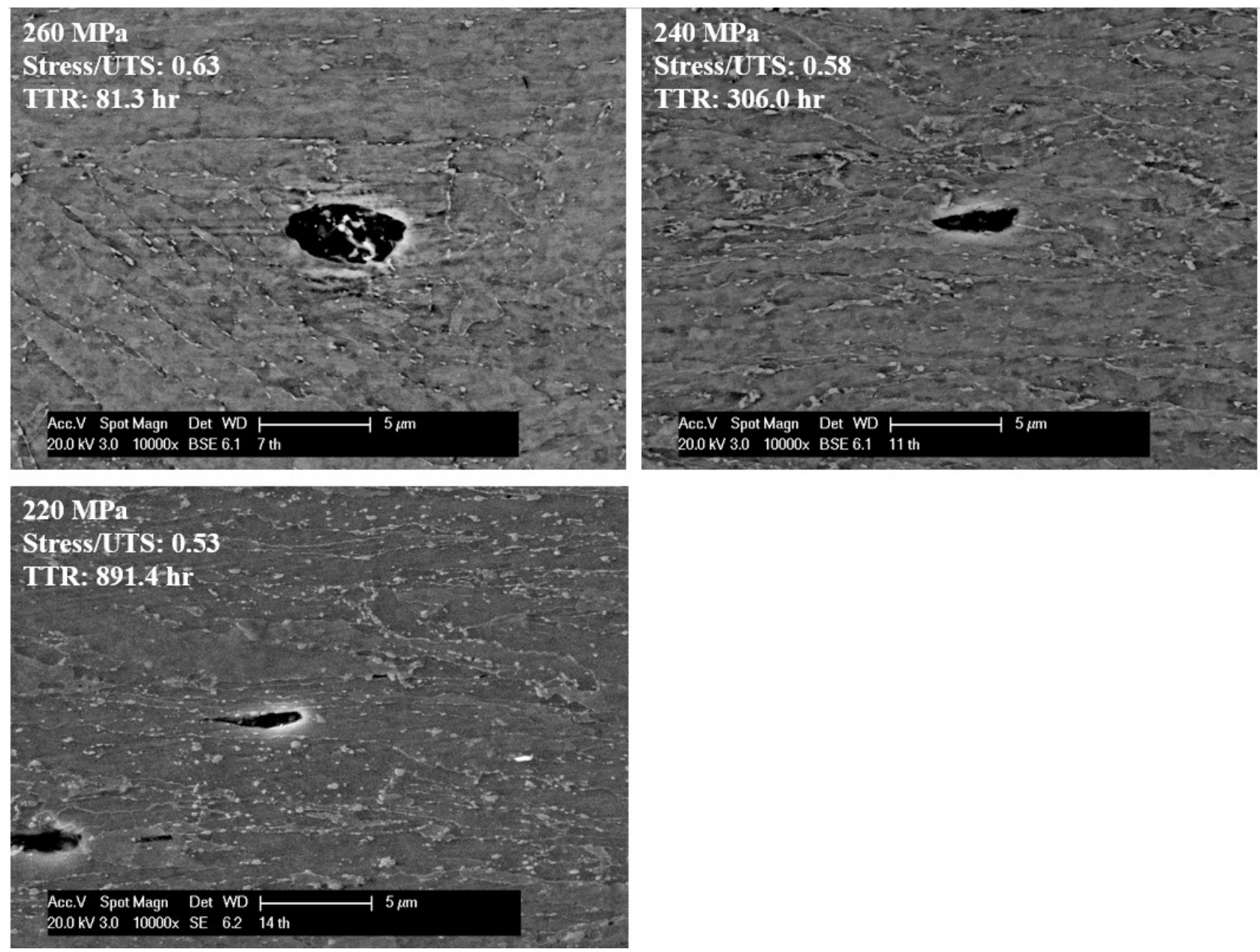

Fig. 5- 18. SEM images of longitudinal cross-section microstructure near the fracture region of the specimen tested at $550^{\circ} \mathrm{C}$ under different stress levels. 

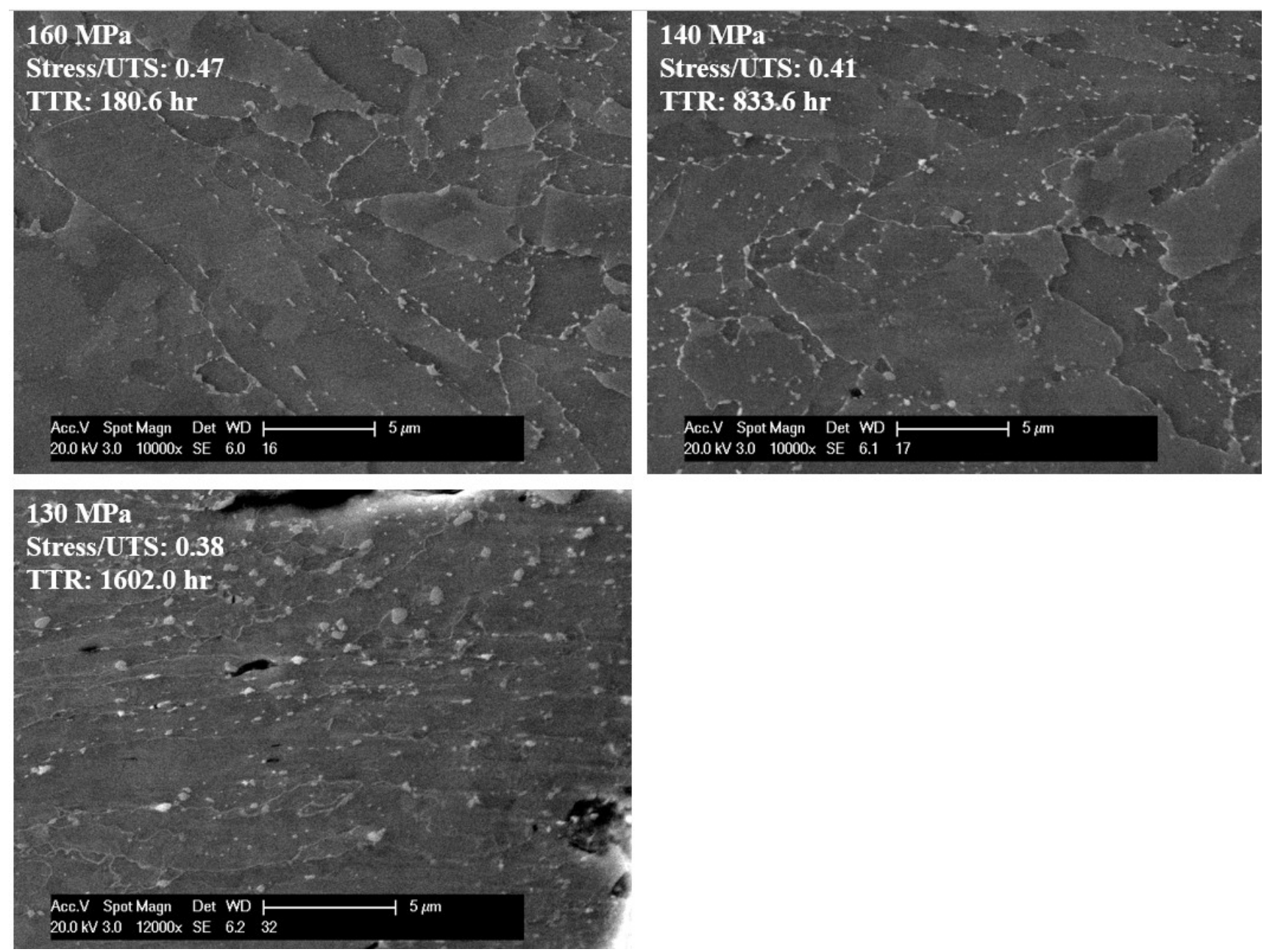

Fig. 5- 19. SEM images of longitudinal cross-section microstructure near the fracture region of the specimen tested at $600^{\circ} \mathrm{C}$ under different stress levels. 


\subsection{Long-term Creep Life Prediction of Grade 91 Steels}

In real-world applications, under the competitive pressure, engineering products need to be fast turn-around and cost-effective. Therefore, designers often encounter the need to predict the product's long-term performance based on limited short-term test data. While empirical short-term based methods are always questionable for long-term extrapolation, the deformation-mechanismbased model offers the promise, because it covers the physics of failure, regardless of the timescale. In this section, attempts are made to use the mechanism parameters (Table 5-5) and shortterm F91 creep testing data $\left(<5,000\right.$ hours) to predict long-term creep lives $\left(>10^{4}\right.$ hours) of Grade 91 steels. The long-term rupture life data of the NIMS Grade 91 steels are used to validate the model prediction. In this way, the allowable stresses of Grade 91 steels at elevated temperatures can be calculated using the DMTS model.

Since Grade 91 steels have similar microstructures in the as-received condition, it can be assumed that the structural parameters $H, \beta$ and $M$ are the same for all Grade 91 steels. These parameters have been determined for F91, as summarized in Table 5- 7 and Table 5- 7. The mechanism parameters for various Grade 91 steels are given in Table 5- 5. In order to predict timeto-rupture (TTR), using Eq. (4-15), a failure strain has to be defined. Considering that at the final moment of TTR creep rupture is often associated with necking, i.e., deformation instability, therefore $90 \%$ TTR is more appropriate to define the failure strain $\varepsilon_{c r}$ level calculated using the stable creep-strain equation. The failure strain $\varepsilon_{c r}$ levels are determined from short-term F91 creep tests, as a function of temperature. For long-term TTR prediction, two terms are negligible in Eq. (4-15): the initial elastic strain, $\varepsilon_{0}$, and the exponential term in the transient term $\left[1-\exp \left(-\frac{t}{t_{T}}\right)\right]$, because TTR $>>t_{T}$. Then, Eq. (4-15) can be re-written as 


$$
T T R=\frac{1}{M^{\prime} k} \ln \left[1+M^{\prime}\left(\varepsilon_{c r}-\frac{\sigma}{H \beta^{2}}\right)\right]
$$

where $\varepsilon_{c r}$ is the critical failure strain. The rationale of defining $\varepsilon_{c r}$ is further explained below.

In a creep test, the critical failure criterion needs to be carefully defined by examining ruptured coupons and strain-time curves. As observed, most of the ruptured F91 coupons experienced necking which led to the rupture of the specimens in no time. Fig. 5- 20 shows necking phenomena on two ruptured coupons, $500^{\circ} \mathrm{C} / 280 \mathrm{MPa}$ and $600^{\circ} \mathrm{C} / 130 \mathrm{MPa}$. Although with necking the final elongation strains are similar for all the F91 crept coupons, e.g., as shown in Fig. 5- 20 for creep at $600^{\circ} \mathrm{C} / 130 \mathrm{MPa}$ and $500^{\circ} \mathrm{C} / 280 \mathrm{MPa}$, in which the final elongation strain are all over $20 \%$, the strain levels at which necking starts are different from examining the strain-time curves in Fig. 5- 21. Necking occurs at a time after $90 \%$ of TTR and by this time creep at $600^{\circ} \mathrm{C} / 130 \mathrm{MPa}$ has $6.15 \%$ strain, but at $500^{\circ} \mathrm{C} / 280 \mathrm{MPa}$ the critical creep strain is only $2.25 \%$. Such observations evidently demonstrate that F91 has a brittle-to-ductile transformation with increasing temperature before necking takes place. Therefore, a critical failure strain, $\varepsilon_{\mathrm{cr}}$, is defined to be at $90 \%$-TTR. Table 5- 8 summarizes $\varepsilon_{\text {cr }}$ at $90 \%$-TTR of F91 ruptured coupons at various temperatures. For example, when the strain of a coupon reaches $6.65 \%$ at $600^{\circ} \mathrm{C}$, the coupon is considered failed. In the present research, the same trend of $\varepsilon_{\mathrm{cr}}$ for F91 is assumed to be true for all Grade 91 steels. Therefore, the creep failure criteria for Grade 91 can be assumed as

$>\varepsilon_{c r}=2-3 \%$ over the temperature range of $450-500^{\circ} \mathrm{C}$.

$\varepsilon_{c r}=6-7 \%$, for the temperature above $500^{\circ} \mathrm{C}$. 


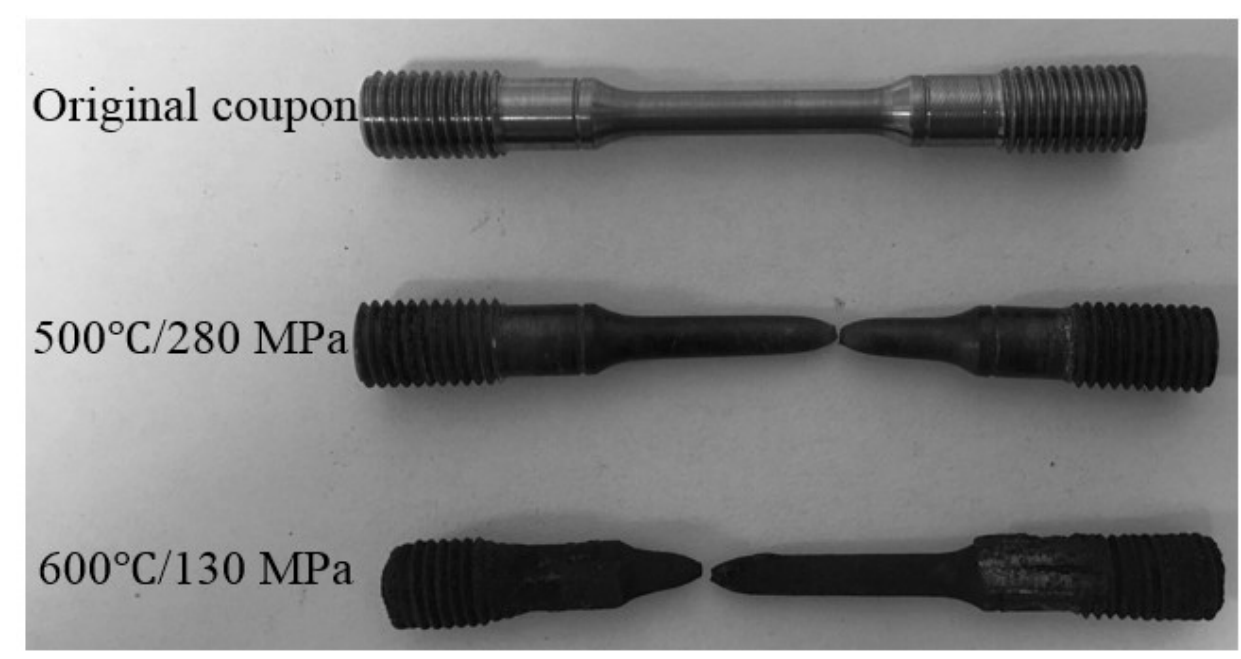

Fig. 5- 20. Ruptured F91 coupons show pronounced necking behavior.

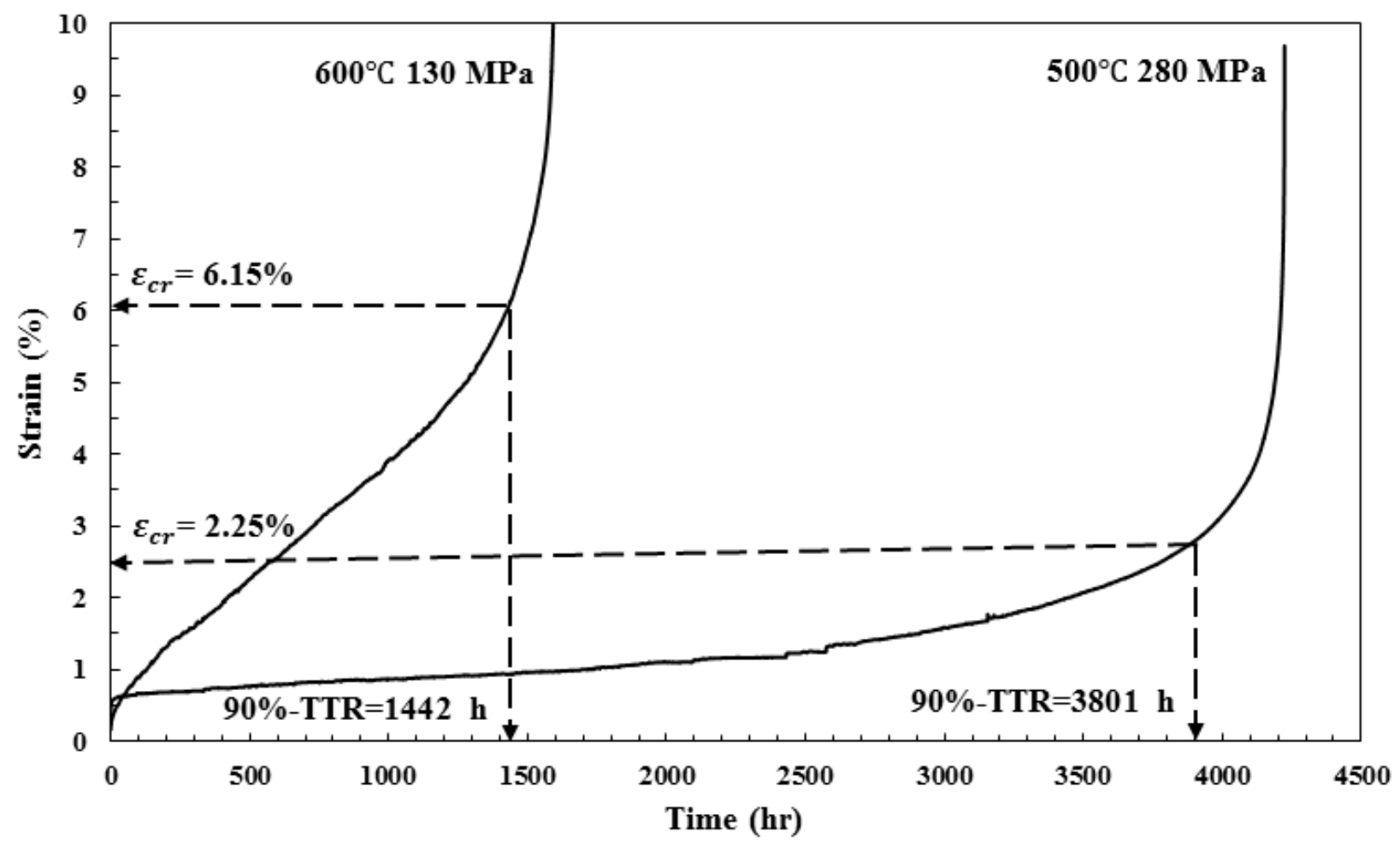

Fig. 5- 21. 90\%-TTR associated with strain. 
Table 5- 8 Critical strains at 90\%-TTR for F91 steel

\begin{tabular}{cccccc}
\hline Temp & Stress & TTR & $90 \%$-TTR & Strain at 90\%-TTR & Average $\varepsilon_{c r}$ \\
\hline${ }^{\circ} \mathrm{C}$ & $\mathrm{MPa}$ & $\mathrm{hr}$ & $\mathrm{hr}$ & $\%$ & $\%$ \\
\hline \multirow{3}{*}{500} & 320 & 2142.5 & 1928.25 & 2.05 & \\
& 300 & 3503.7 & 3153.33 & 2.00 & 2.10 \\
& 280 & 4223.8 & 3801.42 & 2.25 & \\
\hline \multirow{3}{*}{550} & 260 & 81.3 & 73.17 & 7.15 & \multirow{2}{*}{6.00} \\
& 240 & 305.0 & 274.5 & 5.46 & \\
& 220 & 891.4 & 802.26 & 5.38 & 6.65 \\
6 & 160 & 180.6 & 162.54 & 8.40 & \\
600 & 140 & 833.6 & 750.24 & 5.40 & 6.85 \\
& 130 & 1602.0 & 1441.8 & 6.15 & \\
\hline \multirow{3}{*}{650} & 110 & 78.8 & 70.92 & 7.83 & \\
& 100 & 244.8 & 220.32 & 6.45 & \\
& 80 & 873.4 & 786.06 & 6.26 & \\
\hline
\end{tabular}

As standardized by ASME Boiler and Pressure Vessel Code, Section III Subsection NH (ASME BPVC-III-NH-2015), three criteria are recommended to determine Grade 91 steel allowable stress: (1) the average strength for $1 \%$ total strain for time duration up to 600,000 hours; (2) $80 \%$ of the minimum strength for tertiary creep for time duration up to 600,000 hours; (3) $67 \%$ of the minimum rupture strength for time duration up to 600,000 hours $\left[{ }^{128},{ }^{129}\right]$. The allowable stresses of three forms of Grade 91 steels determined based on the first criterion are given in Table 5- $9\left[{ }^{125},{ }^{130}\right]$. In the present study, the first criterion is also used to compare the predicted values with the reported data.

Table 5- 9 Allowable stresses of Grade 91 steels $\left[{ }^{125},{ }^{130}\right]$

\begin{tabular}{cccccc}
\hline \multirow{2}{*}{ Product form } & \multicolumn{5}{c}{ Allowable stress (MPa) } \\
\cline { 2 - 6 } & $550^{\circ} \mathrm{C}$ & $575^{\circ} \mathrm{C}$ & $600^{\circ} \mathrm{C}$ & $625^{\circ} \mathrm{C}$ & $650^{\circ} \mathrm{C}$ \\
\hline Pipe & 94 & 81 & 63 & 45 & 29 \\
\hline Plate & 94 & 73 & 53 & 36 & 21 \\
\hline Tube & 94 & 77 & 56 & 39 & 25 \\
\hline
\end{tabular}


The life prediction procedures are summarized as follows:

1. Use the $\beta$ and $H$ values of F91 steel in Eq. (5-1) for all Grade 91 steels.

2. Use the mechanism parameters in Table 5- 5 to obtain $M^{\prime}$ and $k$ for particular NIMS Grade 91 steel.

3. Calculate TTR with the $\varepsilon_{c r}$ value pre-defined for the temperature condition using Eq. (5-1).

4. Generate stress-TTR diagrams to compare the predicted values with the experimental data.

5. Predict allowable stress at elevated temperatures for particular NIMS Grade 91. 


\subsubsection{Long-term creep lifetime prediction of NIMS Plate MgB}

The minimum creep rates of NIMS Plate MgB were collated with F91 short-term data to calibrate the DMTS model. Thus, the long-term lifetime prediction for $\mathrm{MgB}$ can be expected to be the same as F91. Following the life prediction procedures discussed above, the predicted lives of MgB are summarized in Table 5-10. Experimental TTR is taken $10 \%$ off to satisfy the pre-defined critical strains. Predicted $90 \%$ lifetime is statistically evaluated by coefficient of correlations $\left(R^{2}\right)$ and hypothesis testing ( $P$-value). $R^{2}$ is a statistic value between 0 and 1 , which provides a measurement of how well the model replicates the experimental observation. The closer the value to 1 , the more accurate the model prediction is. $P$-value is widely used in the context of null hypothesis testing in order to determine the significance of the model. A small $P$-value, typically $\ll 0.05$, indicates strong evidence against the null hypothesis; $\geq 0.05$ indicates week evidence against the null hypothesis, i.e., fail to reject the null hypothesis. In the present model prediction, $P$-value $\ll 0.05$ means good prediction, $P$-value close to 0.05 or $\geq 0.05$ indicates statistically insufficient prediction.

The predicted creep lives of $\mathrm{MgB}$ have an average $R^{2}=0.91$ compared to the experimental data, and $P$-value $\ll 0.05$ at all temperatures, which indicates that the model prediction is statistically successful. Fig. 5- 22 illustrates the predicted stress-TTR results along with the experimental data. The allowable stresses can be estimated by insert $\varepsilon_{c r}=1 \%$ in Eq. (5-1), which are also listed in Table 5- 10. From Fig. 5- 22, life prediction results fall shorter than the experimental data for temperatures below $500^{\circ} \mathrm{C}$, which indicates that the model creep rates for mechanism IDG are under-estimated for $\mathrm{MgB}$. At temperatures above $500^{\circ} \mathrm{C}$, TTR values are overestimated after $10^{4}$ hours, resulting in over-estimated allowable stresses. For example, at $550^{\circ} \mathrm{C} / 130$ MPa, the experimental $90 \%$ TTR is $87,884.4$ hours, compared to the predicted value of 352,470 
hours at the same condition, which leads the allowable stress to $99 \mathrm{MPa}$, higher than the reported $94 \mathrm{MPa}$. Possible reasons for this over-estimation may be oxidation effect which is accumulated during high-temperature creep, and also microstructural degradation such as the appearance of Laves phase in creep process. These two factors will be addressed in Chapter 6 and Chapter 7 in detail. 
Table 5- 10 Summary of creep Life prediction of NIMS Plate MgB

\begin{tabular}{|c|c|c|c|c|c|c|c|c|}
\hline Temp & Stress & $\varepsilon_{t r}^{P}$ & $\varepsilon_{c r}$ & $\begin{array}{l}90 \%- \\
\text { TTR }\end{array}$ & $\begin{array}{l}\text { Predicted } \\
\text { life }\end{array}$ & $\begin{array}{c}\text { Predicted } \\
\text { allowable } \\
\text { stress }\end{array}$ & $\begin{array}{l}\text { Coefficient } \\
\text { of } \\
\text { correlation }\end{array}$ & $\begin{array}{l}\text { Statistical } \\
\text { hypothesis } \\
\text { testing }\end{array}$ \\
\hline${ }^{\circ} \mathrm{C}$ & $\mathrm{MPa}$ & & $\%$ & $\mathrm{hr}$ & $\mathrm{hr}$ & $\mathrm{MPa}$ & $R^{2}$ & $P$-value \\
\hline \multirow{7}{*}{450} & 420 & $6.52 \mathrm{E}-03$ & & 271.9 & 130 & \multirow{7}{*}{268} & \multirow{7}{*}{0.88} & \multirow{7}{*}{$1.89 \mathrm{E}-03$} \\
\hline & 400 & $6.21 \mathrm{E}-03$ & & 701.6 & 499 & & & \\
\hline & 390 & $6.05 \mathrm{E}-03$ & & 6324.8 & 985 & & & \\
\hline & 380 & $5.90 \mathrm{E}-03$ & 2.10 & 14923.5 & 1946 & & & \\
\hline & 370 & $5.74 \mathrm{E}-03$ & & 8243.0 & 3838 & & & \\
\hline & 360 & $5.59 \mathrm{E}-03$ & & 21062.7 & 7519 & & & \\
\hline & 340 & $5.28 \mathrm{E}-03$ & & 40202.5 & 27886 & & & \\
\hline \multirow{7}{*}{500} & 320 & $6.68 \mathrm{E}-03$ & & 496.4 & 197 & \multirow{7}{*}{186} & \multirow{7}{*}{0.98} & \multirow{7}{*}{$1.13 \mathrm{E}-05$} \\
\hline & 310 & $6.47 \mathrm{E}-03$ & & 1869.3 & 414 & & & \\
\hline & 300 & $6.26 \mathrm{E}-03$ & & 3107.3 & 859 & & & \\
\hline & 280 & $5.84 \mathrm{E}-03$ & 2.10 & 6256.3 & 3478 & & & \\
\hline & 270 & $5.63 \mathrm{E}-03$ & & 5503.8 & 6834 & & & \\
\hline & 260 & $5.43 \mathrm{E}-03$ & & 21996.4 & 13295 & & & \\
\hline & 240 & $5.01 \mathrm{E}-03$ & & 59006.2 & 49689 & & & \\
\hline \multirow{7}{*}{550} & 240 & $5.74 \mathrm{E}-03$ & & 142.8 & 147 & \multirow{7}{*}{99} & \multirow{7}{*}{0.92} & \multirow{7}{*}{$6.14 \mathrm{E}-04$} \\
\hline & 220 & $5.26 \mathrm{E}-03$ & & 1754.9 & 749 & & & \\
\hline & 200 & $4.78 \mathrm{E}-03$ & & 3217.0 & 3539 & & & \\
\hline & 190 & 4.54E-03 & 6.00 & 10215.5 & 7535 & & & \\
\hline & 180 & $4.31 \mathrm{E}-03$ & & 13332.9 & 15708 & & & \\
\hline & 160 & $3.83 \mathrm{E}-03$ & & 40938.8 & 61580 & & & \\
\hline & 130 & $3.11 \mathrm{E}-03$ & & 87884.4 & 352470 & & & \\
\hline \multirow{8}{*}{600} & 160 & $6.20 \mathrm{E}-03$ & \multirow{8}{*}{6.65} & 159.8 & 88 & \multirow{8}{*}{44} & \multirow{8}{*}{0.88} & \multirow{8}{*}{$5.42 \mathrm{E}-04$} \\
\hline & 140 & $5.42 \mathrm{E}-03$ & & 758.4 & 570 & & & \\
\hline & 130 & $5.04 \mathrm{E}-03$ & & 2511.5 & 1320 & & & \\
\hline & 120 & $4.65 \mathrm{E}-03$ & & 5826.3 & 2831 & & & \\
\hline & 110 & $4.26 \mathrm{E}-03$ & & 9593.6 & 5689 & & & \\
\hline & 100 & $3.87 \mathrm{E}-03$ & & 14166.1 & 11057 & & & \\
\hline & 90 & $3.49 \mathrm{E}-03$ & & 32429.1 & 21696 & & & \\
\hline & 70 & $2.71 \mathrm{E}-03$ & & 56383.6 & 100375 & & & \\
\hline \multirow{7}{*}{650} & 100 & $1.26 \mathrm{E}-02$ & \multirow{7}{*}{6.85} & 147.1 & 191 & \multirow{7}{*}{22} & \multirow{7}{*}{0.89} & \multirow{7}{*}{$1.50 \mathrm{E}-03$} \\
\hline & 90 & $1.15 \mathrm{E}-02$ & & 564.1 & 469 & & & \\
\hline & 80 & $1.03 \mathrm{E}-02$ & & 1683.7 & 1073 & & & \\
\hline & 70 & $9.18 \mathrm{E}-03$ & & 2375.1 & 2510 & & & \\
\hline & 60 & 8.03E-03 & & 5922.0 & 6464 & & & \\
\hline & 40 & $6.88 \mathrm{E}-03$ & & 36446.3 & 75424 & & & \\
\hline & 30 & $4.59 \mathrm{E}-03$ & & 68350.5 & 428210 & & & \\
\hline
\end{tabular}




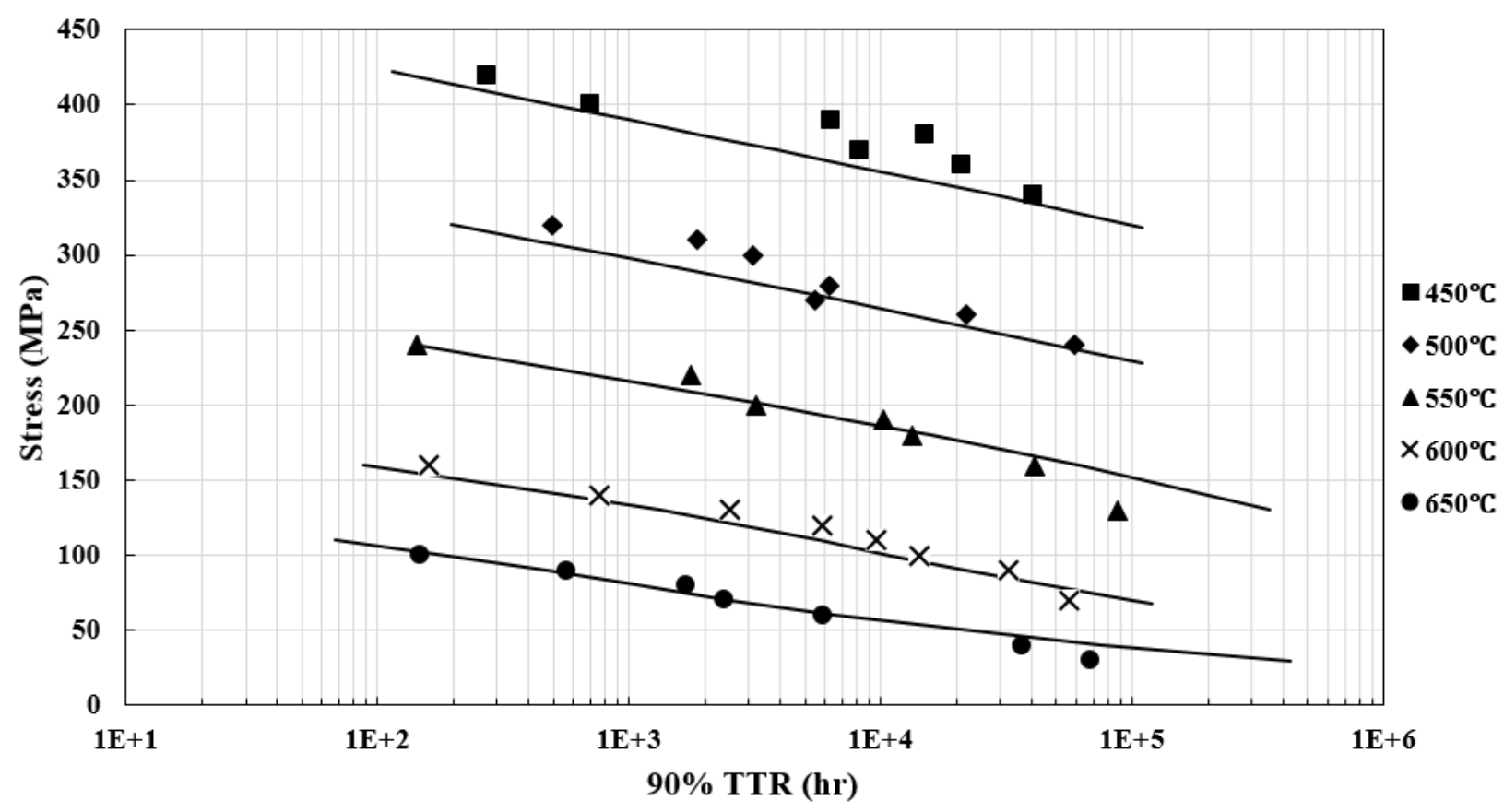

Fig. 5- 22. Creep life prediction of NIMS Plate MgB. 


\subsubsection{Long-term creep lifetime prediction of various NIMS products}

To test the applicability of the DMTS model further, three additional Grade 91 steels are selected to follow the same life prediction procedures. They are NIMS Plate MgD, Tube MGD, and Pipe MGQ.

\subsubsection{NIMS Plate MgD}

Another NIMS Plate, $\mathrm{MgD}$, is selected due to its different heat treatment history from $\mathrm{MgB}$. Compared to $\mathrm{MgB}$, which had a $770^{\circ} \mathrm{C}$ tempering for 1 hour followed by additional 1 hour stress relieving at $740^{\circ} \mathrm{C}, \mathrm{MgD}$ had a slightly higher tempering temperature of $780^{\circ} \mathrm{C}$ for 30 minutes but without stress relieving treatment. The model parameters reveal the effects of different heat treatment history, as shown in Table 5- 5, MgD does not show significant IDG mechanism which will affect the creep mainly at low temperature $\left(\leq 550^{\circ} \mathrm{C}\right)$ with high stress $(\geq 0.65)$. The absence of IDG may indicate that $\mathrm{MgD}$ has a longer creep life than $\mathrm{MgB}$ under specified conditions. For example, at $500^{\circ} \mathrm{C} / 270 \mathrm{MPa}, \mathrm{MgB}$ has a significantly shorter life than $\mathrm{MgD}, 5,503$ versus 15,779 hours; at $550^{\circ} \mathrm{C} / 180 \mathrm{MPa}, \mathrm{MgB}$ has creep life of 13,333 hours, and $\mathrm{MgD}$ has creep life of 24,010 hours.

The predicted $\mathrm{MgD}$ creep lives are summarized in Table 5- 11 for temperatures from $500^{\circ} \mathrm{C}$ to $650^{\circ} \mathrm{C}$. Statistical evaluation, $R^{2} \approx 1.00$, shows that the predicted lives have a good correlation at all temperatures; the $P$-values are all far less than the critical threshold 0.05. Fig. 5- 23 shows the life predictions for $\mathrm{MgD}$ in a stress-TTR diagram. In general, the model provides satisfactory life prediction for Plate $\mathrm{MgD}$. 
Table 5- 11 Summary of creep life prediction of NIMS Plate MgD

\begin{tabular}{|c|c|c|c|c|c|c|c|c|}
\hline Temp & Stress & $\varepsilon_{t r}^{P}$ & $\varepsilon_{c r}$ & $\begin{array}{c}90 \%- \\
\text { TTR }\end{array}$ & $\begin{array}{l}\text { Predicted } \\
\text { life }\end{array}$ & $\begin{array}{l}\text { Predicted } \\
\text { allowable } \\
\text { stress }\end{array}$ & $\begin{array}{l}\text { Coefficient } \\
\text { of } \\
\text { correlation }\end{array}$ & $\begin{array}{l}\text { Statistical } \\
\text { hypothesis } \\
\text { testing }\end{array}$ \\
\hline${ }^{\circ} \mathrm{C}$ & $\mathrm{MPa}$ & & $\%$ & $\mathrm{hr}$ & $\mathrm{hr}$ & $\mathrm{MPa}$ & $R^{2}$ & $P$-value \\
\hline \multirow{5}{*}{500} & 320 & $6.68 \mathrm{E}-03$ & & 1001.0 & 958 & \multirow{5}{*}{163} & \multirow{5}{*}{1.00} & \multirow{5}{*}{$3.71 \mathrm{E}-05$} \\
\hline & 310 & $6.47 \mathrm{E}-03$ & & 1674.2 & 1577 & & & \\
\hline & 300 & $6.26 \mathrm{E}-03$ & 6 & 2528.2 & 2612 & & & \\
\hline & 290 & $6.05 \mathrm{E}-03$ & & 5349.1 & 4344 & & & \\
\hline & 270 & $5.63 \mathrm{E}-03$ & & 15779.3 & 11969 & & & \\
\hline \multirow{5}{*}{550} & 240 & $5.74 \mathrm{E}-03$ & & 447.2 & 353 & \multirow{5}{*}{92} & \multirow{5}{*}{0.99} & \multirow{5}{*}{$1.79 \mathrm{E}-04$} \\
\hline & 220 & $5.26 \mathrm{E}-03$ & & 1572.8 & 1300 & & & \\
\hline & 200 & $4.78 \mathrm{E}-03$ & 6 & 7771.5 & 4663 & & & \\
\hline & 180 & $4.31 \mathrm{E}-03$ & & 24010.2 & 15087 & & & \\
\hline & 170 & $4.07 \mathrm{E}-03$ & & 36545.9 & 25757 & & & \\
\hline \multirow{5}{*}{600} & 160 & $6.20 \mathrm{E}-03$ & & 551.3 & 487 & \multirow{5}{*}{48} & \multirow{5}{*}{0.98} & \multirow{5}{*}{$1.18 \mathrm{E}-03$} \\
\hline & 140 & $5.42 \mathrm{E}-03$ & & 2698.9 & 1975 & & & \\
\hline & 120 & $4.65 \mathrm{E}-03$ & 7 & 8295.8 & 6558 & & & \\
\hline & 110 & $4.26 \mathrm{E}-03$ & & 15078.5 & 11657 & & & \\
\hline & 100 & $3.87 \mathrm{E}-03$ & & 35830.0 & 21173 & & & \\
\hline \multirow{4}{*}{625} & 140 & 7.92E-03 & & 236.0 & 220 & \multirow{4}{*}{36} & \multirow{4}{*}{0.98} & \multirow{4}{*}{$1.06 \mathrm{E}-02$} \\
\hline & 120 & $6.79 \mathrm{E}-03$ & & 1302.7 & 1172 & & & \\
\hline & 100 & $5.65 \mathrm{E}-03$ & 7 & 5914.8 & 4646 & & & \\
\hline & 90 & $5.09 \mathrm{E}-03$ & & 16142.2 & 9119 & & & \\
\hline \multirow{4}{*}{650} & 120 & $1.38 \mathrm{E}-02$ & & 110.5 & 83 & \multirow{4}{*}{25} & \multirow{4}{*}{1.00} & \multirow{4}{*}{$1.20 \mathrm{E}-03$} \\
\hline & 100 & $1.15 \mathrm{E}-02$ & 7 & 645.6 & 644 & & & \\
\hline & 80 & $9.18 \mathrm{E}-03$ & 1 & 3077.1 & 3323 & & & \\
\hline & 70 & $8.03 \mathrm{E}-03$ & & 6376.2 & 7685 & & & \\
\hline
\end{tabular}




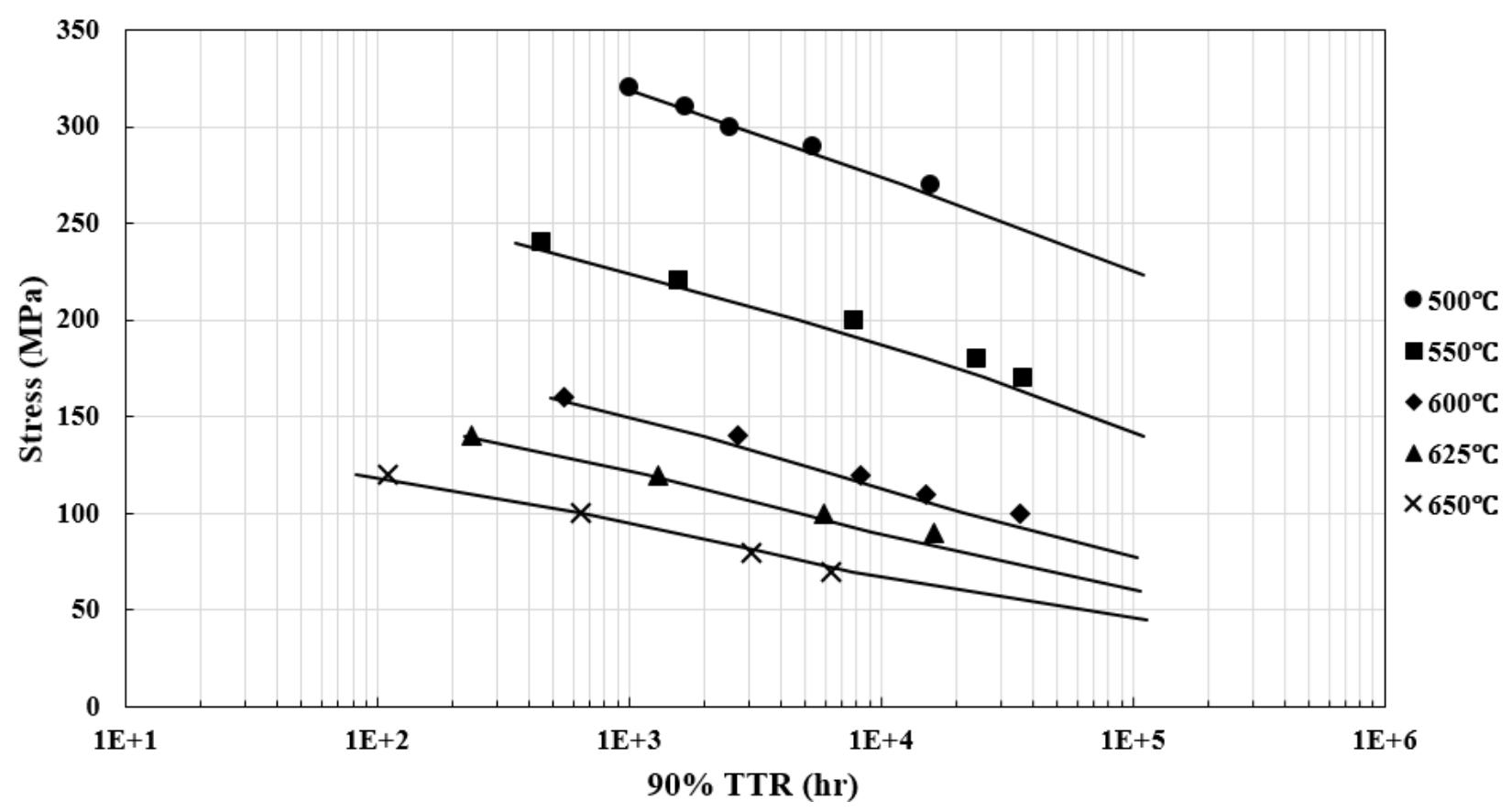

Fig. 5- 23. Creep life prediction of NIMS Plate MgD. 


\subsubsection{NIMS Tube MGD}

NIMS Tube MGD is chosen from the NIMS Tube products to assess the DMTS model. Tube MGD was manufactured through hot extrusion and cold drawing. MGD model parameters in Table 5- 5 show smaller power exponents and activation energies for GBS and IDG than NIMS plate products, while these mechanisms have the most effect on low temperature and high stress creep. Again, taking a low-temperature/high-stress creep test as an example, $500^{\circ} \mathrm{C} / 270 \mathrm{MPa}$, Tube MGD has 32,739 hours compared to 15,779 hours of Plate MgD. The model parameters corroborate this evidence.

MGD life prediction results are summarised in Table 5- 12. The predicted lives are tested with $R^{2}$ and $P$-value. The $R^{2}$ values, from $550^{\circ} \mathrm{C}$ to $700^{\circ} \mathrm{C}$, are all closed to 1 , indicating reliable model prediction. $P$-values are far less than 0.05 at all temperatures. Fig. 5- 24 illustrates stressTTR for MGD along with the experimental data. Same as Plate MgB, life predictions are over-

estimated after $10^{4}$ hours, which indicates that microstructure and environmental factors should be taken into account in the DMTS model, but in general, the DMTS model shows promising applicability for NIMS Tube MGD. 
Table 5- 12 Summary of creep life prediction results of NIMS Tube MGD

\begin{tabular}{|c|c|c|c|c|c|c|c|c|}
\hline Temp & Stress & $\varepsilon_{t r}^{P}$ & $\varepsilon_{c r}$ & $\begin{array}{l}90 \%- \\
\text { TTR }\end{array}$ & $\begin{array}{l}\text { Predicted } \\
\text { life }\end{array}$ & $\begin{array}{l}\text { Predicted } \\
\text { allowable } \\
\text { stress }\end{array}$ & $\begin{array}{l}\text { Coefficient } \\
\text { of } \\
\text { correlation }\end{array}$ & $\begin{array}{l}\text { Statistical } \\
\text { hypothesis } \\
\text { testing }\end{array}$ \\
\hline${ }^{\circ} \mathrm{C}$ & $\mathrm{MPa}$ & & $\%$ & $\mathrm{hr}$ & $\mathrm{hr}$ & $\mathrm{MPa}$ & $R^{2}$ & $P$-value \\
\hline \multirow{6}{*}{500} & 360 & $7.51 \mathrm{E}-03$ & & 114.9 & 118 & \multirow{6}{*}{185} & \multirow{6}{*}{0.99} & \multirow{6}{*}{$2.70 \mathrm{E}-05$} \\
\hline & 340 & $7.10 \mathrm{E}-03$ & & 302.3 & 340 & & & \\
\hline & 320 & $6.68 \mathrm{E}-03$ & 2 & 1012.6 & 1026 & & & \\
\hline & 300 & $6.26 \mathrm{E}-03$ & 3 & 3847.9 & 3208 & & & \\
\hline & 290 & $6.05 \mathrm{E}-03$ & & 7675.6 & 5703 & & & \\
\hline & 270 & $5.63 \mathrm{E}-03$ & & 32739.1 & 17719 & & & \\
\hline \multirow{4}{*}{550} & 240 & $5.74 \mathrm{E}-03$ & & 498.0 & 410 & \multirow{4}{*}{140} & \multirow{4}{*}{0.98} & \multirow{4}{*}{$8.50 \mathrm{E}-03$} \\
\hline & 220 & $5.26 \mathrm{E}-03$ & 6 & 2095.7 & 1757 & & & \\
\hline & 200 & $4.78 \mathrm{E}-03$ & 6 & 12656.9 & 6933 & & & \\
\hline & 180 & $4.31 \mathrm{E}-03$ & & 30341.9 & 22918 & & & \\
\hline \multirow{4}{*}{575} & 160 & $5.15 \mathrm{E}-03$ & & 8520.2 & 6455 & \multirow{4}{*}{102} & \multirow{4}{*}{1.00} & \multirow{4}{*}{$2.44 \mathrm{E}-03$} \\
\hline & 150 & 4.83E-03 & 7 & 12552.1 & 11599 & & & \\
\hline & 140 & $4.51 \mathrm{E}-03$ & 1 & 20340.5 & 20140 & & & \\
\hline & 130 & $4.19 \mathrm{E}-03$ & & 30076.6 & 34659 & & & \\
\hline \multirow{6}{*}{600} & 160 & $6.20 \mathrm{E}-03$ & & 432.0 & 539 & \multirow{6}{*}{75} & \multirow{6}{*}{0.98} & \multirow{6}{*}{$1.63 \mathrm{E}-04$} \\
\hline & 140 & $5.42 \mathrm{E}-03$ & & 2347.9 & 2327 & & & \\
\hline & 120 & $4.65 \mathrm{E}-03$ & 7 & 7193.7 & 8007 & & & \\
\hline & 110 & 4.26E-03 & 1 & 12526.6 & 14784 & & & \\
\hline & 100 & $3.87 \mathrm{E}-03$ & & 23000.6 & 28299 & & & \\
\hline & 80 & $3.10 \mathrm{E}-03$ & & 62641.3 & 125858 & & & \\
\hline \multirow{4}{*}{625} & 140 & 7.92E-03 & & 130.1 & 175 & \multirow{4}{*}{55} & \multirow{4}{*}{1.00} & \multirow{4}{*}{ 4.45E-04 } \\
\hline & 120 & $6.79 \mathrm{E}-03$ & 7 & 557.9 & 1089 & & & \\
\hline & 100 & $5.65 \mathrm{E}-03$ & 1 & 3298.6 & 4731 & & & \\
\hline & 90 & $5.09 \mathrm{E}-03$ & & 6900.9 & 9871 & & & \\
\hline \multirow{4}{*}{650} & 110 & $1.26 \mathrm{E}-02$ & & 176.2 & 200 & \multirow{4}{*}{28} & \multirow{4}{*}{1.00} & \multirow{4}{*}{ 4.11E-04 } \\
\hline & 100 & $1.15 \mathrm{E}-02$ & 7 & 352.5 & 564 & & & \\
\hline & 80 & $9.18 \mathrm{E}-03$ & 1 & 1957.7 & 3276 & & & \\
\hline & 70 & $8.03 \mathrm{E}-03$ & & 4552.7 & 8244 & & & \\
\hline \multirow{3}{*}{700} & 60 & $1.97 \mathrm{E}-02$ & & 302.4 & 245 & \multirow{3}{*}{14} & \multirow{3}{*}{1.00} & \multirow{3}{*}{$1.49 \mathrm{E}-02$} \\
\hline & 50 & $1.64 \mathrm{E}-02$ & 7 & 826.7 & 894 & & & \\
\hline & 40 & $1.31 \mathrm{E}-02$ & & 3059.4 & 4131 & & & \\
\hline
\end{tabular}




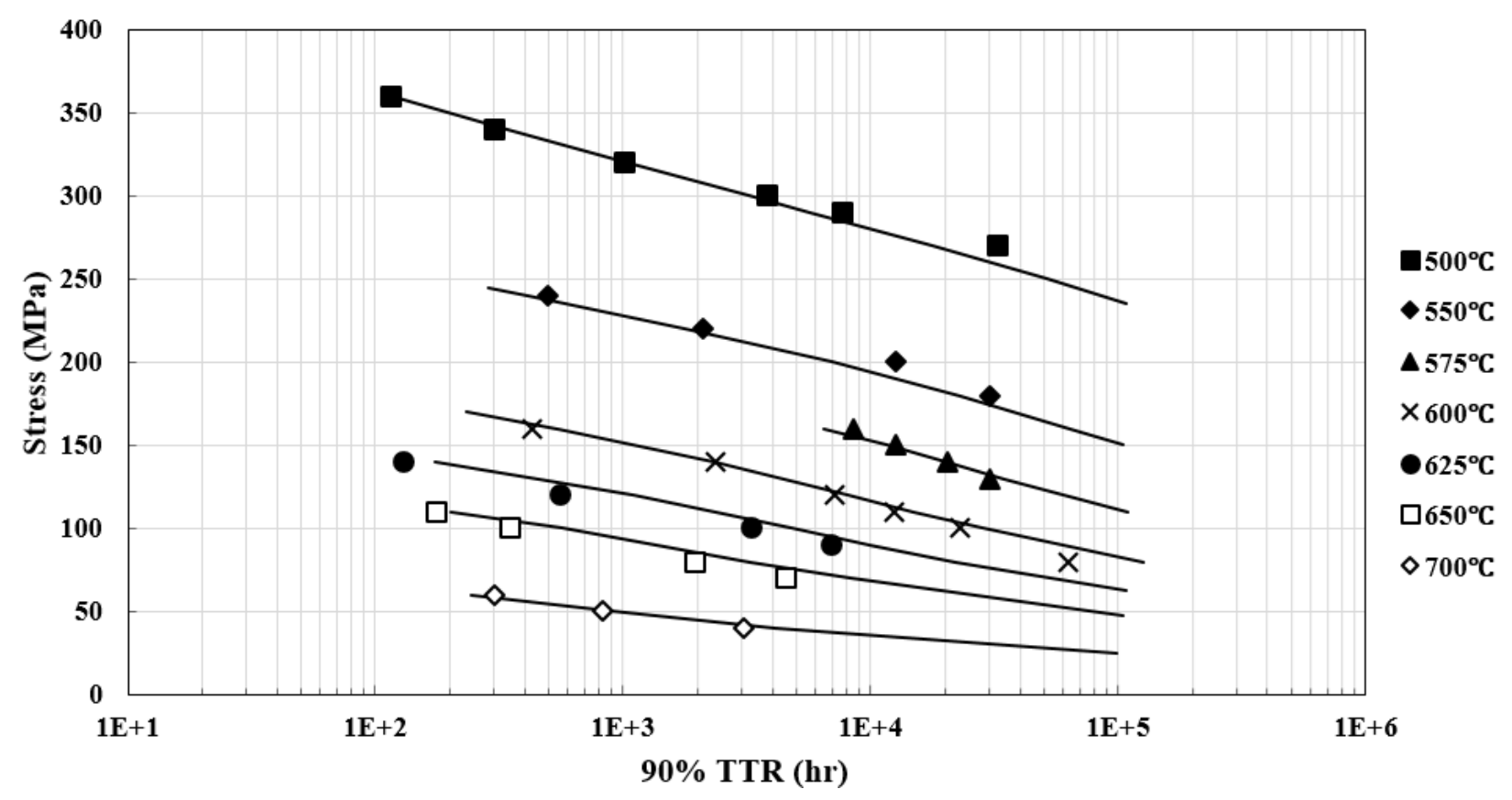

Fig. 5- 24. Creep life prediction of NIMS Tube MGD. 


\subsubsection{NIMS Pipe MGQ}

NIMS Pipe MGQ is a hot rolled product without additional stress relieving heat treatment. The model parameters in Table 5- 5 show that MGQ is similar to MgD in that both do not have IDG and they have similar TTR at $500^{\circ} \mathrm{C}$ and $550^{\circ} \mathrm{C}$. Table 5- 13 summarizes the life predictions for Pipe MGQ. $R^{2}$ values show good agreement between experimental and predicted lives at all temperatures. $P$-values at all temperatures are far less than 0.05 . Fig. 5 - 25 illustrates the life prediction of MGQ at different temperatures in a stress-TTR diagram. 
Table 5- 13 Summary of creep life prediction results of NIMS Pipe MGQ

\begin{tabular}{|c|c|c|c|c|c|c|c|c|}
\hline Temp & Stress & $\varepsilon_{t r}^{P}$ & $\varepsilon_{c r}$ & $\begin{array}{l}90 \%- \\
\text { TTR }\end{array}$ & $\begin{array}{l}\text { Predicted } \\
\text { life }\end{array}$ & $\begin{array}{c}\text { Predicted } \\
\text { allowable } \\
\text { stress }\end{array}$ & $\begin{array}{l}\text { Coefficient } \\
\text { of } \\
\text { correlation }\end{array}$ & $\begin{array}{l}\text { Statistical } \\
\text { hypothesis } \\
\text { testing }\end{array}$ \\
\hline${ }^{\circ} \mathrm{C}$ & $\mathrm{MPa}$ & & $\%$ & $\mathrm{hr}$ & $\mathrm{hr}$ & $\mathrm{MPa}$ & $R^{2}$ & $P$-value \\
\hline \multirow{5}{*}{500} & 320 & $6.68 \mathrm{E}-03$ & & 823.3 & 906 & \multirow{5}{*}{225} & \multirow{5}{*}{1.00} & \multirow{5}{*}{$9.11 \mathrm{E}-06$} \\
\hline & 310 & $6.47 \mathrm{E}-03$ & & 1639.6 & 1552 & & & \\
\hline & 300 & $6.26 \mathrm{E}-03$ & 3 & 2458.3 & 2650 & & & \\
\hline & 290 & $6.05 \mathrm{E}-03$ & & 4821.1 & 4579 & & & \\
\hline & 270 & $5.63 \mathrm{E}-03$ & & 14278.0 & 14093 & & & \\
\hline \multirow{4}{*}{550} & 240 & $5.74 \mathrm{E}-03$ & \multirow{4}{*}{6} & 251.1 & 393 & \multirow{4}{*}{107} & \multirow{4}{*}{1.00} & \multirow{4}{*}{$3.20 \mathrm{E}-04$} \\
\hline & 220 & $5.26 \mathrm{E}-03$ & & 1046.7 & 1559 & & & \\
\hline & 200 & $4.78 \mathrm{E}-03$ & & 4106.2 & 6442 & & & \\
\hline & 180 & $4.31 \mathrm{E}-03$ & & 18089.6 & 25545 & & & \\
\hline \multirow{3}{*}{575} & 160 & $5.15 \mathrm{E}-03$ & \multirow{3}{*}{7} & 5995.8 & 5050 & \multirow{3}{*}{73} & \multirow{3}{*}{1.00} & \multirow{3}{*}{$1.92 \mathrm{E}-02$} \\
\hline & 150 & $4.83 \mathrm{E}-03$ & & 11421.7 & 10768 & & & \\
\hline & 140 & $4.51 \mathrm{E}-03$ & & 23190.1 & 21739 & & & \\
\hline \multirow{5}{*}{600} & 160 & $6.20 \mathrm{E}-03$ & & 328.1 & 392 & \multirow{5}{*}{53} & \multirow{5}{*}{0.99} & \multirow{5}{*}{ 3.93E-04 } \\
\hline & 140 & $5.42 \mathrm{E}-03$ & & 2327.0 & 2271 & & & \\
\hline & 120 & $4.65 \mathrm{E}-03$ & 7 & 13829.9 & 10380 & & & \\
\hline & 110 & $4.26 \mathrm{E}-03$ & & 21770.2 & 20224 & & & \\
\hline & 100 & $3.87 \mathrm{E}-03$ & & 49969.2 & 38543 & & & \\
\hline \multirow{4}{*}{625} & 140 & 7.92E-03 & & 161.6 & 119 & \multirow{4}{*}{39} & \multirow{4}{*}{0.98} & \multirow{4}{*}{ 7.81E-03 } \\
\hline & 120 & 6.79E-03 & 7 & 867.6 & 1020 & & & \\
\hline & 100 & $5.65 \mathrm{E}-03$ & 1 & 4975.6 & 6322 & & & \\
\hline & 90 & $5.09 \mathrm{E}-03$ & & 14435.1 & 13701 & & & \\
\hline \multirow{4}{*}{650} & 120 & $1.38 \mathrm{E}-02$ & & 103.3 & 38 & \multirow{4}{*}{28} & \multirow{4}{*}{1.00} & \multirow{4}{*}{ 2.29E-03 } \\
\hline & 100 & $1.15 \mathrm{E}-02$ & 7 & 644.9 & 636 & & & \\
\hline & 80 & $9.18 \mathrm{E}-03$ & 1 & 2996.6 & 5033 & & & \\
\hline & 70 & 8.03E-03 & & 8359.7 & 12361 & & & \\
\hline
\end{tabular}




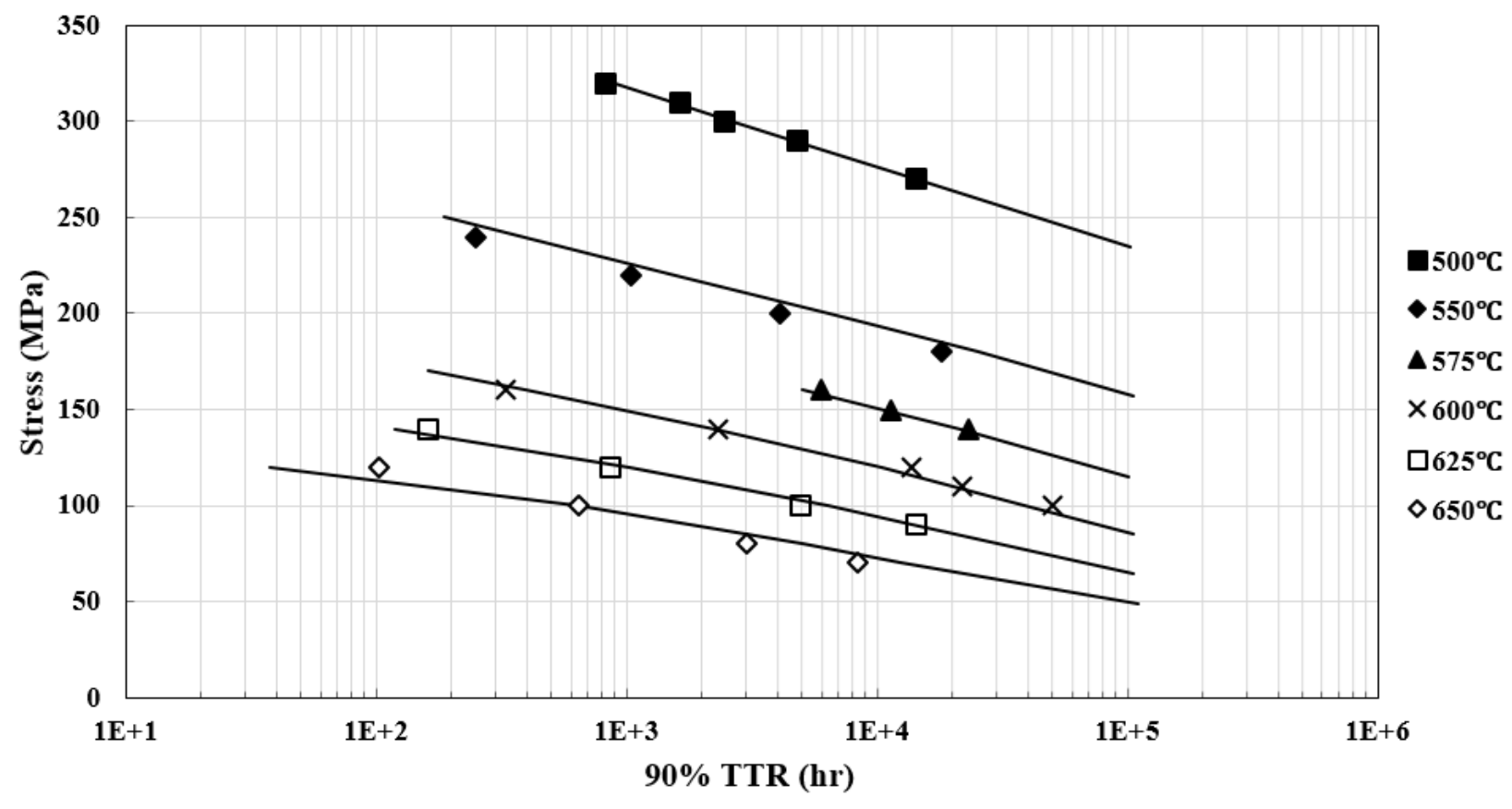

Fig. 5- 25. Creep life prediction of NIMS Pipe MGQ. 


\subsection{Summary of Model Validation}

Creep rate data mostly reported from NIMS testing on tubes, plates, and pipes of modified Grade 91, and from the present research, testing on forged modified Grade 91 (F91), are analyzed using the DMTS model based on the well-recognized deformation mechanisms such as IDG, IDC, and GBS. The model parameters are obtained through a best-fit scheme to the experimental data. By comparing the activation energies and power-exponent values for the identified mechanisms in these materials, the following conclusions can be derived:

- $\quad$ Comparing extruded (tubes) and hot-rolled (plates and pipes) modified Grade 91, the power exponent $p$ of GBS increases from 12 (for tubes) to 16 (for plates and pipe), while the power exponent $n$ of IDG increases from 18 (for tubes) to 26 (for plates). The forged modified Grade 91 (F91) has similar creep performance to plate $\mathrm{MgB}$. The activation energies in the hot-rolled plates tempered at a lower temperature of $760^{\circ} \mathrm{C}$ are larger than that of the extruded ones. These differences are perhaps due to the fact that the hot-rolled and forged microstructures are heavier "worked" with higher dislocation density than the extruded ones.

- $\quad$ On the other hand, the hot-rolling process followed by tempering at higher temperatures above $780^{\circ} \mathrm{C}$ tends to eliminate IDG of the plates in the tested stress range (or pushing it beyond this range). This is perhaps due to the fact that tempering at higher temperatures can relieve the martensitic laths to allow more inter-lath sliding or GBS.

- F91-model parameters obtained from experimental data of this study are collated with NIMS Plate MgB creep data. In general, the DMTS model is valid for a variety of modified Grade 91 products, exhibiting excellent agreement with the vast experimental data for steady-state creep rate. Furthermore, the DMTS model can predict the creep curves of 
modified Grade 91 steels having experienced similar thermo-mechanical processes. Because IDC, IDG, and GBS are competing (or overlapping) in nature, it is often difficult to delineate them in short-term creep tests, which may lead to errors in the present analyses. Therefore, more long-term creep test data are needed for further calibration of the proposed model.

From time-to-rupture prediction of various NIMS Grade 91 steels, the following conclusions can be obtained:

- Using short-term creep test data of F91 steel to determine the creep-curve parameters $H, \beta$ and $M$, as well as pre-defined failure strain $\varepsilon_{c r}$, long-term creep lives of the three forms of NIMS Grade 91 steels are predicted based on their own operating deformation mechanisms. In general, life predictions of these steels using the DMTS model are satisfactory as compared with experimental data with high $R^{2}$ values (very close to 1 ) and low $P$-values (much less than 0.05).

- Life predictions longer than $10^{4}$ hours are over-estimated for most steels, especially at higher temperatures. This indicates that in addition to GBS, IDC, and IDG deformation mechanisms, there are other life-limiting factors such as microstructural evolution and environment condition which may affect long-term creep life. Chapter 6 will discuss oxidation effects, and Chapter 7 addresses Laves phase effects on the long-term creep behavior of Grade 91 steels. 


\section{Chapter 6 Model Modification with Oxidation Effect}

\subsection{High-temperature Oxidation}

Under high-temperature creep test conditions in stagnant air, metals will oxidize, which would obviously have impacts on the creep strain and creep life of the materials. However, studies to quantify the oxidation effects on creep strain and creep life are very few, because vacuum creep tests are almost cost-prohibitive for long-term experiments such that oxidation-free creep data are rarely available for most materials. Therefore, most previous creep analyses were performed on creep data with the coupon-borne influence of oxidation. As discussed in Chapter 5, the creep lives of Grade 91 steels are over-estimated after $10^{4}$ hours by the DMTS model. Also, massive creep rupture life data generated by NIMS, as shown in Fig. 6- 1, suggest that there is a life breakdown phenomenon for Grade 91 steels, in particular, at high temperatures $\left[{ }^{131},{ }^{132},{ }^{133}\right]$. The life breakdown from short-term creep test extrapolation indicates the existence of other life-limiting factors for long-term creep - oxidation can be one of them. This chapter attempts to evaluate the impact of oxidation on creep life breakdown, by incorporating the oxide growth into the DMTS model. First of all, a series of creep tests are conducted on MCrAlY-coated F91 coupons. Second, the DMTS model will be applied to the creep data of oxidation-free/coated F91 coupons. Finally, the modified DMTS model will be used to re-predict the long-term creep lives of NIMS Grade 91 steels. The results of this study have already been presented at conferences $\left[{ }^{134},{ }^{135}\right]$. 


\subsection{Oxide Scale Measurement and Modeling}

In the present study, severe oxidation was observed on uncoated F91 coupons under creep testing. Fig. 6- 2 shows the cross-section views of selected coupons after creep tests at temperatures from $500^{\circ} \mathrm{C}$ to $650^{\circ} \mathrm{C}$. The cross-sections were cut off from the gauge sections away from the necking region, such that they represent scenarios of F91 oxidation during stable creep deformation. Oxidation occurred all over the gauge section and became more and more severe as the testing temperature increased. However, because the oxides (mainly iron oxides with minor chromium oxides) were loose and brittle, most of the scales were spalled off during either creep testing or sectioning of the coupons. For examples, as seen in Fig. 6-1, a thin oxide layer could be observed on the surface of 500 and $550^{\circ} \mathrm{C}$-exposed coupons; a thicker oxide scale was observed on the $600^{\circ} \mathrm{C}$-exposed coupon; on the $650^{\circ} \mathrm{C}$-exposed coupon, most oxidation products spalled off, which resulted in an irregular-shaped surface layer, as opposed to the perfect circular cross-section of the coupons. Therefore, the effective way to quantify the oxidation is to subtract the remaining unoxidized area from the deformation-corrected coupon cross-section area. 

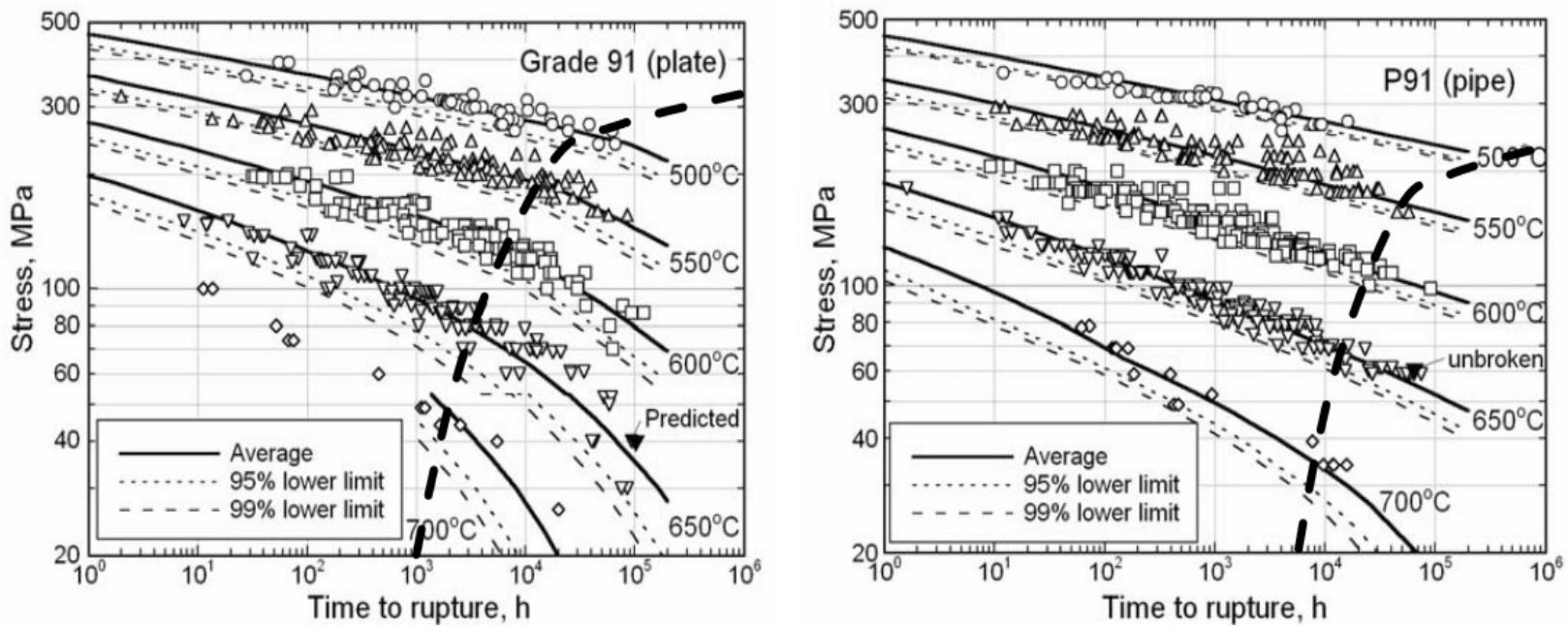

Fig. 6- 1. Bold dot-lines indicate the life breakdown of Grade 91 steels [ $\left.{ }^{131}\right]$.
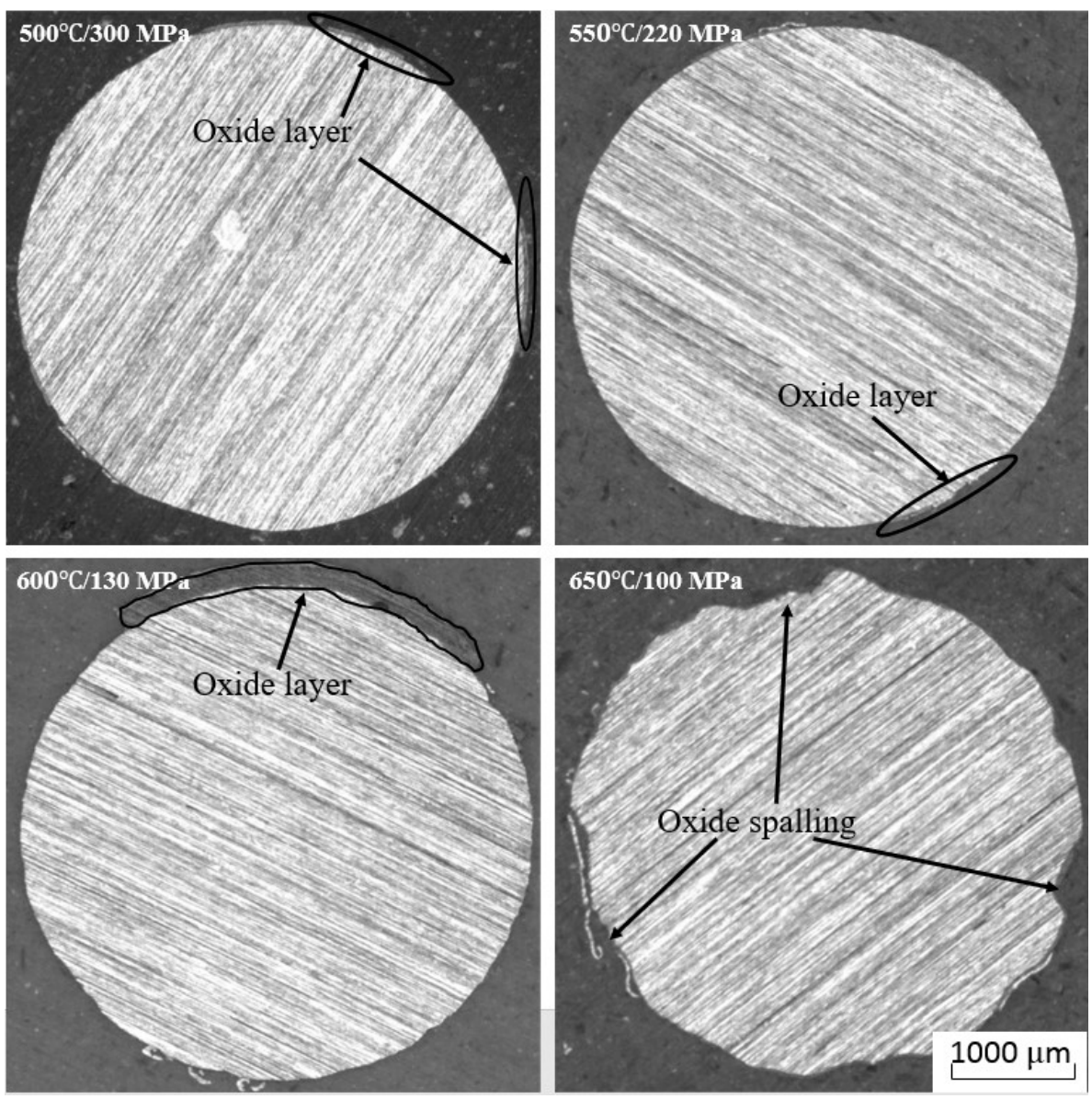

Fig. 6- 2. Optical microscope observations of cross-sections of ruptured uncoated F91 coupons showing oxide scale formation on the coupon surfaces. 
Using image processing softwares, Adobe Photoshop and ImageJ, the cross-section images in Fig. 6- 2 were analyzed to measure the remaining cross-section area for each coupon after the creep tests. Then the total loss is defined as the deformation-corrected original area subtracting the remaining unoxidized area. The nominal diameter of the coupon at rupture was then calculated from the measured cross-section area equivalent to a circular cross-section. The deformation effect on the cross-section deduction is corrected using Eq. (4-5), because creep elongation would lead to a reduced cross-section area, as $A=A_{0} /\left(1+\varepsilon_{c r}\right)$. Therefore,

$$
\text { Oxidation loss }=\text { Total loss }- \text { Elongation loss }
$$

where all terms are measured/calculated with the area in $\mu \mathrm{m}^{2}$, and then the diameters can be derived to calculate thickness loss $(\mu \mathrm{m})$. Fig. 6- 3 is a schematic drawing of a ruptured coupon cross-section. The shadowed area represents the remaining cross-section and the loss terms of Eq. (6-1) are indicated. Note that the cross-section measurement shall avoid the necking region.

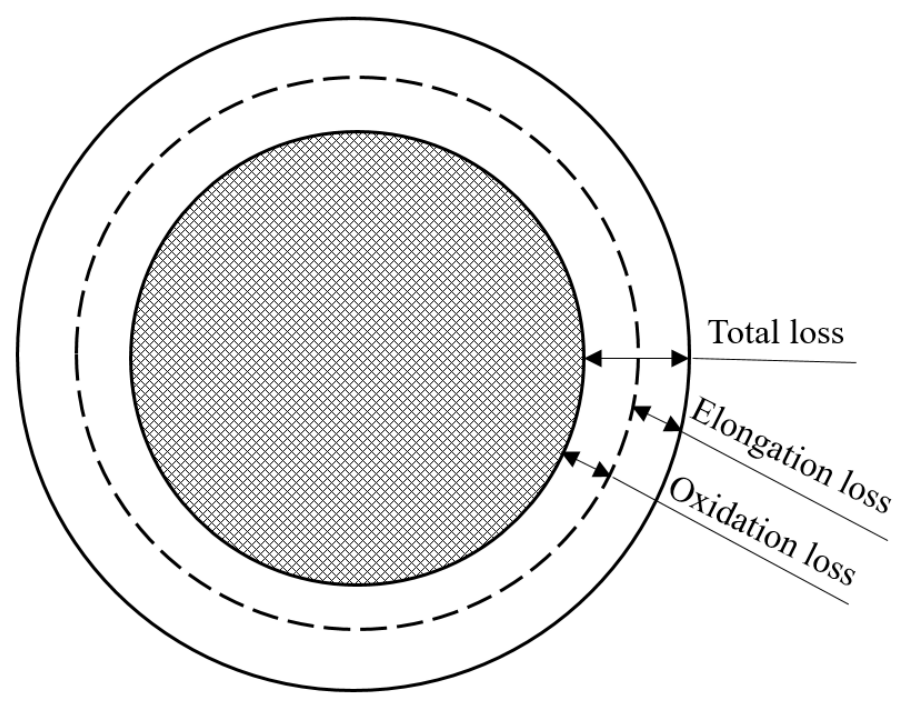

Fig. 6- 3. Schematic drawing of creep-ruptured coupon cross section. 
As discussed in Chapter 4, the parabolic oxidation law is often used to describe the oxidation behavior of metals, so that it is applied to the study of F91 steel. The first step is to determine the thickness of oxide layer of ruptured F91 coupons under various test conditions, from which the oxide rate coefficient $\left(K_{o x}\right)$ at a temperature under a stress is determined. Then, the average oxide rate coefficient $\left(K_{o x}\right)$ at each temperature is expressed as an Arrhenius-plot, from which the activation energy and proportional constant of $K_{o x}$ are determined (Fig. 6- 4). Note that in the above calculation, oxidation is assumed to have uniform scale formation around the coupon gauge section. Using Eq. (6-1), the oxidation losses are obataind and summarized in Table 6- 1. $K_{o x}$ values calculated using Eq. (4-18) are also reported in the table.

Table 6- 1 Summary of oxidation loss and oxide rate coefficient $K_{o x}$

\begin{tabular}{ccccccccc}
\hline Temp & Stress & TTR & $\begin{array}{c}\text { Nominal } \\
\text { diameter } \\
\text { at } \\
\text { rupture }\end{array}$ & $\begin{array}{c}\text { Total } \\
\text { loss }\end{array}$ & $\begin{array}{c}\text { Elongation } \\
\text { loss }\end{array}$ & $\begin{array}{c}\text { Oxidation } \\
\text { loss }\end{array}$ & $\begin{array}{c}K_{\text {ox }} \text { per } \\
\text { test }\end{array}$ & $\begin{array}{c}\text { Average } \\
K_{\text {ox }} \text { per } \\
\text { temperature }\end{array}$ \\
\hline${ }^{\circ} \mathrm{C}$ & $\mathrm{MPa}$ & $\mathrm{hr}$ & $\mu \mathrm{m}$ & $\mu \mathrm{m}$ & $\mu \mathrm{m}$ & $\mu \mathrm{m}$ & $\mu \mathrm{m}^{2} / \mathrm{hr}$ & $\mu \mathrm{m}^{2} / \mathrm{hr}$ \\
\hline \multirow{3}{*}{500} & 280 & 4223.9 & 3925.61 & 17.19 & 14.88 & 2.31 & $6.34 \mathrm{E}-04$ & \\
& 300 & 3503.7 & 3917.68 & 21.16 & 14.85 & 6.31 & $5.69 \mathrm{E}-03$ & $9.37 \mathrm{E}-03$ \\
& 320 & 2142.5 & 3911.03 & 24.48 & 14.82 & 9.67 & $2.18 \mathrm{E}-02$ & \\
\hline \multirow{3}{*}{550} & 220 & 891.4 & 3895.10 & 32.45 & 23.22 & 9.24 & $4.78 \mathrm{E}-02$ & \\
& 240 & 306 & 3893.18 & 33.41 & 24.62 & 8.79 & $1.26 \mathrm{E}-01$ & $1.96 \mathrm{E}-01$ \\
& 260 & 81.3 & 3894.72 & 32.64 & 24.45 & 8.19 & $4.13 \mathrm{E}-01$ & \\
\hline \multirow{3}{*}{600} & 130 & 1602 & 3752.34 & 103.83 & 63.17 & 40.66 & $5.16 \mathrm{E}-01$ & \\
& 140 & 833.6 & 3773.93 & 93.03 & 63.40 & 29.63 & $5.27 \mathrm{E}-01$ & $4.25 \mathrm{E}-01$ \\
& 160 & 180.6 & 3814.96 & 72.52 & 63.34 & 9.18 & $2.33 \mathrm{E}-01$ & \\
\hline \multirow{6}{*}{650} & 80 & 873.4 & 3792.31 & 83.85 & 68.12 & 15.72 & $1.41 \mathrm{E}-01$ & \\
& 100 & 244.8 & 3793.66 & 83.17 & 68.04 & 15.13 & $4.68 \mathrm{E}-01$ & $6.56 \mathrm{E}-01$ \\
& 110 & 78.8 & 3794.09 & 82.95 & 68.32 & 14.63 & $1.36 \mathrm{E}+00$ & \\
\hline
\end{tabular}

The average $K_{o x}$ at a temperature is assumed to obey the Arrhenius relationship, such that the temperture-dependent oxide rate coefficient for F91 steel is obtained according to Eq. (6-2), in unit of $\mu \mathrm{m}^{2} / \mathrm{hr}$. 


$$
K_{o x}=2.04 \times 10^{9} e^{-19698 / T}
$$

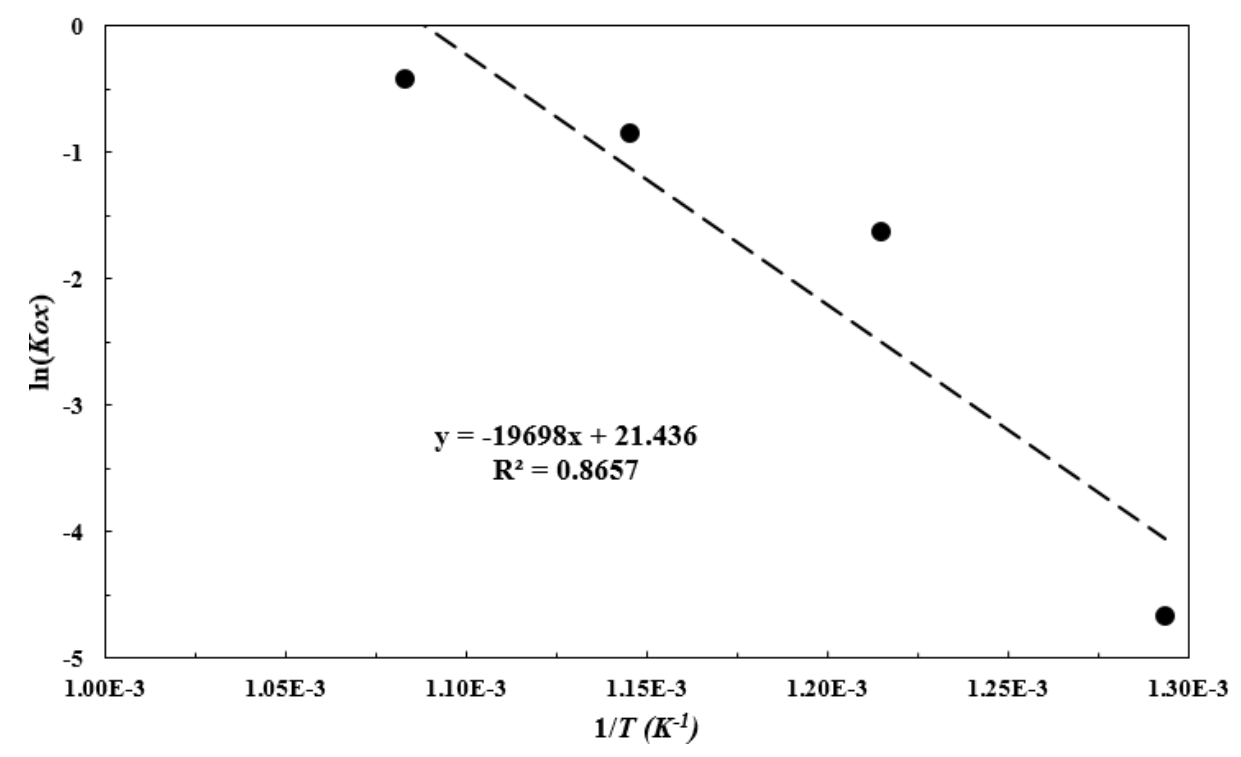

Fig. 6- 4. $K_{o x}$ Arrhenius-plot for activation energy and proportinal constant determination. 


\subsection{Creep Strain-time Behavior of Coated F91}

\subsubsection{Stress distribution in coated coupons}

MCrAlY-coated F91 coupon has a coating thickness about $280 \mu \mathrm{m}$, as shown in Fig. 3- 2. No coating spallation was observed at the gauge section on all the tested coupons, except the separation at the final necking period due to the high strain rate of the F91 substrate. However, the necking stage is only a very small portion of the entire lifetime as discussed in Chapter 5. Fig. 65(a) shows a ruptured coated-coupon after 1256.4 hours of creep, and (b) shows its longitudinal section indicating the coating layer well adhere to F91 substrate until necking. Also, there is no oxidation observed in all ruptured coupons.

Hence, the MCrAlY coating and F91 substrate together can be considered as a composite system to carry the total creep load during the creep test. To evaluate the stress distribution in such MCrAlY-F91 composite, the following assumptions are made:

$>$ The coating layer deforms compatibly with F91 substrate;

$>$ Stresses in the coating layer are distributed uniformly;

$>$ Stresses in the F91 substrate are distributed uniformly.

In this case, upon initial loading when deformation is purely elastic, the classical composite rule applies:

$$
F_{\text {app }}=F_{\text {steel }}+F_{\text {coating }}
$$

and

$$
\frac{\sigma_{\text {steel }}}{E_{\text {steel }}}=\frac{\sigma_{\text {coating }}}{E_{\text {coating }}}
$$


where $F_{\text {steel }}=\sigma_{\text {steel }} \cdot A_{\text {steel }}, F_{\text {coating }}=\sigma_{\text {coating }} \cdot A_{\text {coating }} ; E_{\text {steel }}$ and $E_{\text {coating }}$ are Young's modulus of F91 steel and coating material, respectively; and $F_{a p p}$ is the applied load.

From Eq. (6-3), the stresses in steel substrate and the coating layer are obtained, respectively:

$$
\begin{gathered}
\sigma_{\text {steel }}=\frac{E_{\text {steel }}}{E_{\text {steel }} \cdot A_{\text {steel }}+E_{\text {coating }} \cdot A_{\text {coating }}} \cdot F_{\text {app }} \\
\sigma_{\text {coating }}=\frac{E_{\text {coating }}}{E_{\text {steel }} \cdot A_{\text {steel }}+E_{\text {coating }} \cdot A_{\text {coating }}} \cdot F_{\text {app }}
\end{gathered}
$$

The Young's modulus of Grade 91 steels and MCrAlY coating at elevated temperatures can be found/extracted from the data reported in the literature $\left[{ }^{109},{ }^{1}\right]$. For $5 \mathrm{Cr}$ to $9 \mathrm{Cr}$ steels, $E_{\text {steel }}=$ 174 and $168 \mathrm{GPa}$ at $550^{\circ} \mathrm{C}$ and $600^{\circ} \mathrm{C}$, respectively. The Young's moduli of HVOF-MCrAlY coating are given in Fig. 6- 6, where $E_{\text {coating }}=66 \mathrm{GPa}$ at $550^{\circ} \mathrm{C}$ and $51 \mathrm{GPa}$ at $600^{\circ} \mathrm{C}$ are extrapolated from the curve by second-order polynomial regression $\left[{ }^{108},{ }^{109},{ }^{136}\right]$. The calculated $\sigma_{\text {steel }}$ and $\sigma_{\text {coating }}$ using Eq. (6-4) and Eq. (6-5) are reported in Table 6- 2. 


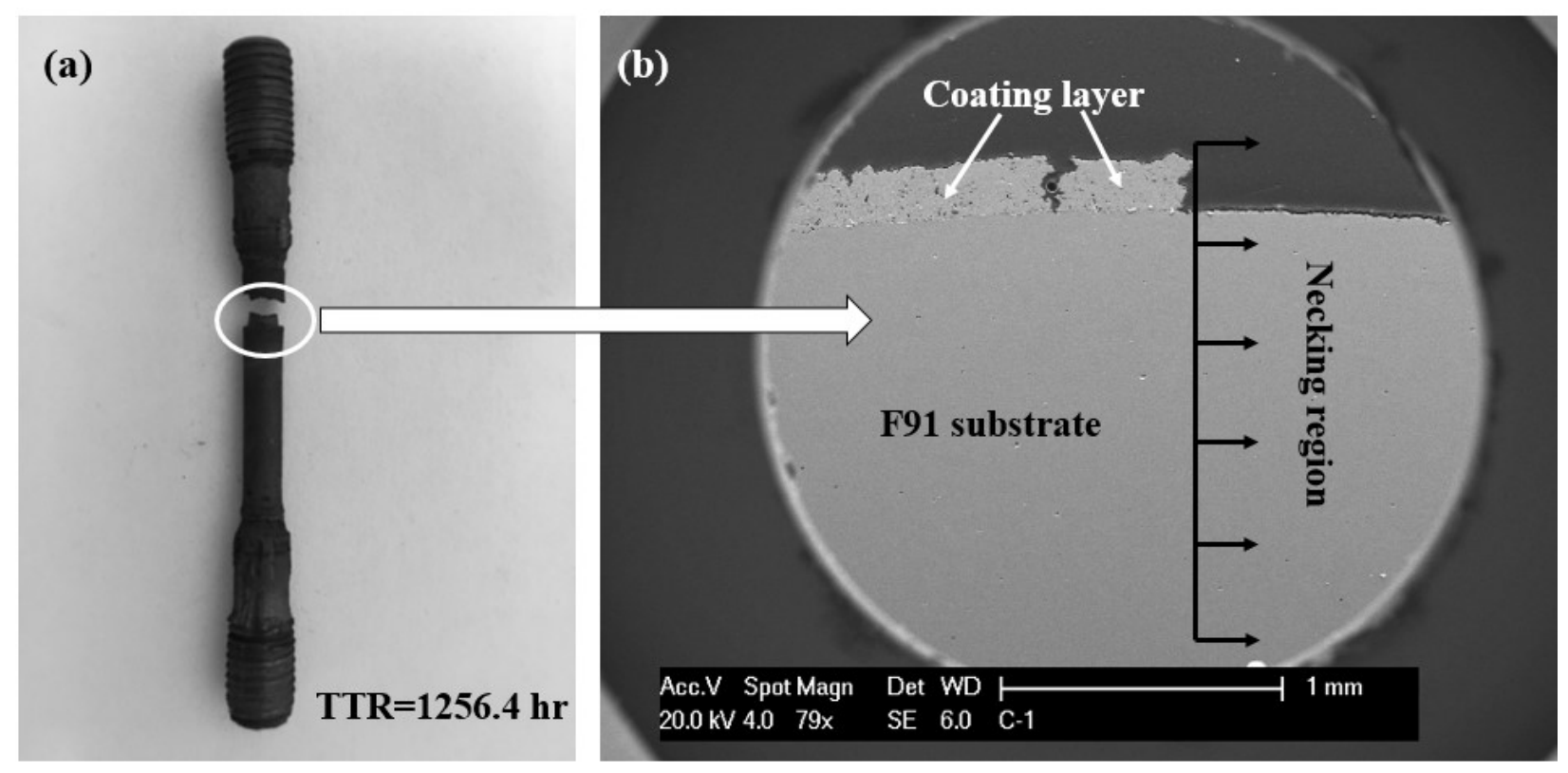

Fig. 6- 5. Coating adhesiveness analysis of a ruptured coated-coupon: (a) as-ruptured state;

(b) longitudinal cut.

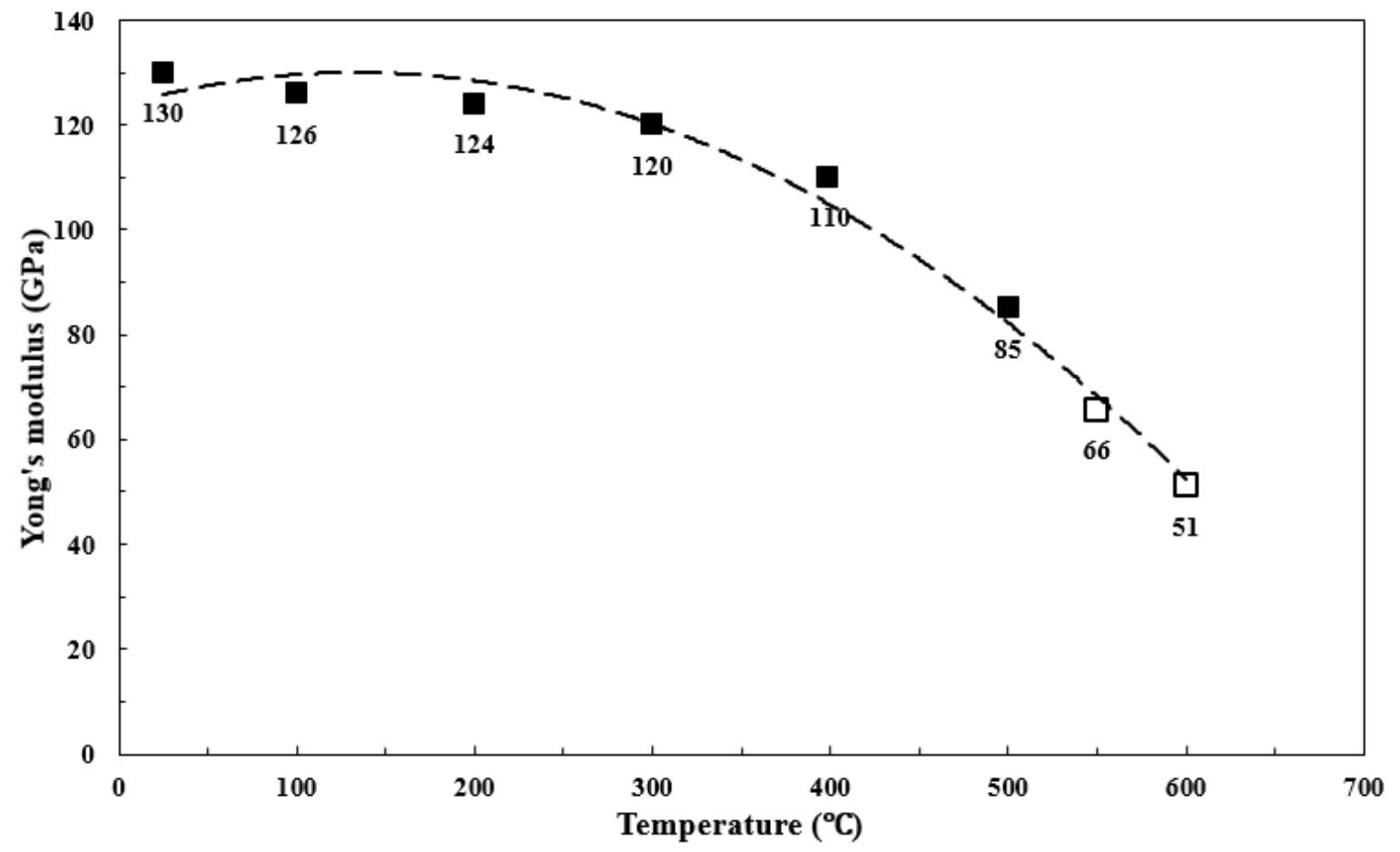

Fig. 6- 6. The Young's modulus at elevated temperatures of HVOF coated F91 with MCrAlY (close symbol: experimental data; open symbol: extrapolated value) $\left[{ }^{109}\right]$. 
Table 6- 2 Summary of stress distribution and coated-coupon creep test results

\begin{tabular}{ccccccc}
\hline Temp & $\begin{array}{c}\text { Nominal stress } \\
\text { on uncoated } \\
\text { coupon }\end{array}$ & $F_{\text {app }}$ & $\sigma_{\text {steel }}$ & $\sigma_{\text {coating }}$ & $\dot{\varepsilon}_{\text {ss }}$ & TTR \\
\hline${ }^{\circ} \mathrm{C}$ & $\mathrm{MPa}$ & $\mathrm{N}$ & $\mathrm{MPa}$ & $\mathrm{MPa}$ & $\% / \mathrm{hr}$ & $\mathrm{hr}$ \\
\hline \multirow{2}{*}{550} & 260 & 3202.14 & 233 & 88 & $4.70 \mathrm{E}-05$ & 1256.4 \\
& 240 & 2955.82 & 215 & 82 & $3.79 \mathrm{E}-05$ & $(1121.9)$ \\
& 220 & 2709.51 & 197 & 75 & $2.99 \mathrm{E}-05$ & 4178.3 \\
\hline 600 & 160 & 1970.55 & 147 & 44 & $6.56 \mathrm{E}-04$ & $(276.2)$ \\
& 140 & 1724.23 & 128 & 39 & $3.56 \mathrm{E}-04$ & $(1146.9)$ \\
& 130 & 1601.07 & 119 & 36 & $2.13 \mathrm{E}-04$ & 6112.7 \\
\hline
\end{tabular}

Note: Time in parentheses indicates the test still in progress as of Nov. $1^{\text {st }}, 2017$.

\subsubsection{Creep strain-time curves of coated F91}

From previous analyses, the tertiary creep parameter $M$ is obviously affected by oxidation. With coating protection, the substrate is observed to be un-oxidized. For best-fitting, in the creep-curve analyses of coated F91 coupons, the dislocation multiplication factor $(M)$ has to be re-adjusted with correction for oxidation effect. The oxidation-free $M$ values are listed in Table 6- 3 . These reduced values should truly represent dislocation multiplication without the oxidation effect. Then, the new $M$-factor is used in the DMTS model to describe the oxidation-free creep strain-time curves as well as the modified DMTS model to describe the creep strain-time curves of F91 under oxidation-creep conditions. 
For coated F91 under the same constant-load conditions, the DMTS model at $\sigma_{\text {steel }}$ and with new $M$ values describes the creep curves of coated-coupons very well, as shown in Fig. 6- 7 and Fig. 6- 8 for the two temperature conditions, $550^{\circ} \mathrm{C}$ and $600^{\circ} \mathrm{C}$, respectively. Also, Fig. $6-9$ shows the creep-tested final microstructures of coated-coupons. As the DTMS model infers, at stress/UTS ratios $0.35-0.6$, GBS dominates the failure mode where the martensitic laths tend to maintain the original shape with intergranular defects. These results prove that the DTMS model is suitable to simulate the behavior of oxide-free creep with the proposed GBS, IDC, and IDG deformation mechanisms. The next step is to couple the DMTS model with oxidation to generate the modified DMTS model for simulation of creep of uncoated F91 coupons.

Table 6- 3 Modified dislocation multiplication factor $M$

\begin{tabular}{cc}
\hline Temp $\left({ }^{\circ} \mathrm{C}\right)$ & $M$ \\
\hline 550 & 200 \\
575 & 120 \\
600 & 110 \\
625 & 10 \\
650 & 5 \\
\hline
\end{tabular}




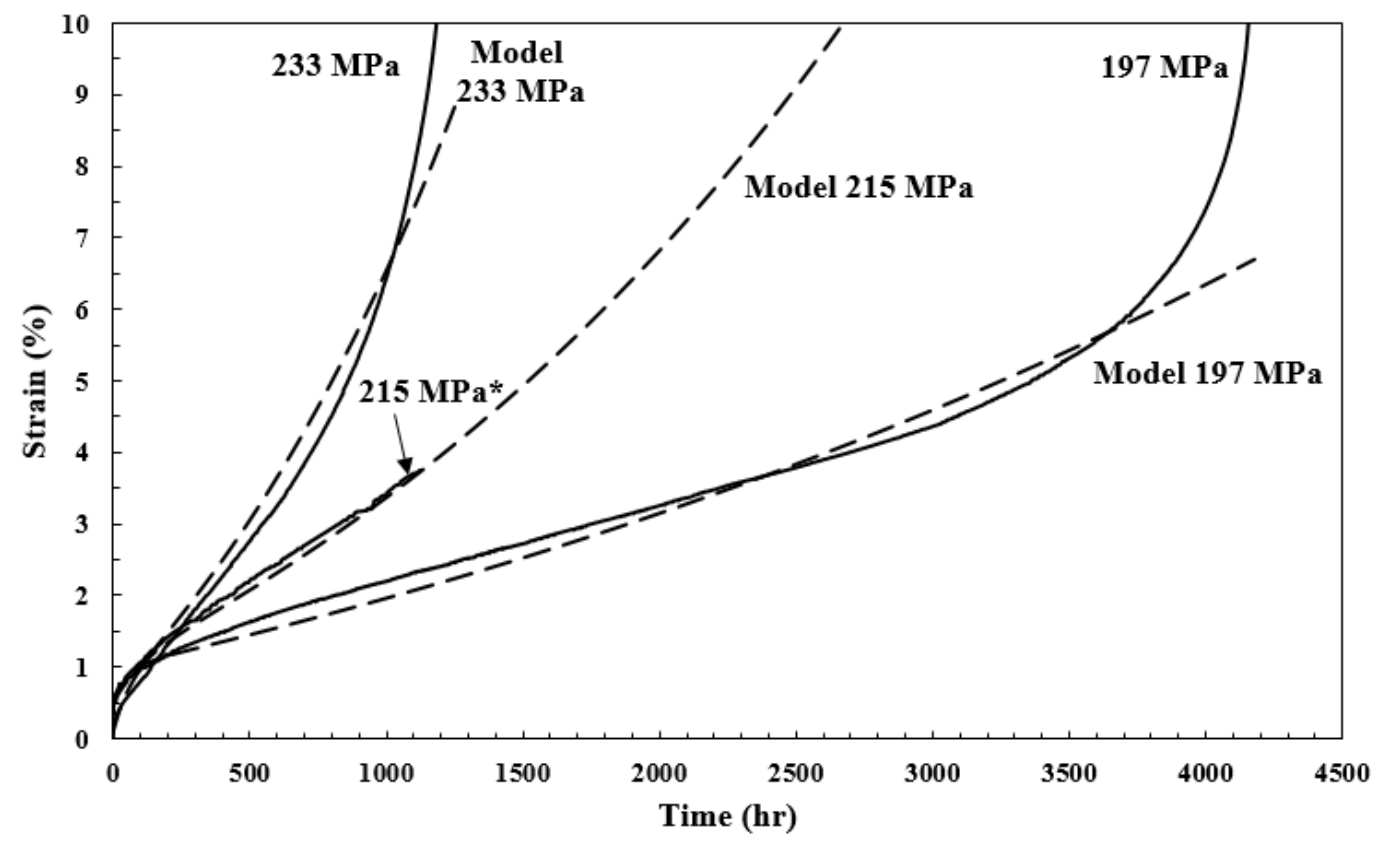

Fig. 6- 7. Creep strain-time curves of coated-coupons at $550^{\circ} \mathrm{C}$ and the DTMS model description.

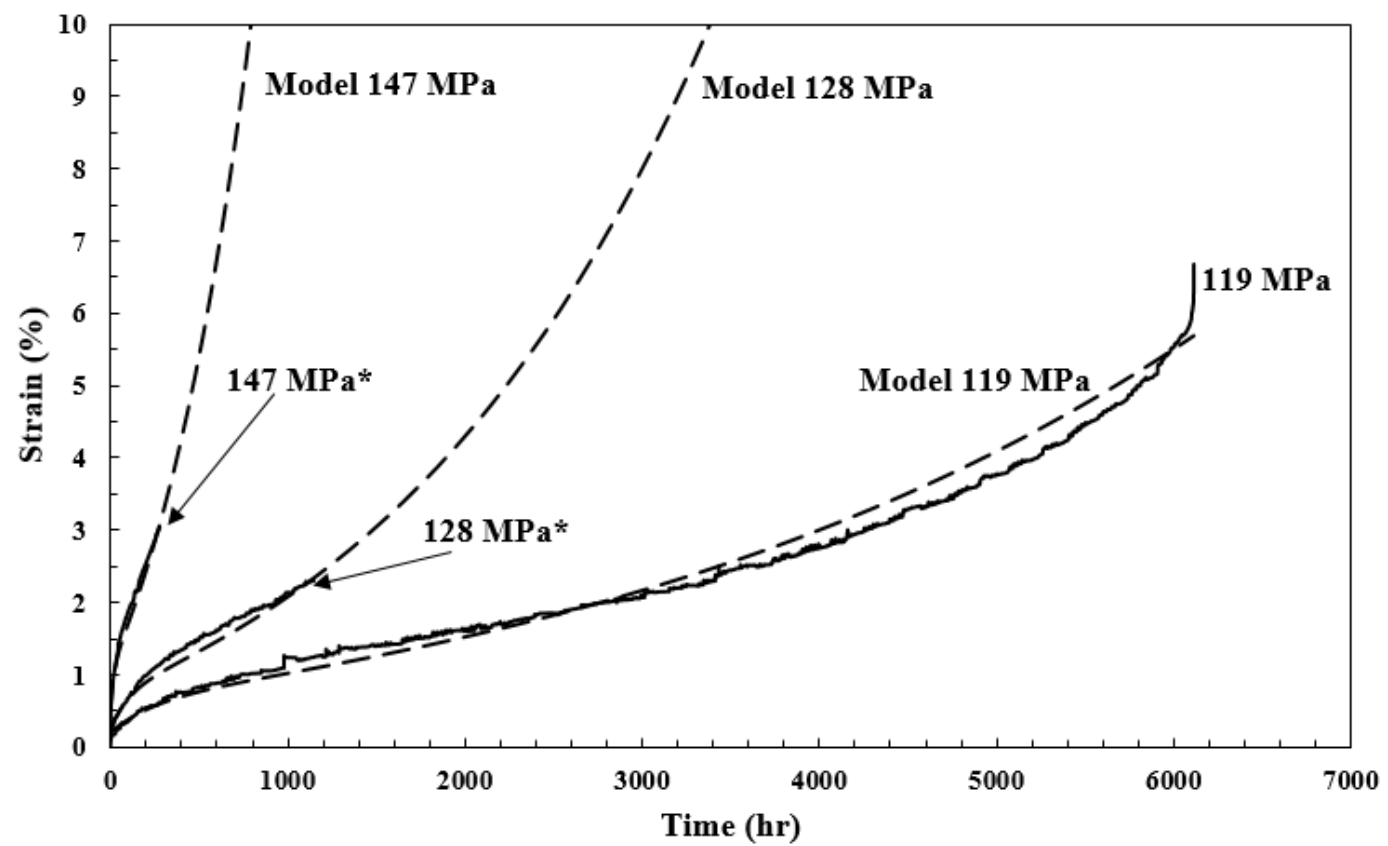

Fig. 6- 8. Creep strain-time curves of coated-coupons at $600^{\circ} \mathrm{C}$ and the DTMS model description. 

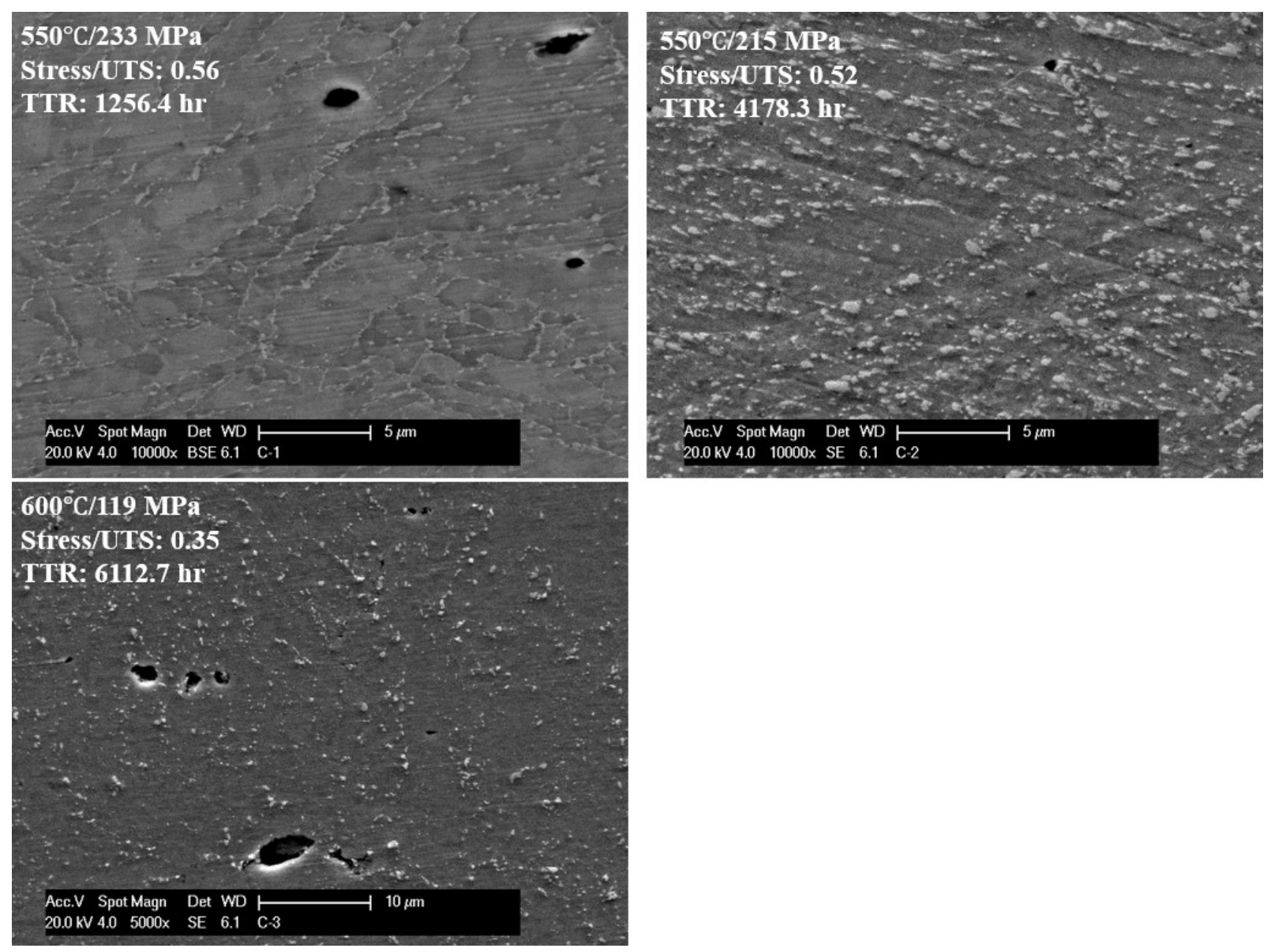

Fig. 6- 9. SEM microstructures of the longitudinal cross section near the fracture region of the coated-coupons at $550^{\circ} \mathrm{C}$ and $600^{\circ} \mathrm{C}$. 


\subsection{Modified DMTS Model for Uncoated F91}

In Chapter 5, it has been shown that the DMTS model underestimated the minimum creep rate $\left(\dot{\varepsilon}_{S S}\right)$ and the onset of the tertiary stage for creep over 300 hours. With inclusion of the oxidation effect as expressed by Eq. (4-18), the modified DMTS equation with $M^{\prime}$ and $k$, from Eq. (4-26) and Eq. (4-27), respectively, is used to depict the uncoated F91 creep curves, as shown in Fig. 6- 10 to Fig. 6- 13 with TTR over 300 hours. In general, the modified DMTS model improves the predictions at all temperatures from $500-650^{\circ} \mathrm{C}$. First of all, the creep rate $\dot{\varepsilon}_{s S}$ is increased because of the oxidation effect, indicating that beside the material- intrinsic deformation mechanisms, GBS, IDC, and IDG, oxidation effect is now validated for the modified DMTS model. In particular, for longer time creep, where the oxide growth becomes more and more influential, the modified DMTS describes the creep behavior better than the basic DMTS model. This implies that although for short-term creep tests the two models have little difference, oxidation can contribute significantly to the deviation towards long-term creep. This issue has not been emphasized much in the existing literature on creep. 


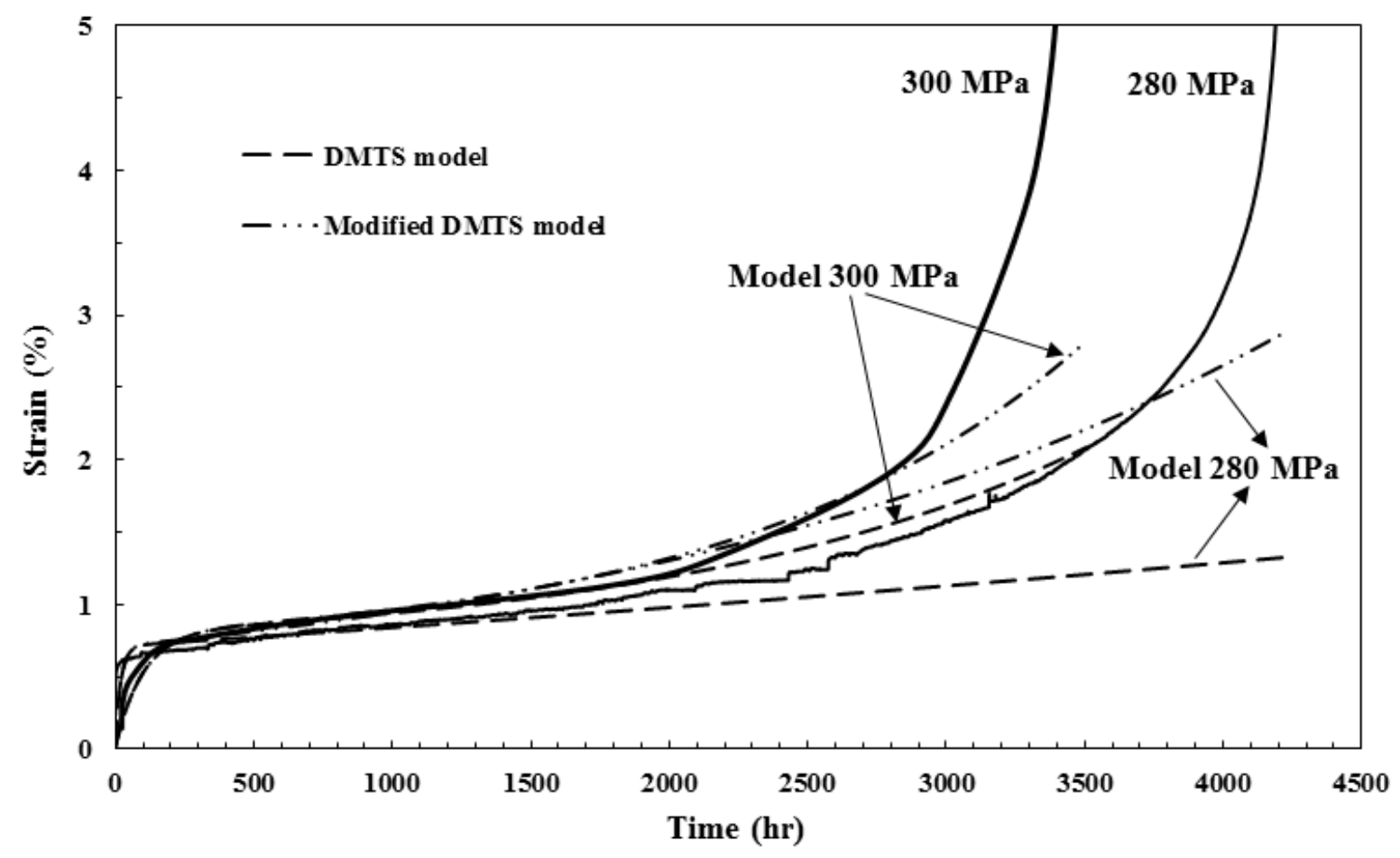

Fig. 6- 10. Comparison between basic and modified DMTS models for creep strain-time curves of uncoated F91coupons at $500^{\circ} \mathrm{C}$.

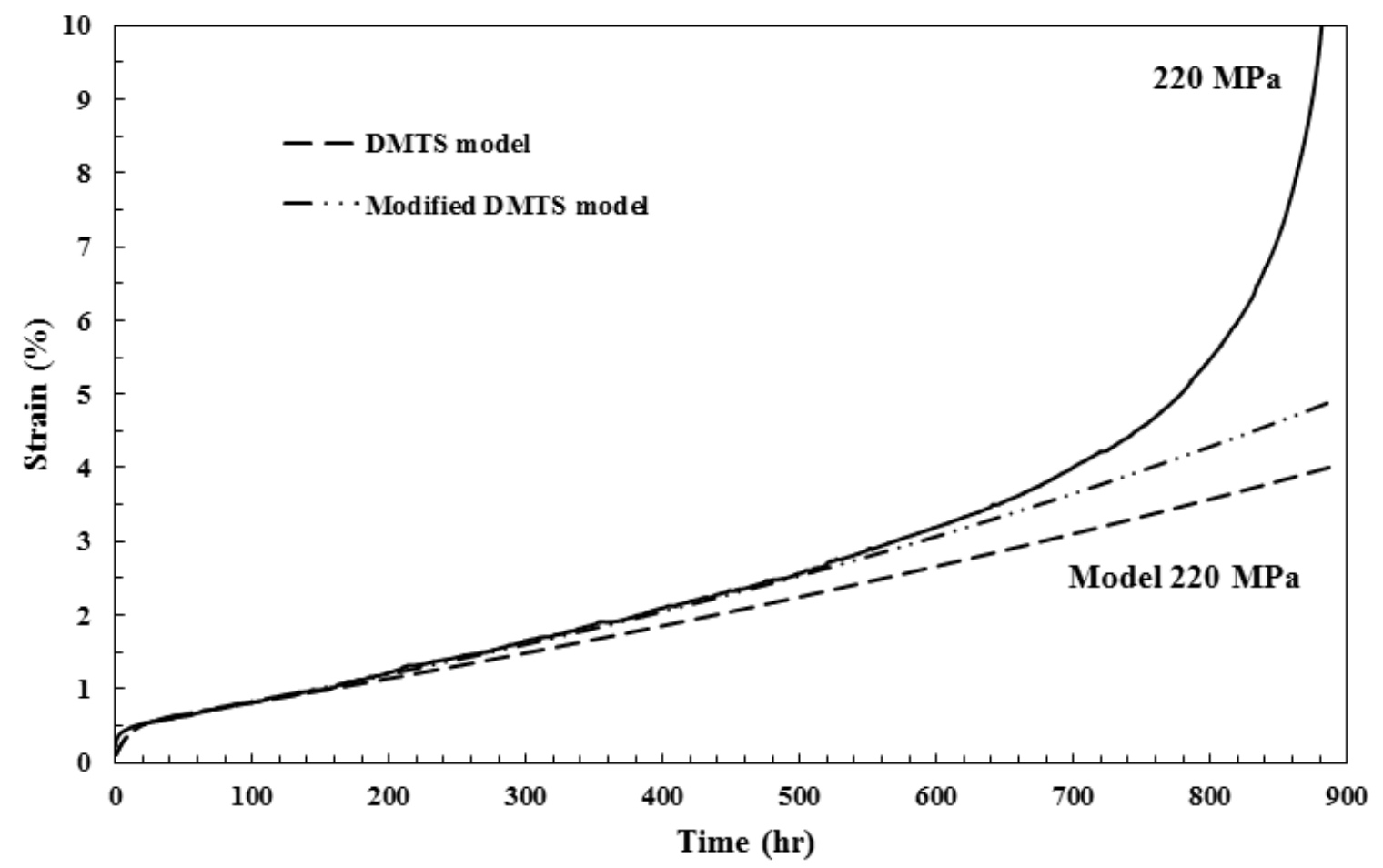

Fig. 6- 11. Comparison between basic and modified DMTS models for creep strain-time curves of uncoated F91 coupons at $550^{\circ} \mathrm{C}$. 


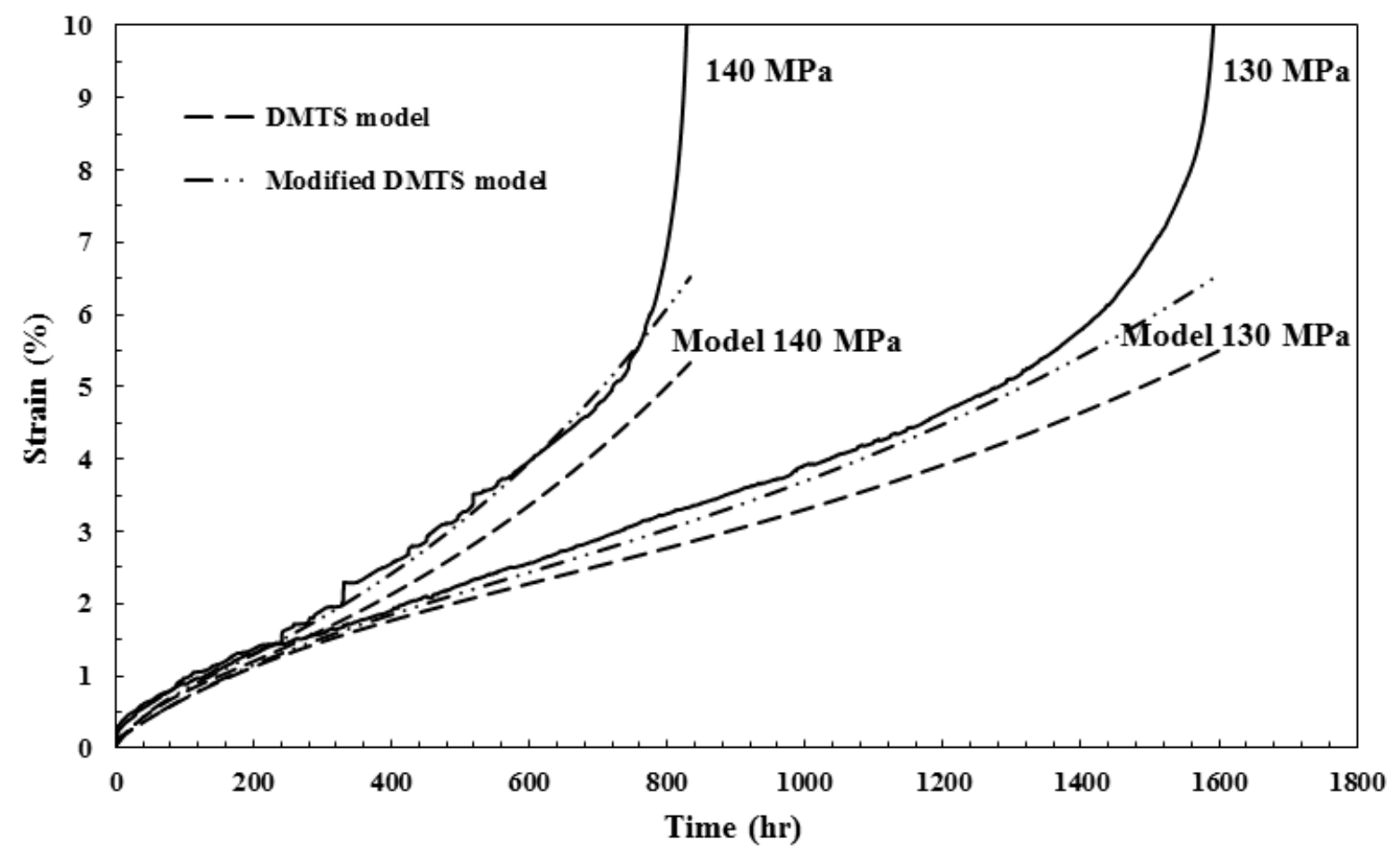

Fig. 6- 12. Comparison between basic and modified DMTS models for creep strain-time curves of uncoated F91coupons at $600^{\circ} \mathrm{C}$.

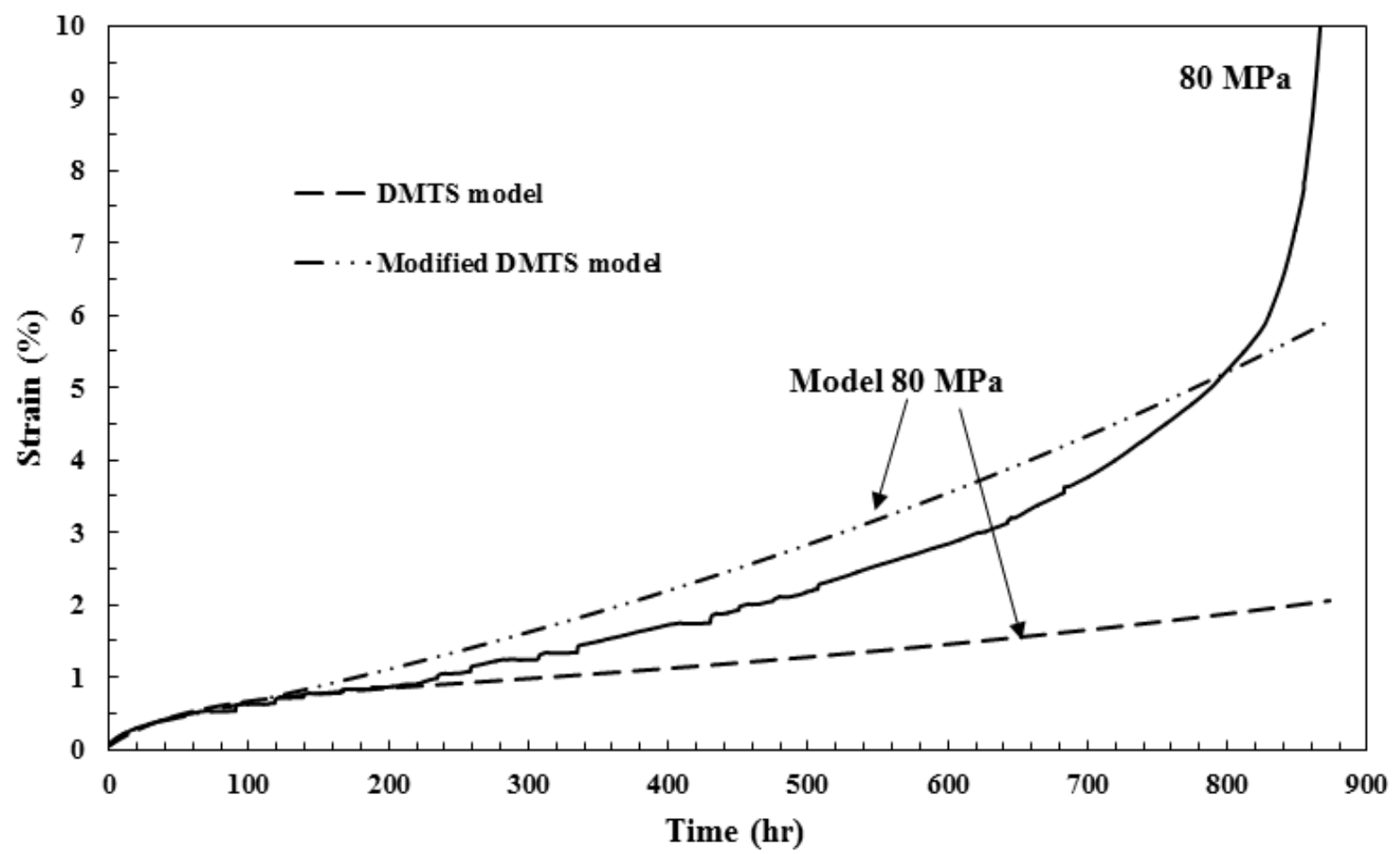

Fig. 6- 13. Comparison between basic and modified DMTS models for creep strain-time curves of uncoated F91coupons at $650^{\circ} \mathrm{C}$. 


\subsection{Modified DMTS Model for Creep Life Prediction}

In Chapter 5, it has also been shown that the basic DMTS model tends to over-estimate the longterm creep life. With the inclusion of the oxidation-effect terms, the modified DMTS model improves the accuracy of long-term creep life prediction. In Fig. 6- 14 to Fig. 6- 17, the two models are compared for long-term life prediction of NIMS Grade 91 steels, which shows that the two models have similar performance at TTR $<10^{4}$ region. The difference starts to show up at creep time durations over $\sim 10^{4}$ hours and longer. The modified DMTS model describes the "life breakdown" phenomenon in agreement with the experimental observations for long-term creep. The allowable stress is also brought down by considering the oxidation effect. For example, the DMTS model predicts the allowable stress for $\mathrm{MgB}$ at $500^{\circ} \mathrm{C}$ is $99 \mathrm{MPa}$, while the modified DMTS model predicts $74 \mathrm{MPa}$. In essence, these phenomena are the results of creep-oxidation interaction, rather than artificially divided "two stress regions" through numerical fitting $\left[{ }^{75}\right]$. In this sense, no other creep models have genuinely represented the long-term creep performance with inevitable oxidation influence. 


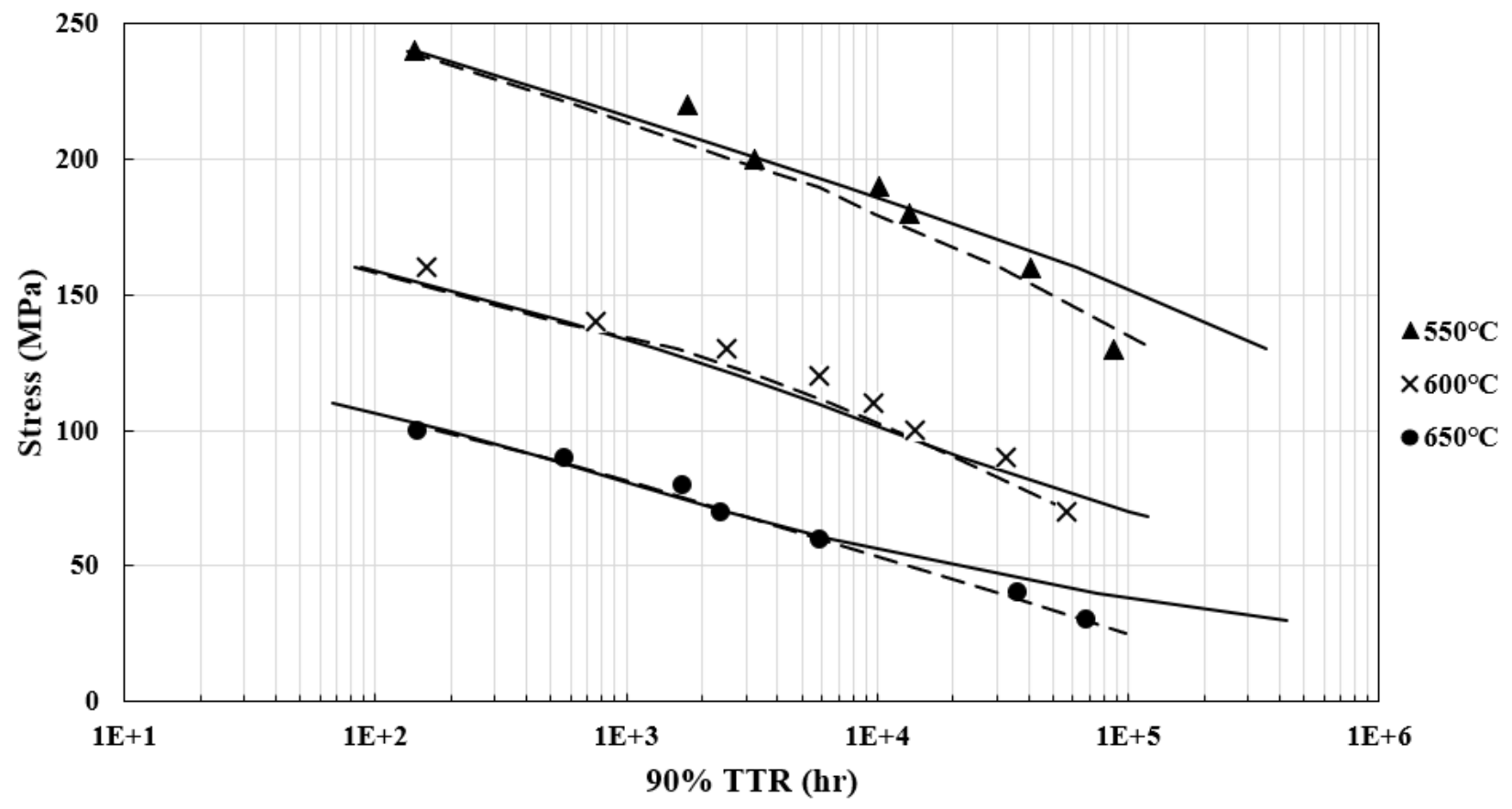

Fig. 6- 14. Comparison between basic and modified DMTS models for life prediction of MgB (symbols: experimental; solid lines: DMTS model; dash lines: modified DMTS model).

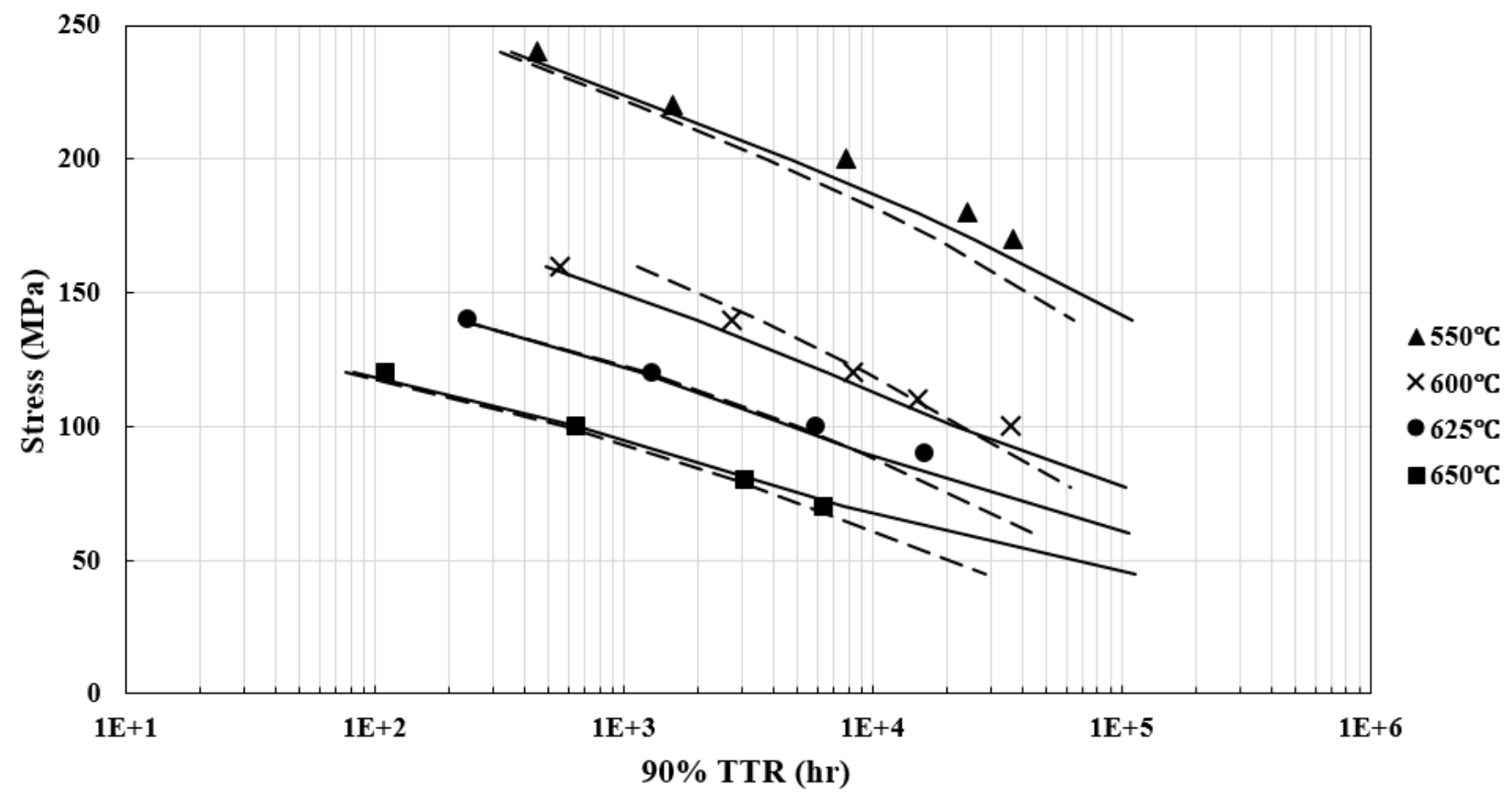

Fig. 6- 15. Comparison between basic and modified DMTS models for life prediction of $\mathrm{MgD}$ (symbols: experimental; solid lines: DMTS model; dash lines: modified DMTS model). 


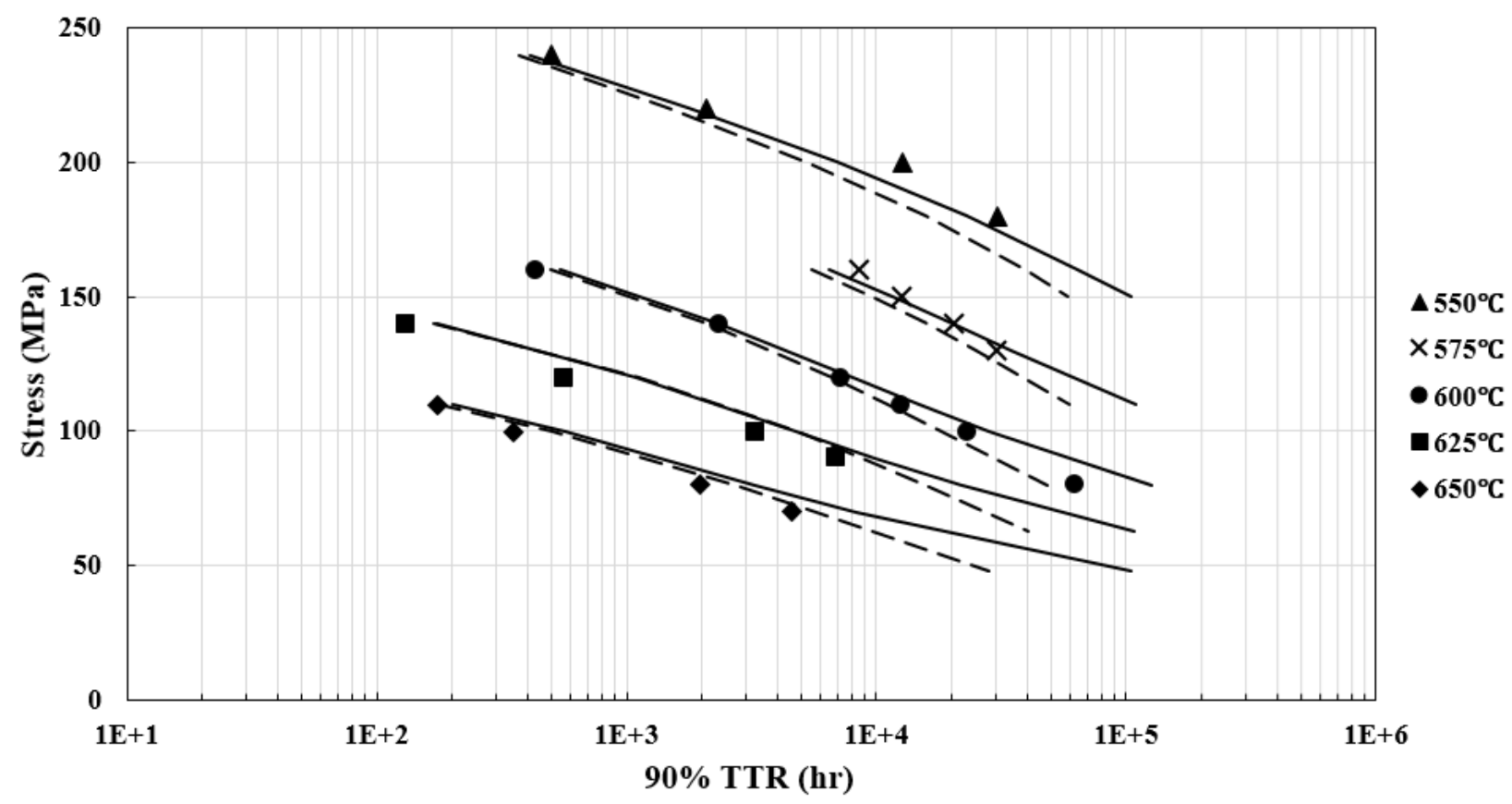

Fig. 6- 16. Comparison between basic and modified DMTS models for life prediction of MGD (symbols: experimental; solid lines: DMTS model; dash lines: modified DMTS model).

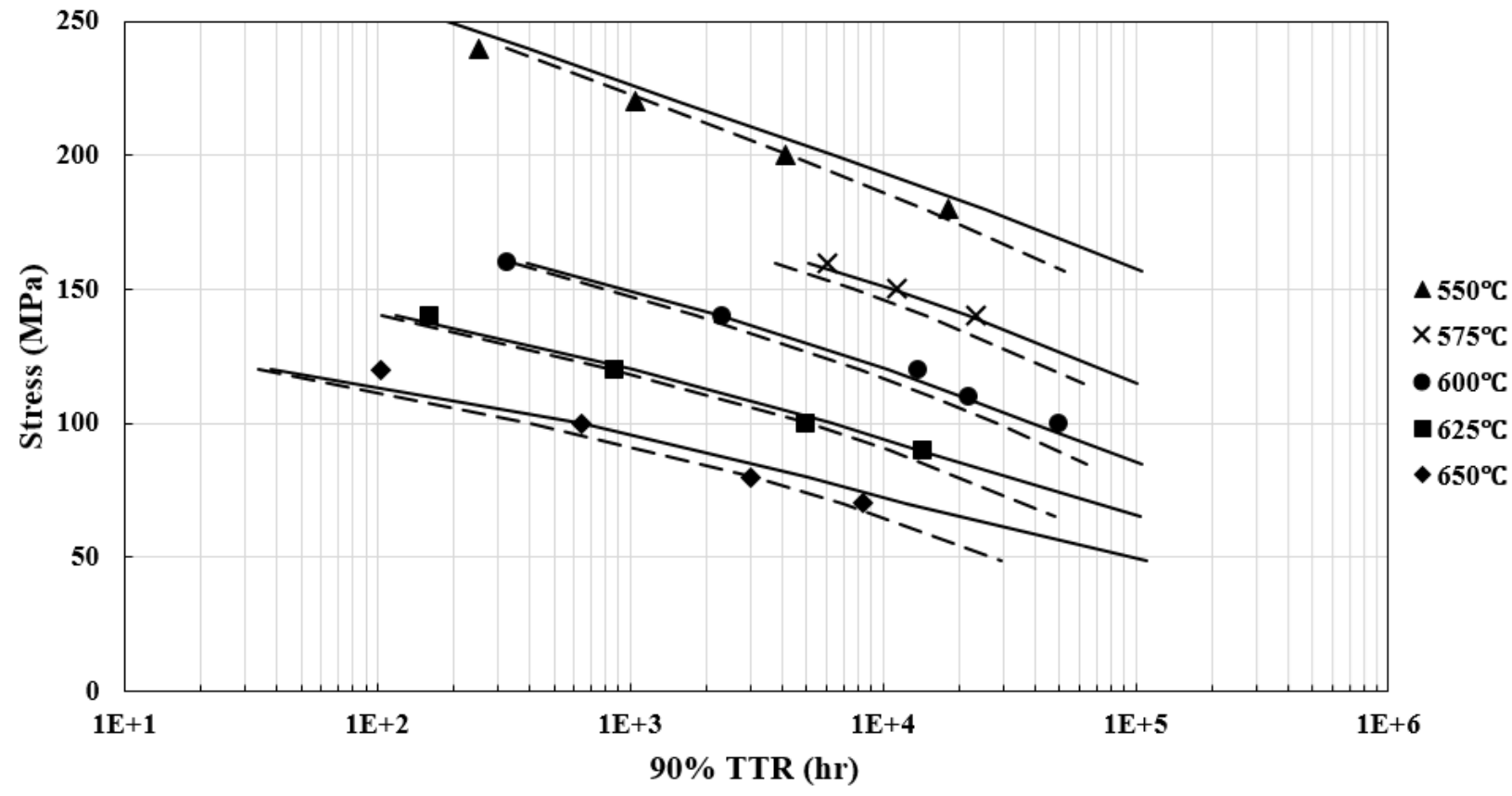

Fig. 6- 17. Comparison between basic and modified DMTS models for life prediction of MGQ (symbols: experimental; solid lines: DMTS model; dash lines: modified DMTS model). 


\subsection{Comparison between Larson-Miller Parameter Method and the Modified DMTS Model}

In Chapter 2, the Larson-Miller parameter is discussed because of its popularity on creep life prediction for industrial applications. In order to establish the correlations between the applied stress and TTR, a large amount of data are needed to construct an LMP plot, as shown in Fig. 214. Usually, for the purpose of quick assessment of creep strength, high stresses are applied to obtain short-term TTR data. As indicated by Fig. 2- 14, extrapolation from the high-stress region $(>100 \mathrm{MPa})$ to the low-stress region $(<100 \mathrm{MPa})$ is not a reliable option. To have the low-stress region fulfilling the stress- $P_{L M}$ plot, a large amounts of low-stress creep rupture data must be obtained, which is time-consuming and costly. On the contrary, the modified DMTS model requires much less data input to provide more accurate creep life/strength prediction. Fig. 6- 18 indicates the minimum data input for the modified DMTS model in a rate-stress map. To obtain model parameters for IDC, GBS, and IDG, a minimum of three temperature-sets and two TTR creep tests per temperature $(<5,000$ hours per test) are needed for each mechanism. The oxidation coefficient can also be achieved by analyzing the oxide layer thickness after the rupture of shortterm creep coupons. To improve the model accuracy, minimum creep rate $\left(\dot{\varepsilon}_{s S}\right)$ is sufficient for the modified DMTS model, the values of which can be obtained in no more than 1,000 hours per test, rather than requiring the entire TTR test. In addition, with the built-in oxidation terms, the modified DMTS model has successfully depicted the strength-drop phenomena. Moreover, the modified DMTS model provides engineers more information about the material failure modes, which feeds back useful information for material design. Table 6- 4 summarizes the features of two models. 


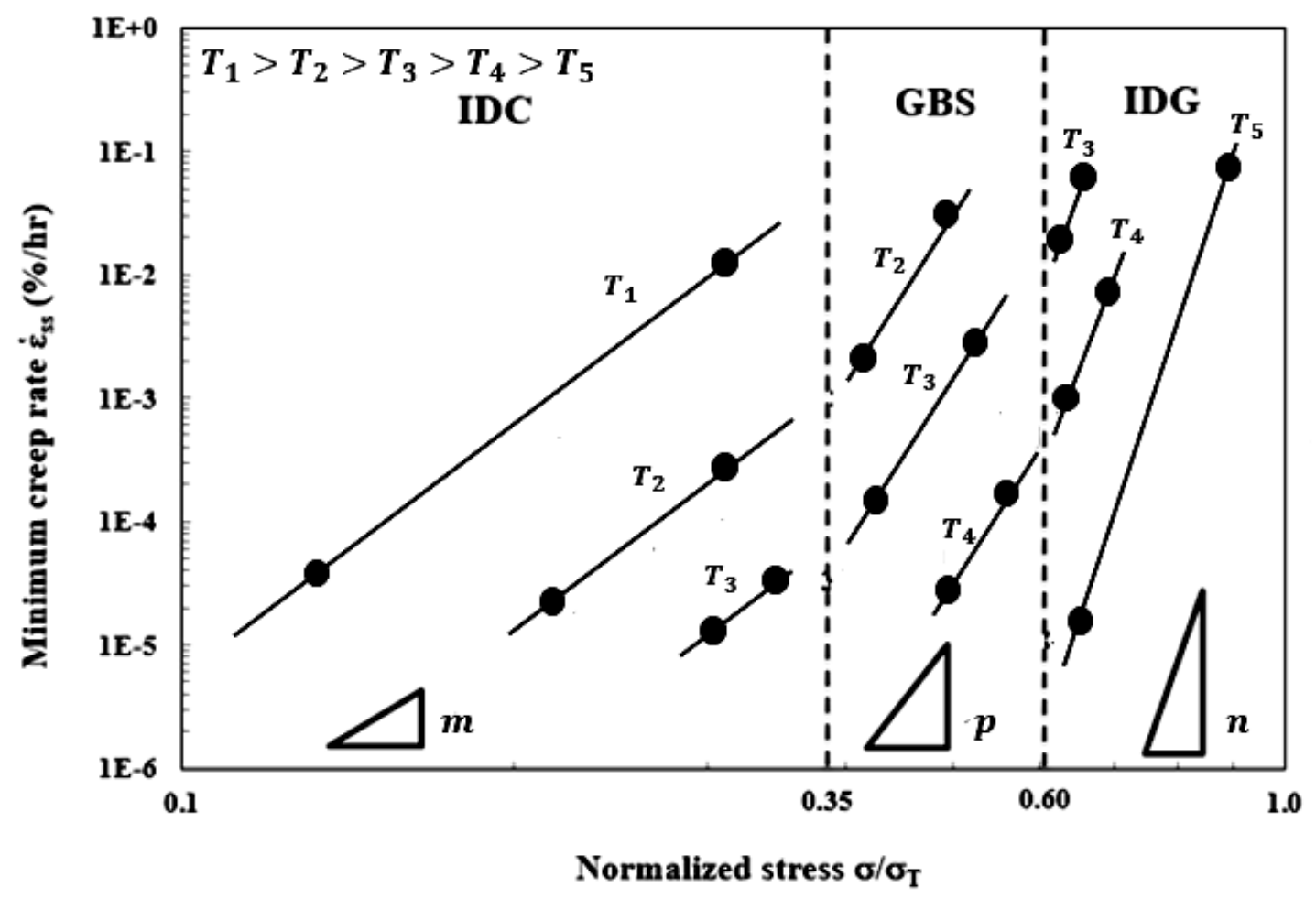

Fig. 6- 18. Data required for the modified DMTS model.

Table 6- 4 Comparison between LMP method and the modified DMTS model

\begin{tabular}{ccccc}
\hline Model & Data input & $\begin{array}{c}\text { Rupture } \\
\text { mode } \\
\text { indication }\end{array}$ & $\begin{array}{c}\text { Microstructure } \\
\text { evolution effect }\end{array}$ & $\begin{array}{c}\text { Oxidation } \\
\text { effect }\end{array}$ \\
\hline $\begin{array}{c}\text { Larson- } \\
\text { Miller } \\
\text { parameter }\end{array}$ & $\begin{array}{c}\text { Large amount of TTR data to } \\
\text { cover the entire temperature- } \\
\text { stress range }\end{array}$ & No & No & No \\
\hline $\begin{array}{c}\text { Modified } \\
\text { DMTS } \\
\text { model }\end{array}$ & $\begin{array}{c}\text { Small amount of data: } \\
\text { Minimum 6 TTR } \\
\text { points/mechanism of IDC, } \\
\text { GBS, and IDG }\end{array}$ & Yes & Yes & Yes \\
\hline
\end{tabular}


For the comparison purpose, the predicted creep lives of NIMS Plate MgB by the modified DMTS model are plotted in the LMP diagram to compare with the experimental 90\%-TTR data. The Larson-Miller constant, $C_{L M}$, in Eq. (2-7) is $33\left[{ }^{34}\right]$. Fig. 6- 19 shows that the predicted lives agree with the experimental data very well. In addition, each creep rupture failure mode can be identified by the modified DMTS model, in a manner showing the participating portions of the three mechanisms: GBS, IDG and IDC. Fig. 6- 20 shows two microstructures at creep rupture under $600^{\circ} \mathrm{C} / 160 \mathrm{MPa}$ and $650^{\circ} \mathrm{C} / 100 \mathrm{MPa}$, along with the mechanism pie-chart made up by the contributions from the three mechanisms to the total strain rate. In the $600^{\circ} \mathrm{C} / 160 \mathrm{MPa}$ case, GBS predominated ( $94 \%)$ and the microstructure retained its original lath structure; whereas in the $650^{\circ} \mathrm{C} / 100 \mathrm{MPa}$ case, the model predicts that a significant portion $(\sim 38 \%)$ of creep deformation occurred by IDC, accordingly the lath structure did become more elongated. The model prediction agrees with the metallurgical evidence. Using the modified DMTS model, such pie-charts can be drawn for every creep condition. In this way, engineers are able to understand the physics of failure and identify the failure modes in quantitative details, whereas the LMP plot does not provide such information, from a life prediction point of view. 


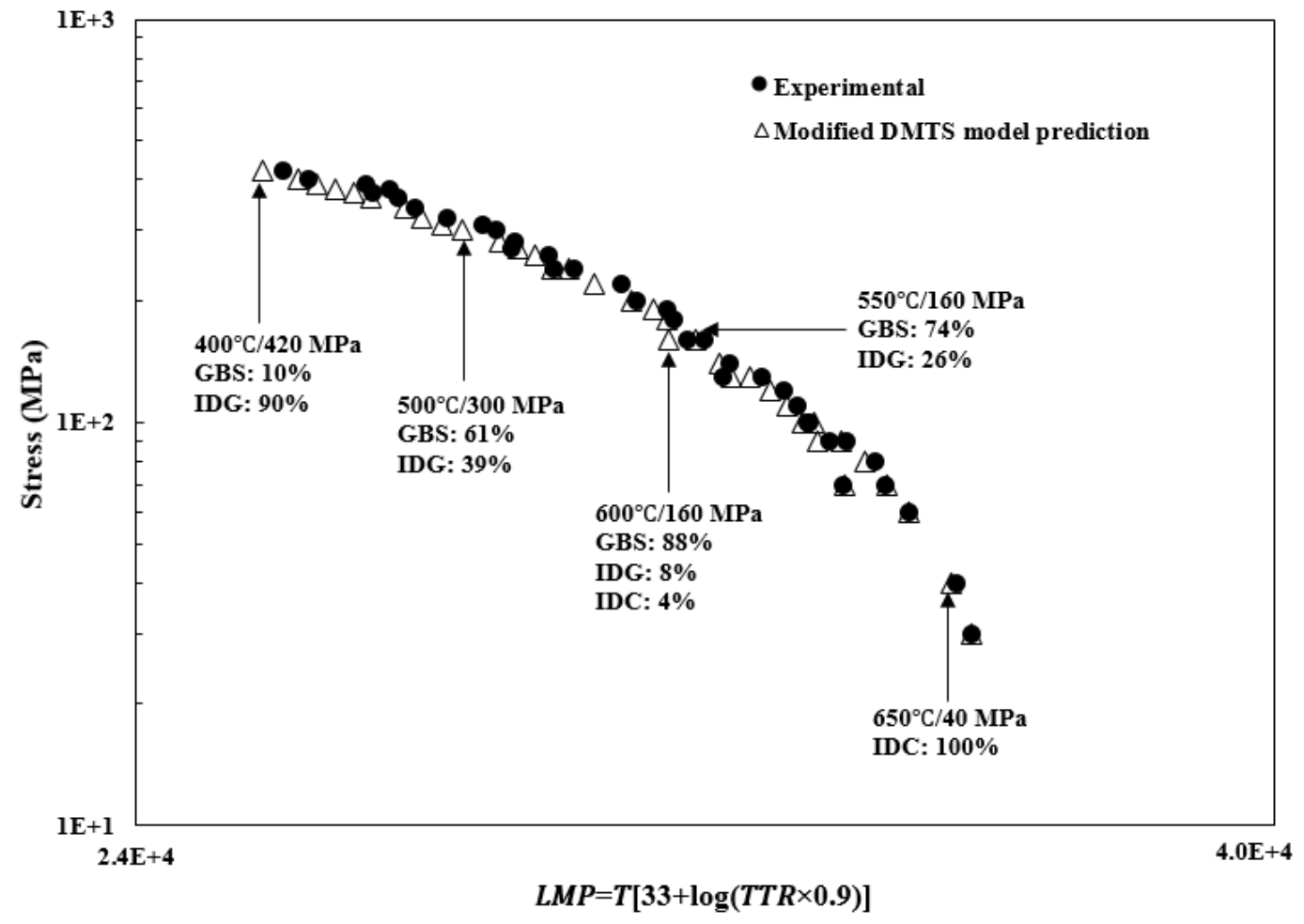

Fig. 6- 19. The modified DMTS model prediction of NIMS Plate MgB in LMP plot with experimental data. 

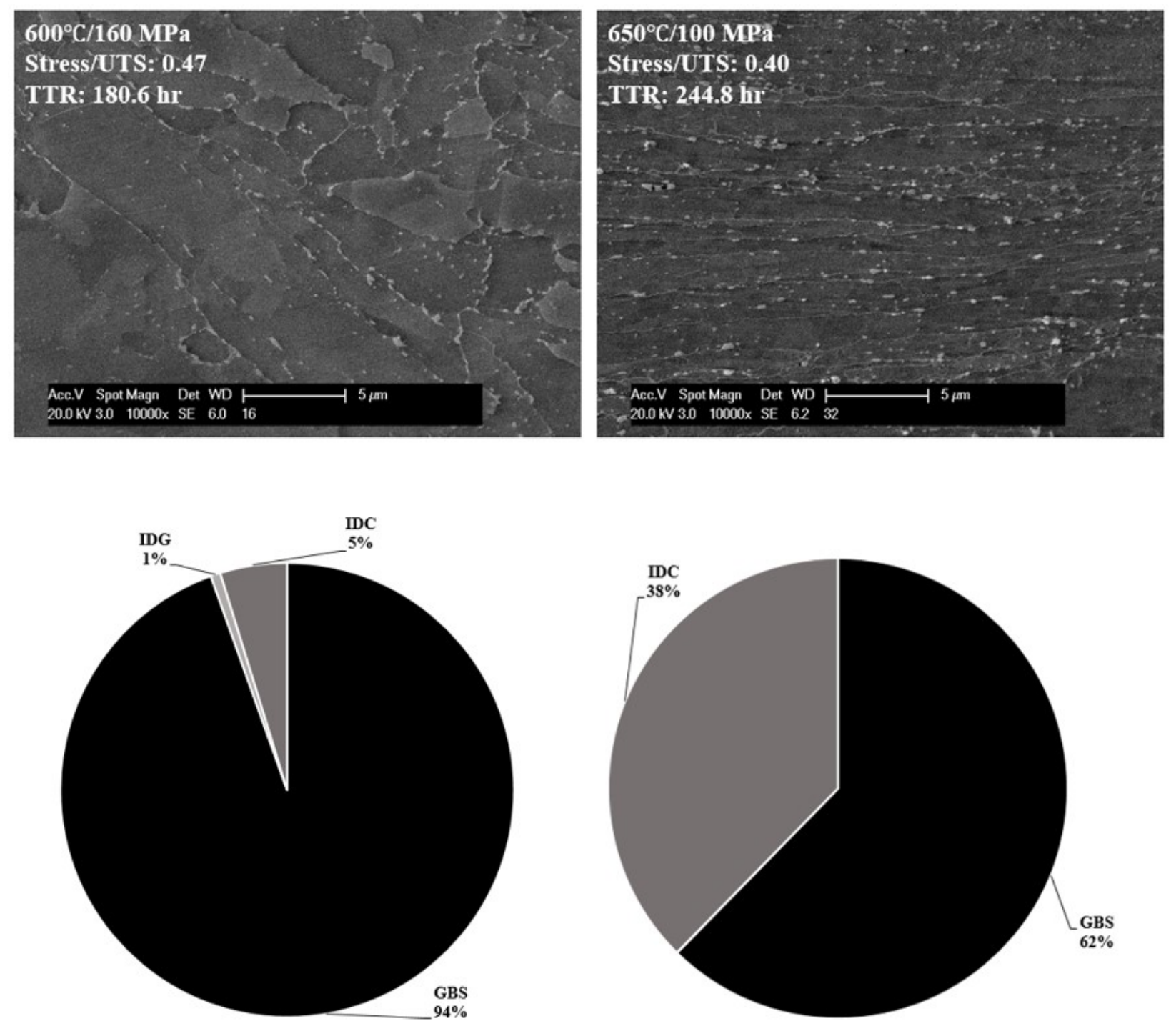

Fig. 6- 20. Microstructural analyses with mechanism indication pie-charts. 


\subsection{Summary}

Both the basic and modified DMTS models are validated against oxidation-free creep behavior of MCrAlY-coated F91 and oxidation-effected creep behavior of uncoated F91. The following conclusions can be drawn:

- The present study proposed an area-reduction method, for the first time, to quantify oxide scale growth during creep. From such measurements, the oxidation growth rate coefficient, $K_{o x}$, is determined, and the average of this coefficient at a temperature is assumed to obey the Arrhenius relationship.

- MCrAlY coating has a beneficial effect on creep resistance of F91 steel by preventing oxidation attack on the substrate during long-time creep. The DMTS model (with the adjusted $M$ values for oxidation-free conditions) describes the creep strain-time curve of coated F91 coupons very well.

- By taking oxidation effect into account, the modified DMTS model (with the same oxidation-free $M$ but additional oxide growth terms) better describes the creep strain-time curve of uncoated F91 coupons than the basic DMTS model with coupon-borne oxidation influence. In addition, the modified DMTS model also predicts the long-term creep lives of Grade 91 steels in excellent agreement with NIMS creep data. This signifies the importance of the separation of oxidation effect from material intrinsic deformation mechanisms such as IDG, IDC and GBS. 


\section{Chapter 7 Creep Performance of Heat-treated F91 Steel}

\subsection{Heat-treated High-chromium Steels}

Grade 91 steels are often tempered at 650 to $780^{\circ} \mathrm{C}$, to allow the brittle martensitic lath structure to transform into a fine elongated micrograin structure, with a typical micrograin size of $2 \mu \mathrm{m}$ in length and $0.5 \mu \mathrm{m}$ in width $\left[{ }^{137},{ }^{138}\right]$. After tempering, the microstructure transforms from martensite to ferrite $\left[{ }^{139}\right]$. The material is thus called "tempered martensite", merely to reflect this heat treatment history $\left[{ }^{140}\right]$. Tempered ferritic steels are aimed to obtain secondary precipitations, such as $\mathrm{M}_{23} \mathrm{C}_{6}$ and $\mathrm{MX}$, which are desirable because it enhances creep strength via precipitation hardening. However, such materials inevitably suffer everlasting microstructural evolution and degradation during service, which may affect its long-term performance at elevated temperatures. The influence of Laves phase on the creep strength of F91 is investigated in this study, the results of which have already been published $\left[{ }^{29},{ }^{141}\right]$. Through additional aging heat treatment up to 5,000 hours, a pronounced increase of Mo-rich Laves phase was found around $\mathrm{Cr}$-rich carbide $\mathrm{M}_{23} \mathrm{C}_{6}$, which was present at the prior-austenite grain boundaries and martensitic lath boundaries. This secondary precipitation hardening provided by the Laves phase was rapidly offset by its coarsening into large clusters during long-term thermal exposure and under creep conditions, leading to earlier creep rupture than the unaged material. Uniaxial constant-load creep test was conducted on both aged and un-aged coupons under the same creep conditions. The creep rupture behavior of both materials was rationalized with the assistance of the DMTS creep model that was developed in this study.

F91 steel had undergone normalization at $1080^{\circ} \mathrm{C}$ for 4 hours, followed by tempering at $800^{\circ} \mathrm{C}$ for 5 hours. Such conventional heat treatment provided the tempered martensite ferritic steel a 
complex nonequilibrium microstructure, which tended to evolve with decreasing dislocation density, coarsening of carbides and precipitation of new phase particles when the steel was exposed to elevated temperatures for a long time duration $\left[{ }^{142}\right]$. Precipitations in $9-12 \% \mathrm{CrMoW}$ system, such as $\mathrm{M}_{23} \mathrm{C}_{6}, \mathrm{MX}, \mathrm{M}_{2} \mathrm{X}$, Laves phase and Z-phase, have been studied extensively for decades. Table 2- 5 categorizes these precipitates with their compositions, sizes, and shapes; Fig. 2- 25 illustrates these data in one micrograph [ ${ }^{101}$ ]. Among these precipitates, $\mathrm{Cr}$-rich $\mathrm{M}_{23} \mathrm{C}_{6}$ carbide has a large size, which is the dominant precipitates at prior austenite grain boundaries and prior martensitic lath boundaries during the normalization treatment. Fine MX, Nb and/or V-rich carbides precipitate at the same time at micrograin boundaries, which prevent grain growth during normalization and also increase the toughness of the steel $\left[{ }^{101}\right]$. These two precipitations strengthen the material by pinning the precipitates at internal interfaces to hinder dislocation movement, thus offering precipitation hardening. $\mathrm{M}_{2} \mathrm{X}, \mathrm{Cr}$-rich nitride (sometimes, $\mathrm{Cr}$ can be replaced by $\mathrm{V}$, which is often confused with Z-phase) are generally formed in steels with high $\mathrm{N}$ contents [ $\left.{ }^{101}\right] . \mathrm{M}_{2} \mathrm{X}$ phase was not detected in F91 in the present study. Laves phase, an $\mathrm{A}_{2} \mathrm{~B}$ intermetallic particle, is formed when the steel is exposed to elevated temperatures along with the $\mathrm{M}_{23} \mathrm{C}_{6}$ and $\mathrm{MX}$ coarsening.

Laves phase normally has a composition of $\mathrm{Fe}_{2}(\mathrm{Mo}, \mathrm{W})$ in $9-12 \% \mathrm{Cr}$ steels. For most of CrMoW steels, there is no Laves phase in their original tempered state. Rather it forms during aging or creep at $500-650^{\circ} \mathrm{C}$ and then quickly coarsens. The applied stress might assist the formation process. The intermetallic compound $\mathrm{Fe}_{2} \mathrm{Mo}$ precipitates at $500^{\circ} \mathrm{C}$ with an exposure time of 2,7000 hours, but it does not precipitate at $675^{\circ} \mathrm{C}$ because at this temperature its solubility is below the limit $\left[{ }^{75}\right]$. The concentrations of Mo and $\mathrm{W}$ in precipitate clusters are the essential indicator of Laves phase formation. For F91, the Laves phase was found at $600^{\circ} \mathrm{C}$ but almost none 
found at $650^{\circ} \mathrm{C}$. However, with additional $1 \% \mathrm{~W}$ in E911, Laves phase was observed at $650^{\circ} \mathrm{C}$ after exposure for 105 hours. Because of the higher concentrations of Mo and $\mathrm{W}$, the Laves phase could be stabilized at a higher temperature $\left[{ }^{18}\right]$. Isik et al. studied the mechanism of Laves phase nucleation in a $12 \mathrm{Cr}-1$ Mo tempered ferric steel $\left[{ }^{140}\right]$; they found Mo and Si solutes from the matrix first segregated at micrograin boundaries to nucleate Laves phase and then coarsened rapidly to form bulky clusters during further thermal exposure. However, the kinetics of Laves phase nucleation and growth as a function of stress and temperature remains unclear, which is the primary concern in the present investigation. In the ideal case, Mo is distributed uniformly in the matrix as a solid-solution strengthening element rather than segregated at the grain or lath-boundaries. The concentration of Mo at boundaries and/or formation of Laves phase are undesirable for creep resistance. Although the Laves phase particles are present at the boundaries, their rapid coarsening would soon erase the pinning effect. Therefore, as the thermal exposure continues, Laves phase could progressively cause embrittlement instead of strengthening $\left[{ }^{18},{ }^{143}\right]$. Furthermore, the size of the precipitates plays a vital role in providing creep resistance, according to the Orowan stress formula $\left[{ }^{95}\right]$ :

$$
\sigma_{\text {orowan }}=3.32 \frac{G b \sqrt{f_{p}}}{d_{p}}
$$

where $G$ is the shear modulus of the material, $b$ is Burgers vector, $f_{p}$ is precipitate volume fraction, and $d_{p}$ is precipitate mean diameter. Thus, if one type of precipitate is in an equilibrium state, finely dispersed particles are more desirable than coarsened clusters having larger mean diameters.

Z-phase (size $\sim 50 \mathrm{~nm}$ ) is a type of Cr-rich nitride compound (sometimes, with $\mathrm{Nb}$ and/or $\mathrm{V}$ as substitutes of $\mathrm{Cr}$ ). It is still in debate whether the effect of Z-phase is beneficial or deleterious to creep strength, but there is little argument that it absorbs MX, or MX transforms into Z-phase. 
High $\mathrm{Nb}$ concentration may accelerate precipitation of Z-phase, as found by Danielsen and Hald $\left[{ }^{96},{ }^{97}\right]$. In their studies, few Z-phase was found in $12 \mathrm{CrMoV}$ steel X20 with high $\mathrm{Cr}$ but without $\mathrm{Nb}$ after exposure at $600^{\circ} \mathrm{C}$ for an extended period (150,000 hours). However, $12 \% \mathrm{CrVNb}$ steels,

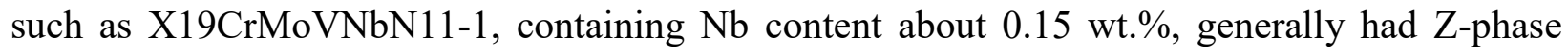
precipitated after a period of exposure between $10,000 \sim 30,000$ hours at $600^{\circ} \mathrm{C}$ and presented a dramatic drop in creep strength. Strang and Vodared revealed the relationship between Z-phase and creep strength, and suggested that Z-phase shortened creep lifetime for $11-12 \% \mathrm{Cr}-\mathrm{Mo}-\mathrm{V}$ $\mathrm{Nb}-\mathrm{N}$ steel $\left[{ }^{100}\right]$. A small amount of Z-phase was also detected in one creep rupture specimen in this study. 


\subsection{Laves Phase Nucleation and Growth during Aging}

One slice of aged F91 was sectioned from the traveling coupon every 1,000 hours to observe Laves phase nucleation and growth. Mo was the trace element to detect Laves phase nucleation according to $\mathrm{Fe}_{2} \mathrm{Mo}$ chemical composition. Also, Mo-containing precipitates appear bright when observed using SEM-backscattered electrons (BSE) imaging, due to molybdenum's high atomic mass. In the un-aged state of F91, Cr-rich $\mathrm{M}_{23} \mathrm{C}_{6}$ is dominant in the matrix. There is an average Mo content of 0.76 wt. $\%$ detected in the $\mathrm{M}_{23} \mathrm{C}_{6}$ particles. However, this concentration is close to the Mo content of $0.94 \mathrm{wt} . \%$ at the entire material level, which indicates that Mo participated as a minor element in forming of the carbides during the tempering process. The EDX spectra patterns of the matrix, $\mathrm{M}_{23} \mathrm{C}_{6}$, Laves phase and Z-phase are presented in Fig. 7- 1, where the matrix and $\mathrm{M}_{23} \mathrm{C}_{6}$ were from un-aged coupons before creep testing, Laves phase was detected in aged-coupons and some of the ruptured un-aged coupons, and Z-phase was only found in the ruptured un-aged coupon tested at $600^{\circ} \mathrm{C} / 130 \mathrm{MPa}$. 

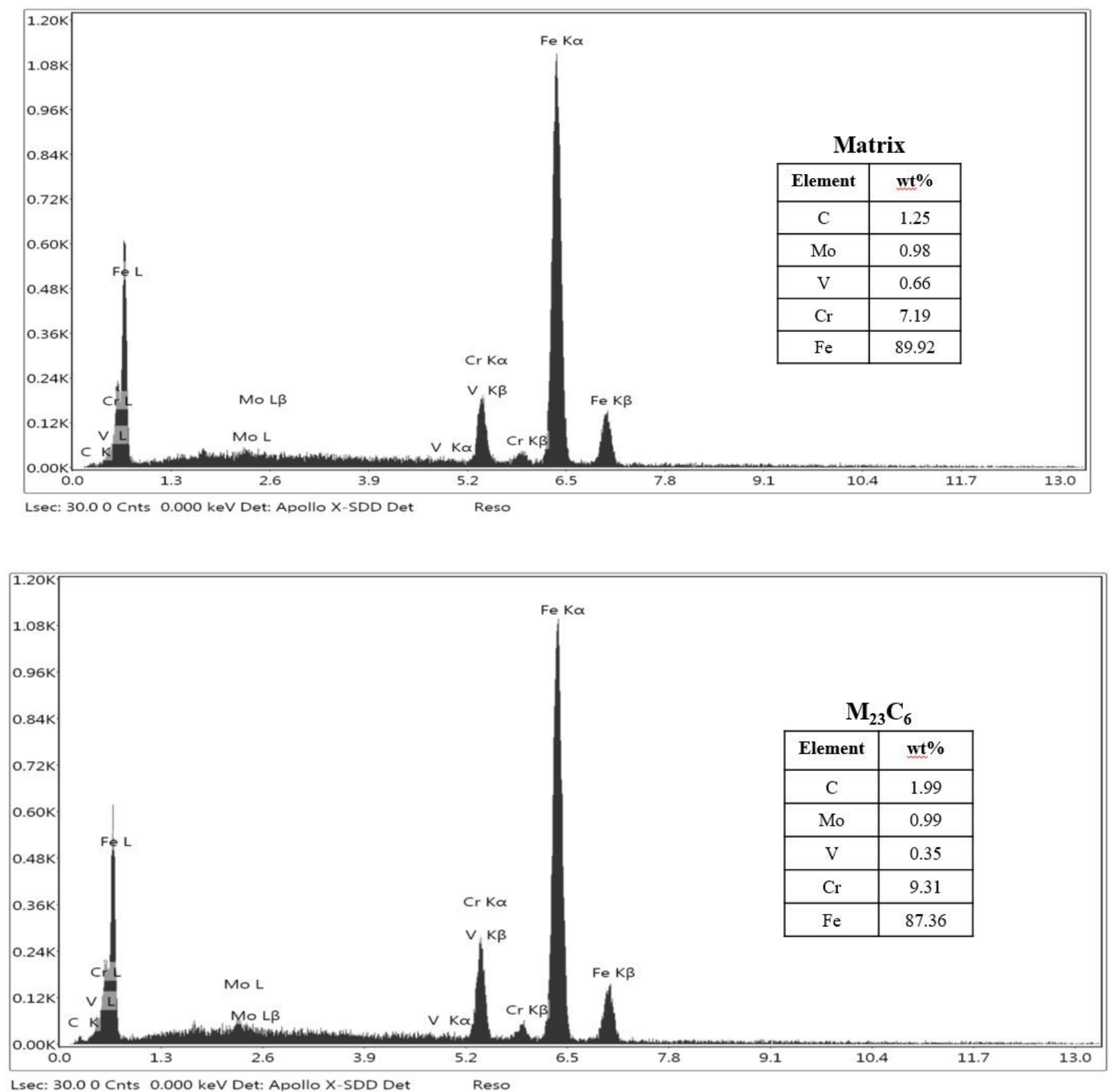

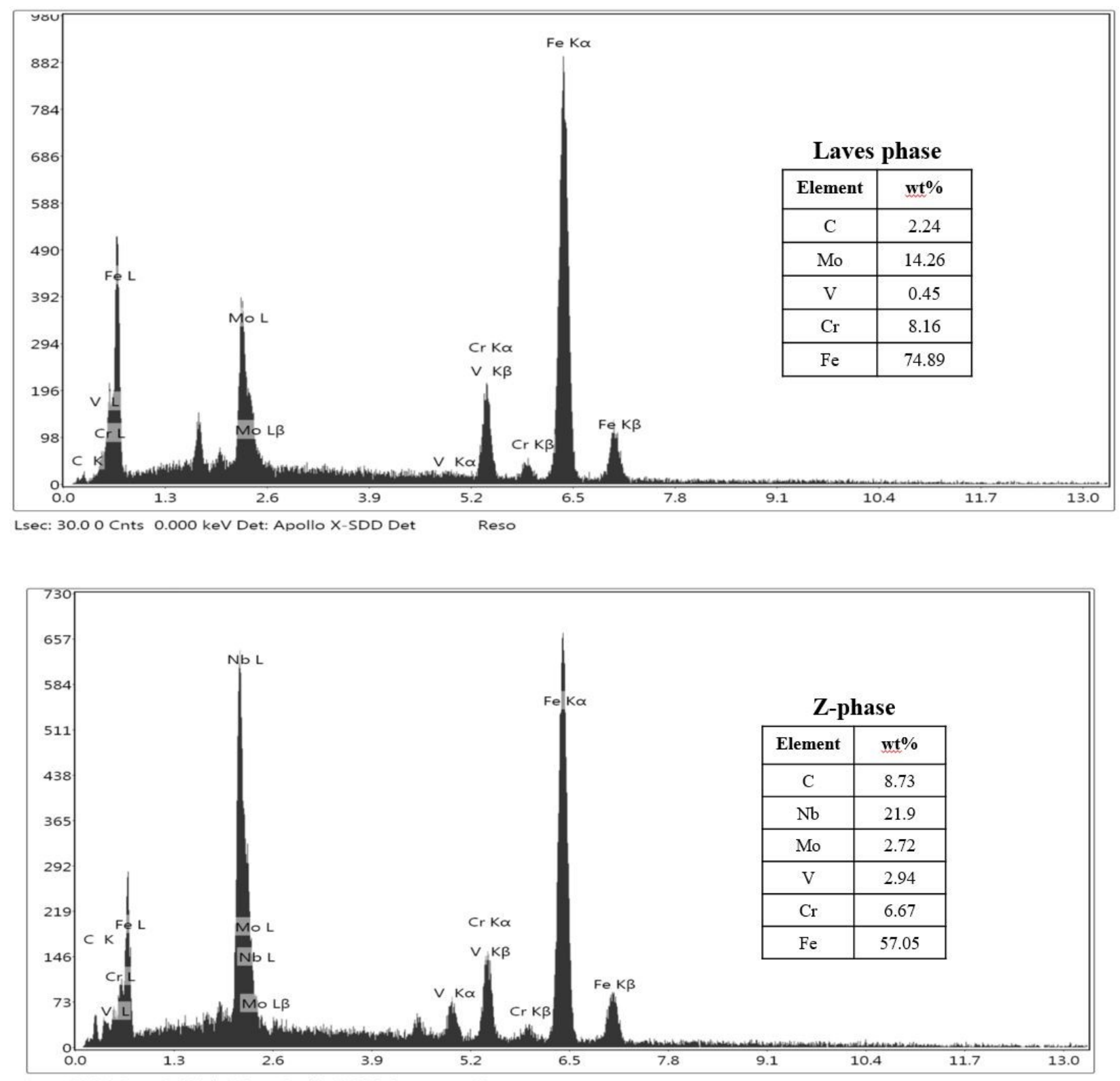

Lsec: 30.0 o Cnts $0.000 \mathrm{keV}$ Det: Apollo X-SDD Det Reso

Fig. 7- 1. EDX spectra of the matrix, M23C6, Laves phase and Z-phase in un-aged F91. 
Microstructures evolved after each 1,000-hour stage, up to 5,000 hours, are compared with the un-aged specimen in Fig. 7- 2. Laves phase was first observed with a significant amount of Mo in some precipitates after thermal exposure for 1,000 hours. Most of the Laves phase was observed at grain/lath boundaries adjacent or attached to $\mathrm{M}_{23} \mathrm{C}_{6}$ particles, while a few were found within the grain interior. The microstructure after aging for 1,000 hours in Fig. 7- 2 is an example showing that two types of precipitate are present at boundaries and clustered together - the $\mathrm{M}_{23} \mathrm{C}_{6}$ circlemarked has low brightness, and the Laves phase rectangle-marked appears much brighter under SEM-BSE imaging. Note that the rectangle marks only to emphasize a few of the large Laves phase observed within the matrix, more are easily identified based on the brightness. Clustering of precipitates makes the Laves phase particle size measurement difficult since it is often attached to other precipitates. The formation of Laves phase is analogous to a vacuum that sucks Mo from the surrounding solid solution, which is then chemically compounded with Fe and other elements to form Laves phase. A study by Panait et al. showed that the chemical composition of Cr-rich $\mathrm{M}_{23} \mathrm{C}_{6}$ carbides had only mild variations that the Cr content increased from 61.2 to 70.5 at.\%, and Mo content only increased from 5.7 to 6.8 at.\% in modified grade 91 steel undergoing creep at $600^{\circ} \mathrm{C}$ and $80 \mathrm{MPa}$ for 113,431 hours [ $\left.{ }^{144}\right]$. Therefore, the drastic increase in Mo content must be attributed to Laves phase nucleation and growth. The EDX analyses revealed that the brighter particle clusters absorbed a significant amount of Mo to form $\mathrm{Fe}_{2} \mathrm{Mo}$ compound (Fig. 7- 2). In addition, not only the Mo content but also the size of the particle clusters increased during aging. Fig. 7- 3 shows the Mo content variation during the 5,000-hour aging treatment at $600^{\circ} \mathrm{C}$, an almost linearly increasing trend is observed for the Laves phase $/ \mathrm{M}_{23} \mathrm{C}_{6} / \mathrm{MX}$ clusters. The cluster particle size is also found to increase (Fig. 7- 3). After 5,000-hour aging heat treatment, Mo content 
increased to an average of $6.78 \mathrm{wt} . \%$, and the particle size was almost double that measured in the pristine material.
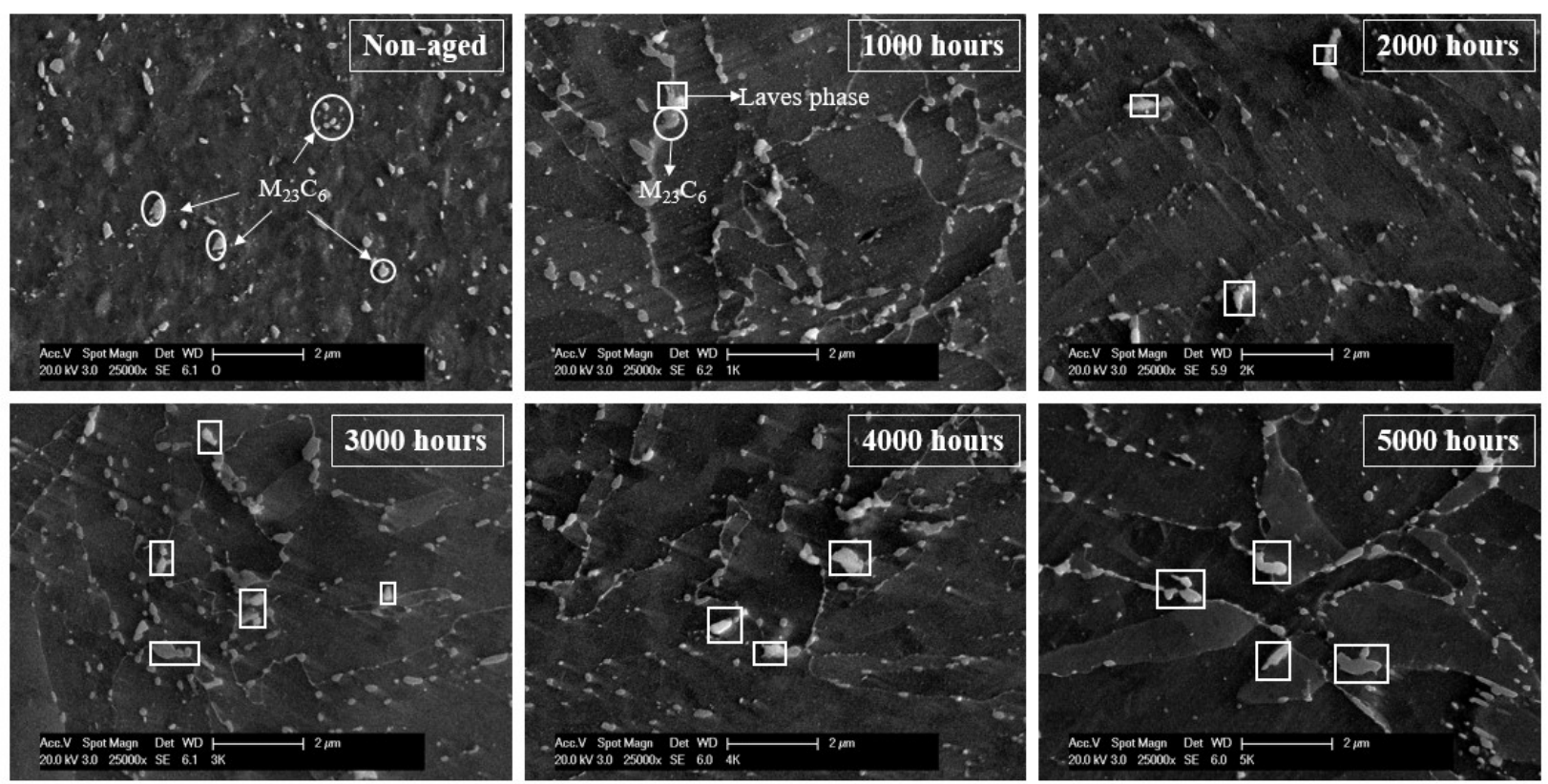

Fig. 7- 2. Laves phase nucleation during aging heat treatment. 


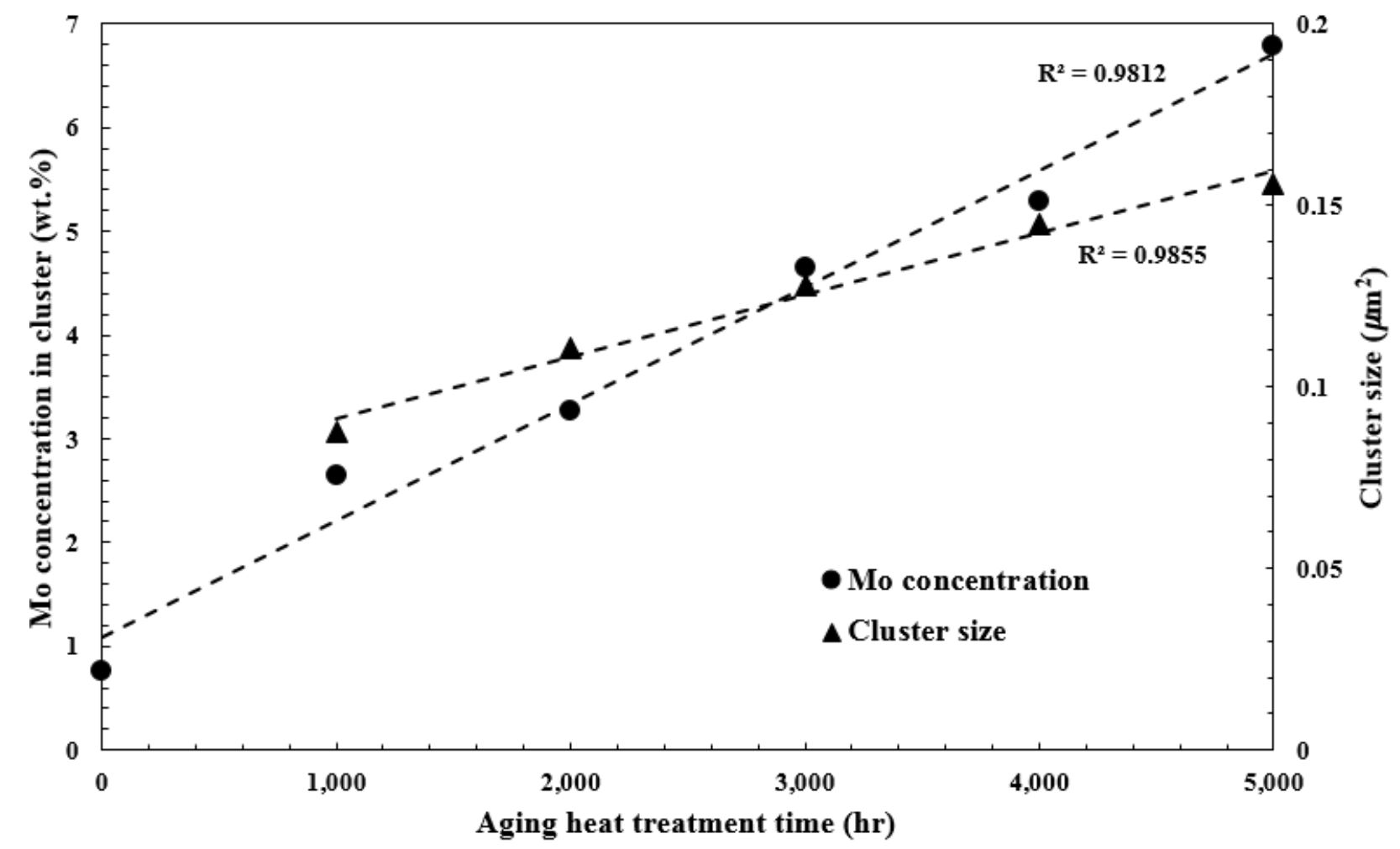

Fig. 7- 3. Variations of Mo concentration in Mo-rich clusters and particle size during aging.

The hardness of the specimen was also measured after the heat treatment using a Clemex Microhardness Tester. In total five indents were made on the specimen for every 1,000-hour heat treatment. The results are reported in Table 7- 1, which show that the average hardness only drops from 194 to $180 \mathrm{HV}$ after 1,000-hour aging and then remains constant for the remainder of the heat treatment duration.

Table 7- 1 Hardness of the F91 coupon after aging heat treatment for different time durations

\begin{tabular}{ccccccc}
\hline Aging time (hr) & \multicolumn{7}{c}{ Hardness (HV) } & Mean (HV) \\
\hline 0 & 196 & 198 & 194 & 190 & 193 & 194 \\
1,000 & 183 & 179 & 180 & 185 & 174 & 180 \\
2,000 & 177 & 186 & 186 & 184 & 187 & 184 \\
3,000 & 186 & 181 & 180 & 180 & 181 & 182 \\
4,000 & 187 & 186 & 185 & 181 & 186 & 185 \\
5,000 & 162 & 189 & 190 & 184 & 186 & 182 \\
\hline
\end{tabular}




\subsection{Laves Phase Nucleation during Creep}

In the previous section, Laves phase formation during thermal exposure under zero stress condition was investigated. It is also important to understand Laves phase growth under the combined effect of temperature, applied stress and exposure time during creep. In this study, the changes of Mo content in the precipitates were examined and analyzed in ruptured coupons. For un-aged F91, Laves phase was found in all the creep-rupture coupons at $600^{\circ} \mathrm{C}$. Although the increase was not remarkable, about $1.09 \mathrm{wt} . \%$, at stresses of 140 and $160 \mathrm{MPa}$, except the one crept under $130 \mathrm{MPa}$ stress at $600^{\circ} \mathrm{C}$ with a TTR of 1602 hours, the average increase of Laves phase was 6.97 wt. $\%$. There was no significant Laves phase detected in the coupons crept at $550^{\circ} \mathrm{C}$. The Mo contents in large clusters of all coupons after creep rupture can be found in Table 7-2. Moreover, one ruptured un-aged coupon (at $130 \mathrm{MPa}$ and $600^{\circ} \mathrm{C}$ ) appeared to have a few Z-phase precipitates. Fig. 7- 4 and Fig. 7- 5 compare two types of coupons after rupture. The microstructures show that although aged-coupons have more Laves phase than un-aged ones, the fracture mode remains the same for each stress level, which indicates that Laves phase could shorten the creep life, but may not change the creep mechanisms under the same test condition. 

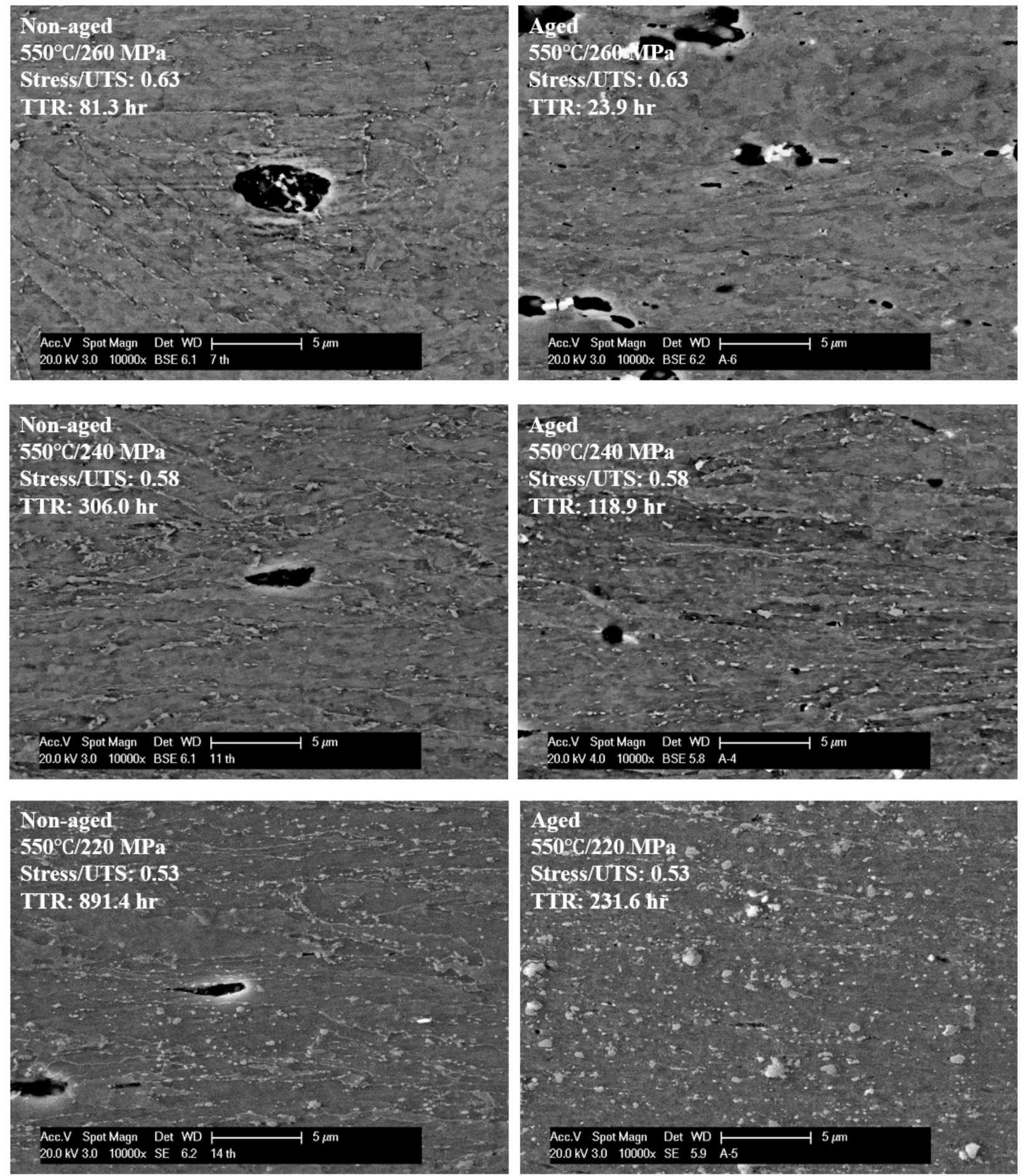

Fig. 7- 4. Comparison in microstructure between un-aged and aged ruptured coupons tested at $550^{\circ} \mathrm{C}$. 

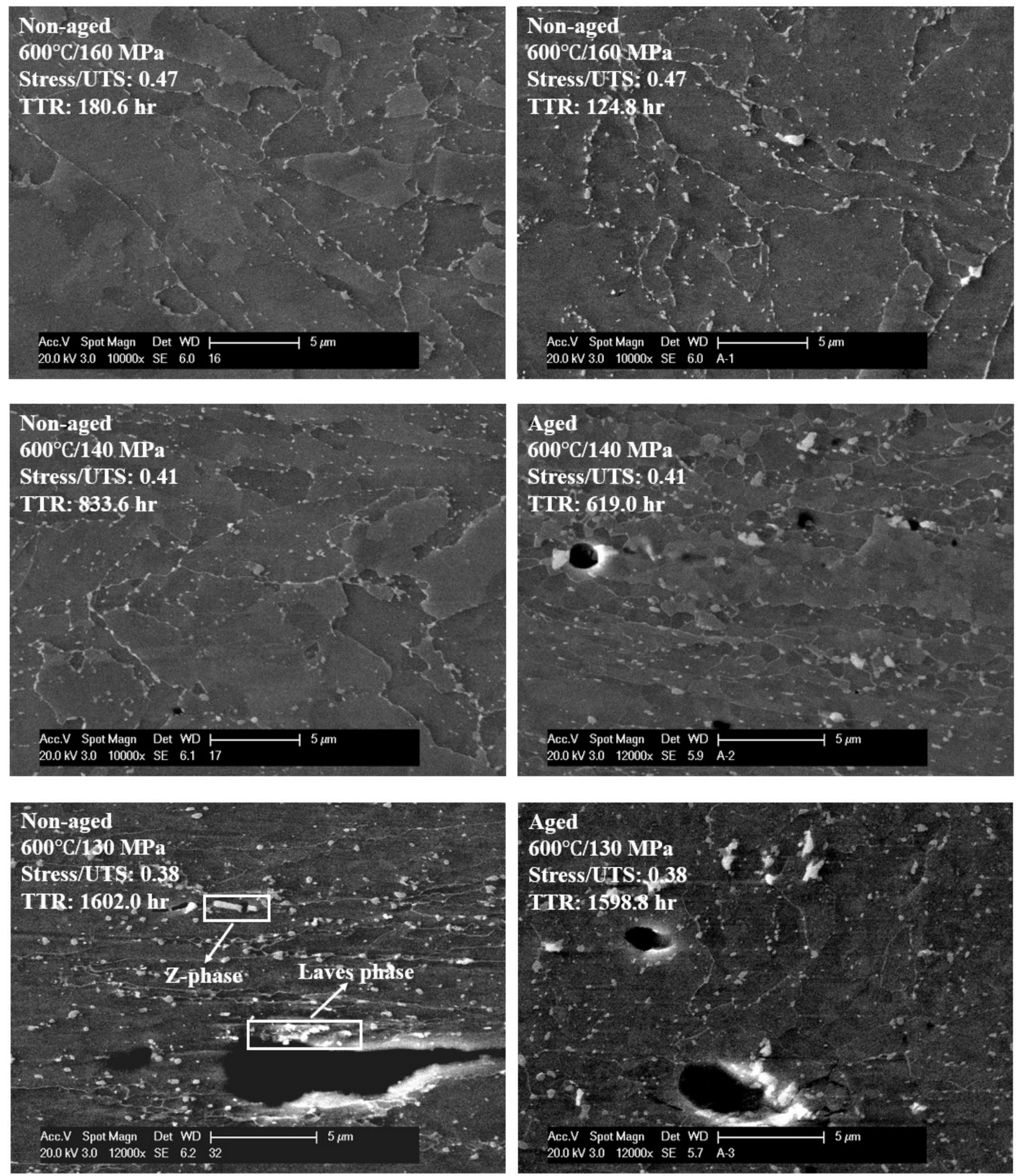

Fig. 7- 5. Comparison in microstructure between un-aged and aged ruptured coupons tested at $600^{\circ} \mathrm{C}$. 
For aged F91, Mo concentration continued to increase significantly during creep. Fig. 7- 6 depicts the Mo concentration in the ruptured aged coupons at $550^{\circ} \mathrm{C}$ and $600^{\circ} \mathrm{C}$ respectively. Apparently, the Mo content increased at higher rates under the effect of stress. The average growth rate can be estimated by the final amount of Mo subtracting the initial amount, then dividing by the TTR value. Fig. 7- 7 shows the Laves phase (Mo concentration) growth rates as a function of stress at $550^{\circ} \mathrm{C}$ and $600^{\circ} \mathrm{C}$ respectively, and both have a stress exponent of approximately 10. Although the Mo concentration growth rate was higher under high stresses, the specimens failed in relatively shorter time with less Laves phase precipitated. Under low stresses, however, the creep process was prolonged, which allowed longer exposure time for the Laves phase to grow, leading to high Mo content at rupture. For example, in the aged coupon at $600^{\circ} \mathrm{C}$ and $130 \mathrm{MPa}$, there is a significant increase of Mo content, about $14.21 \mathrm{wt} . \%$ compared to $6.78 \mathrm{wt} . \%$ just after aging and before creep test. Fig. 7- 5 compares the microstructures from two types of coupon crept under the same condition, at $600^{\circ} \mathrm{C}$ under $130 \mathrm{MPa}$, and both show that large voids grew around Laves phase clusters, which resulted in a decrease of creep strength. In addition to Laves phase, un-aged coupon had a small amount of Z-phase developed during creep testing, which could also nucleate defects. 


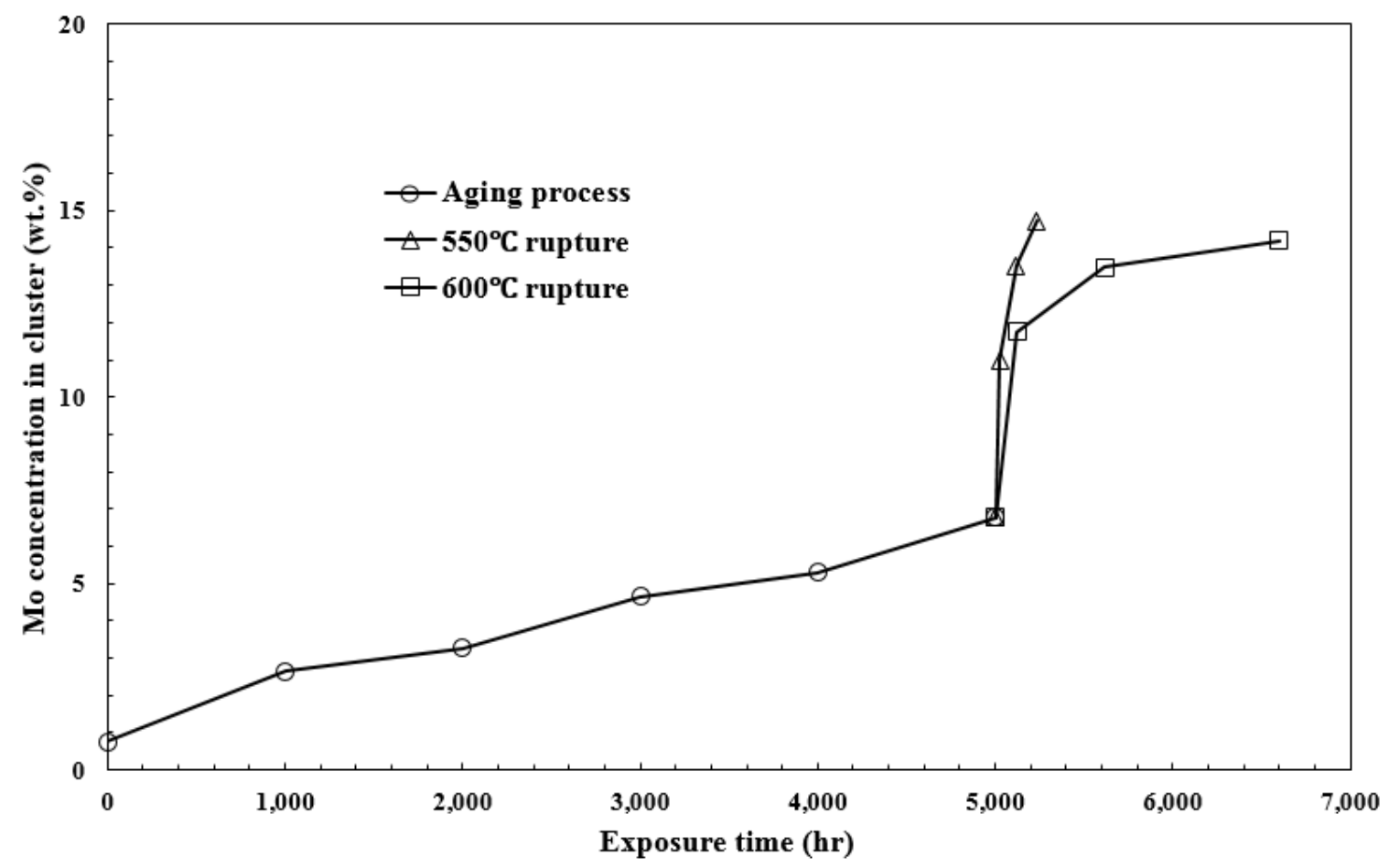

Fig. 7- 6. Variations of Mo concentration with test duration in creep ruptured aged-coupons.

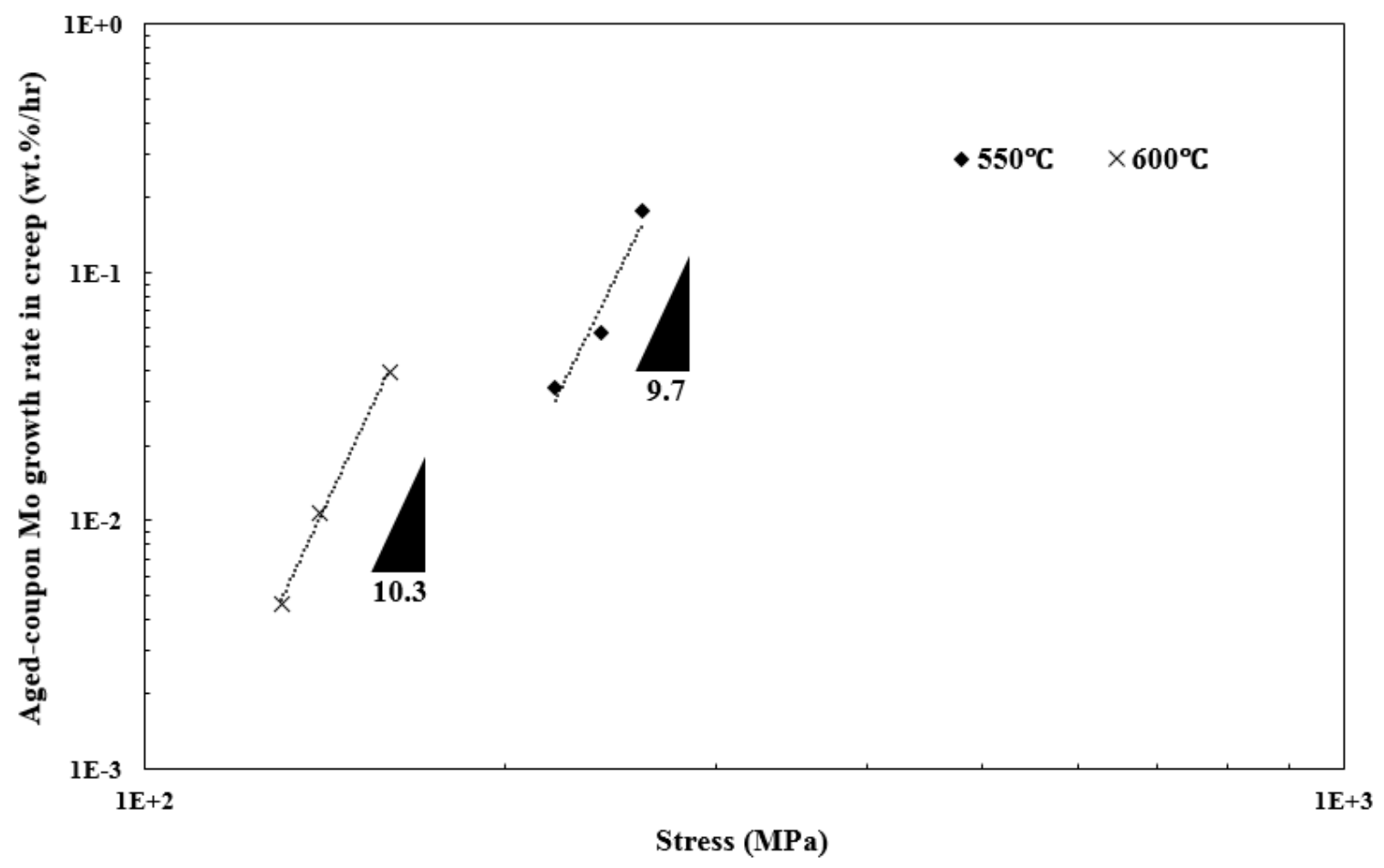

Fig. 7- 7. Laves phase growth rates as a function of stress in aged-coupons during creep tests. 


\subsection{Creep Strain-time Curves}

The minimum creep rate, the TTR, and the Mo content in the Laves phase of un-aged and aged coupons, along with the creep test conditions are given in Table 4. Upon comparing the TTR data, most of the aged coupons have shorter lifetime due to increased Laves phase formation. One exception is the test condition of $600^{\circ} \mathrm{C}$ and $130 \mathrm{MPa}$, the two types of coupon have the same lifetime around 1,600 hours. As mentioned earlier, a large amount of Laves phase particles and a few Z-phase particles were observed in the un-aged coupon after 1,600 hours of creep testing.

Table 7- 2 Comparison of aged-coupon and un-aged coupon creep test results

\begin{tabular}{|c|c|c|c|c|c|c|c|}
\hline \multirow[t]{2}{*}{$\begin{array}{c}\text { Temperature } \\
\left({ }^{\circ} \mathrm{C}\right)\end{array}$} & \multirow[t]{2}{*}{$\begin{array}{c}\text { Engineering stress } \\
(\mathrm{MPa})\end{array}$} & \multicolumn{2}{|c|}{$\begin{array}{l}\text { Mo content } \\
\text { (wt.\%) }\end{array}$} & \multicolumn{2}{|c|}{$\begin{array}{l}\text { TTR } \\
\text { (hr) }\end{array}$} & \multicolumn{2}{|c|}{$\begin{array}{c}\text { Minimum creep } \\
\text { rate } \\
(\% / \mathrm{hr})\end{array}$} \\
\hline & & Un-aged & Aged & Un-aged & Aged & Un-aged & Aged \\
\hline \multirow{3}{*}{550} & 220 & 1.01 & 14.72 & 891.4 & 231.6 & 4.6E-03 & $1.4 \mathrm{E}-02$ \\
\hline & 240 & 0.80 & 13.54 & 306.0 & 118.9 & $1.1 \mathrm{E}-02$ & $3.4 \mathrm{E}-02$ \\
\hline & 260 & 1.23 & 10.99 & 43.1 & 23.9 & $1.1 \mathrm{E}-01$ & $2.2 \mathrm{E}-01$ \\
\hline \multirow{3}{*}{600} & 130 & 7.73 & 14.21 & 1602 & 1598.8 & $3.1 \mathrm{E}-03$ & $2.7 \mathrm{E}-03$ \\
\hline & 140 & 1.73 & 13.48 & 833.6 & 619.0 & $6.2 \mathrm{E}-03$ & $4.3 \mathrm{E}-03$ \\
\hline & 160 & 1.97 & 11.76 & 180.6 & 124.8 & $3.4 \mathrm{E}-02$ & $3.6 \mathrm{E}-02$ \\
\hline
\end{tabular}

Fig. 7- 8 and Fig. 7- 9 show the creep strain-time curves of aged and un-aged coupons at the temperatures of $550^{\circ} \mathrm{C}$ and $600^{\circ} \mathrm{C}$, respectively. At $550^{\circ} \mathrm{C}$, aged coupons exhibited higher minimum creep rate at the steady-state stage and led to earlier onset of a tertiary creep than the un-aged coupon. At $600^{\circ} \mathrm{C}$, although the minimum creep rates of the two types of coupon were close in the transient stage, the aged coupons exhibited an earlier transition to tertiary creep. Given the 
evidence of Mo segregation and the associated void growth, it is reasonable to believe that the formation of Laves phase caused an increase in creep rate and reduction in creep rupture life.

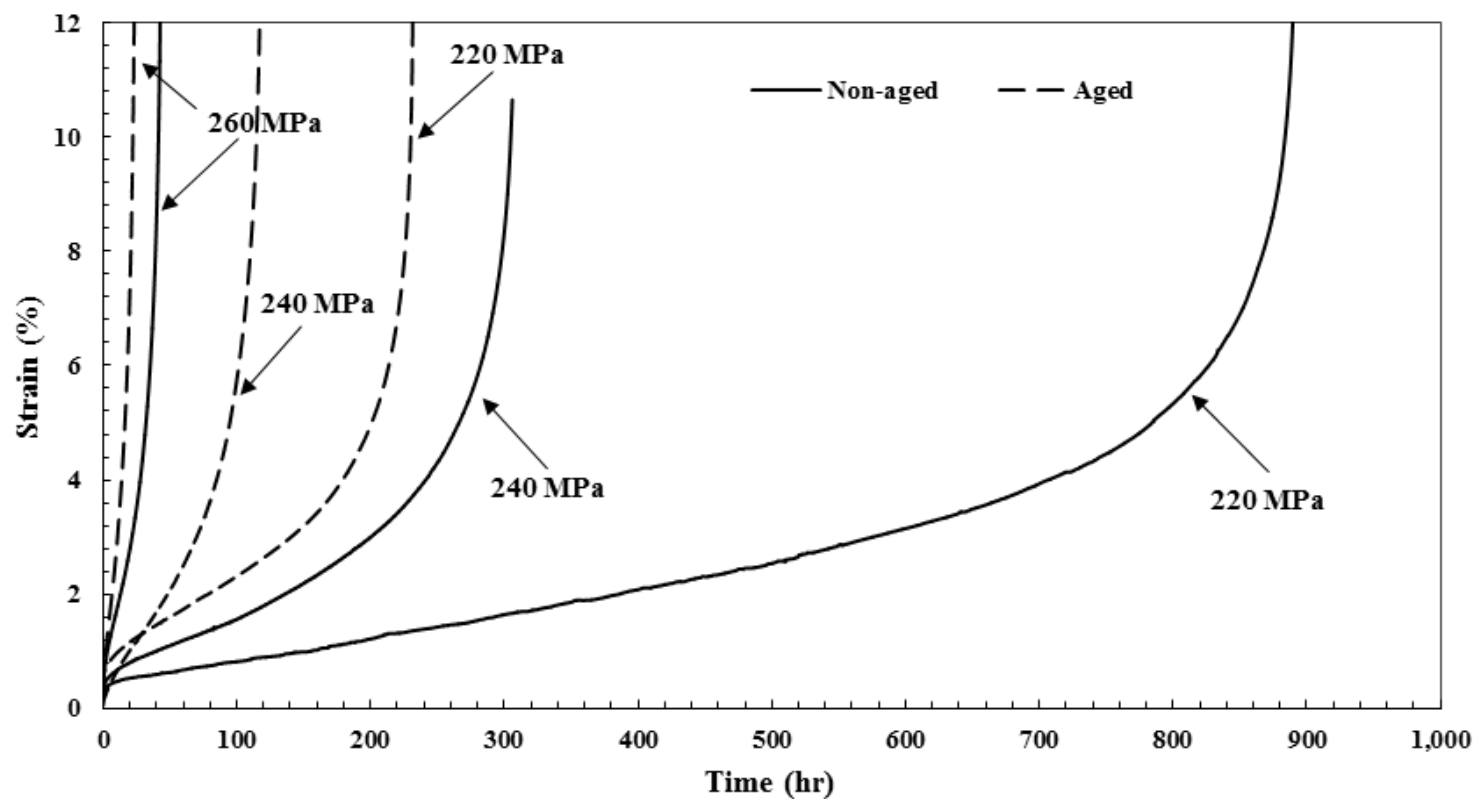

Fig. 7- 8. Creep strain-time curves of un-aged and aged coupons tested at $550^{\circ} \mathrm{C}$.

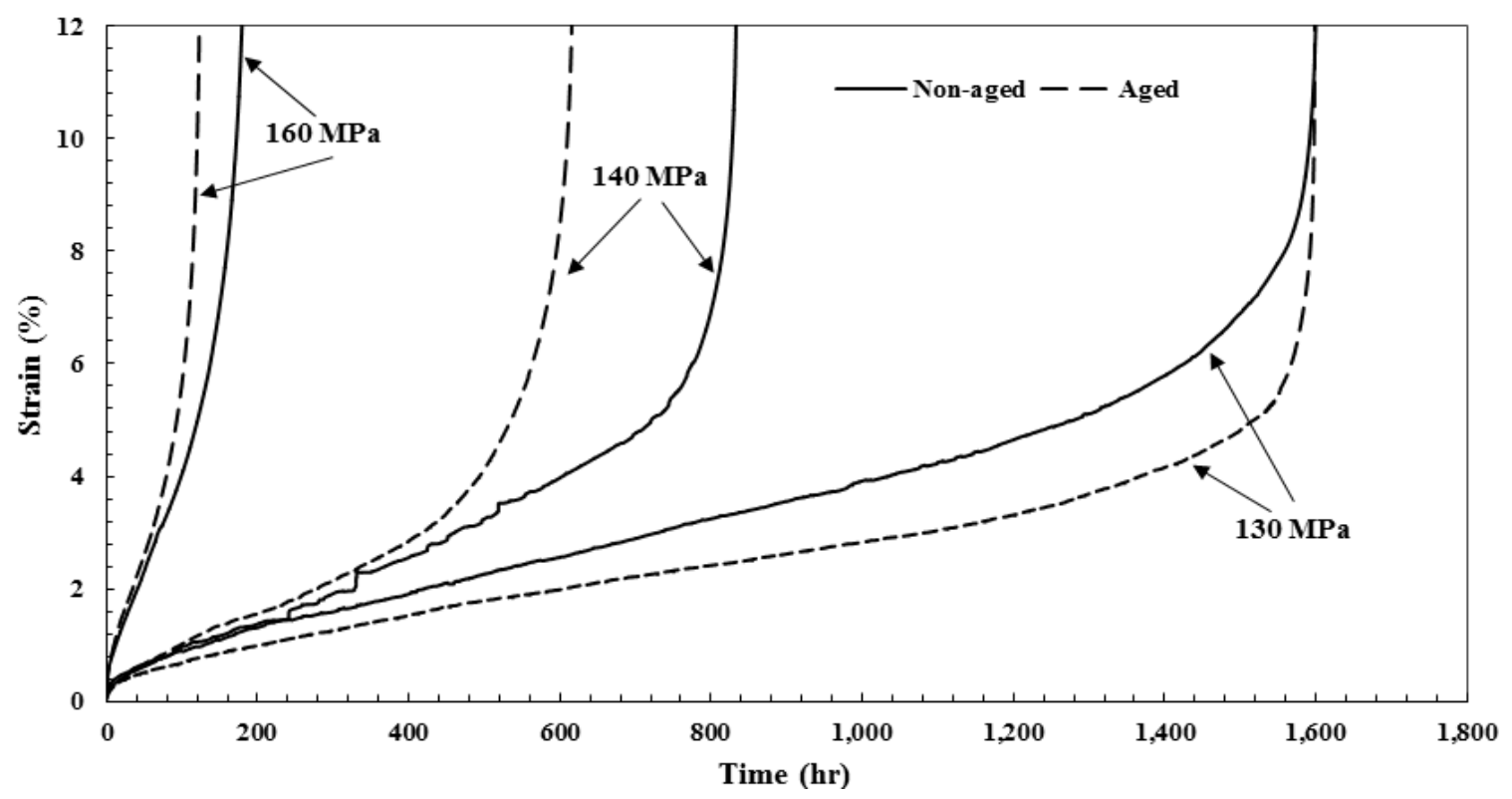

Fig. 7- 9. Creep strain-time curves of un-aged and aged coupons tested at $600^{\circ} \mathrm{C}$. 


\subsection{Model Analysis}

IDC, IDG, and GBS assume a constant power exponent for each of the mechanisms in the DMTS model. For Grade 91 group, IDC has an exponent of 6, GBS has an exponent in the range of 10 to 17, and IDG has the highest exponent, ranging from 18 to 29 (Table 5- 5). The wide variations for GBS and IDG are due to different heat treatment histories and/or manufacturing processes as described in Chapter $5\left[{ }^{65}\right]$.

Power exponents of un-aged and aged coupons are shown on a log-log scale curve of minimum creep rate versus normalized stress in Fig. 7- 10, obtained by power fitting. At $550^{\circ} \mathrm{C}$, the creep rate power-exponent of the un-aged coupon is 19.1 , but that of aged coupons reduces to 16.2. At $600^{\circ} \mathrm{C}$, power-law exponents of the two types of coupon are very close. Considering that the Laves phase mostly formed at the grain and lath boundaries rather than in the interior matrix, it is reasonable to postulate that Laves phase primarily affected GBS. Then, assuming that the IDG creep rate in the two types of coupons is the same and subtracting this rate from the total minimum creep rate, the GBS+IDC rate is shown in Fig. 7- 11, where open symbols represent the rates for un-aged coupons and closed symbols represent that for aged coupons, calculated using Eq. (4-10) subtracting $\dot{\varepsilon_{g}}$. It is noticed that the aged material exhibits a power-law exponent almost identical to the GBS of the un-aged specimen, which supports the above postulation. The power-law proportional constant increased after aging of the material. This is because the formation of Laves phase reduced the pinning effect of $\mathrm{M}_{23} \mathrm{C}_{6} / \mathrm{MX}$ at the grain/lath boundaries. It is also noticed, interestingly, that this power-exponent is very close to that of the Laves phase formation. 


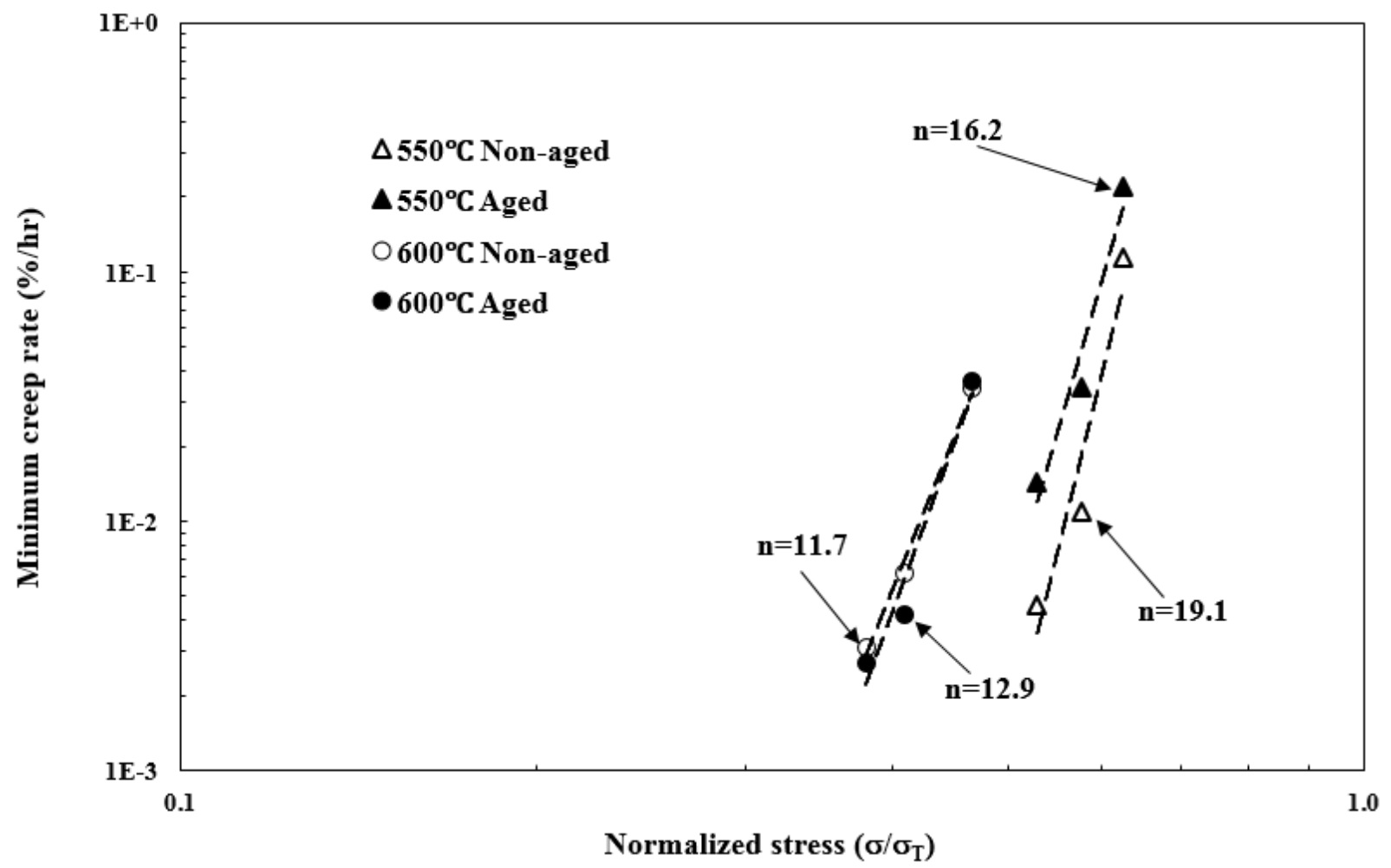

Fig. 7- 10. Minimum creep rate vs. normalized stress.

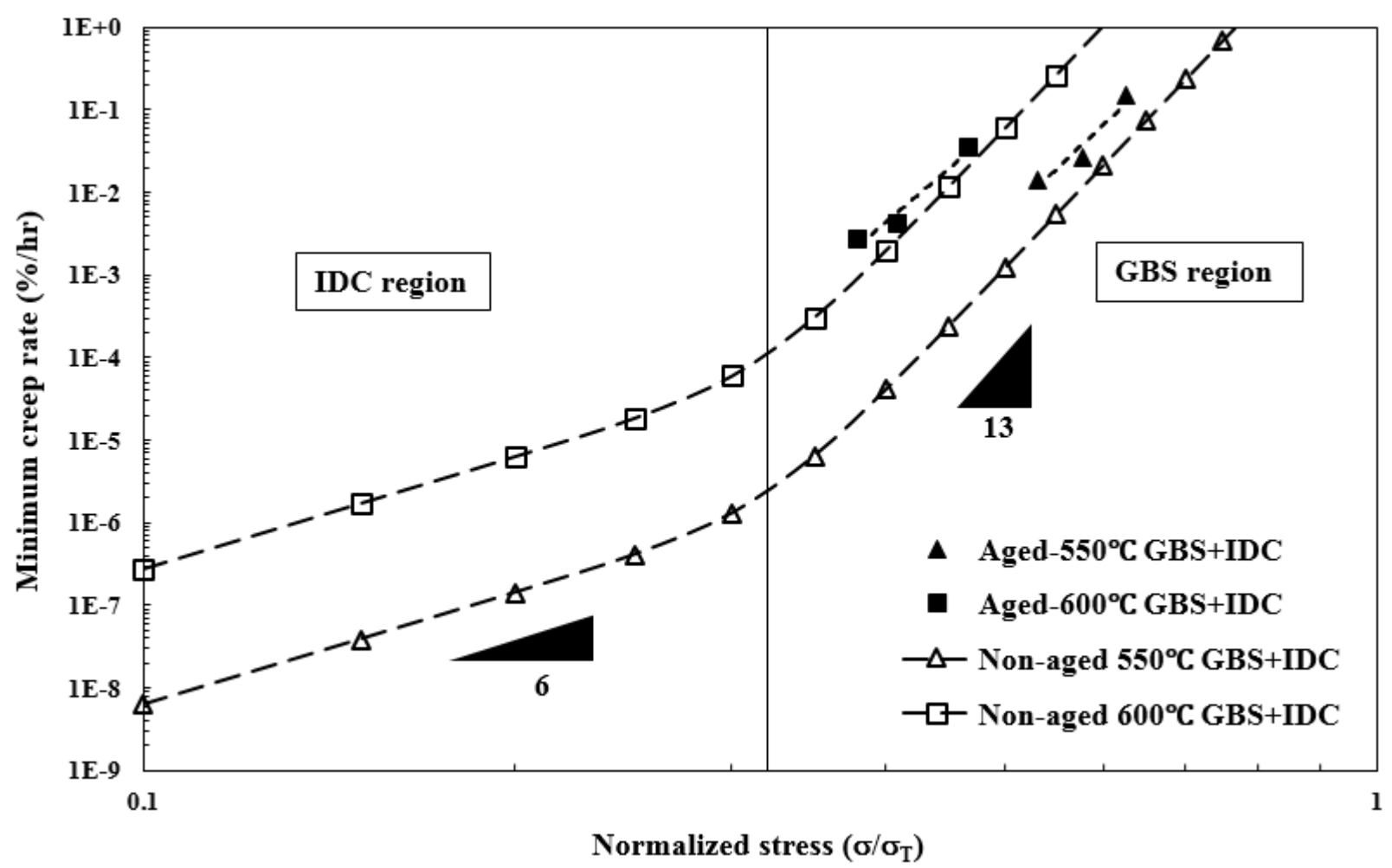

Fig. 7- 11. Comparison of minimum creep rate between two types of coupon without IDG. 


\subsection{Summary}

The aging heat treatment effect on the microstructural degradation of F91 has been investigated. The main outcomes can be summarized as follows.

- Laves phase generally did not exist in the regular tempered state (at $760-800^{\circ} \mathrm{C}$ for 8 hours) of F91, but it can nucleate and grow during aging heat treatment at $600^{\circ} \mathrm{C}$, which is the service temperature of most F91 components in steam turbines. Therefore, this finding is an essential issue that must be addressed in the component creep resistance. The Laves phase tended to nucleate very closely to $\mathrm{M}_{23} \mathrm{C}_{6}$ precipitates at the grain/lath boundaries, and further agglomerated into large clusters. Moreover, both Mo concentration and Morich cluster size increased almost linearly with thermal exposure up to 5,000 hours in stressfree condition.

- The Laves phase formation exhibited dependence on stress and temperature, in a fashion similar to minimum creep rate. Interestingly, its power-exponent is very close to that of GBS.

- For the above reason, Laves phase in aged coupons continued to grow at higher rates during the creep tests. Although Laves phase grew at a higher rate under a higher stress, Mo concentration accumulated the most with the longest time-to-rupture at the same test temperatures. For un-aged coupons, all ruptured coupons at $550^{\circ} \mathrm{C}$ contained no Laves phase; and at $600^{\circ} \mathrm{C}$, all ruptured coupons contained Laves phase, which was more pronounced for the coupon having longer time-to-rupture at $130 \mathrm{MPa}$.

- Laves phase is thought to be responsible for premature creep failure of F91 because it facilitated void growth. All aged coupons had shorter creep lifetimes as compared to unaged coupons under the same test conditions, except at $600^{\circ} \mathrm{C}$ and $130 \mathrm{MPa}$. In this case, 
the un-aged material had a significant amount of Laves phase, and additional Z-phase and the two types of coupon had the similar rupture time.

- Comparing the GBS+IDC rates of the two types of the coupons, the aged material has a power-law exponent almost identical to the GBS of the un-aged specimen, with an increased proportional constant. This seemed to corroborate the fact that the Laves phase clusters mostly formed on the grain/lath boundaries and deteriorated the pinning effect of $\mathrm{M}_{23} \mathrm{C}_{6} / \mathrm{MX}$. 


\section{Chapter 8 Conclusions and Future Work}

\subsection{Conclusions}

In the present study, three types of F91 steel coupon (pristine, aged, MCrAlY-coated) were tested under high-temperature conditions for creep, and their microstructures at creep-ruptured conditions were examined. The basic DMTS creep model was developed and further modified with consideration of oxidation effect. These mechanism-based models have been validated for Grade 91 steels. In particular, the basic model has been successfully applied to NIMS Grade 91 steels of various product forms including tubes, plates, pipes, and forging products, showing excellent agreement with the experimental data. It is shown that the modified DMTS creep model improves the prediction accuracy by incorporating oxidation effect into the basic DMTS model. The microstructural degradation of F91 steel with the formation of Laves phase during long-time thermal exposure (aging) has a detrimental effect on the creep strength of F91 steel. Furthermore, the modified DMTS model is capable of accurately predicting the long-term creep lives of Grade 91 steels along with providing the information on failure modes, as long as it is calibrated based on a few short-term creep tests.

Through analysing the NIMS creep data and the data generated from the present research, using the DMTS model based on the well-recognized deformation mechanisms such as GBS, IDG, and IDC, and the modified DMTS model with oxidation effect included, meaningful insights were obtained, which were mostly for the first time to be proposed, to the best knowledge of the author. The present study provided a systematic physics-based approach to characterize the creep behavior of Grade 91 steels with the following major conclusions: 
1. Manufacturing process and heat treatment history affected elevated-temperature creep behavior of modified Grade 91 steels, such as creep rate, creep rupture mode and creep life. The differences in these aspects were characterized by the DMTS model parameters. Comparing extruded (tubes) and hot-rolled (plates and pipes) modified Grade 91, the power exponent $p$ of GBS increased from 12 (for tubes) to 16 (for plates and pipe), while the power exponent $n$ of IDG increased from 18 (for tubes) to 26 (for plates). The forged modified Grade 91 (F91) had similar creep behavior to plate MgB. The activation energies in the hot-rolled plates tempered at a lower temperature of $760^{\circ} \mathrm{C}$ were larger than that of the extruded ones. These differences were perhaps due to the fact that the hot-rolled and forged microstructures were heavier "worked" with a higher dislocation density than the extruded ones. On the other hand, the hot-rolling process followed by the tempering process at higher temperatures above $780^{\circ} \mathrm{C}$ tended to eliminate IDG of the coupon in the tested stress range (or pushing it beyond this range). This was perhaps due to the fact that tempering at higher temperatures relieves the martensitic laths to allow more inter-lath sliding or GBS, which resulted in longer creep life at high stresses.

2. Collated with NIMS Plate MgB creep data, experimental F91 creep data generated from this study were used to derive F91-model parameters. In general, the DMTS model was valid for a variety of modified Grade 91 products including tubes, plates, pipes and forging, exhibiting excellent agreement with the vast experimental data for the steady-state creep rates.

3. From short-term creep curve analyses, the critical failure strain $\varepsilon_{c r}$ was established at $90 \%$ TTR, before unstable deformation, i.e., necking occurred at the final stage of rupture. The temperature dependence of this critical failure strain exhibited a "brittle to ductile" 
transition phenomenon: $\varepsilon_{c r}=2-3 \%$ over the temperature range of $450-500^{\circ} \mathrm{C}$; and $\varepsilon_{c r}=$ 6 - $7 \%$ over the temperature above $500^{\circ} \mathrm{C}$. This failure criterion was set for long-term creep life prediction for modified Grade 91 steels.

4. Using short-term creep test data of F91 to determine the creep strain-time curve parameters $H, \beta, M$, and with the above-define failure strain $\varepsilon_{c r}$, long-term creep lives of the three forms of NIMS Grade steels were predicted based on the involved deformation mechanisms. In general, creep life predictions of these steels using the proposed DMTS model were satisfactory as compared with experimental data with high $R^{2}$ values (very close to 1 ) and low $P$-values (much less than 0.05 ).

5. MCrAlY coating has a beneficial effect on the creep resistance of F91 steel by preventing oxidation attack on the substrate during long-time creep in that it can generally reduce the creep rate and prolongs the onset of the tertiary creep, thus increasing the creep life. Once the coated coupon was treated with composite stress partition, the basic DMTS creep model described well the oxidation-free creep behavior of coated F91.

6. The present study first proposed an area-reduction method to examine the oxide scale growth during creep quantitatively. From such measurements, the oxidation growth rate coefficient, $K_{o x}$, under each creep condition was determined, and the average of this coefficient at a temperature showed to obey the Arrhenius relationship.

7. By taking oxidation effect into account, the modified DMTS model (with the same oxidation-free $M$ but additional oxide growth terms) showed to better describe the creep behavior of uncoated F91 coupons than the basic DMTS model with coupon-borne oxidation influence for creeping time longer than $10^{4}$ hours. In addition, the modified DMTS model also predicted the long-term creep life of F91, showing excellent agreement 
with NIMS creep data. This signified the oxidation effect as a life-limiting factor separated from material-intrinsic deformation mechanisms such as IDG, IDC and GBS. On the other hand, empirical models could impossibly include the oxidation effect, if long-term creep tests were not conducted.

8. The modified DMTS model performance was compared with the Larson-Miller parameter method. The former exhibited the advantage of better accuracy in life prediction with less experimental data required. In addition, the modified DMTS model also provided insights into the controlling deformation mechanisms and potential failure mode, feeding back information for further material improvement.

9. Laves phase formation and growth were found to be a key factor influencing microstructural evolution during long-time thermal exposure. Laves phase usually did not exist in the regular tempered state (at $760-800^{\circ} \mathrm{C}$ for 8 hours) of F91, but it can nucleate and grow during aging heat treatment at $600^{\circ} \mathrm{C}$, which is the service temperature of most F91 components in steam turbines. Therefore, this finding is an essential issue in the component creep resistance. The Laves phase tended to nucleate very close to $\mathrm{M}_{23} \mathrm{C}_{6}$ precipitates at the grain/lath boundaries, and further agglomerated into large clusters. Moreover, both Mo concentration and Mo-rich cluster size increased almost linearly with thermal exposure up to 5,000 hours in stress-free condition.

10. The Laves phase formation exhibited stress and temperature dependence in a fashion similar to the minimum creep rate. Interestingly, its power-exponent was very close to that of GBS.

11. Laves phase in aged coupons continued to grow at higher rates during the creep tests. Although the Laves phase grew at a higher rate under higher stresses, Mo concentration 
accumulated the most with the longest time-to-rupture at the same test temperatures. For un-aged coupons, all ruptured coupons at $550^{\circ} \mathrm{C}$ contained no Laves phase; and at $600^{\circ} \mathrm{C}$, all ruptured coupons contained Laves phase, which was more pronounced for the coupon having longer time-to-rupture at $130 \mathrm{MPa}$.

12. Laves phase was thought to be responsible for premature creep failure of F91 because it facilitated void growth. All aged coupons had shorter creep lifetimes as compared to unaged coupons under the same test conditions, except at $600^{\circ} \mathrm{C}$ and $130 \mathrm{MPa}$. In this case, the un-aged material had a significant amount of Laves phase and additional Z-phase, and the two types of coupon had the similar rupture time.

13. Although Laves phase was responsible for creep rate increase and premature onset of the tertiary stage, the rupture microstructure analysis indicated that its existence did not affect the rupture failure mode.

14. By comparing the GBS+IDC rates of the two types of coupons, the aged material exhibited a power-law exponent almost identical to the GBS of the un-aged one, with an increased proportional constant. This was corroborated by the fact that the Laves phase clusters mostly formed on the grain/lath boundaries and deteriorated the pinning effect of $\mathrm{M}_{23} \mathrm{C}_{6} / \mathrm{MX}$. 


\subsection{Significant Contributions}

Compared to the state-of-the-art understanding of creep of Grade 91 steels, significant contributions of this thesis study are highlighted below. For a long time when the industry has been adopting empirical models, the modified DMTS model, for the first time, provides a new perspective of assessing material long-term creep performance with the ability to identify deformation mechanisms within one constitutive equation. The deformation mechanisms that are built in the model, GBS, IDC, and IDG, have been categorized and validated by Grade 91 creep study, and furthermore, the oxidation impact on creep is also implanted into the modified DMTS model. This new tool hence can be applied to evaluate a wide range of materials by inputting only short-term creep data. The long-term creep life assessment can be improved significantly with physical meanings. In the boiler and pressure vessel industry, the precise evaluation of material life is the most critical issue which has long been concerned. The last but not the least, the DMTS model provides a base from which many future studies can be launched to explore the effects of more mechanisms and microstructure degradation on long-term creep performance.

- The deformation-mechanism-based true-stress creep model (DMTS) is further modified to include the effect of oxide scale formation on the true stress during creep process. This model, for the first time, gives a quantitative description of the environmental effect separated from the material-intrinsic deformation mechanisms: IDG, IDC, and GBS. It then predicts the long-term creep performance with true oxidation contribution, as opposed to other empirical methods where short-term data are extrapolated without this consideration. In the present thesis study, although the modified DMTS model is validated with the creep data of this study as well as the NIMS creep data for modified 9Cr-1Mo steels only, it can be applied to a wide variety of metallic materials which have IDG, IDC and GBS as 
common deformation mechanisms, and can suffer oxidation at high temperatures. Therefore, the most significant contribution of this thesis work is to establish a mechanismdelineated approach for prediction of long-term creep performance of metallic materials, which is the first time over the last hundred years of creep study.

- Using the DMTS model, a complete characterization of creep behavior can be given in terms of mechanism (IDG, IDC, and GBS) parameters. With such relations, the effects of the manufacturing process and heat treatment history on elevated-temperature creep behavior of modified Grade 91 steels, such as creep rate, creep rupture mode and creep life has also been quantified, which can be in turn feedback to material designers for tailoring the material creep properties through processing. Furthermore, it can also predicate the microstructural change and failure mode of creep rupture, and this understanding is also useful to structural integrity engineer for maintaining the safe operation of the equipment.

- The present thesis study, also for the first time, explores the application of MCrAlY coating as a means to enhance the long-term creep performance of the modified Grade 91 steel (F91), and the results are beneficial to design of material integrity for high-temperature applications.

- The present study first proposed an area-reduction method to assess the oxide scale growth during creep quantitatively. This approach can be helpful to separate the oxidation effect from conventional creep testing in air. Since vacuum creep test is expensive, and therefore oxidation-free creep data are not readily available, this method can be effectively used to estimate the oxidation growth rate coefficient, $K_{o x}$, for metals that suffer oxidation during creep. With this method, the modified DMTS model can also be extended for long-term creep life prediction of other materials. 
- The modified DMTS model developed in this thesis study has refurbished the LarsonMiller parameter method with mechanism partition feature, providing insights into the controlling deformation mechanisms and potential failure mode. This is a significant improvement to the state-of-the-art creep design methodology.

- This thesis study presents a physics-based method to quantify the effect of microstructural evolution (for Grade 91 steels, in terms of Laves phase formation and growth) in relation to the controlling deformation mechanisms, which also has a significant implication concerning the long-term creep performance of materials.

- This thesis study has resulted in two journal publications in Materials Science and Engineering A, one conference publication at International Conference on Fracture, and one poster at European Creep Collaborative Committee (ECCC) Conference. 


\subsection{Future Work}

The present research systematically studied the creep rate, strain-time and creep life behavior of modified Grade 91 steels using proposed models. The outcomes contributed significantly to scientific understanding of these materials under high-temperature creep. However, further improvements on the proposed models can be made in the following aspects:

- It is necessary to find the correlation of mechanism parameters with processing parameters such as heat treatment temperature and processing time. This planned work could provide further understanding of Grade 91 steels deformation mechanisms systematically.

- To facilitate the engineering application of the models mathematical algorithms or even computer codes to efficiently extract mechanism parameters from typical stress-rate maps and strain-time plots are needed. Because IDC, IDG, and GBS are competing (or overlapping) in nature, thus it is often difficult to delineate them in short-term creep tests, which may lead to errors in the analyses. Therefore, more long-term creep test data, i.e., strain-time curve, are needed for further calibration of the proposed models. Also, with the strain-time curve of a particular material, the accuracy of material parameters $\beta, H$ and $M$ should be improved.

- The oxidation growth behavior may be stress-dependent under creep conditions. The present study first conducted area-reduction analysis for a limited case at different stresses and temperatures between $500^{\circ} \mathrm{C}$ and $650^{\circ} \mathrm{C}$, since limited information is available in the literature. In order to understand the oxidation behavior of the materials under creep conditions, the stress influence on oxidation nucleation and growth needs to be systematically studied. In addition, gas permeation assisted oxidation or void growth also 
needs to be evaluated. Coupon thickness deduction measurement can be facilitated by computed tomography (CT) scan technique.

- Microstructural evolution plays a crucial role in the long-term creep performance of F91. Laves phase precipitation and growth during the service need to be further quantified, especially in the temperature range of $550-650^{\circ} \mathrm{C}$. Conduct creep test on aged $\mathrm{F} 91$ steel is planned to assess the effect of Laves phase formation in IDC and IDG regions.

- To split Laves phase with $\mathrm{M}_{23} \mathrm{C}_{6}$, further measurement of the Laves phase volume fraction will enhance the model precision. TEM is an advanced technique that can be used for such research. A mathematical model should be built to describe Laves phase nucleation and growth behavior, as a continuous function of time under stresses at elevated temperatures, and then be integrated into the DMTS model. In the same way, other secondary precipitates such as Z-phase may also need to be modeled for better accuracy of long-term creep life prediction. 


\section{References}

1. ASME International. Power Piping, ASME Code for Pressure Piping,B31. 2016, (ASME International, 2016).

2. BPVC-ASME. Boiler and Pressure Vessel Code. (American Society of Mechanical Engineers, New York, NY., 2017).

3. Masuyama, F. \& Shingledecker, J. P. Recent status of ASME code on creep strength enhanced ferritic steels. Procedia Eng. 55, 314-325 (2013).

4. The USGS Water Science School. A Coal-Fired Thermoelectric Power Plant. Available at: https://water.usgs.gov/edu/wupt-coalplant-diagram.html.

5. Lee, H. Y., Kim, W. G. \& Kim, N. H. Behavior of Grade 91 material specimens with and without defect at elevated temperature. Int. J. Press. Vessel. Pip. 125, 3-12 (2015).

6. Allen, D. \& Garwood, S. Energy Materials-Strategic Research Agenda. Q2, Materials Energy Review. (2007).

7. Whittaker, M., Harrison, W., Deen, C., Rae, C. \& Williams, S. Creep deformation by dislocation movement in waspaloy. Materials (Basel). 10, (2017).

8. Y. Yamamoto. in Advanced Heat Resistant Steel for Power Generation 560-573 (1998).

9. Cohn, M. \& Pterson, S. Fitness for service of degraded Grade 91 pipe. in ASME 2012 Pressure Vessels and Piping Conference 669-675 (2012).

10. $\mathrm{ABe}, \mathrm{F}$. Effect of fine precipitation and subsequent coarsening of Fe2W laves phase on the creep deformation behavior of tempered martensitic 9Cr-W steels. Metall. Mater. Trans. A 36, 321-332 (2005).

11. Gurrappa, I. Effect of aluminum on hot corrosion resistance of MCrAlY-based bond coatings. J. Mater. Sci. Lett. 20, 2225-2229 (2001).

12. Taylor, T. A. \& Walsh, P. N. Thermal expansion of MCrAlY alloys. Surf. Coatings Technol. 177-178, 24-31 (2004).

13. Thompson, J. A., Tsui, Y. C., Reed, R. C., Rickerby, D. S. \& Clyne, T. W. Creep of plasma sprayed CoNiCrAlY and NiCrAlY bond coats and its effects on residual stresses during thermal cycling of thermal barrier coating systems. High Temp. Surf. Eng. 199-212 (2000).

14. Brandi, W., Grabke, H. J., Toma, D. \& Krüger, J. The oxidation behaviour of sprayed MCrAlY coatings. Surf. Coatings Technol. 86-87, 41-47 (1996).

15. Zhang, X. C., Liu, C. J., Xuan, F. Z., Wang, Z. D. \& Tu, S. T. Effect of NiCr and NiCrAl coatings on the creep resistance of a Ni alloy. Mater. Sci. Eng. A 528, 2282-2287 (2011).

16. Chang, Y. Y., Tsaur, C. C. \& Rock, J. C. Microstructure studies of an aluminide coating on 9Cr-1Mo steel during high temperature oxidation. Surf. Coatings Technol. 200, 6588- 
6593 (2006).

17. Emami, M., Hadavi, S. M. M., Hayashi, S. \& Shahverdi, H. R. High temperature performance of an FeAl laser coated 9Cr1Mo steel. Oxid. Met. 80, 437-451 (2013).

18. Klueh, R. L. Elevated-temperature ferritic and martensitic steels and their application to future nuclear reactors. Int. Mater. Rev. 1-66 (2004). doi:10.1179/174328005X41140

19. Mayer, K. H. \& Masuyama, F. in Creep-Resistant Steels (eds. Abe, F., Kern, T.-U. \& Viswanathan, R.) 15-77 (Woodhead Publishing Limited, 2008).

20. Muramatsu, K. Development of ultra-super critical plant in Japan. in Advanced Heat Resistant Steels for Power Generation 543-559 (IMO Communications Ltd, 1999).

21. Viswanathan, R. \& Bakker, W. Materials for ultrasupercritical coal power plants - boiler materials: Part 1. Jmepeg 10, 81-95 (2001).

22. Viswanathan, R. \& Bakker, W. Materials for ultrasupercritical coal power plants - turbine materials: Part II. J. Mater. Eng. Perform. 10, 96-101 (2001).

23. Computational Thermodynamics. (2006). Available at: http://www.calphad.com/ironcarbon.html.

24. Blau, P. J. ASM Handbook Vol. 18: Friction, Lubrication and Wear Technology. ASM (1992). doi:10.1361/asmhba00

25. Klueh, R. L. \& Bloom, E. E. The development of ferritic steels for fast inducedradioactivity decay for fusion reactor applications. Nucl. Eng. Des. Fusion 2, 383-389 (1985).

26. Klueh, R. L. \& Nelson, A. T. Ferritic/martensitic steels for next-generation reactors. J. Nucl. Mater. 371, 37-52 (2007).

27. Swindeman, R. W., Santella, M. L., Maziasz, P. J., Roberts, B. W. \& Coleman, K. Issues in replacing Cr-Mo steels and stainless steels with 9Cr-1Mo-V steel. Int. J. Press. Vessel. Pip. 81, 507-512 (2004).

28. Cipolla, L. et al. Conversion of MX nitrides to Z-phase in a martensitic $12 \% \mathrm{Cr}$ steel. Acta Mater. 58, 669-679 (2010).

29. Zhang, X. Z., Wu, X. J., Liu, R., Liu, J. \& Yao, M. X. Influence of Laves phase on creep strength of modified 9Cr-1Mo steel. Mater. Sci. Eng. A 706, 279-286 (2017).

30. Taneike, M., Abe, F. \& Sawada, K. Creep-strengthening of steel at high temperatures using nano-sized carbonitride dispersions. Nature 424, 294-296 (2003).

31. Larson, F. \& Miller, J. A time-temperature relationship for rupture and creep stresses. Trans. ASME 74, 765 (1952).

32. Betten, J. Creep mechanics (Third Edition). Creep Mechanics (Third Edition) (2008). doi:10.1007/978-3-540-85051-9

33. Raj, B. \& Vijayalakshmi, M. in Comprehensive Nuclear Materials 4, 97-121 (2012). 
34. Shrestha, T., Basirat, M., Charit, I., Potirniche, G. P. \& Rink, K. K. Creep rupture behavior of Grade 91 steel. Mater. Sci. Eng. A 565, 382-391 (2013).

35. Kimura, K., Kushima, H. \& Sawada, K. Long-term creep deformation property of modified 9Cr-1Mo steel. Mater. Sci. Eng. A 510-511, 58-63 (2009).

36. Sklenička, V. et al. Long-term creep behavior of $9-12 \% \mathrm{Cr}$ power plant steels. Mater. Charact. 51, 35-48 (2003).

37. Meyers, M. A. \& Chawla, K. K. Mechanical Behavior of Materials. (2009).

38. Harold J. Frost \& Michael F. Ashby. Deformation-Mechanism Maps.

39. Langdon, T. G. Creep at low stresses: an evaluation of diffusion creep and Harper-Dorn creep as viable creep mechanisms. Metall. Mater. Trans. A 33, 249-259 (2002).

40. Storey, C. D. \& Prior, D. J. Plastic deformation and recrystallization of garnet: A mechanism to facilitate diffusion creep. J. Petrol. 46, 2593-2613 (2005).

41. Blum, W. \& Eisenlohr, P. Dislocation mechanics of creep. Mater. Sci. Eng. A 510-511, 713 (2009).

42. Herring, C. Diffusional viscosity of a polycrystalline solid. J. Appl. Phys. 21, 437-445 (1950).

43. Coble, R. L. A model for boundary diffusion controlled creep in polycrystalline materials. J. Appl. Phys. 34, 1679-1682 (1963).

44. Hazzledine, P. M. \& Schneibel, J. H. Theory of coble creep for irregular grain structures. Acta Metall. Mater. 41, 1253-1262 (1993).

45. Norman E., D. Mechanical Behavior of Materials: Engineering Methods for Deformation, Fracture, and Fatigue. (Pearson Education Limited, 2013).

46. Meyers, M. A. \& Chawla, K. K. Mechanical Behavior of Materials. (2009).

47. Kassner, M. E. Harper-Dorn Creep. Fundam. Creep Met. Alloy. Third Ed. 23, 109-128 (2015).

48. Orowan, E. Problems of plastic gliding. Proc. Phys. Soc. 52, 8 (1940).

49. Norman E., D. Mechanical Behavior of Materials: Engineering Methods for Deformation, Fracture, and Fatigue. (Pearson Education Limited, 2013).

50. Weertman, J. Creep of polycrystalline aluminium as determined from strain rate tests. $J$. Mech. Phys. Solids 4, 230-234 (1956).

51. Weertman, J. Creep of indium, lead and some of their alloys. Trans. Metall. Soc. AIME 218, 207-218 (1960).

52. Weertman, J. Theory of steady-state creep based on dislocation climb. J. Appl. Phys. 26, 1213-1217 (1955).

53. Cannon, W. R. \& Sherby, O. D. High temperature creep behavior of class I and class II 
solid solution alloys. Metall. Trans. 1, 1030-1032 (1970).

54. Langdon, T. G. Grain boundary sliding revisited: Developments in sliding over four decades. Journal of Materials Science 41, 597-609 (2006).

55. Chokshi, A. H. An evaluation of the grain-boundary sliding contribution to creep deformation in polycrystalline alumina. J. Mater. Sci. 25, 3221-3228 (1990).

56. Basirat, M., Shrestha, T., Potirniche, G. P., Charit, I. \& Rink, K. A study of the creep behavior of modified 9Cr-1Mo steel using continuum-damage modeling. Int. J. Plast. 37, 95-107 (2012).

57. Wu, X. J. \& Koul, A. K. Grain boundary sliding in the presence of grain boundary precipitates during transient creep. Metall. Mater. Trans. A 26, 905-914 (1995).

58. Wu, X. J. \& Koul, A. K. Grain Boundary Sliding at Serrated Grain Boundaries. Adv. Perform. Mater. 4, 409-420 (1997).

59. Reducing Canada's greenhouse gas emissions. Enviroment and Climate Change Canada (2017). Available at: https://www.ec.gc.ca/dd-sd/default.asp?lang=En\&n=AD1B22FD-1.

60. Sundararajan, G. The Monkman-Grant relationship. Mater. Sci. Eng. A 112, 205-214 (1989).

61. Shibli, A. \& Holdsworth, S. Creep and fracture in high-temperature components-Design and life assessment issues. International Journal of Pressure Vessels and Piping 85, 1 (2008).

62. Wu, X., Williams, S. \& Gong, D. A true-stress creep model based on deformation mechanisms for polycrystalline materials. J. Mater. Eng. Perform. 21, 2255-2262 (2012).

63. X. J., W. An integrated creep-fatigue theory for material damage modeling. Key Eng. Mater. 627, 341-344 (2015).

64. Xijia, W., Z., Z., L., J. \& P., P. Material Selection Issues for A Nozzle Guide Vane against Service Induced Failure. J. Eng. Gas Turbines Power 139, 6 (2017).

65. Zhang, X. Z., Wu, X. J., Liu, R., Liu, J. \& Yao, M. X. Deformation-mechanism-based modeling of creep behavior of modified 9Cr-1Mo steel. Mater. Sci. Eng. A 689, 345-352 (2017).

66. Dunand, D. C., Han, B. Q. \& Jansen, a. M. Monkman-grant analysis of creep fracture in dispersion-strengthened and particulate-reinforced aluminum. Metallurgical and Materials Transactions A 30, 829-838 (1999).

67. Larson, F. \& Miller, J. A time-temperature relationship for rupture and creep stresses. Trans. ASME 74, 765 (1952).

68. Furillo, F. T., Purushothaman, S. \& Tien, J. K. Understanding the Larson-Miller Parameter. Scr. Metall. 11, 493-496 (1977).

69. eFatigue LLC. Thermal Mechanical Technical Background. Available at: https://www.efatigue.com/hightemp/background/tmf.html. 
70. Tamura, M., Abe, F., Shiba, K., Sakasegawa, H. \& Tanigawa, H. Larson-miller constant of heat-resistant steel. Metall. Mater. Trans. A Phys. Metall. Mater. Sci. 44, 2645-2661 (2013).

71. Abdallah, Z., Gray, V., Whittaker, M. \& Perkins, K. A critical analysis of the conventionally employed creep lifing methods. Materials (Basel). 7, 3371-3398 (2014).

72. Furillo, F. T., Purushothaman, S. \& Tien, J. K. Further discussion on 'understanding the Larson-Miller parameter'. Scr. Metall. 12, 331-332 (1978).

73. Kloc, L., Sklenicka, V., Dlouhy, A. \& Kucharova, K. in Microstructural Stability of Creep Resistant Alloys for High Temperature Plant Applications 445-456 (Institute of Materials, 1998).

74. Evans, R. W., Wilshire, B. \& Metals, I. of. Creep of Metals and Alloys. Predictive and quantitative metallurgy series. 304, (1985).

75. ABE, F. Creep behavior, deformation mechanisms, and creep Life of Mod.9Cr-1Mo Steel. Metall. Mater. Trans. A Phys. Metall. Mater. Sci. 46, 5610-5625 (2015).

76. Abe, F. Stress to produce a minimum creep rate of $10-5 \% / \mathrm{h}$ and stress to cause rupture at $105 \mathrm{~h}$ for ferritic and austenitic steels and superalloys. Int. J. Press. Vessel. Pip. 85, 99107 (2008).

77. Li, J. C. M. Comment 'on dislocation kinetics'. Acta Metall. 13, 37-39 (1965).

78. Harrison, W., Whittaker, M. \& Williams, S. Recent advances in creep modelling of the nickel base superalloy, Alloy 720Li. Materials (Basel). 6, 1118-1137 (2013).

79. Massé, T. \& Lejeail, Y. Creep behaviour and failure modelling of modified 9Cr1Mo steel. in Nuclear Engineering and Design 246, 220-232 (2012).

80. Hall, F. R. \& Hayhurst, D. R. Continuum damage mechanics modelling of high temperature deformation and failure in a pipe weldment. in Proceedings of the Royal Society of London A: Mathematical, Physical and Engineering Sciences 433, 383-403 (1991).

81. Hayhurst, R. J., Vakili-Tahami, F., Mustata, R. \& Hayhurst, D. R. Thickness and multiaxial stress creep rupture criteria of the Type IV component of a ferritic steel weld. $J$. Strain Anal. Eng. Des. 39, 729-743 (2004).

82. Xue, W., Qian-Gang, P., Zhi-Jun, L., Hui-Qiang, Z. \& Yong-Shun, T. Creep rupture behaviour of $\mathrm{P} 92$ steel weldment. Eng. Fail. Anal. 18, 186-191 (2011).

83. Shrestha, T. et al. Creep deformation mechanisms in modified 9Cr-1Mo steel. J. Nucl. Mater. 423, 110-119 (2012).

84. Wu, X. J. \& Koul, A. K. Modeling creep in complex engineering alloys. in Creep and stress relaxation in miniature structures and components 3-19 (1996).

85. Ashby, M. F. A first report on deformation-mechanism maps. Acta Metall. 20, 887-897 (1972). 
86. Ashby, M. F. \& Frost, H. J. Deformation-mechanism maps. Oxford Pergamon Press. 4445 (1982).

87. Gorash, Y. Development of a creep-damage model for non-isothermal long-term strength analysis of high-temperature components operating in a wide stress range. Martin Luther University of Halle-Winttenberg, Halle Germany (2008).

88. Harold J. Frost \& Michael F. Ashby. Deformation-Mechanism Maps. Available at: http://engineering.dartmouth.edu/defmech/.

89. Mohamed, F. A. \& Langdon, T. G. Deformation mechanism maps based on grain size. Metall. Trans. 5, 2339-2345 (1974).

90. Langdon, T. G. \& Mohamed, F. A. A new type of deformation mechanism map for hightemperature creep. Mater. Sci. Eng. 32, 103-112 (1978).

91. Lüthy, H., White, R. A. \& Sherby, O. D. Grain boundary sliding and deformation mechanism maps. Mater. Sci. Eng. 39, 211-216 (1979).

92. Abe, F. Coarsening behavior of lath and its effect on creep rates in tempered martensitic 9Cr-W steels. Mater. Sci. Eng. A 387-389, 565-569 (2004).

93. Pandey, C., Giri, A. \& Mahapatra, M. M. Evolution of phases in P91 steel in various heat treatment conditions and their effect on microstructure stability and mechanical properties. Mater. Sci. Eng. A 664, 58-74 (2016).

94. Abe, F., Taneike, M. \& Sawada, K. Alloy design of creep resistant $9 \mathrm{Cr}$ steel using a dispersion of nano-sized carbonitrides. Int. J. Press. Vessel. Pip. 84, 3-12 (2007).

95. Hald, J. Microstructure and long-term creep properties of 9-12\% Cr steels. Int. J. Press. Vessel. Pip. 85, 30-37 (2008).

96. Danielsen, H. K. Review of Z phase precipitation in $9-12$ wt- $\%$ Cr steels. Mater. Sci. Technol. 32, 126-137 (2016).

97. Danielsen, H. K. \& Hald, J. Behaviour of Z phase in $9-12 \%$ Cr steels. Energy Mater. 1, 49-57 (2006).

98. Strong, A. \& Gooch, D. J. Microstructural Development and Stability in High Chromium Ferritic Power Plant Steels. (Institute of Materials, 1997).

99. Zhu, S., Yang, M., Song, X. L., Tang, S. \& Xiang, Z. D. Characterisation of Laves phase precipitation and its correlation to creep rupture strength of ferritic steels. Mater. Charact. 98, 60-65 (2014).

100. Strang, A. \& Vodarek, V. Z phase formation in martensitic $12 \mathrm{CrMoVNb}$ steel. Mater. Sci. Technol. 12, 552-556 (1996).

101. Danielsen, H. K., Somers, M. A. J. \& Hald, J. Z-phase in 9-12\% Cr Steels. (Technical University of Denmark, 2007).

102. Fedorova, I. et al. Laves-phase precipitates in a low-carbon $9 \% \mathrm{Cr}$ martensitic steel during aging and creep at 923K. Mater. Sci. Eng. A 615, 153-163 (2014). 
103. McLean, M. \& Dyson., B. F. Modeling the effects of damage and microstructural evolution on the creep behavior of engineering alloys. Trans. Soc. Mech. Eng. J. Eng. Mater. Technol. 122, 273-278 (2000).

104. Yurechko, M., Schroer, C., Wedemeyer, O., Skrypnik, A. \& Konys, J. Creep-to-rupture of $9 \% \mathrm{Cr}$ steel T91 in air and oxygen-controlled lead at $650^{\circ} \mathrm{c}$. in Journal of Nuclear Materials 419, 320-328 (2011).

105. Tian, S. J., Jiang, Z. Z. \& Luo, L. Oxidation behavior of T91 steel in flowing oxygencontaining lead-bismuth eutectic at 500 ??C. Mater. Corros. 67, 1274-1285 (2016).

106. Tobar, M. J., Amado, J. M. \& Pereira, J. C. Laser cladding of MCrAlY coatings on stainless steel. in Physics Procedia 56, 276-283 (2014).

107. Taylor, M. P., Evans, H. E., Ponton, C. B. \& Nicholls, J. R. A method for evaluating the creep properties of overlay coatings. Surf. Coatings Technol. 124, 13-18 (2000).

108. Chen, H., Hyde, T. H., Voisey, K. T. \& McCartney, D. G. Application of small punch creep testing to a thermally sprayed CoNiCrAlY bond coat. Mater. Sci. Eng. A 585, 205213 (2013).

109. Saeidi, S., Voisey, K. T. \& McCartney, D. G. Mechanical properties and microstructure of VPS and HVOF CoNiCrAlY coatings. J. Therm. Spray Technol. 20, 1231-1243 (2011).

110. Brandl, W., Toma, D., Krüger, J., Grabke, H. J. \& Matthäus, G. The oxidation behaviour of HVOF thermal-sprayed MCrAlY coatings. Surf. Coatings Technol. 94-95, 21-26 (1997).

111. De Oliveira Bueno, L. Effect of oxidation on creep data: Part 1 - Comparison between some constant load creep results in air and vacuum on 21/4Cr-1Mo steel from 600 to $700^{\circ} \mathrm{C}$. in Materials at High Temperatures 25, 213-221 (2008).

112. FileZilla ${ }^{\circledR}$. FileZilla ${ }^{\circledR}$ The free FTP solution. Available at: https://filezilla-project.org/.

113. Yokogawa Test \& Measurement Corporation. MW100 DATA ACQUISITION UNIT. Available at: http://tmi.yokogawa.com/ca/products/data-acquisition-equipment/low-speeddaq-industrial-recorders/mw100-data-acquisition-unit/.

114. Materials, S.-G. C. COMBAT® Boron Nitride Industrial Coatings. Available at: http://www.bn.saint-gobain.com/coatings.

115. ASTM. ASTM E3-11 Standard Guide for Preparation of Metallographic Specimens. ASTM Copyright. i, 1-12 (2011).

116. Practice, S. Standard Practice for Microetching Metals and Alloys ASTM E-407. 7, 1-22 (2016).

117. Method, S. T. ASTM E384-17 Standard Test Method for Microindentation Hardness of MaterialsKnoop and Vickers Hardness of Materials. Annu. B. ASTM Stand. 1-42 (2010). doi:10.1520/E0384-10.2

118. Norton, F. H. The creep of steel at high temperatures. (McGraw-Hill Book Company, Incorporated, 1929). 
119. Cverna, F., Conti, P. \& ASM International. Materials Properties Database Committee. Worldwide Guide to Equivalent Irons and Steels: Fifth Edition. (ASM International, 2006).

120. Kassner, M. E. Fundamentals of Creep in Metals and Alloys: Third Edition (2015). doi:10.1016/C2012-0-06071-1

121. Ennis, P. J., Zielinska-Lipiec, a., Wachter, O. \& Czyrska-Filemonowicz, a. Microstructural stability and creep rupture strength of the martensitic steel P92 for advanced power plant. Acta Mater. 45, 4901-4907 (1997).

122. Deal, B. E. \& Grove, A. S. General relationship for the thermal oxidation of silicon. $J$. Appl. Phys. 36, 3770-3778 (1965).

123. Hollauer, C. Modeling of thermal oxidation and stress effects. (Vienna University of Technology, 2007).

124. Sarrazin, P., Galerie, A. \& Caillet, M. Contribution to understanding parabolic oxidation kinetics of dilute alloys. Part II: Oxides with metal deficit or oxygen excess. Oxid. Met. 46, 299-312 (1996).

125. Kimura, K. \& Sawada, K. Influence of chemical composition and materials processing on creep strength of Grade 91 steels. in 4th International ECCC Conference (2017).

126. Abe, F. Effect of quenching, tempering, and cold rolling on creep deformation behavior of a tempered martensitic 9Cr-1W steel. Metall. Mater. Trans. aPhysical Metall. Mater. Sci. 34A, 913-925 (2003).

127. National Institute for Materials Science (Japan). Creep Data Sheet (CDS), No. 43A. (2014). Available at: http://smds.nims.go.jp/creep/index_en.html.

128. ASME. 2015 ASME Boiler and Pressure Vessel Code Section III. The American Society of Mechanical Engineers (2010). doi:10.1115/1.3454473

129. Swindeman, R. W., Swindeman, M. J., Roberts, B. W., Thurgood, B. E. \& Marriott, D. L. Verification of allowable stresses in ASME section III, subsection NH for Grade 91 steel. (2007).

130. Kimura, K. \& Yaguchi, M. Re-evaluation of long-term creep strength of base metal of ASME Grade 91 type steel. in ASME. Pressure Vessels and Piping Conference, Volume 6B: Materials and Fabrication 9 (2016). doi:10.1115/PVP2016-63355

131. Kimura, K. \& Takahashi, Y. Evaluation of long-term creep strength of ASME Grades 91, 92, and 122 type steels. ASME 2012 Press. Vessel. Pip. Conf. 1-8 (2012). doi:10.1115/PVP2012-78323

132. Kimura, K., Tabuchi, M., Takahashi, Y., Yoshida, K. \& Yagi, K. Long-term creep strength and strength reduction factor for welded joints of ASME Grades 91, 92 and 122 type steels. Int. J. Microstruct. Mater. Prop. 6, 72 (2011).

133. Masatsugu, Y., Kaoru, N. \& Sosuke, N. Re-evaluation of long-term creep strength of welded joint of ASME Grade 91 type steel. in Proceedings of ASME 2016 Pressure 
Vessels and Piping Conference (PVP 2016) 1-7 (ASME, 2017).

134. Zhang, X. Z., Wu, X. J., Liu, R., Liu, J. \& Yao, M. X. Impact of oxidation on creep life for $9 \mathrm{Cr}-1 \mathrm{Mo}-\mathrm{V}-\mathrm{Nb}$ steels. in Poster of 4th International ECCC Creep \& Fracture Conference (2017).

135. Zhang, X. Z., Wu, X. J., Liu, R., Liu, J. \& Yao, M. X. Impact of oxidation on creep life for modified 9Cr-1Mo steels. in ASM Ottawa Valley Chapter: Student Poster Night (2017).

136. Wood, M. I. The mechanical properties of coatings and coated systems. Mater. Sci. Eng. A 120-121, 633-643 (1989).

137. Eggeler, G., Earthman, J. C., Nilsvang, N. \& Ilschner, B. Microstructural study of creep rupture in a 12\% chromium ferritic steel. Acta Metall. 37, 49-60 (1989).

138. Maruyama, K., Sawada, K. \& Koike, J. Advances in physical metallurgy and processing of steels. Strengthening mechanisms of creep resistant tempered martensitic steel. ISIJ Int. 41, 641-653 (2001).

139. Eggeler, G. The effect of long-term creep on particle coarsening in tempered martensite ferritic steels. Acta Metall. 37, 3225-3234 (1989).

140. Isik, M. I., Kostka, A. \& Eggeler, G. On the nucleation of Laves phase particles during high-temperature exposure and creep of tempered martensite ferritic steels. Acta Mater. 81, 230-240 (2014).

141. Zhang, X. Z., Wu, X. J., Liu, R., Liu, J. \& Yao, M. X. Microstructure and modeling of creep resistance of modified 9Cr-1Mo steel. in Proceedings of 14th International Conference on Fracture (ICF 14) (2017).

142. Aghajani, A. et al. On the formation and growth of Mo-rich Laves phase particles during long-term creep of a 12\% chromium tempered martensite ferritic steel. Scr. Mater. 61, 1068-1071 (2009).

143. Spigarelli, S. Microstructure-based assessment of creep rupture strength in $9 \mathrm{Cr}$ steels. Int. J. Press. Vessel. Pip. 101, 64-71 (2013).

144. Panait, C. G., Bendick, W., Fuchsmann, A., Gourgues-Lorenzon, A. F. \& Besson, J. Study of the microstructure of the Grade 91 steel after more than 100,000 h of creep exposure at $600{ }^{\circ}$ C. Int. J. Press. Vessel. Pip. 87, 326-335 (2010). 


\section{Appendices}

\section{Appendix A: Nomenclature of creep strain-time curve}

Considering a typical creep strain-time curve, shown in Fig. AP- 1 schematically, three creep stage: primary creep, secondary creep, and tertiary creep are illustrated. Conventionally, the sum of primary creep plus secondary creep is named as transient creep. The strain terms are defined as follows:

- $\varepsilon_{0}$ is initial elastic-plastic strain. Theoretically, $\varepsilon_{0}=\sigma / E$, where $E$ is the Young's modulus. However, in reality, the measurement inaccuracy could be easily accumulated due to mechanical errors of creep test equipment. Therefore, it is usually assigned to offset the experimental compliance.

- $\varepsilon_{P}$ is defined as engineering primary strain. It is the tangent point from the secondary creep to primary creep (dash line indicates the tangent line), which is the demarcation point of primary and secondary creep.

- $\varepsilon_{S}$ is defined as engineering secondary strain, which is considered as a linear increase up to the tertiary point.

- $\varepsilon_{t r}^{P}$ is the maximum primary strain component in the transient regime. It is stress-dependent parameter defined as

$$
\varepsilon_{t r}^{P}=\frac{\sigma}{\beta^{2} H}
$$

- $\varepsilon_{t r}^{S}$ is the secondary creep strain component in the transient regime. 
The primary creep time is defined as

$$
t_{t r}^{p}=4.6 \frac{(\beta-1) \sigma}{\beta^{2} H \dot{\varepsilon}_{s s}}
$$

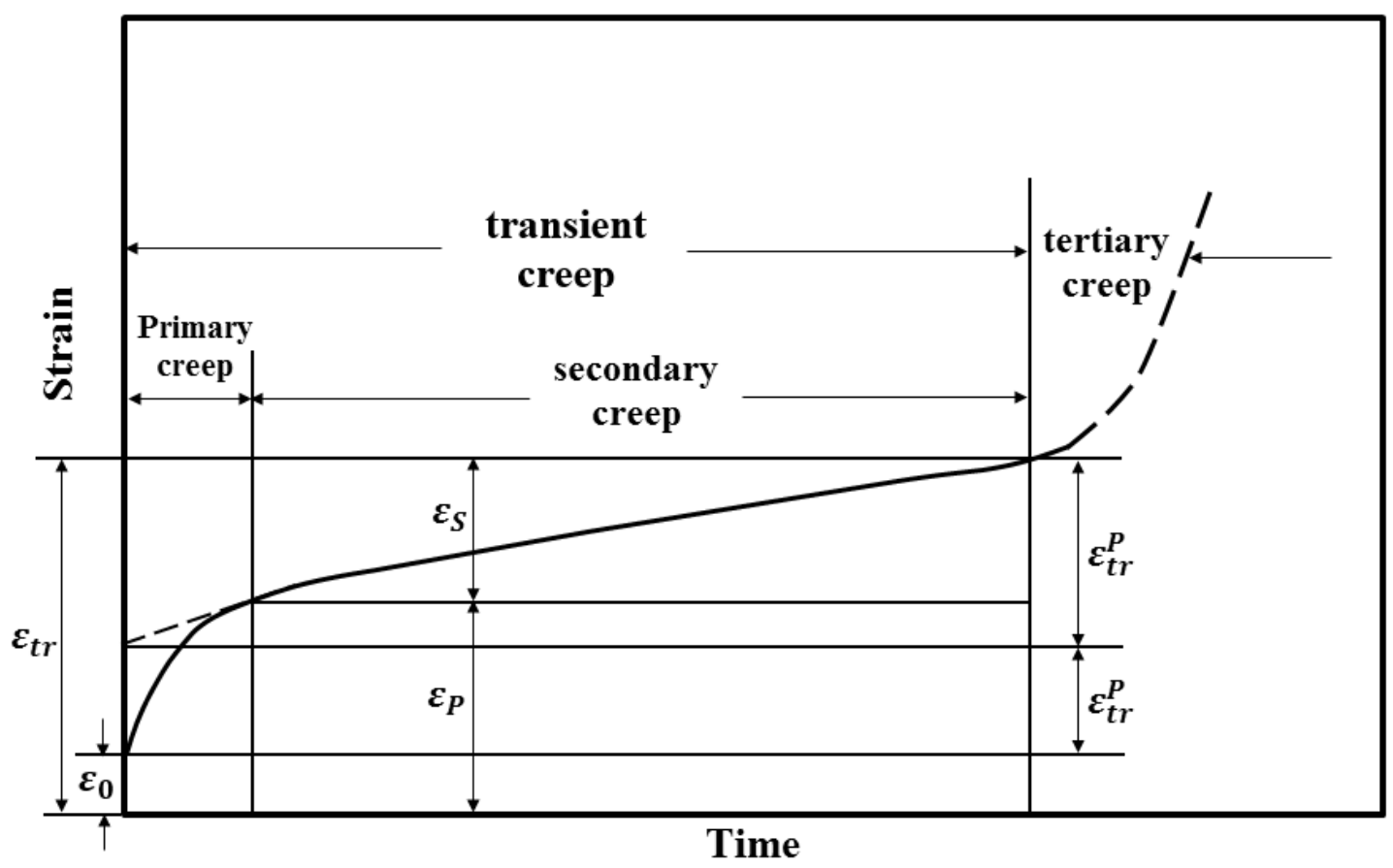

Fig. AP- 1. Typical creep strain-time curve and definition of transient strain $\left[{ }^{57}\right]$. 


\section{Appendix B: Determination of $\boldsymbol{\beta}$ and $\boldsymbol{H}$}

From Eq. (AP-1) and Eq. (AP-2), if $\varepsilon_{t r}^{P}$ and $t_{t r}^{P}$ can be observed from creep strain-time curve, then $\beta$ and $H$ are calculable. Take F91 creep test at $550^{\circ} \mathrm{C} / 220 \mathrm{MPa}$ as an example, $\varepsilon_{t r}^{P}$ is observed to be 0.00515 , and $t_{t r}^{P}$ is 15,100 seconds. Substitute these values into the above equations:

$\varepsilon_{t r}^{P}=\frac{\sigma}{\beta^{2} H}=0.00515$

$t_{t r}^{P}=4.6 \frac{(\beta-1) \sigma}{\beta^{2} H \dot{\varepsilon}_{s S}}=15,100$ second

$\dot{\varepsilon}_{S S}=1.28 \times 10^{-8}$ strain $/$ second

Therefore, $\beta=1.008$, and $H=42.04$. 


\section{Appendix C: Raw data of creep tests and EDX analyses}

\section{C-1 Creep strain vs. time data}

All the raw data from creep tests on pristine, aged and coated F91 coupons are provided in Table AP- 1 and Table AP- 2 . Table AP- 1 summarizes the minimum creep rate $\left(\dot{\varepsilon}_{s s}\right)$ and time-to-rupture (TTR), while Table AP- 2 lists the information that creep strain vs. time data can be extracted from the related figures. If one requires the engineering strain data instead of the true strain in these figures, Eq. (4-6) shall be used to make the conversion.

Table AP- 1 Creep test: minimum creep rate and time-to-rupture

\begin{tabular}{|c|c|c|c|c|c|c|c|}
\hline Temp & Stress & \multicolumn{3}{|c|}{$\dot{\varepsilon}_{S S}$} & \multicolumn{3}{|c|}{ TTR } \\
\hline \multirow{2}{*}{${ }^{\circ} \mathrm{C}$} & \multirow{2}{*}{$\mathrm{MPa}$} & \multicolumn{3}{|c|}{ strain $\% / \mathrm{hr}$} & \multicolumn{3}{|c|}{$\mathrm{hr}$} \\
\hline & & Pristine & Aged & $\mathrm{Co}$ & Pristine & Aged & \\
\hline \multirow{3}{*}{500} & 320 & $4.99 \mathrm{E}-4$ & & & 2142.5 & & \\
\hline & 300 & $2.38 \mathrm{E}-4$ & & & 3503.7 & & \\
\hline & 280 & $2.31 \mathrm{E}-4$ & & & 4223.8 & & \\
\hline \multirow{3}{*}{550} & 260 [233] & $4.99 \mathrm{E}-2$ & $1.4 \mathrm{E}-02$ & $4.70 \mathrm{E}-05$ & 81.3 & 23.9 & 1256.4 \\
\hline & 240 [215] & $1.09 \mathrm{E}-2$ & $3.4 \mathrm{E}-02$ & $3.79 \mathrm{E}-05$ & 306.0 & 118.9 & 1121.9* \\
\hline & 220 [197] & $4.61 \mathrm{E}-3$ & $1.4 \mathrm{E}-02$ & $2.99 \mathrm{E}-05$ & 891.4 & 231.6 & 4178.3 \\
\hline \multirow{3}{*}{600} & 160 [147] & $3.42 \mathrm{E}-2$ & $3.6 \mathrm{E}-02$ & $6.56 \mathrm{E}-04$ & 180.6 & 124.8 & $276.2 *$ \\
\hline & 140 [128] & $6.24 \mathrm{E}-3$ & $4.3 \mathrm{E}-03$ & $3.56 \mathrm{E}-04$ & 833.6 & 619.0 & $1146.9 *$ \\
\hline & 130 [119] & $3.00 \mathrm{E}-3$ & $2.7 \mathrm{E}-03$ & $2.13 \mathrm{E}-04$ & 1602.0 & 1598.8 & 6112.7 \\
\hline \multirow{3}{*}{650} & 110 & $7.98 \mathrm{E}-2$ & & & 78.8 & & \\
\hline & 100 & $1.82 \mathrm{E}-2$ & & & 244.8 & & \\
\hline & 80 & $4.45 \mathrm{E}-3$ & & & 873.4 & & \\
\hline
\end{tabular}

Note: Stress values in brackets [ ] are adjusted only for coated coupons.

An asterisk* indicates the test still ongoing.

Table AP- 2 Creep test: summary of creep strain vs. time data

\begin{tabular}{|c|l|}
\hline Pristine-coupon creep & Fig. 5- 14 to Fig. 5- 17 \\
\hline Coated-coupon creep & Fig. 6- 7, Fig. 6- 8 \\
\hline Aged-coupon creep & Fig. 7- 8, Fig. 7- 9 \\
\hline
\end{tabular}




\section{C-2 Elemental concentrations from EDX analyses}

The SEM images and elemental tables of selected precipitation spots in un-aged and aged F91 coupons from EDX analyses are presented in Fig. AP- 2 to Fig. AP- 19 and Table AP- 3 to Table AP- 20, respectively. The Mo contents of precipitates that are higher than the substrate value, 0.94 wt.\%, were taken to the calculations. The sizes of high Mo content precipitates were also measured using photo processing software, ImageJ and Adobe Photoshop. Thus, Fig. 7- 3, Fig. 7- 6, and Fig. 7- 7 were obtained. 


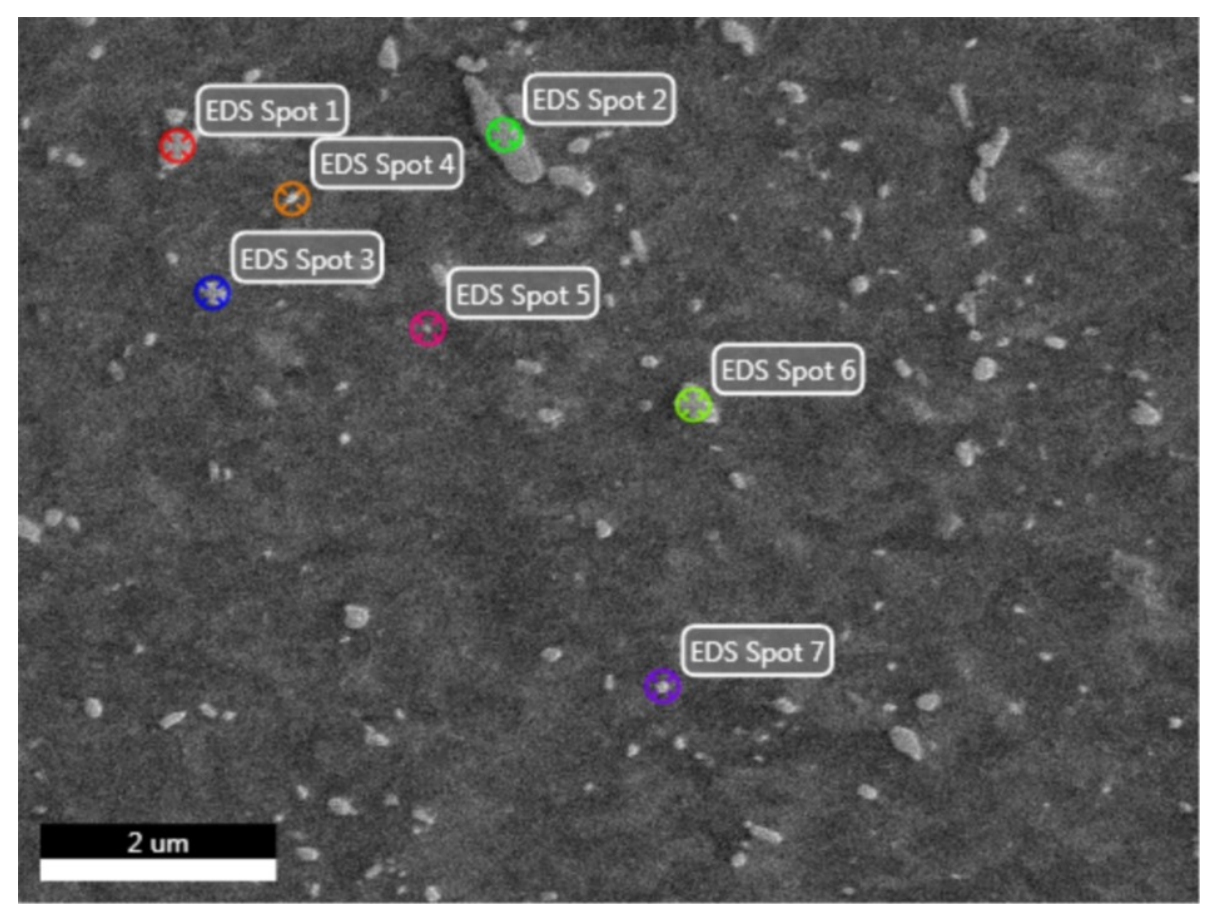

Fig. AP- 2. Selected spots in un-aged coupon for EDX analysis.

Table AP- 3 Elemental concentrations (wt.\%) of selected spots in un-aged coupon

\begin{tabular}{|c|c|c|c|c|c|c|c|}
\hline Element & Spot 1 & Spot 2 & Spot 3 & Spot 4 & Spot 5 & Spot 6 & Spot 7 \\
\hline $\mathrm{C}$ & 1.98 & 3.05 & 1.99 & 1.45 & 1.17 & 1.19 & 1.29 \\
\hline $\mathrm{Mo}$ & 0.91 & 1.16 & 0.99 & 0.76 & 0.84 & 0.28 & 0.63 \\
\hline $0.34 \mathrm{~V}$ & 0.26 & 0.29 & 0.35 & 0.36 & 0.51 & 0.14 & 0.34 \\
\hline $\mathrm{Cr}$ & 7.08 & 9.21 & 9.31 & 6.93 & 6.91 & 6.59 & 7.41 \\
\hline $\mathrm{Fe}$ & 89.76 & 86.26 & 87.36 & 90.5 & 90.58 & 91.8 & 90.33 \\
\hline
\end{tabular}




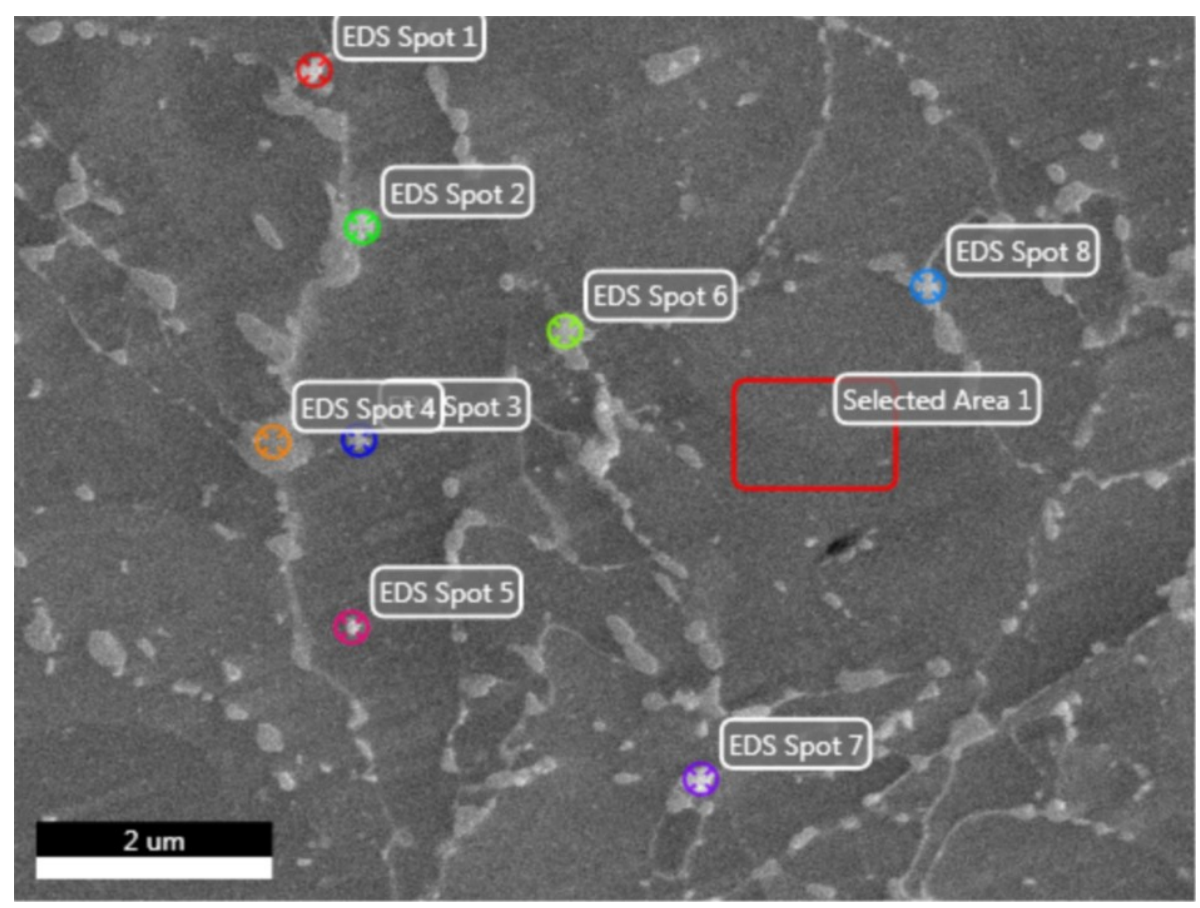

Fig. AP- 3. Selected spots in $1000 \mathrm{hr}$ aged coupon for EDX analysis.

Table AP- 4 Elemental concentrations (wt.\%) of selected spots in $1000 \mathrm{hr}$ aged coupon

\begin{tabular}{|c|c|c|c|c|c|c|c|c|c|}
\hline Element & Spot 1 & Spot 2 & Spot 3 & Spot 4 & Spot 5 & Spot 6 & Spot 7 & Spot 8 & Area 1 \\
\hline $\mathrm{C}$ & 2.02 & 1.7 & 1.37 & 4.39 & 0.6 & 1.42 & 1.48 & 1.38 & 1.25 \\
\hline $\mathrm{Mo}$ & 5.12 & 7.51 & 1.78 & 1.75 & 0.3 & 4.11 & 1.43 & 0.96 & 0.98 \\
\hline $\mathrm{V}$ & 0.58 & 0.44 & 0.63 & 0.41 & 0.12 & 0.71 & 0.4 & 0.49 & 0.66 \\
\hline $\mathrm{Cr}$ & 10.86 & 7.92 & 8.15 & 14.12 & 7.04 & 12.63 & 8.71 & 8.23 & 7.19 \\
\hline $\mathrm{Fe}$ & 81.42 & 82.43 & 88.07 & 79.33 & 91.94 & 81.13 & 87.98 & 88.95 & 89.92 \\
\hline
\end{tabular}




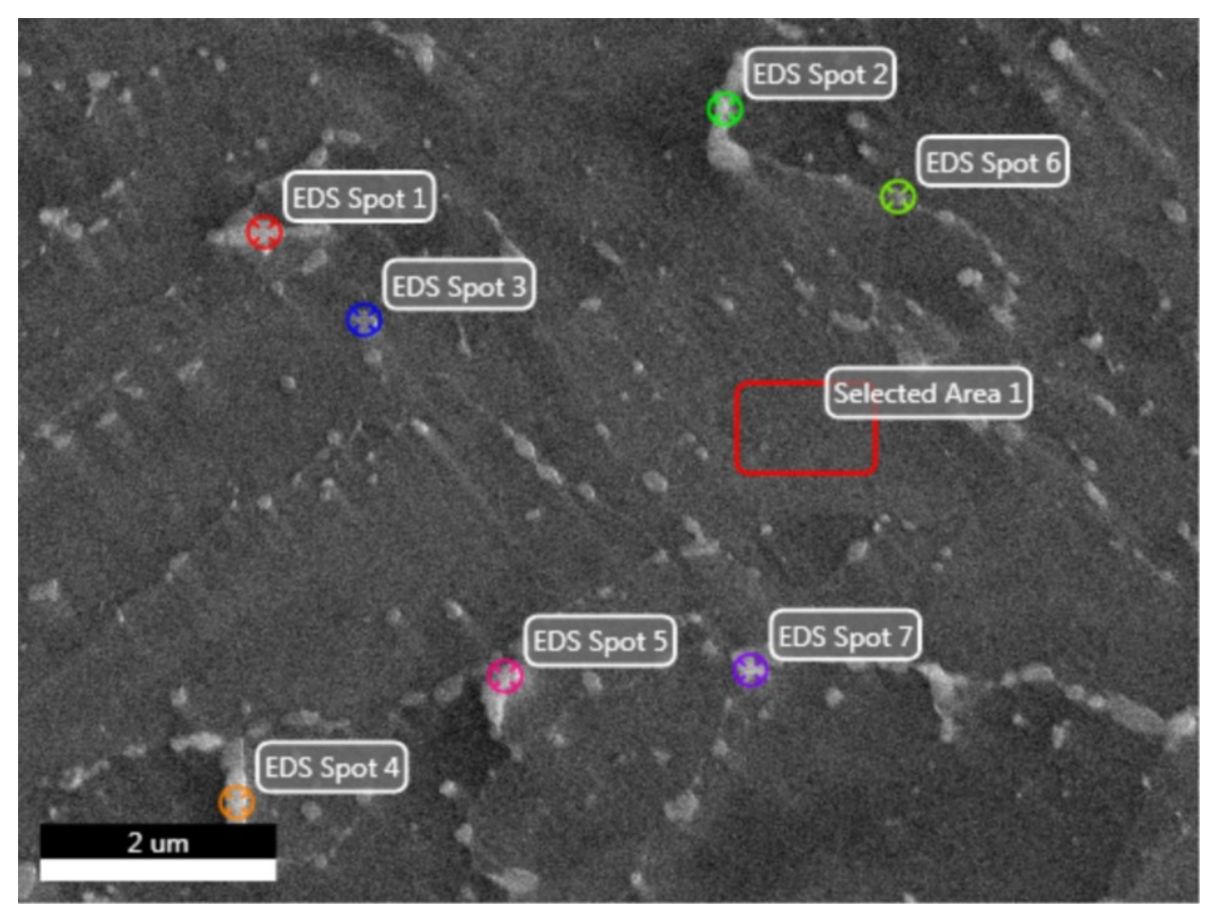

Fig. AP- 4. Selected spots in $2000 \mathrm{hr}$ aged coupon for EDX analysis.

Table AP- 5 Elemental concentrations (wt.\%) of selected spots in $2000 \mathrm{hr}$ aged coupon

\begin{tabular}{|c|c|c|c|c|c|c|c|c|}
\hline Element & Spot 1 & Spot 2 & Spot 3 & Spot 4 & Spot 5 & Spot 6 & Spot 7 & Area 1 \\
\hline $\mathrm{C}$ & 1.14 & 3.14 & 0.92 & 1.32 & 1.9 & 1.44 & 0.98 & 0.93 \\
\hline $\mathrm{Mo}$ & 2.16 & 3.8 & 0.45 & 5.79 & 3.66 & 0.92 & 0.82 & 0.32 \\
\hline $\mathrm{V}$ & 0.37 & 0.47 & 0.14 & 0.42 & 0.37 & 0.23 & 0.37 & 0.09 \\
\hline $\mathrm{Cr}$ & 7.79 & 7.69 & 8.37 & 7.75 & 9.6 & 7.15 & 7.56 & 6.48 \\
\hline $\mathrm{Fe}$ & 88.54 & 84.9 & 90.12 & 84.71 & 84.46 & 90.25 & 90.27 & 92.18 \\
\hline
\end{tabular}




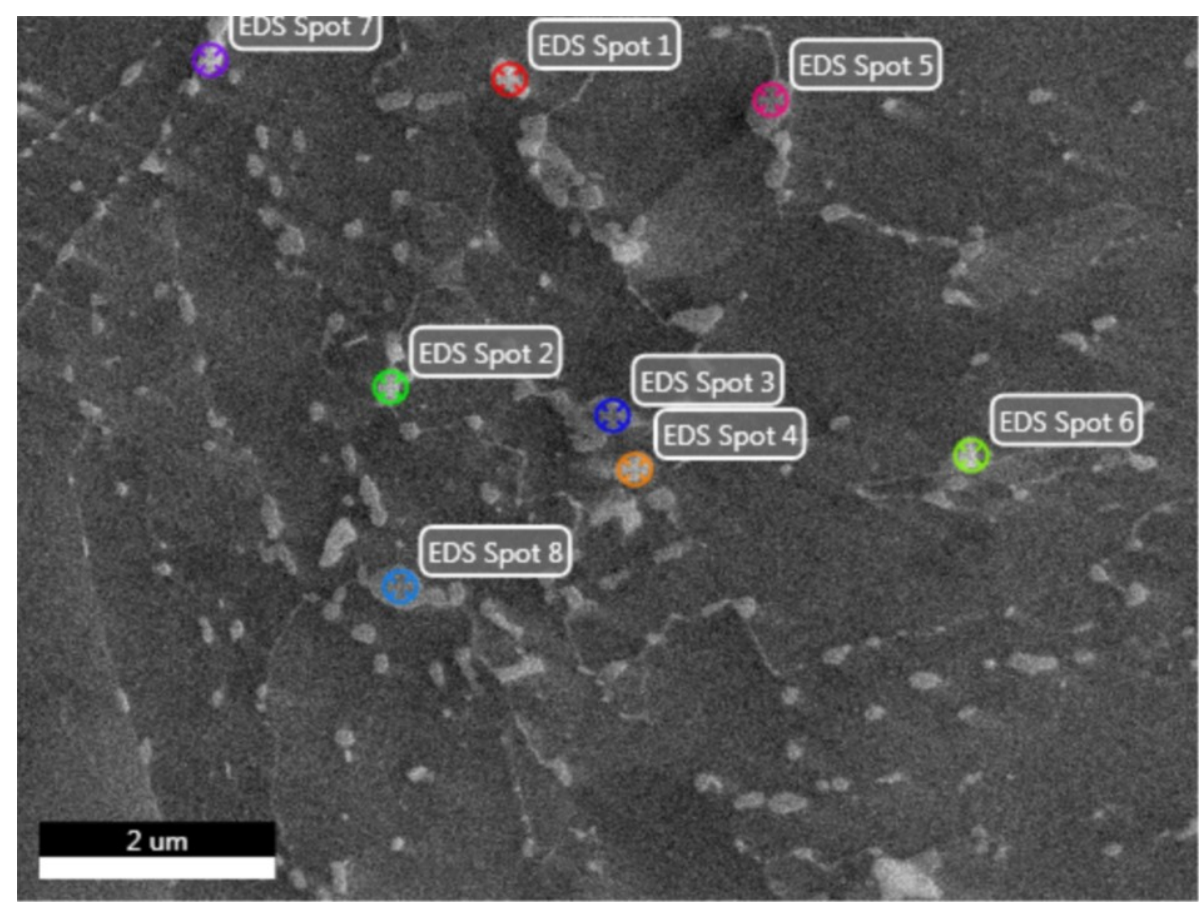

Fig. AP- 5. Selected spots in $3000 \mathrm{hr}$ aged coupon for EDX analysis.

Table AP- 6 Elemental concentrations (wt.\%) of selected spots in $3000 \mathrm{hr}$ aged coupon

\begin{tabular}{|c|c|c|c|c|c|c|c|c|}
\hline Element & Spot 1 & Spot 2 & Spot 3 & Spot 4 & Spot 5 & Spot 6 & Spot 7 & Spot 8 \\
\hline $\mathrm{C}$ & 1.66 & 2.04 & 4.14 & 2.73 & 4.87 & 1.24 & 1.56 & 4.18 \\
\hline $\mathrm{Mo}$ & 12.33 & 10.97 & 3.11 & 11.27 & 2.33 & 4.65 & 7.76 & 2.17 \\
\hline $\mathrm{V}$ & 0.59 & 0.52 & 0.49 & 0.59 & 0.66 & 0.56 & 0.47 & 0.49 \\
\hline $\mathrm{Cr}$ & 9.62 & 8.65 & 15.3 & 11.4 & 17.53 & 9.1 & 7.92 & 17.17 \\
\hline $\mathrm{Fe}$ & 75.8 & 77.83 & 76.95 & 74.01 & 74.6 & 84.45 & 82.29 & 75.99 \\
\hline
\end{tabular}




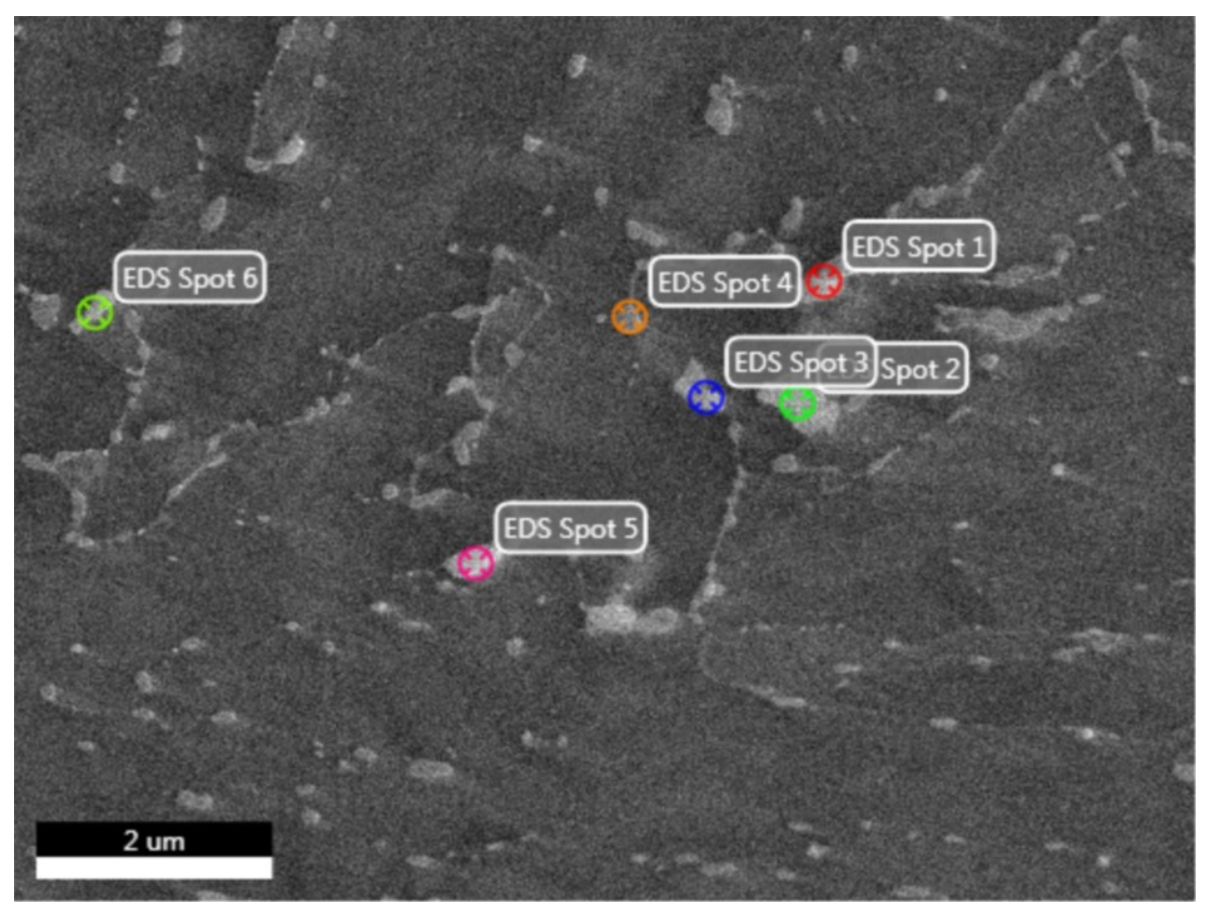

Fig. AP- 6. Selected spots in $4000 \mathrm{hr}$ aged coupon for EDX analysis.

Table AP- 7 Elemental concentrations (wt.\%) of selected spots in $4000 \mathrm{hr}$ aged coupon

\begin{tabular}{|c|c|c|c|c|c|c|}
\hline Element & Spot 1 & Spot 2 & Spot 3 & Spot 4 & Spot 5 & Spot 6 \\
\hline $\mathrm{C}$ & 2.47 & 1.28 & 1.09 & 1.35 & 1.49 & 1.48 \\
\hline $\mathrm{Mo}$ & 6.63 & 8.71 & 3.33 & 1.28 & 6.52 & 1.31 \\
\hline $\mathrm{V}$ & 0.66 & 0.34 & 0.59 & 0.36 & 0.38 & 0.35 \\
\hline $\mathrm{Cr}$ & 8.86 & 8.67 & 8.64 & 8.53 & 10.02 & 8.35 \\
\hline $\mathrm{Fe}$ & 81.37 & 81 & 86.35 & 88.49 & 81.59 & 88.52 \\
\hline
\end{tabular}




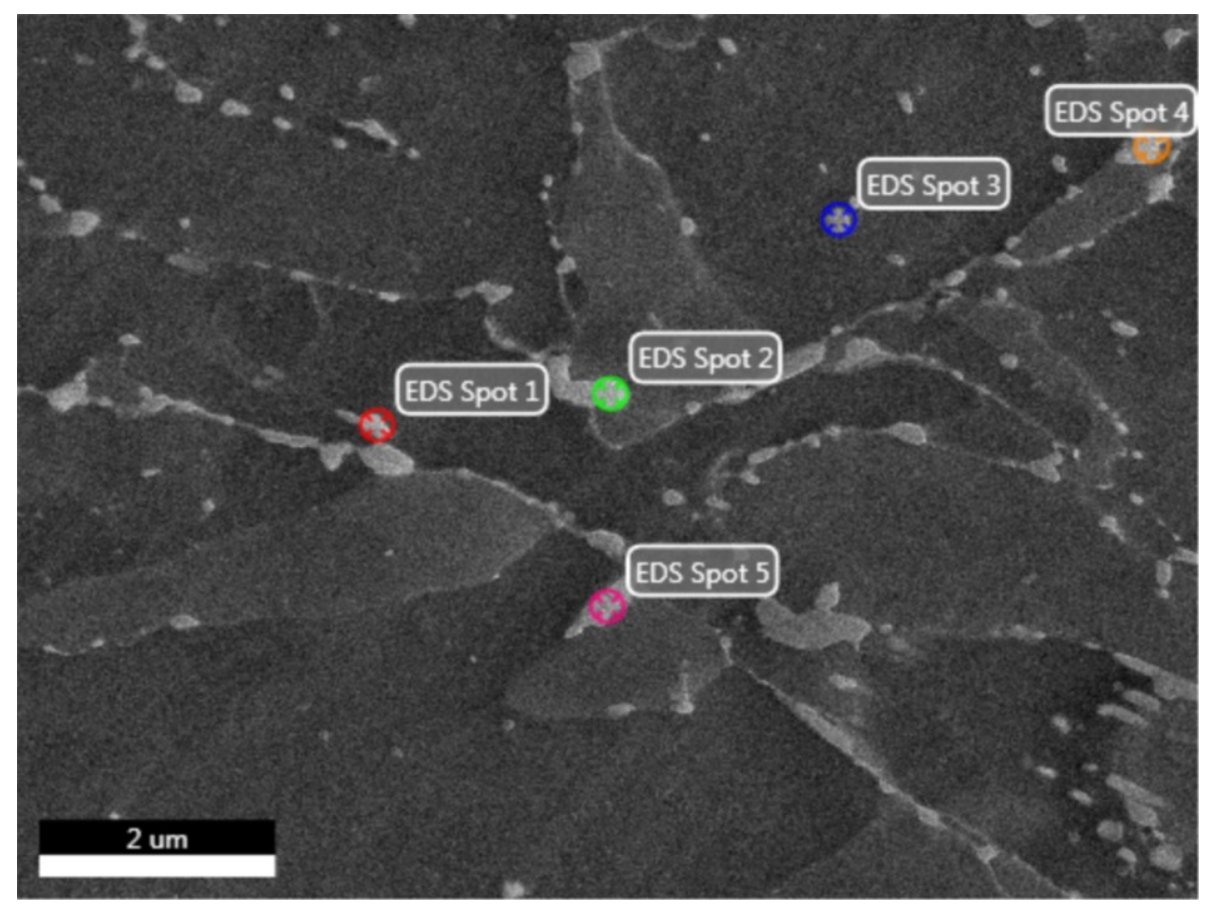

Fig. AP- 7. Selected spots in $5000 \mathrm{hr}$ aged coupon for EDX analysis.

Table AP- 8 Elemental concentrations (wt.\%) of selected spots in $5000 \mathrm{hr}$ aged coupon

\begin{tabular}{|c|c|c|c|c|c|}
\hline Element & Spot 1 & Spot 2 & Spot 3 & Spot 4 & Spot 5 \\
\hline $\mathrm{C}$ & 1.59 & 2.24 & 1.39 & 2.8 & 2.55 \\
\hline $\mathrm{Mo}$ & 3.2 & 14.26 & 0.69 & 13.61 & 10.17 \\
\hline $\mathrm{V}$ & 0.39 & 0.45 & 0.8 & 1.91 & 0.68 \\
\hline $\mathrm{Cr}$ & 7.44 & 8.16 & 7.57 & 9.46 & 8.36 \\
\hline $\mathrm{Fe}$ & 87.38 & 74.89 & 89.55 & 72.23 & 78.25 \\
\hline
\end{tabular}




\section{C-2-2 EDX results of fractured pristine coupons}

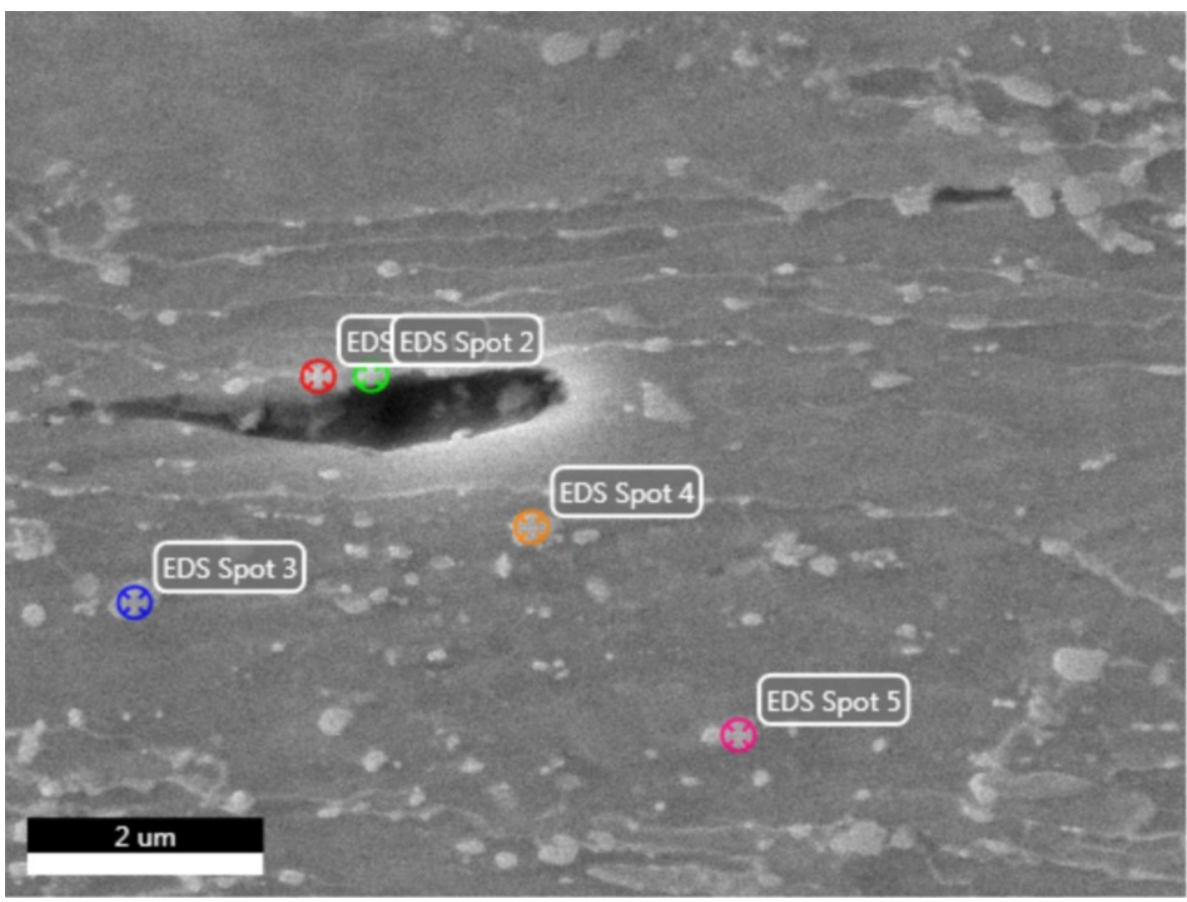

Fig. AP- 8. Selected spots in the fractured pristine coupon at $550^{\circ} \mathrm{C} / 220 \mathrm{MPa}$ for EDX analysis.

Table AP- 9 Elemental concentrations (wt.\%) of selected spots in fractured pristine coupon at $550^{\circ} \mathrm{C} / 220 \mathrm{MPa}$

\begin{tabular}{|c|c|c|c|c|c|}
\hline Element & Spot 1 & Spot 2 & Spot 3 & Spot 4 & Spot 5 \\
\hline $\mathrm{C}$ & 3.83 & 2.49 & 4.28 & 3.21 & 3.63 \\
\hline $\mathrm{Mo}$ & 0.26 & 0.26 & 0.65 & 0.26 & 0.54 \\
\hline $\mathrm{V}$ & 0.32 & 0.33 & 0.28 & 0.21 & 0.31 \\
\hline $\mathrm{Cr}$ & 6.7 & 7.17 & 6.88 & 6.88 & 7.24 \\
\hline $\mathrm{Fe}$ & 88.89 & 89.75 & 87.91 & 89.44 & 88.28 \\
\hline
\end{tabular}




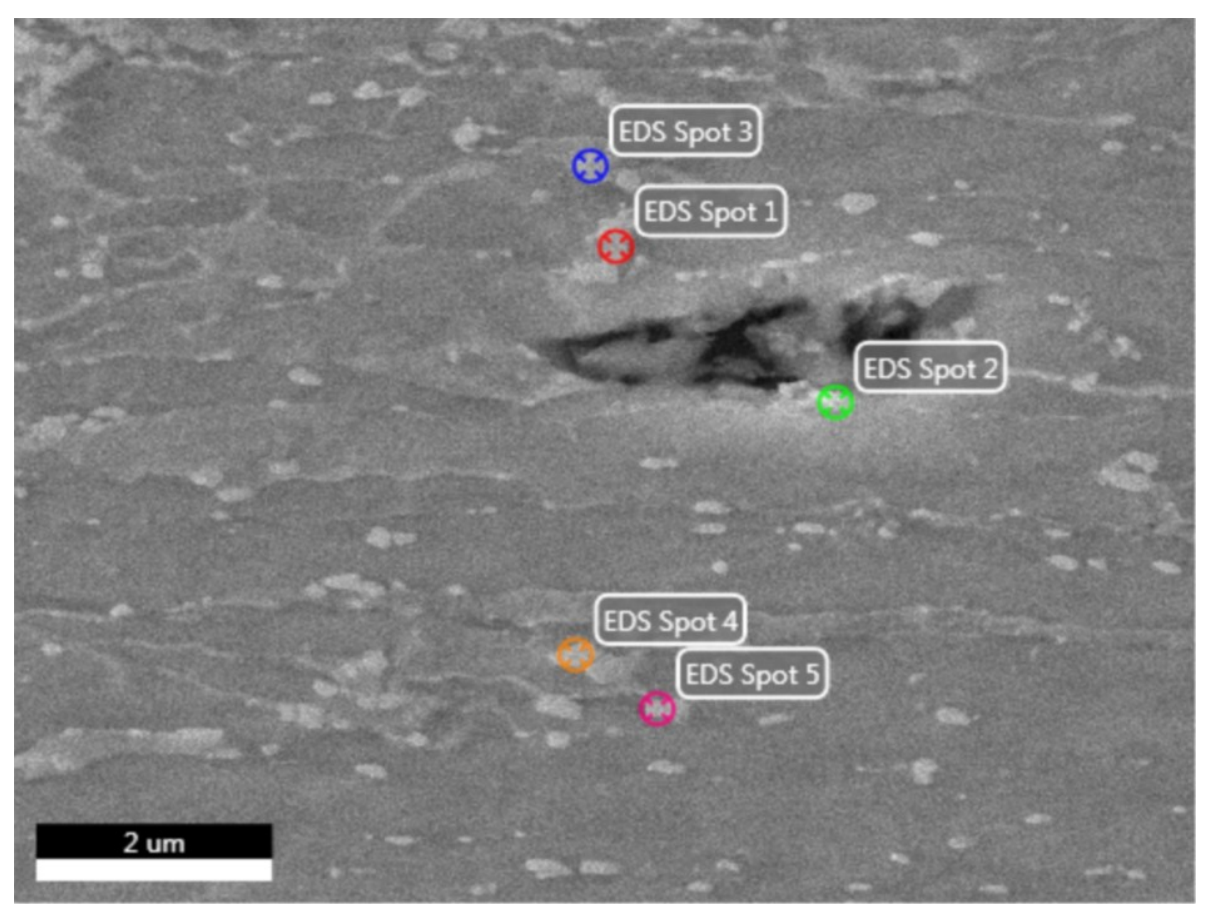

Fig. AP- 9. Selected spots in the fractured pristine coupon at $550^{\circ} \mathrm{C} / 240 \mathrm{MPa}$ for $\mathrm{EDX}$ analysis.

Table AP- 10 Elemental concentrations (wt.\%) of selected spots in fractured pristine coupon at $550^{\circ} \mathrm{C} / 240 \mathrm{MPa}$

\begin{tabular}{|c|c|c|c|c|c|}
\hline Element & Spot 1 & Spot 2 & Spot 3 & Spot 4 & Spot 5 \\
\hline $\mathrm{C}$ & 6.3 & 4.06 & 4.18 & 3.26 & 3.94 \\
\hline $\mathrm{Mo}$ & 0.63 & 0.91 & 0.42 & 0.5 & 0.68 \\
\hline $\mathrm{V}$ & 0.07 & 0.36 & 0.27 & 0.53 & 0.61 \\
\hline $\mathrm{Cr}$ & 10.36 & 7.28 & 7.18 & 7.46 & 7.36 \\
\hline $\mathrm{Fe}$ & 82.64 & 87.39 & 87.94 & 88.25 & 87.4 \\
\hline
\end{tabular}




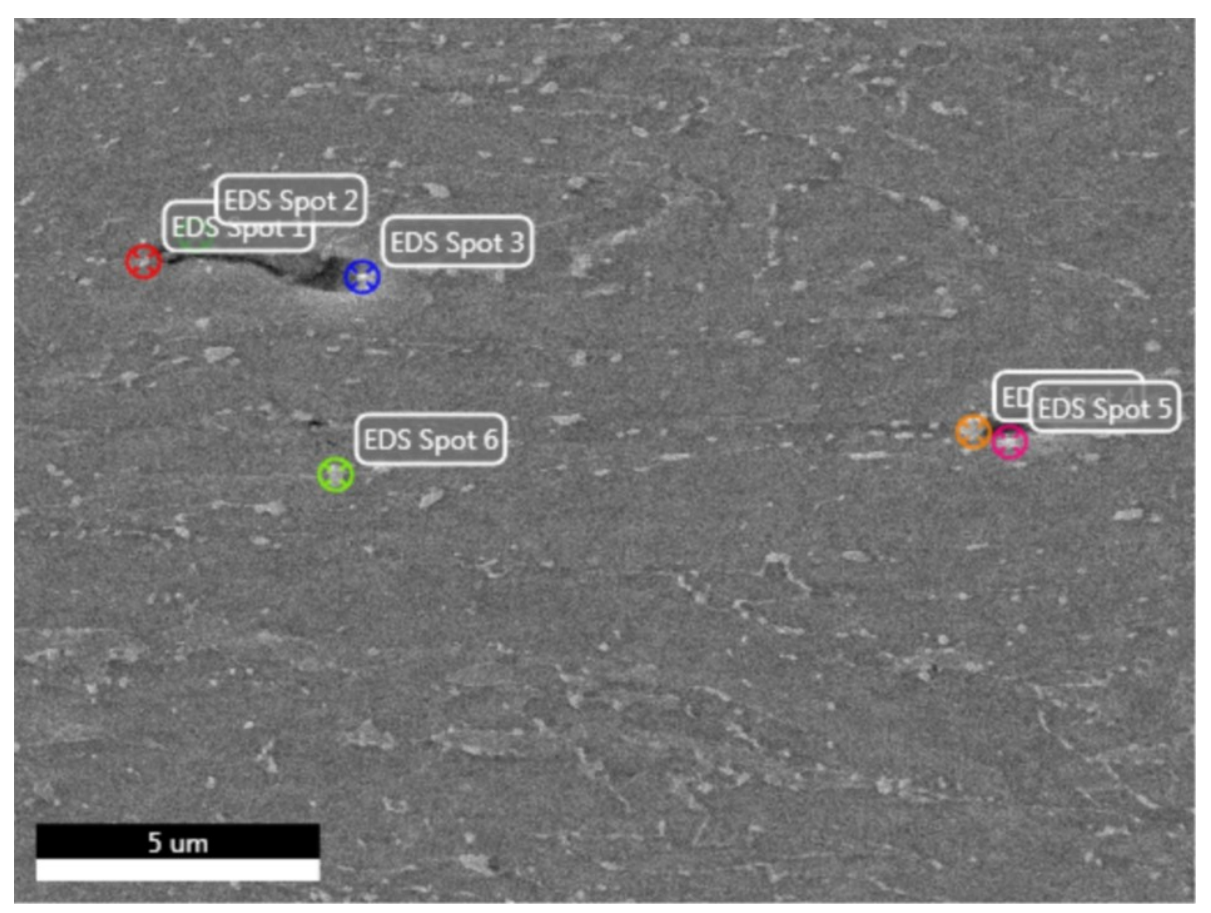

Fig. AP- 10. Selected spots in the fractured pristine coupon at $550^{\circ} \mathrm{C} / 260 \mathrm{MPa}$ for $\mathrm{EDX}$ analysis.

Table AP- 11 Elemental concentrations (wt.\%) of selected spots in fractured pristine coupon at $550^{\circ} \mathrm{C} / 260 \mathrm{MPa}$

\begin{tabular}{|c|c|c|c|c|c|c|}
\hline Element & Spot 1 & Spot 2 & Spot 3 & Spot 4 & Spot 5 & Spot 6 \\
\hline $\mathrm{C}$ & 6.65 & 7.33 & 6.56 & 7.48 & 8.31 & 3.69 \\
\hline $\mathrm{Mo}$ & 1.01 & 1.16 & 1.03 & 1.54 & 1.27 & 0.85 \\
\hline $\mathrm{V}$ & 0.3 & 0.47 & 2.35 & 0.69 & 0.41 & 0.45 \\
\hline $\mathrm{Cr}$ & 10.8 & 10.11 & 8.39 & 13.15 & 11.29 & 6.83 \\
\hline $\mathrm{Fe}$ & 81.23 & 80.93 & 81.67 & 77.15 & 78.72 & 88.17 \\
\hline
\end{tabular}




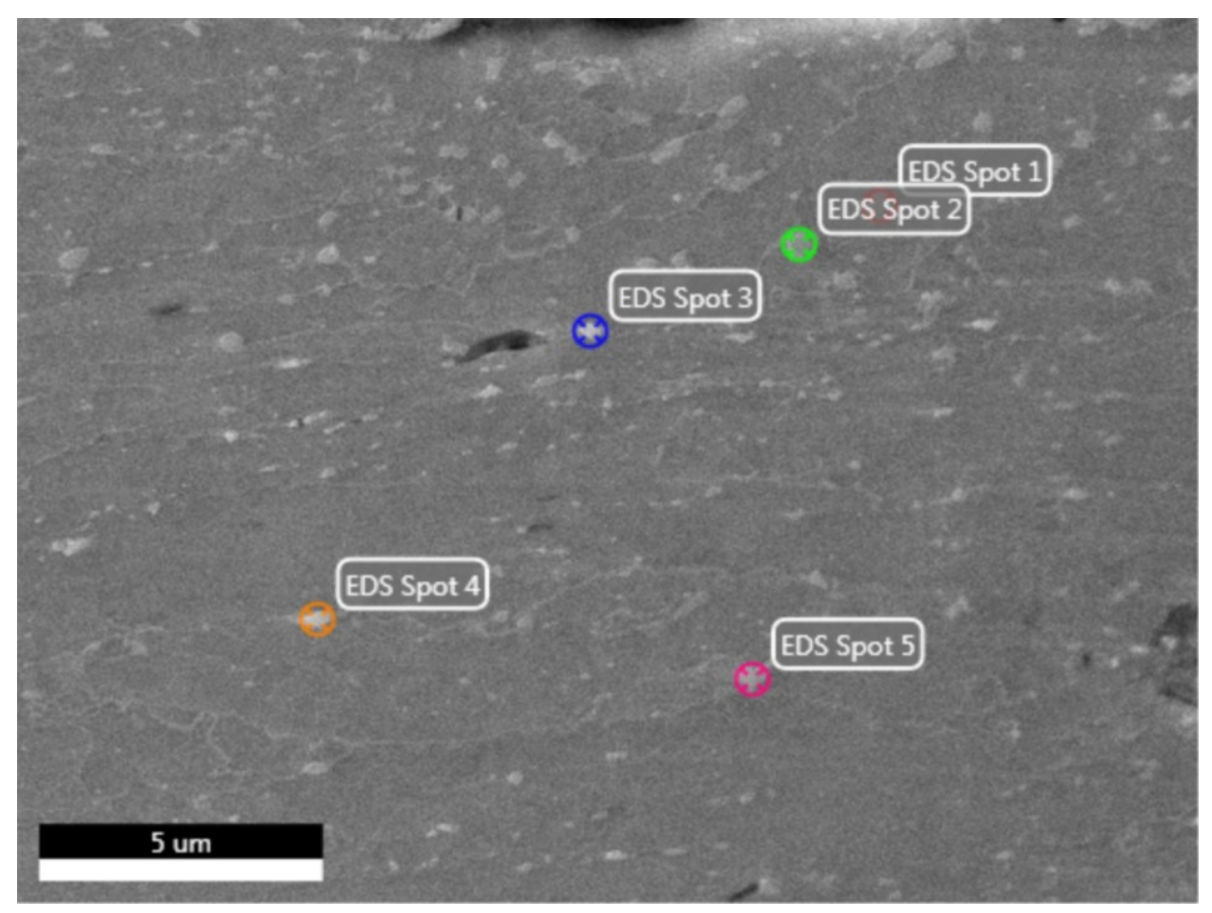

Fig. AP- 11. Selected spots in the fractured pristine coupon at $600^{\circ} \mathrm{C} / 130 \mathrm{MPa}$ for $\mathrm{EDX}$ analysis.

Table AP- 12 Elemental concentrations (wt.\%) of selected spots in fractured pristine coupon at $600^{\circ} \mathrm{C} / 130 \mathrm{MPa}$

\begin{tabular}{|c|c|c|c|c|c|}
\hline Element & Spot 1 & Spot 2 & Spot 3 & Spot 4 & Spot 5 \\
\hline $\mathrm{C}$ & 5.98 & 5.83 & 5.42 & 4.76 & 5.46 \\
\hline $\mathrm{Mo}$ & 1.5 & 1.12 & 10.78 & 11.4 & 3.89 \\
\hline $\mathrm{V}$ & 0.45 & 0.33 & 0.23 & 0.25 & 0.31 \\
\hline $\mathrm{Cr}$ & 10.91 & 11.11 & 7.71 & 7.68 & 6.81 \\
\hline $\mathrm{Fe}$ & 81.16 & 81.61 & 75.85 & 75.92 & 83.53 \\
\hline
\end{tabular}




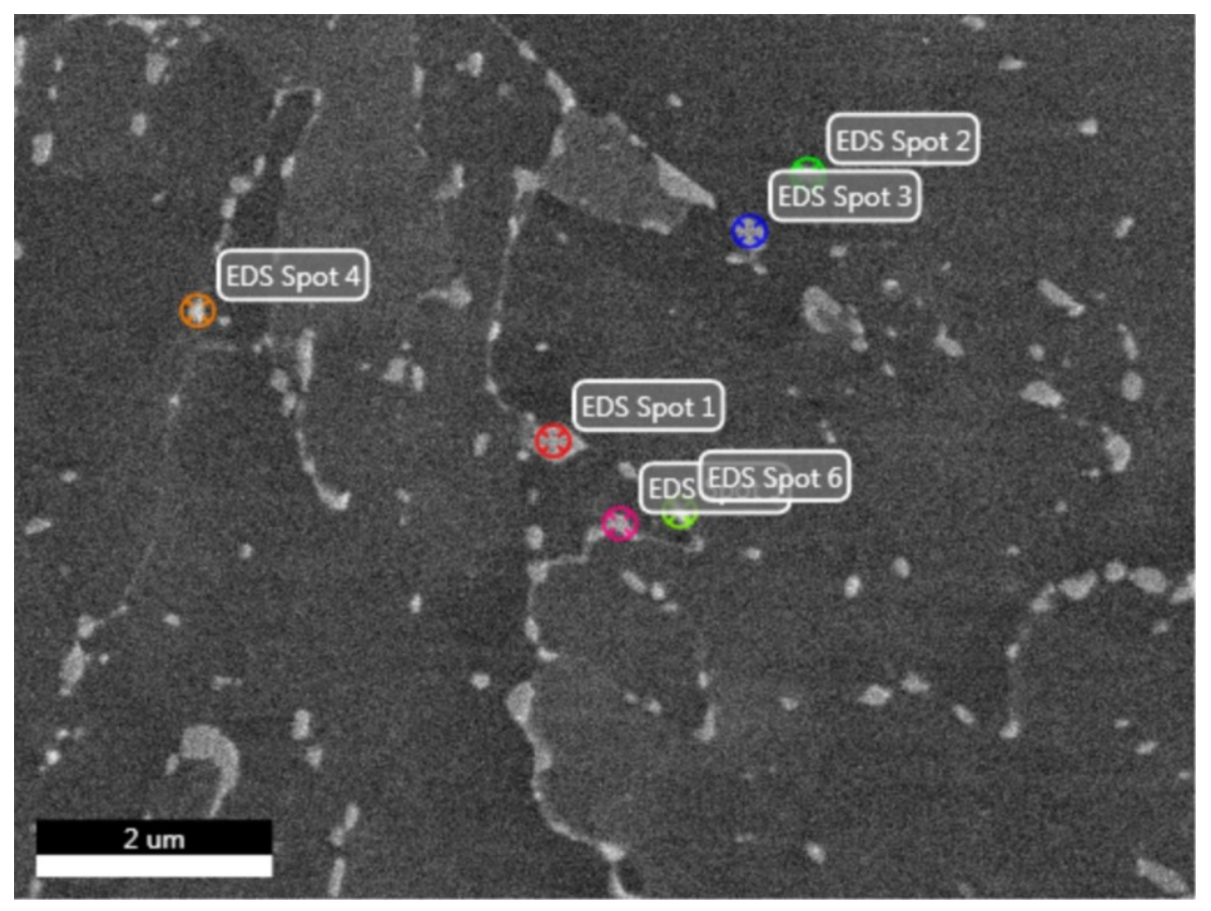

Fig. AP- 12. Selected spots in the fractured pristine coupon at $600^{\circ} \mathrm{C} / 140 \mathrm{MPa}$ for $\mathrm{EDX}$ analysis.

Table AP- 13 Elemental concentrations (wt.\%) of selected spots in fractured pristine coupon at $600^{\circ} \mathrm{C} / 140 \mathrm{MPa}$

\begin{tabular}{|c|c|c|c|c|c|c|}
\hline Element & Spot 1 & Spot 2 & Spot 3 & Spot 4 & Spot 5 & Spot 6 \\
\hline $\mathrm{C}$ & 3.91 & 3.09 & 3.44 & 3.01 & 3.32 & 3.01 \\
\hline $\mathrm{Mo}$ & 1.3 & 0.92 & 0.99 & 0.65 & 1.42 & 0.27 \\
\hline $\mathrm{V}$ & 0.43 & 0.47 & 0.64 & 0.35 & 0.37 & 0.13 \\
\hline $\mathrm{Cr}$ & 8.86 & 7.4 & 7.69 & 7.37 & 8.51 & 7.08 \\
\hline $\mathrm{Fe}$ & 85.5 & 88.12 & 87.23 & 88.62 & 86.37 & 89.52 \\
\hline
\end{tabular}




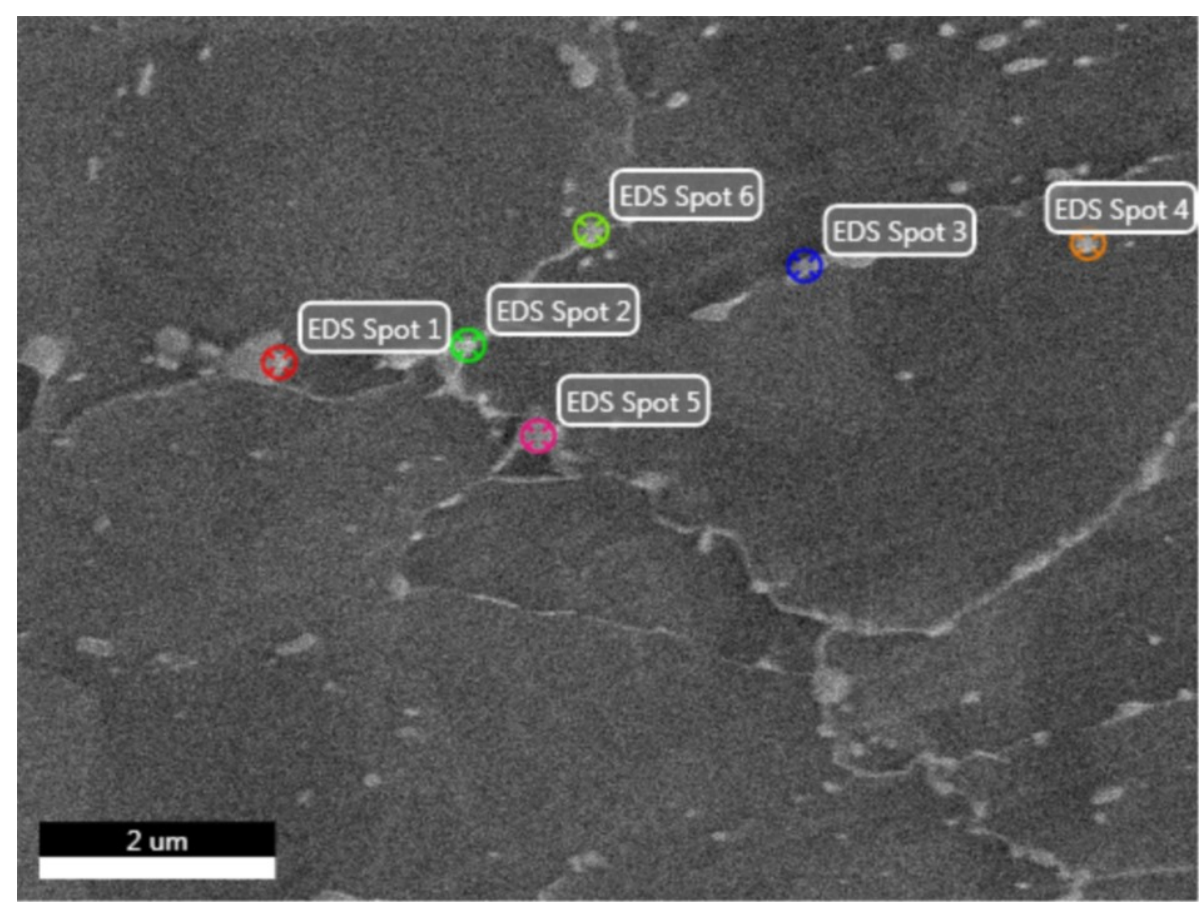

Fig. AP- 13 Selected spots in the fractured pristine coupon at $600^{\circ} \mathrm{C} / 160 \mathrm{MPa}$ for EDX analysis.

Table AP- 14 Elemental concentrations (wt.\%) of selected spots in fractured pristine coupon at $600^{\circ} \mathrm{C} / 160 \mathrm{MPa}$

\begin{tabular}{|c|c|c|c|c|c|c|}
\hline Element & Spot 1 & Spot 2 & Spot 3 & Spot 4 & Spot 5 & Spot 6 \\
\hline $\mathrm{C}$ & 3.36 & 3.53 & 3.43 & 2.92 & 2.99 & 5.37 \\
\hline $\mathrm{Mo}$ & 0.5 & 1.54 & 0.6 & 0.53 & 0.78 & 2.38 \\
\hline $\mathrm{V}$ & 0.43 & 0.5 & 0.66 & 0.45 & 0.24 & 0.4 \\
\hline $\mathrm{Cr}$ & 6.91 & 8.98 & 7.39 & 7.36 & 7.2 & 9.48 \\
\hline $\mathrm{Fe}$ & 88.8 & 85.44 & 87.93 & 88.74 & 88.79 & 82.37 \\
\hline
\end{tabular}




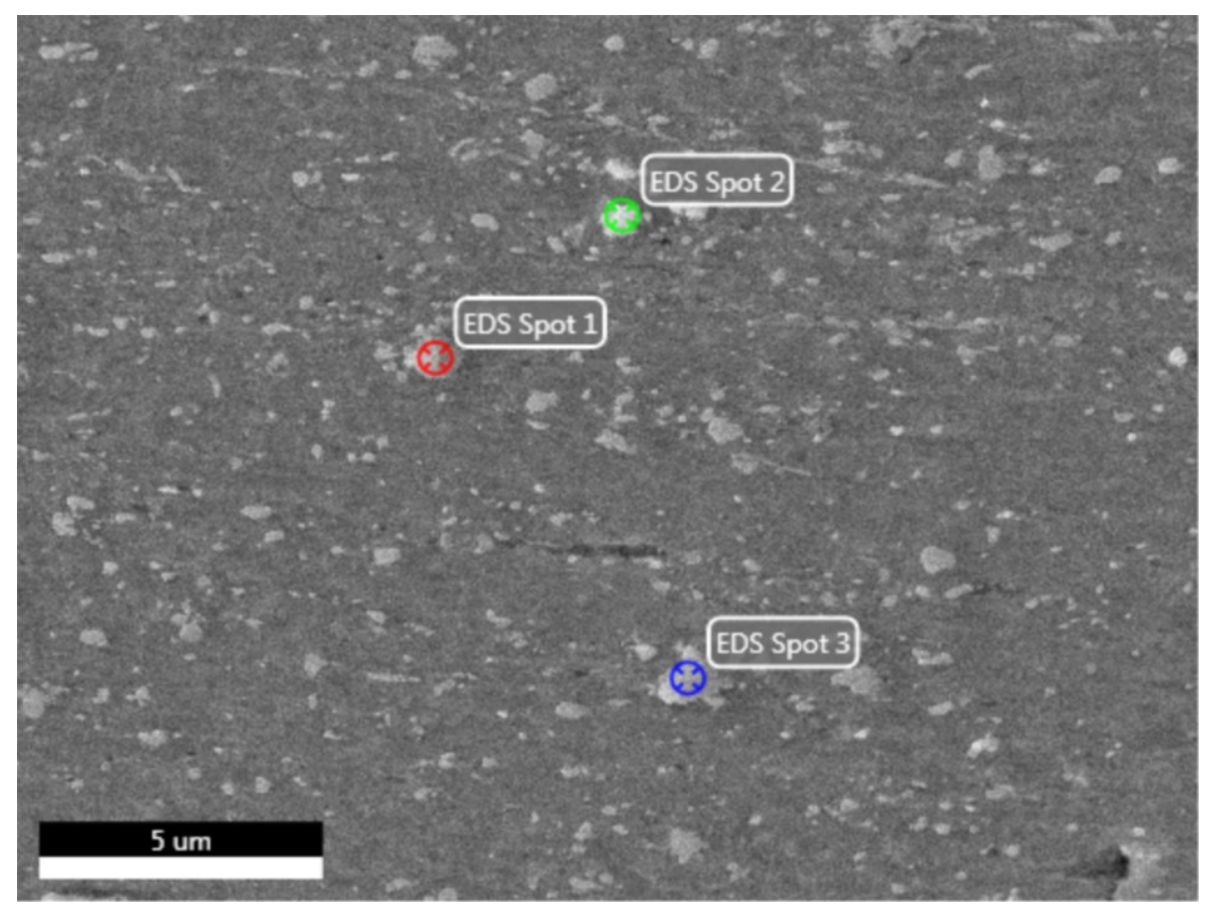

Fig. AP- 14. Selected spots in the fractured aged coupon at $550^{\circ} \mathrm{C} / 220 \mathrm{MPa}$ for EDX analysis.

Table AP- 15 Elemental concentrations (wt.\%) of selected spots in fractured aged coupon at $550^{\circ} \mathrm{C} / 220 \mathrm{MPa}$

\begin{tabular}{|c|c|c|c|}
\hline Element & Spot 1 & Spot 2 & Spot 3 \\
\hline $\mathrm{C}$ & 5.27 & 6.78 & 5.5 \\
\hline $\mathrm{Mo}$ & 12.35 & 23.27 & 8.55 \\
\hline $\mathrm{V}$ & 0.4 & 0.39 & 0.3 \\
\hline $\mathrm{Cr}$ & 9.47 & 9.48 & 7.66 \\
\hline $\mathrm{Fe}$ & 72.52 & 60.08 & 77.99 \\
\hline
\end{tabular}




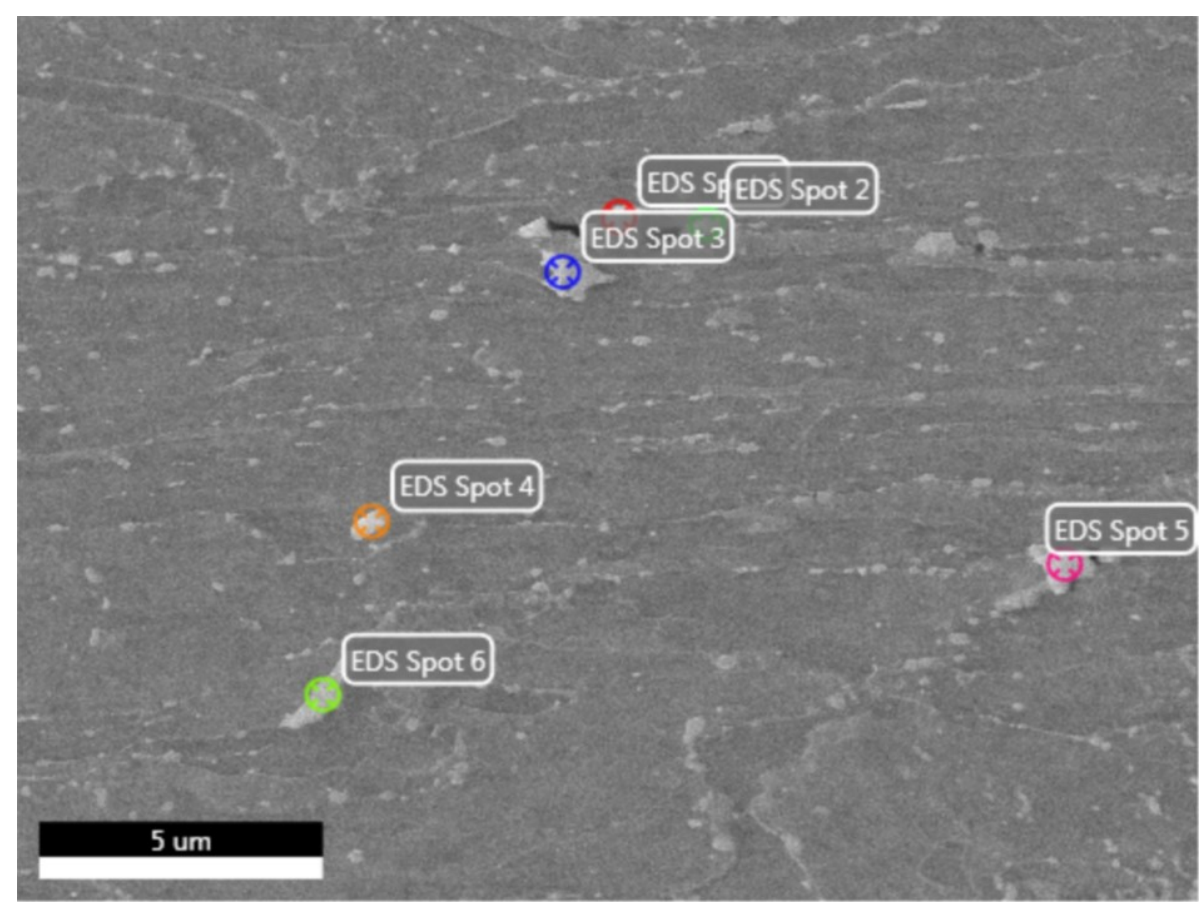

Fig. AP- 15 Selected spots in the fractured aged coupon at $550^{\circ} \mathrm{C} / 240 \mathrm{MPa}$ for $\mathrm{EDX}$ analysis.

Table AP- 16 Elemental concentrations (wt.\%) of selected spots in fractured aged coupon at $550^{\circ} \mathrm{C} / 240 \mathrm{MPa}$

\begin{tabular}{|c|c|c|c|c|c|c|}
\hline Element & Spot 1 & Spot 2 & Spot 3 & Spot 4 & Spot 5 & Spot 6 \\
\hline $\mathrm{C}$ & 5.24 & 4.16 & 4.82 & 3.08 & 4.94 & 4.22 \\
\hline $\mathrm{Mo}$ & 14.44 & 8.2 & 12.86 & 0.51 & 17.26 & 14.92 \\
\hline $\mathrm{V}$ & 0.42 & 0.45 & 0.54 & 0.35 & 0.49 & 0.27 \\
\hline $\mathrm{Cr}$ & 7.66 & 7.9 & 8.52 & 7.41 & 7.82 & 7.5 \\
\hline $\mathrm{Fe}$ & 72.25 & 79.29 & 73.27 & 88.66 & 69.48 & 73.09 \\
\hline
\end{tabular}




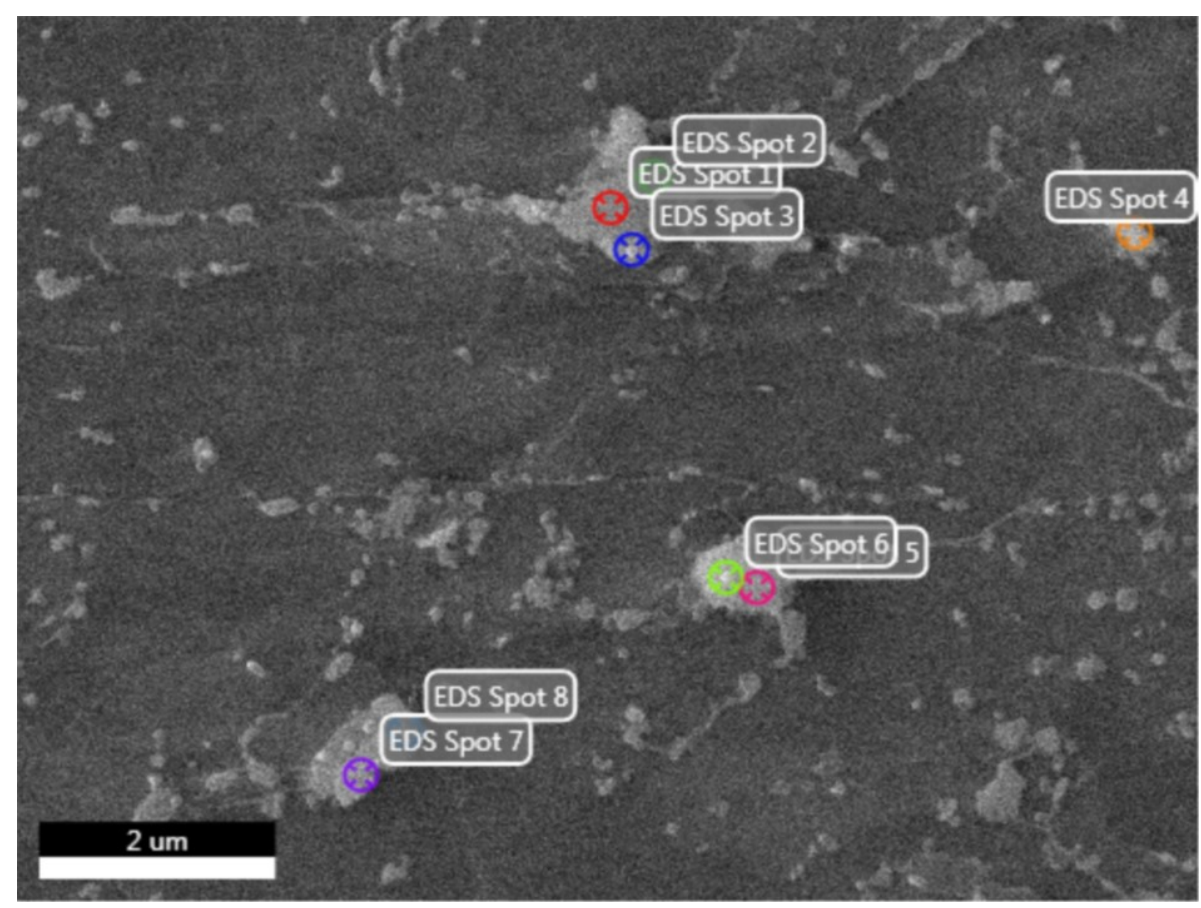

Fig. AP- 16. Selected spots in the fractured aged coupon at $550^{\circ} \mathrm{C} / 260 \mathrm{MPa}$ for EDX analysis.

Table AP- 17 Elemental concentrations (wt.\%) of selected spots in fractured aged coupon at $550^{\circ} \mathrm{C} / 260 \mathrm{MPa}$

\begin{tabular}{|c|c|c|c|c|c|c|c|c|}
\hline Element & Spot 1 & Spot 2 & Spot 3 & Spot 4 & Spot 5 & Spot 6 & Spot 7 & Spot 8 \\
\hline $\mathrm{C}$ & 3.86 & 4.69 & 3.05 & 3.73 & 3.65 & 3.74 & 3.09 & 5.48 \\
\hline $\mathrm{Mo}$ & 11.6 & 13.61 & 2.17 & 7.77 & 3.63 & 1.95 & 3.64 & 18.4 \\
\hline $\mathrm{V}$ & 0.33 & 0.35 & 0.45 & 0.81 & 0.45 & 0.34 & 0.59 & 0.36 \\
\hline $\mathrm{Cr}$ & 7.79 & 8.42 & 8.04 & 11.57 & 14.33 & 9.12 & 7.77 & 9.12 \\
\hline $\mathrm{Fe}$ & 76.42 & 72.94 & 86.29 & 76.12 & 77.93 & 84.85 & 84.91 & 66.63 \\
\hline
\end{tabular}




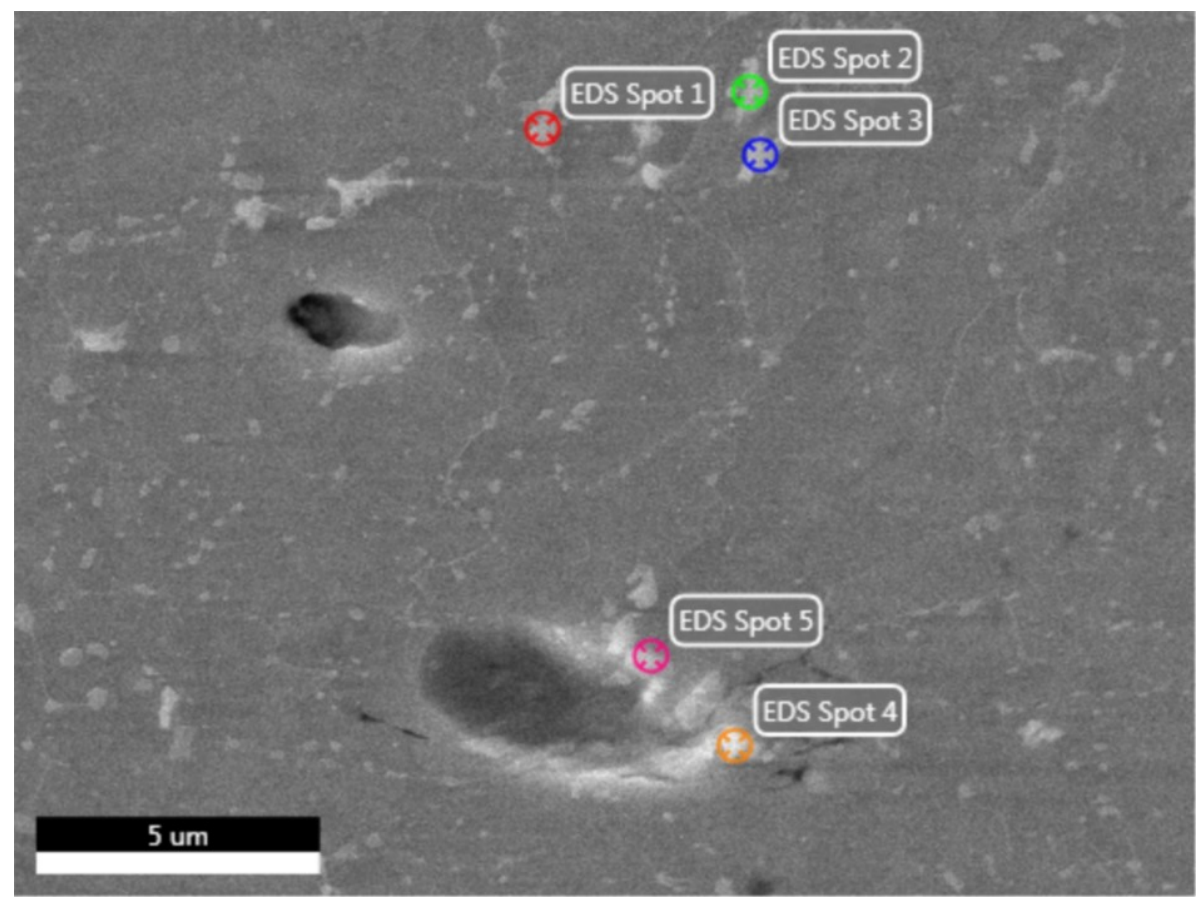

Fig. AP- 17. Selected spots in the fractured aged coupon at $600^{\circ} \mathrm{C} / 130 \mathrm{MPa}$ for EDX analysis.

Table AP- 18 Elemental concentrations (wt.\%) of selected spots in fractured aged coupon at $600^{\circ} \mathrm{C} / 130 \mathrm{MPa}$

\begin{tabular}{|c|c|c|c|c|c|}
\hline Element & Spot 1 & Spot 2 & Spot 3 & Spot 4 & Spot 5 \\
\hline $\mathrm{C}$ & 5.2 & 5.51 & 5.38 & 5.36 & 3.9 \\
\hline $\mathrm{Mo}$ & 14.79 & 13.66 & 22.62 & 10.78 & 9.18 \\
\hline $\mathrm{V}$ & 0.19 & 0.43 & 0.33 & 0.23 & 0.42 \\
\hline $\mathrm{Cr}$ & 9.44 & 11.63 & 8.85 & 8.04 & 7.3 \\
\hline $\mathrm{Fe}$ & 70.38 & 68.77 & 62.82 & 75.6 & 79.21 \\
\hline
\end{tabular}




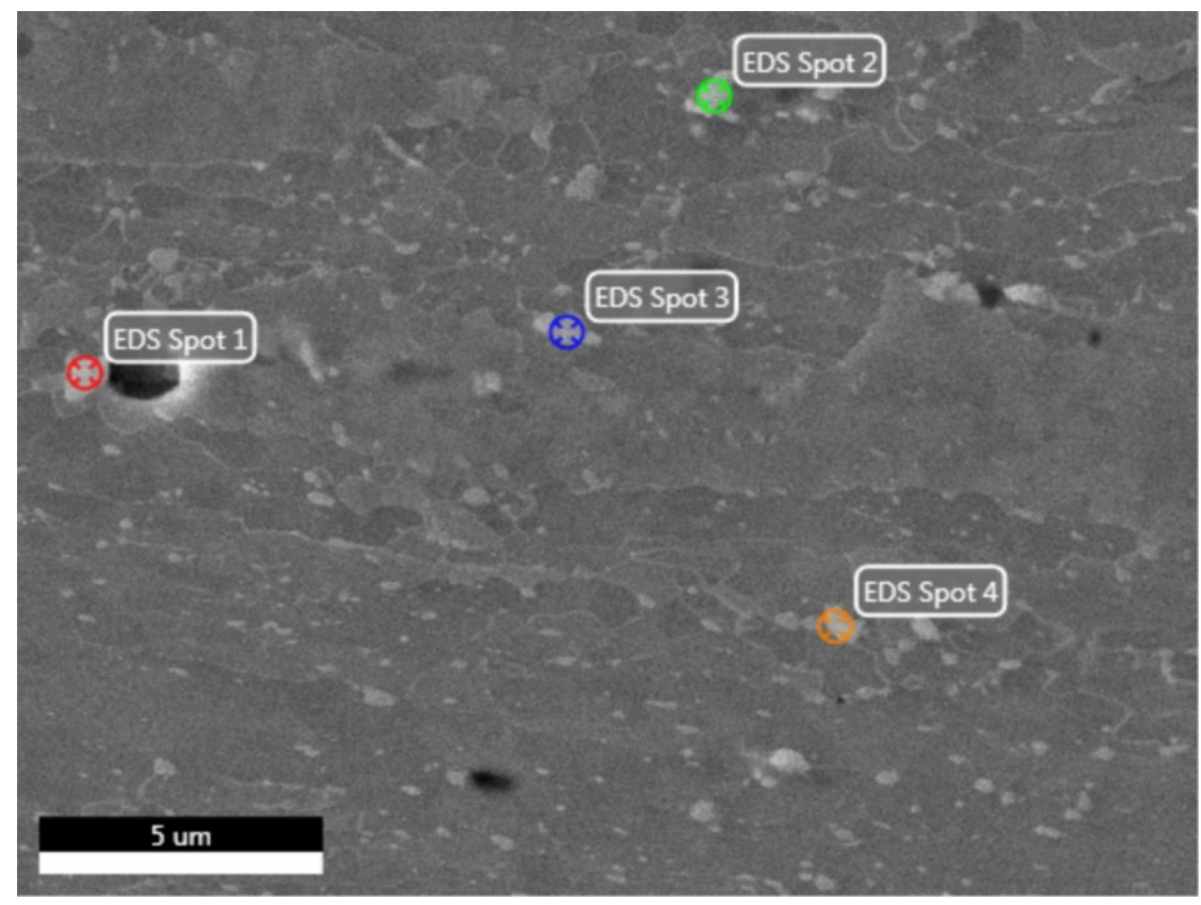

Fig. AP- 18. Selected spots in the fractured aged coupon at $600^{\circ} \mathrm{C} / 140 \mathrm{MPa}$ for EDX analysis.

Table AP- 19 Elemental concentrations (wt.\%) of selected spots in fractured aged coupon at $600^{\circ} \mathrm{C} / 140 \mathrm{MPa}$

\begin{tabular}{|c|c|c|c|c|}
\hline Element & Spot 1 & Spot 2 & Spot 3 & Spot 4 \\
\hline $\mathrm{C}$ & 5.04 & 4.5 & 5.09 & 3.15 \\
\hline $\mathrm{Mo}$ & 19.08 & 15.09 & 16.91 & 2.83 \\
\hline $\mathrm{V}$ & N/A & 0.76 & 0.42 & 0.37 \\
\hline $\mathrm{Cr}$ & 8.26 & 8.11 & 9.33 & 7.82 \\
\hline $\mathrm{Fe}$ & 67.62 & 71.53 & 68.25 & 85.83 \\
\hline
\end{tabular}




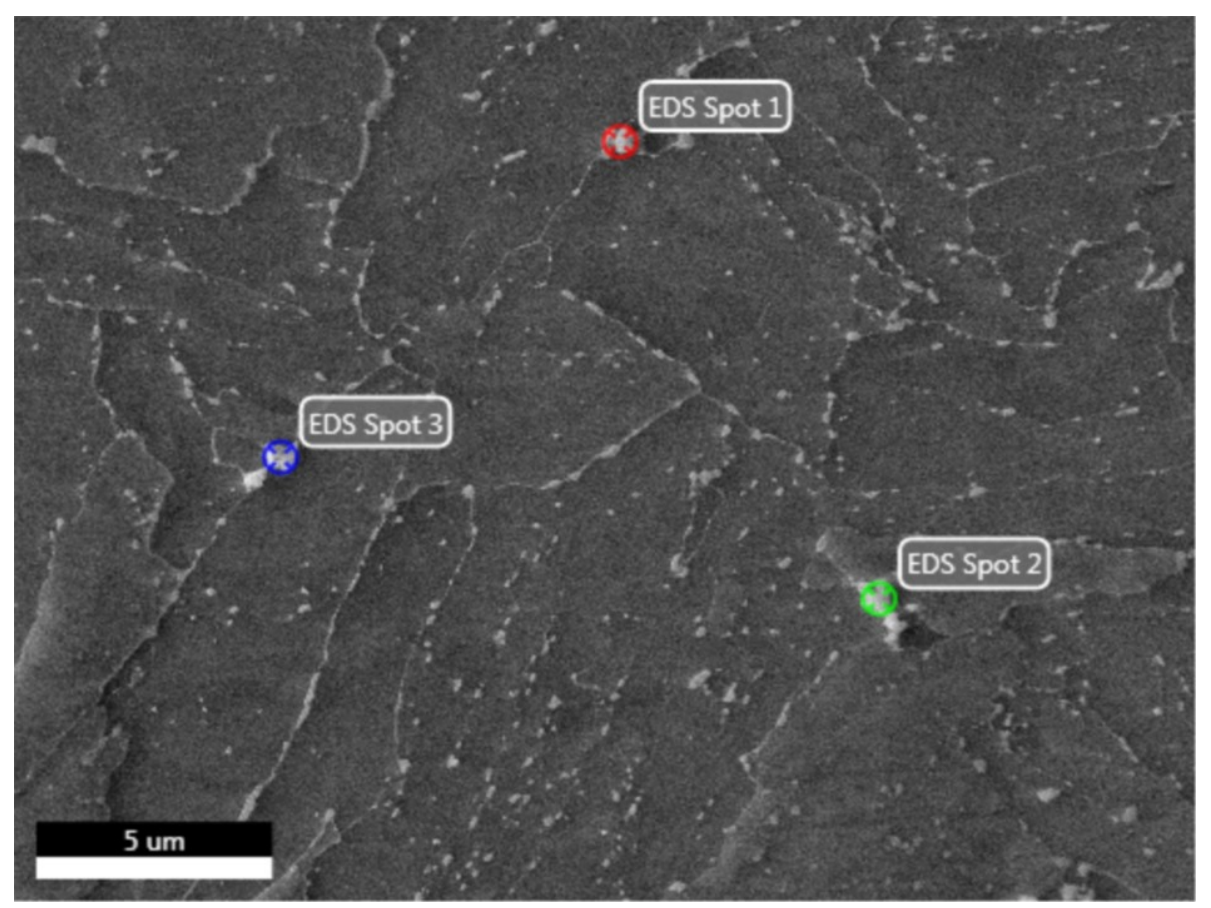

Fig. AP- 19. Selected spots in the fractured aged coupon at $600^{\circ} \mathrm{C} / 160 \mathrm{MPa}$ for $\mathrm{EDX}$ analysis.

Table AP- 20 Elemental concentrations (wt.\%) of selected spots in fractured aged coupon at $600^{\circ} \mathrm{C} / 160 \mathrm{MPa}$

\begin{tabular}{|c|c|c|c|}
\hline Element & Spot 1 & Spot 2 & Spot 3 \\
\hline $\mathrm{C}$ & 4.86 & 5.08 & 2.69 \\
\hline $\mathrm{Mo}$ & 10.79 & 24.41 & 17.77 \\
\hline $\mathrm{V}$ & 0.51 & 0.42 & 0.62 \\
\hline $\mathrm{Cr}$ & 7.65 & 7.95 & 8.5 \\
\hline $\mathrm{Fe}$ & 76.19 & 62.14 & 70.41 \\
\hline
\end{tabular}




\section{C-3 Area reduction measurements of creep-tested coupons}

The area reduction can be calculated by subtracting the cross-sectional area of the ruptured coupon from that of the original coupon. The cross-sectional area of the original coupon is shown in Fig. AP- 20. The ruptured coupons were categorized by test temperatures, and the optical images of their cross sections are shown in Fig. AP- 21 to Fig. AP- 24. The areas of the ruptured coupons were measured using ImageJ and Adobe Photoshop. Thus, Table 6- 1 and Fig. 6- 4 were obtained.

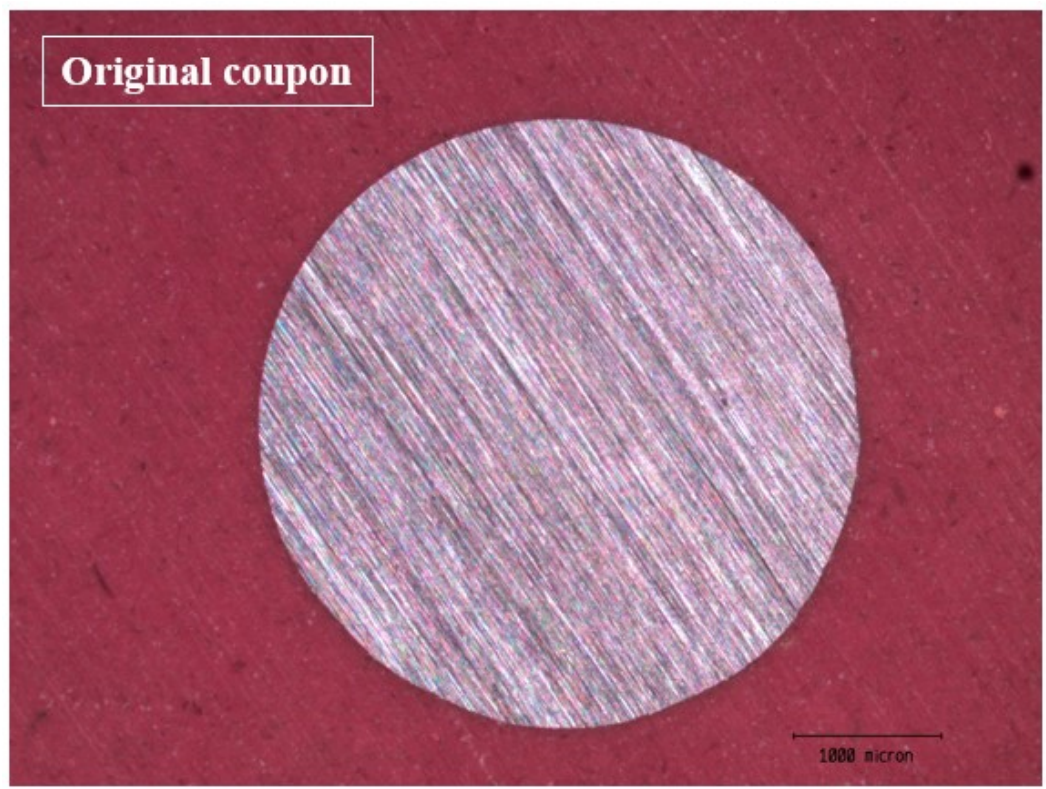

Fig. AP- 20. Cross section of original coupon. 

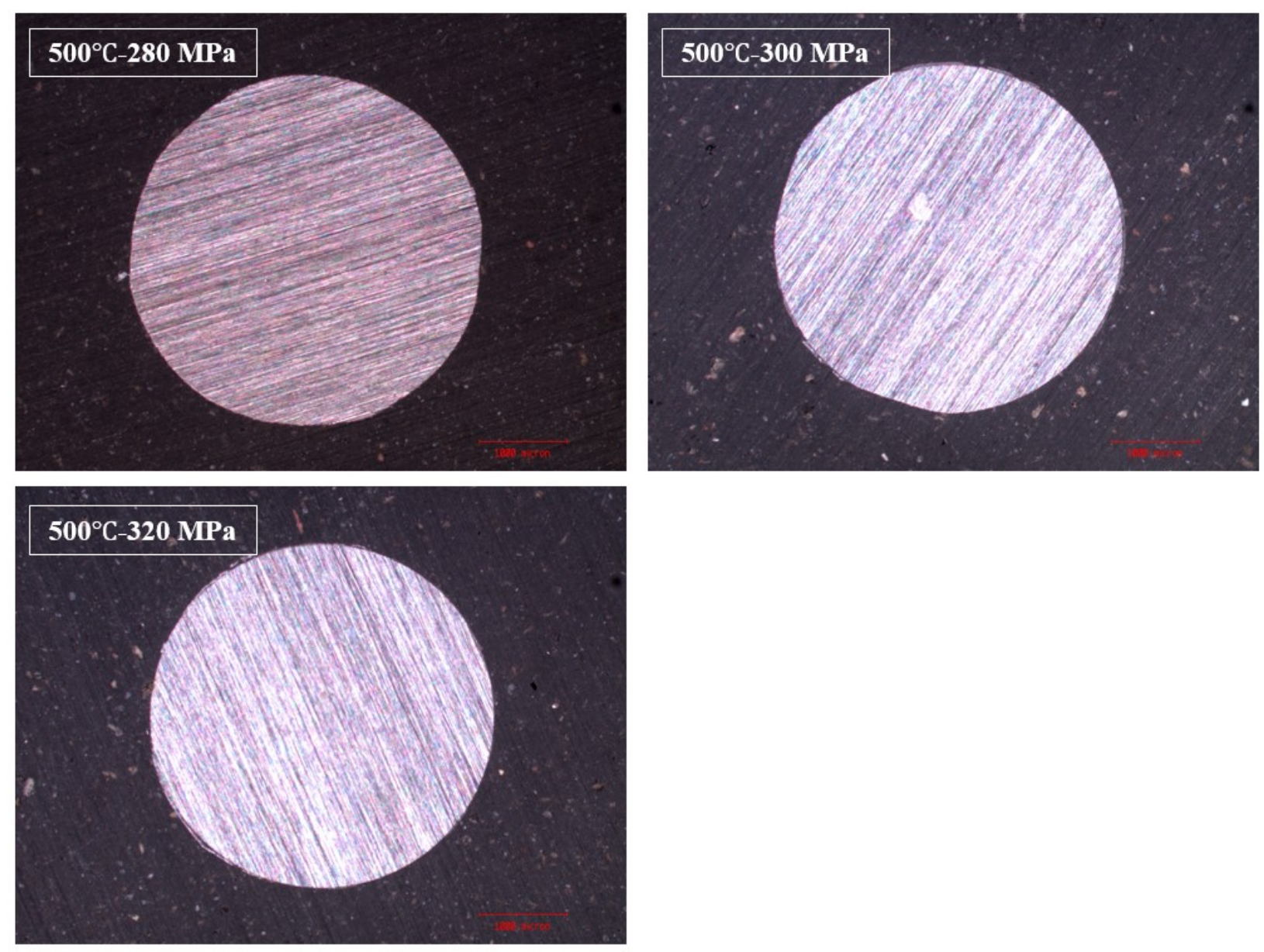

Fig. AP- 21. Cross sections of ruptured coupons at $500^{\circ} \mathrm{C}$. 

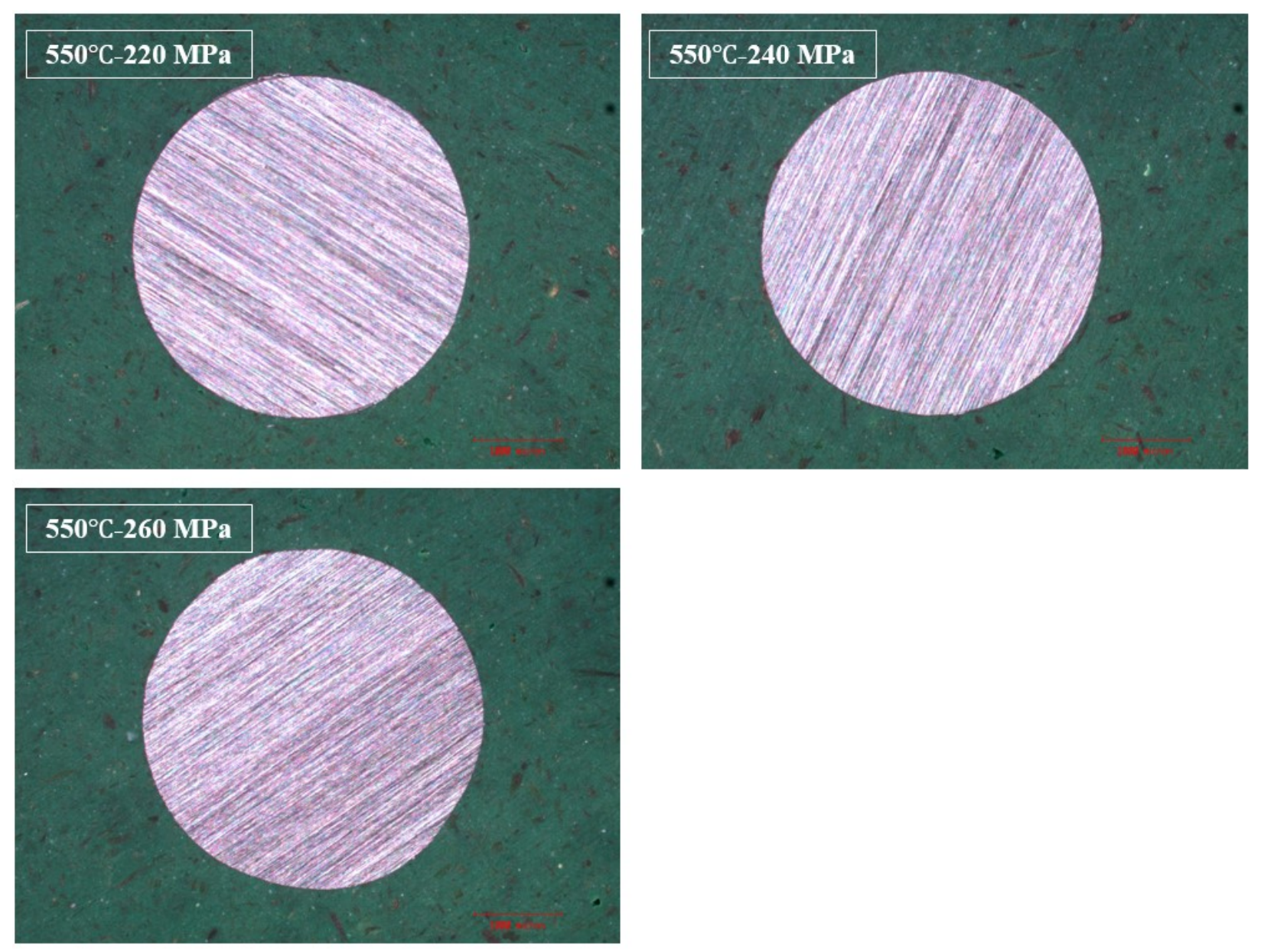

Fig. AP- 22. Cross sections of ruptured coupons at $550^{\circ} \mathrm{C}$. 

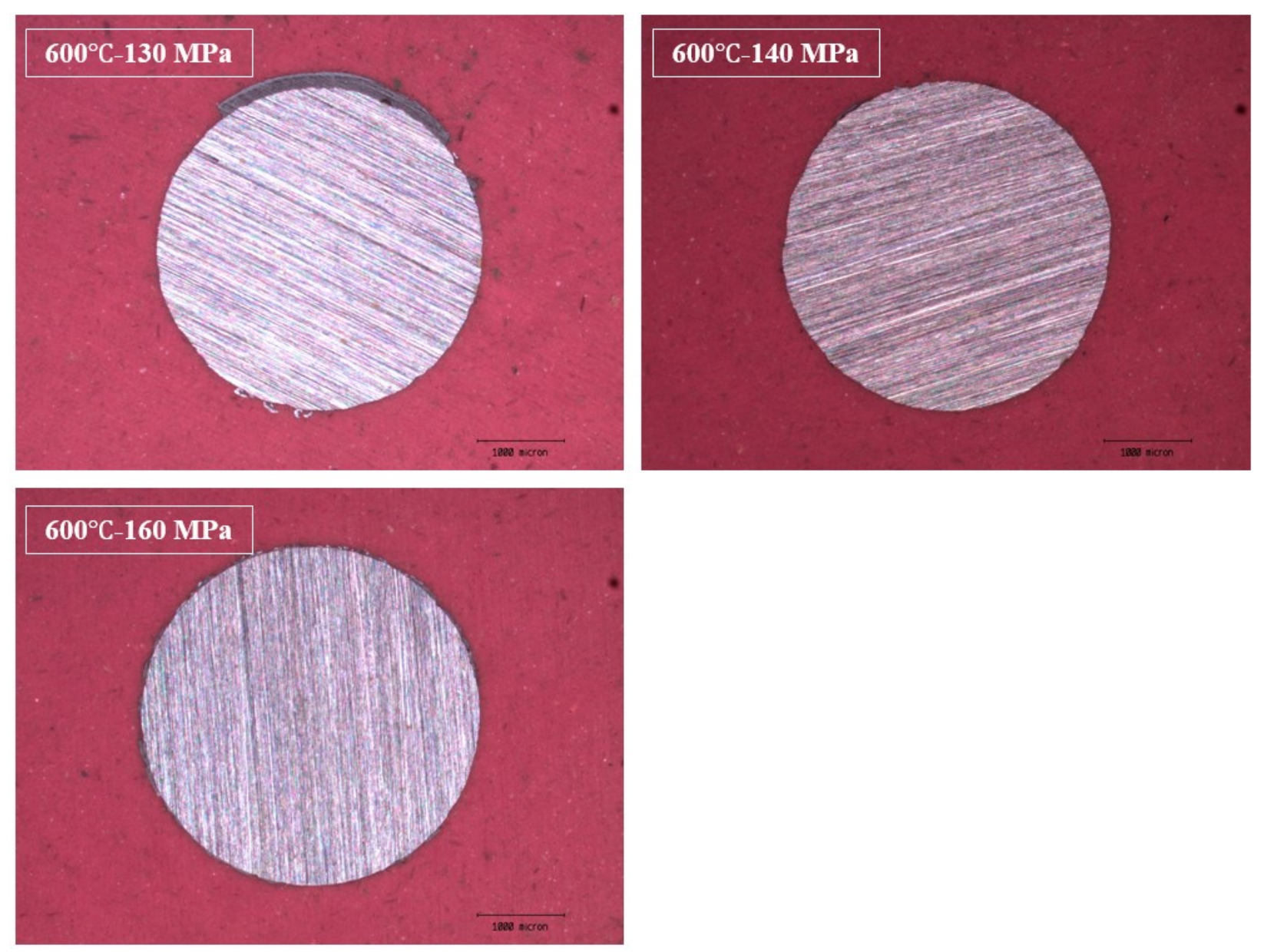

Fig. AP- 23. Cross sections of ruptured coupons at $600^{\circ} \mathrm{C}$. 

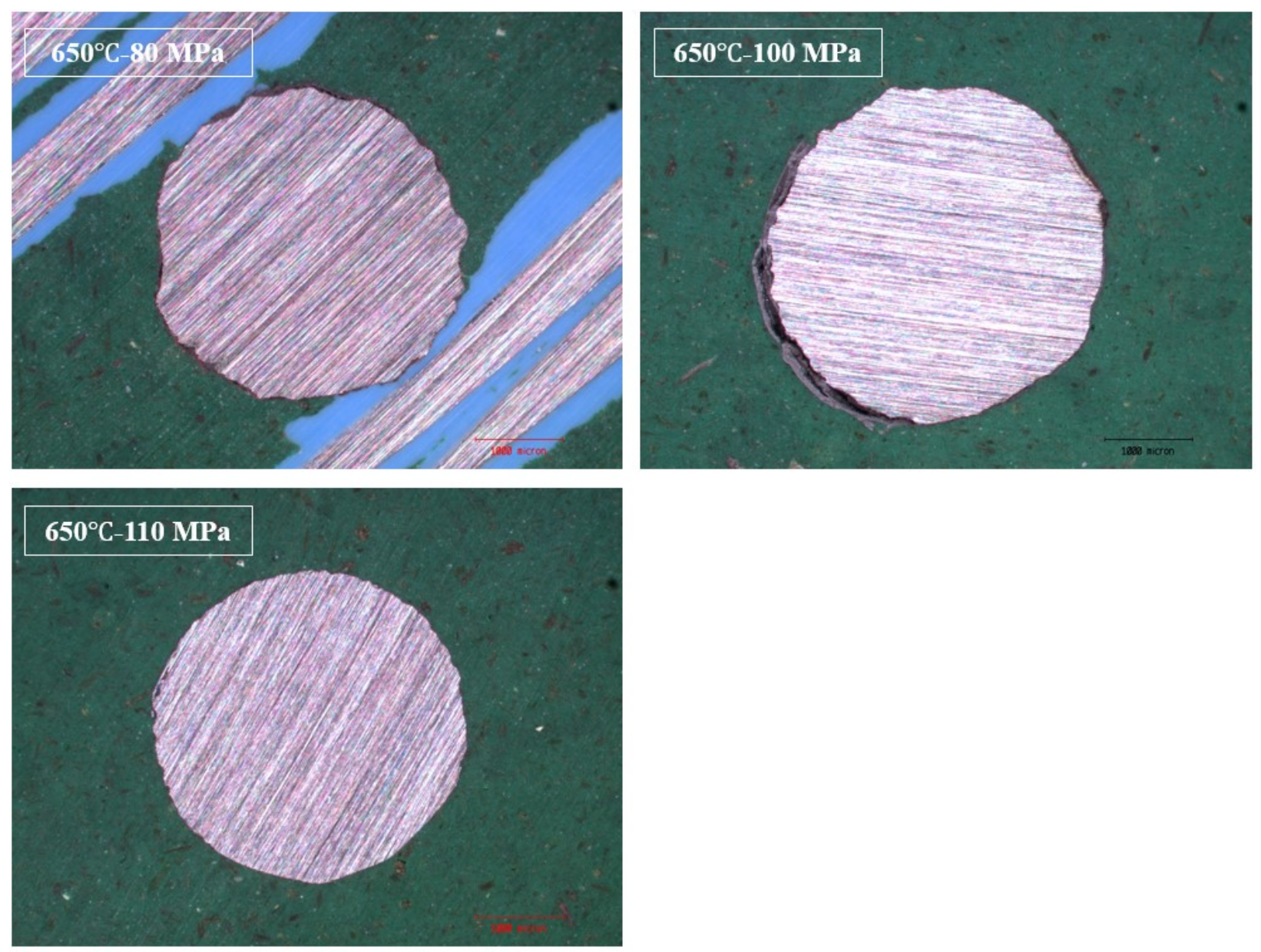

Fig. AP- 24. Cross sections of ruptured coupons at $650^{\circ} \mathrm{C}$. 


\section{C-4 Hardness test results}

At every 1000 hours of aging, the hardness of aged coupons was measured. The un-aged coupon was also tested for comparison. Five tests were made on the coupon at each time, and the average values were taken as the hardness of the coupon in the specific condition. Table $7-1$ reports the hardness data. Fig. AP- 25 gives examples of indention surfaces of an aged coupon at different aging times.
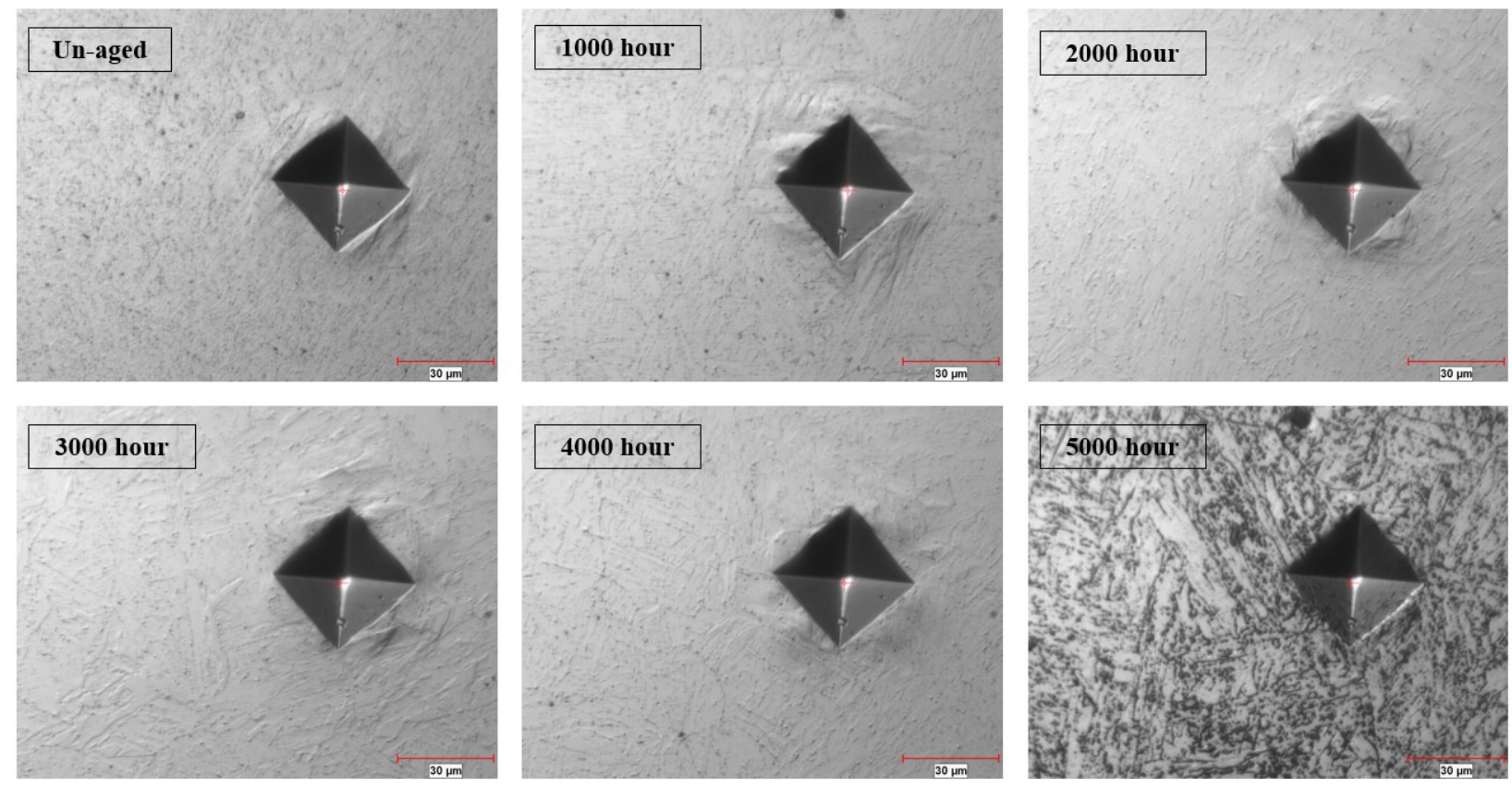

Fig. AP- 25. Indention surfaces of un-aged and aged coupons. 